Coastal Inlets Research Program

\title{
Laboratory Study of Hydrodynamics Near Absorbing and Fully Reflecting Jetties
}
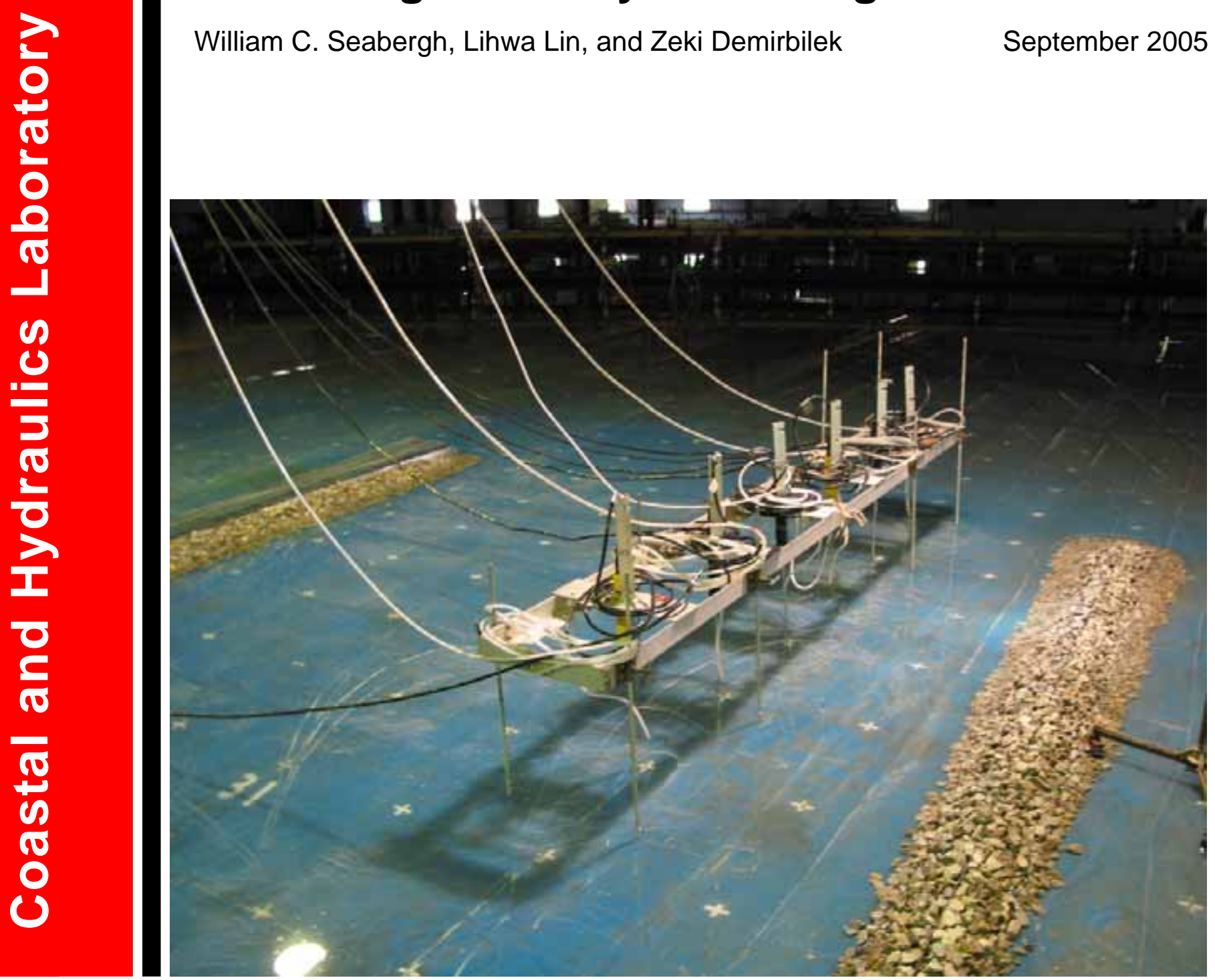


\section{Laboratory Study of Hydrodynamics Near Absorbing and Fully Reflecting Jetties}

William C. Seabergh, Lihwa Lin, Zeki Demirbilek

Coastal and Hydraulics Laboratory

U.S. Army Engineer Research and Development Center

3909 Halls Ferry Road

Vicksburg, MS 39180-6199

Final report

Approved for public release; distribution is unlimited

Prepared for U.S. Army Corps of Engineers

Washington, DC 20314-1000

Under Inlet Engineering Work Unit 32935 
ABSTRACT: This physical model study of absorbing and reflecting jetties at coastal inlets was conducted to provide data sets that would aid in the calibration and verification of numerical wave models. The study was performed in the Coastal Inlet Research Program's (CIRP) idealized inlet experimental basin at the U.S. Army Engineer Research and Development Center (ERDC), Coastal and Hydraulics Laboratory (CHL), Vicksburg, MS. Safe navigation, sediment transport into navigation channels, and shoreline erosion are all concerns at coastal inlets and are related to the transformation of waves as they change direction and height due to complex bathymetry and coastal inlet structures. The idealized inlet physical model, created for inlet studies, provided a facility in which to make wave measurements of height and direction and the associated wave-generated currents in enough detail to document the wave height and current variation in a region with complex interactions. Measurements of wave information included use of wave rods for wave height and acoustic Doppler velocity sensors for wave direction and current. Qualitative dye photographs and videos were also obtained.

Wave height and velocity measurements were collected both upcoast of the jetty and between parallel jetties for a number of waves representative of tidal inlets. The composition of the jetty was designed to portray the extremes of an inlet jetty - a jetty that fully reflects the incident wave toward the upcoast shoreline adjacent to the jetty, and an almost fully absorbing jetty, which reflects very little energy. These two extreme conditions created two different circulation patterns associated with each jetty condition. The nearly fully absorbing jetty setup permitted the wave-generated longshore current to approach the jetty and essentially be deflected seaward ninety degrees, along the jetty. The waves fully reflecting from the jetty created a clockwise circulation cell at the intersection of the jetty and the shoreline. This cell was large enough to deflect the offshore movement of littoral currents a significant distance upcoast rather than approaching the base of the jetty before deflecting seaward as for the absorbing jetty setup.

DISCLAIMER: The contents of this report are not to be used for advertising, publication, or promotional purposes. Citation of trade names does not constitute an official endorsement or approval of the use of such commercial products. All product names and trademarks cited are the property of their respective owners. The findings of this report are not to be construed as an official Department of the Army position unless so designated by other authorized documents. 


\section{Contents}

Conversion Factors Non-SI to SI Units of Measurement................................... ix

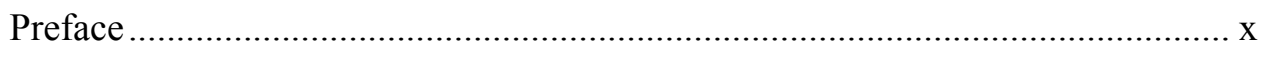

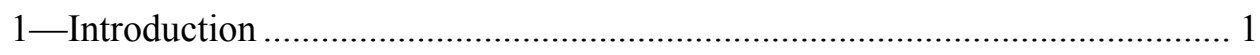

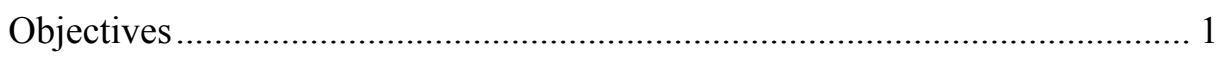

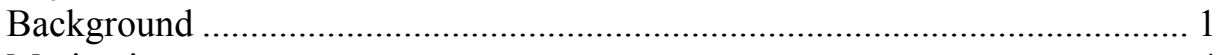

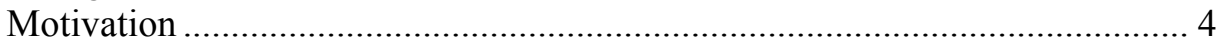

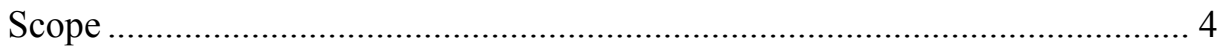

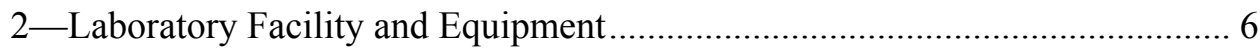

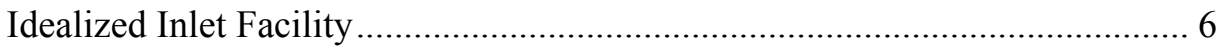

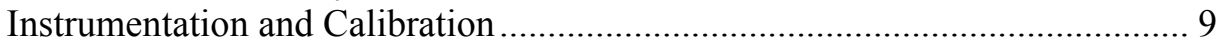

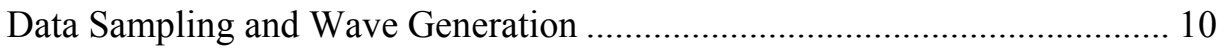

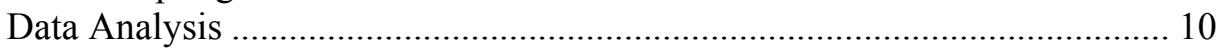

3-Experiment Gauge Setup, Layout, and Conditions .................................... 13

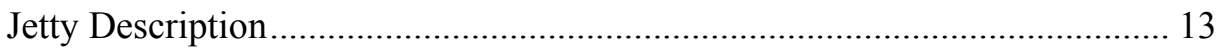

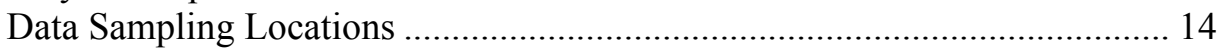

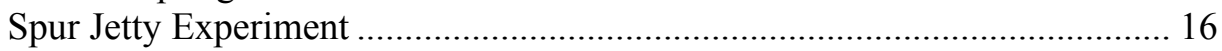

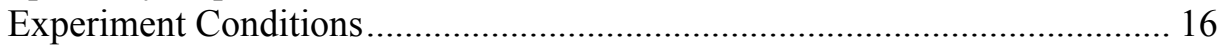

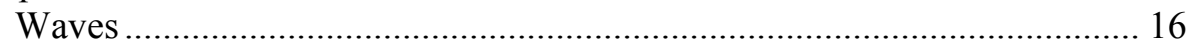

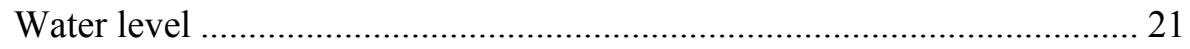

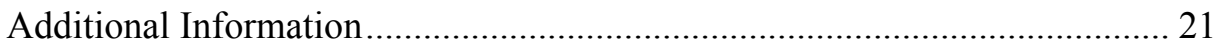

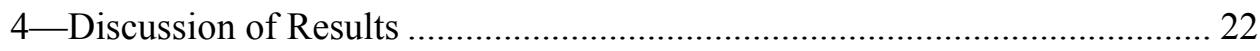

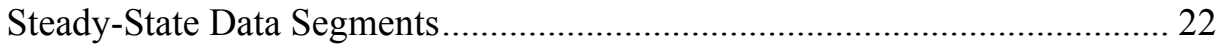

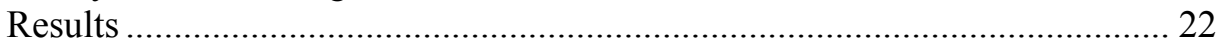

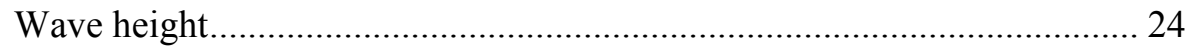

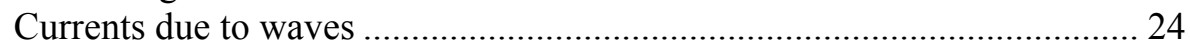

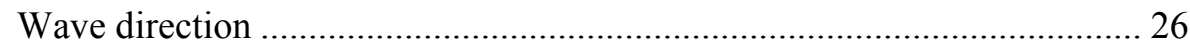

Circulation Near Reflective and Wave-Absorbing Jetties............................ 26

Spur Jetty Velocity Examples .................................................................... 33

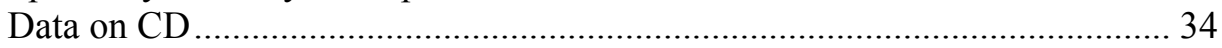

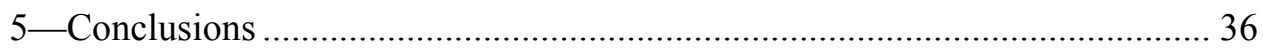

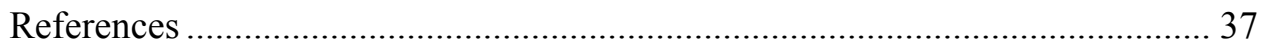


Appendix A: Gauge Layouts and Locations

Appendix B: Wave Height Data Tables ............................................................ B1

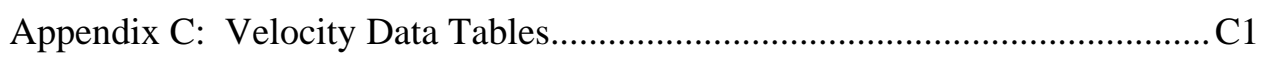

SF 298

\section{List of Figures}

Figure 1. Wave-generated longshore currents entering Grays Harbor, WA, during flood tide .................................................................2

Figure 2. Jetty examples of varying wave reflectivity discussed in text .....5

Figure 3. Idealized inlet model research facility......................................

Figure 4. Contours in model units in idealized inlet..................................8

Figure 5. Idealized inlet entrance channel with obligue wave approaching inlet (spacing 0.62 m between "+" marking on research facility basin floor)......................................................8

Figure 6. Capacitance wave gauge ..........................................................

Figure 7. Acoustic Doppler Velocimeter ................................................10

Figure 8. Coordinate system convention for data. Upper left (x,y) coordinate system for gauge locations and final velocity data. Lower (x,y) coordinate system for raw velocity data upcoast of jetties

Figure 9. Wave-absorbing jetty perpendicular to shore in physical

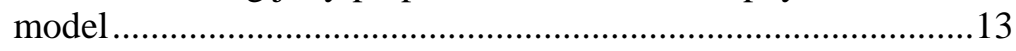

Figure 10. Plywood reflecting jetty face ............................................................14

Figure 11. Wave gauges near jetty ..........................................................15

Figure 12. Current meters seaward of jetty................................................15

Figure 13. Rack holding six current meters in entrance channel.................16

Figure 14. Wave gauge locations upcoast of jetties...................................17

Figure 15. Current meter locations upcoast of jetties with probe number shown for various range numbers. Unscaled contours shown in feet and centimeters

Figure 16. Wave gauge locations (a) in outer portion of channel and (b) inside portion. Range numbers shown at top of figure. 
Figure 17. Spur jetty

Figure 18. Wave height measurements (in meters) showing (a) waves at generator and (b) waves along Transect 1 , channel 6 ... .23

Figure 19. Current speed at Range 26, probe 0 ….....................................23

Figure 20. Current speed at Range 26, probe 0, for time 198 to $208 \mathrm{sec}$

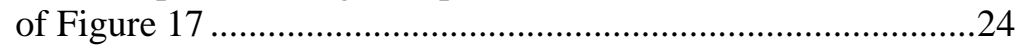

Figure 21. Contours of wave height for 2-m, 11-sec wave, absorbing

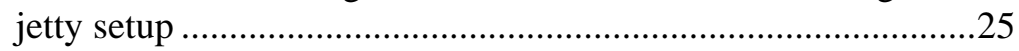

Figure 22. Contours of wave height for 2-m, 11-sec wave, reflecting jetty setup .25

Figure 23. Contours of wave height for 3-m, 8-sec wave, absorbing jetty setup

Figure 24. Wave-generated current for 2-m, 11-sec wave, absorbing jetty setup

Figure 25. Wave direction vectors and scaled wave height for (a) wave absorbing jetty and (b) reflective jetty

Figure 26. Sequence of photographs (1-7) of dye patch approaching absorbing jetty (2-m, 11-sec wave).

Figure 27. Sequence of photographs (1-5) of dye patch approaching reflecting jetty (2-m, 11-sec wave)...

Figure 28. Comparison of (a) absorbing jetty and (b) reflecting jetty for 1-m, 11-sec wave... .30

Figure 29. Comparison of (a) absorbing jetty and (b) reflecting jetty for

2-m, 11-sec wave.

Figure 30. Comparison of (a) absorbing jetty and (b) reflecting jetty for 3.4-m, 8-sec wave. .32

Figure 31. Spur jetty velocities for (a) 2.0-m, 11-sec wave and (b) 3.4-m, 8-sec wave.

Figure 32. Contours of bathymetry in prototype meters relative to water level.

Figure A1. Orientation of axis system for describing gauge locations........A1

Figure A2. Wave gauge layout upcoast of jetty ......................................A2

Figure A3. Current meter layout upcoast of jetty ......................................A3

Figure A4. Wave gauge layout in outer channel ......................................A4

Figure A5. Current meter layout in outer channel ....................................A5

Figure A6. Wave gauge layout in inner channel .....................................A6 
Figure A7. Current meter layout in inner channel ....................................A7

Figure A8. Wave gauge layout 1 for spur jetty ….....................................8

Figure A9. Current meter layout for spur jetty .........................................A9

\section{List of Tables}

Table 1. Model-Prototype Scale Relations at 1:50 Undistorted Scale .......9

Table 2. Experiment Conditions.........................................................21

Table A1. Wave Gauge Locations Upcoast of Jetty, T1-T9 ....................A10

Table A2. Wave Gauge Locations Between Jetties, Transects C29, C29A, C31, C31A, C33, and 33A.........................................A13

Table A3. $\quad$ Wave Gauge Locations Upcoast of Jetty, Transects C17C19 and C21-C26 .................................................................. 15

Table A4. Velocity Gauge Locations Between Jetties, Transects C27C29, C29A, C31, C31A, C33, and C33A................................A17

Table A5. Velocity Gauge Locations, Spur Jetty Experiments, Transects C17-C19, C21-C26, T1, and T3.

Table B1. Wave Height and Interpolated Wave Direction, Reflective Jetty, 3.4-m, 8-sec Wave, Transects T1-T9.

Table B2. Wave Height and Interpolated Wave Direction, Reflective Jetty, 2.0-m, 11-sec Wave, Transects T1-T9............................. B5

Table B3. Wave Height and Interpolated Wave Direction, Reflective Jetty, 1.0-m, 11-sec Wave, Transects T1-T9. . B8

Table B4. Wave Height and Interpolated Wave Direction, Reflective Jetty, 0.75-m, 11-sec Wave, Transects T1-T9.

Table B5. Wave Height and Interpolated Wave Direction, Absorbing Jetty, 1.65-m, 11-sec Wave, Transects T1-T9.

Table B6. Wave Height and Interpolated Wave Direction, Absorbing Jetty, 1.1-m, 11-sec Wave, Transects T1-T9...

Table B7. Wave Height and Interpolated Wave Direction, Absorbing Jetty, 3.4-m, 8-sec Wave, Transects T1-T9.

Table B8. Wave Height and Interpolated Wave Direction, Absorbing Jetty, 1.0-m, 11-sec Wave, Transects T1-T9. 
Table B9. Wave Height and Interpolated Wave Direction, Absorbing Jetty, 2.0-m, 11-sec Wave, Transects T1-T9.

Table B10. Wave Height and Interpolated Wave Direction, Channel, 1.0-m, 11-sec Wave, Transects T29, T29A, T31, T31A, $\mathrm{T} 33$, and T33A

Table B11. Wave Height and Interpolated Wave Direction, Channel, 2.0-m, 11-sec Wave, Transects T29, T29A, T31, T31A, T33, and T33A

Table B12. Wave Height and Interpolated Wave Direction, Channel, 3.4-m, 8-sec Wave, Transects T29, T29A, T31, T31A, T33, and T33A.

Table B13. Wave Height and Interpolated Wave Direction, Spur Jetty, 2.0-m, 11-sec Wave, Transects C17-C19, C21-C26, T1, and $\mathrm{T} 3$

Table B14. Wave Height and Interpolated Wave Direction, Spur Jetty, 1.0-m, 11-sec Wave, Transects C17-C19, C21-C26, T1, and $\mathrm{T} 3$

Table B15. Wave Height and Interpolated Wave Direction, Spur Jetty, 3.4-m, 8-sec Wave, Transects C17-C19, C21-C26, T1, and T3.

Table C1. Velocities, Wave Direction, and Interpolated Wave Height, Reflective Jetty, 0.75-m, 11-sec Wave, Ranges C17-C19, C21, and C23-C26.

Table C2. Velocities, Wave Direction, and Interpolated Wave Height, Reflective Jetty, 3.4-m, 8-sec Wave, Ranges C17-C19, C21, and C23-C26 .

Table C3. Velocities, Wave Direction, and Interpolated Wave Height, Reflective Jetty, 2.0-m, 11-sec Wave, Ranges C17-C19, C21, and C23-C26.

Table C4. Velocities, Wave Direction, and Interpolated Wave Height, Reflective Jetty, 1.0-m, 11-sec Wave, Ranges C17-C19, C21, and C23-C26.

Table C5. Velocities, Wave Direction, and Interpolated Wave Height, Absorbing Jetty, 1.65-m, 11-sec Wave, Ranges C17-C19, C21, and C23-C26.

Table C6. Velocities, Wave Direction, and Interpolated Wave Height, Absorbing Jetty, 3.25-m, 8-sec Wave, Ranges C17-C19, C21, and C23-C26.

Table C7. Velocities, Wave Direction, and Interpolated Wave Height, Absorbing Jetty, 1.0-m, 11-sec Wave, Ranges C17-C19, and C21-C26. 
Table C8. Velocities, Wave Direction, and Interpolated Wave Height, Absorbing Jetty, 2.0-m, 11-sec Wave, Ranges C17-C19, and C21-C26

Table C9. Velocities, Wave Direction, and Interpolated Wave Height, in Channel, 1.0-m, 11-sec Wave, Ranges C29, C29A, C31,

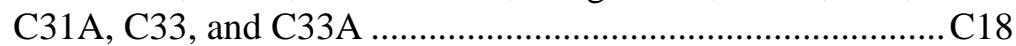

Table C10. Velocities, Wave Direction, and Interpolated Wave Height, in Channel, 2.0-m, 11-sec Wave, Ranges C29, C29A, C31, C31A, C33, and C33A

Table C11. Velocities, Wave Direction, and Interpolated Wave Height, in Channel, 3.4-m, 8-sec Wave, Ranges C29, C29A, C31, C31A, C33, and C33A

Table C12. Velocities, Wave Direction, and Interpolated Wave Height, Spur, 2.0-m, 11-sec Wave, Ranges C17, C19, C21-C26, T1, and T3.....

Table C13. Velocities, Wave Direction, and Interpolated Wave Height, Spur, 1.0-m, 11-sec Wave, Ranges C17-C19, C21-C26, T1, and $\mathrm{T} 3$

Table C14. Velocities, Wave Direction, and Interpolated Wave Height, Spur, 3.4-m, 8-sec Wave, Ranges C17-C19, C21-C26, T1, and $\mathrm{T} 3$ 


\section{Conversion Factors Non-SI to SI Units of Measurement}

Non-SI units of measurement used in this report can be converted to SI units as follows:

\begin{tabular}{||l|l|l||}
\hline \hline Multiply & By & To Obtain \\
\hline \hline degree & 0.01745329 & radians \\
\hline feet & 0.3048 & meters \\
\hline inches & 2.54 & centimeters \\
\hline gallons & 3.785 & liters \\
\hline \hline
\end{tabular}




\section{Preface}

The research investigation described herein was conducted as part of the Coastal Inlets Research Program (CIRP) under Work Unit 32935, "Inlet Laboratory Investigations." Overall program management for CIRP is directed by Headquarters, U.S. Army Corps of Engineers (HQUSACE). Program Monitors for the CIRP at HQUSACE are Messrs. Barry W. Holliday and Charles B. Chesnutt. Technical Director for CIRP was Dr. Sandra Knight, U.S. Army Engineer Research and Development Center (ERDC), Coastal and Hydraulics Laboratory (CHL), Vicksburg, MS. The Program Manager was Dr. Nicholas C. Kraus, CHL. Mr. William C. Seabergh, CHL, is Principal Investigator of the Inlet Laboratory Investigations Work Unit.

The mission of the CIRP is to conduct applied research to improve USACE capability to manage Federally maintained inlets, which exist on all coasts of the United States (including the Atlantic, Gulf, Pacific, and the Great Lakes regions). Objectives are to (a) make management of channels - design, maintenance, and operation--more effective to reduce the cost of dredging, and (b) preserve the adjacent beaches in a systems approach that treats the inlet and beach together. To achieve these objectives, CIRP includes work units on short-wave and circulation modeling, channels and adjacent shorelines, inlet scour, laboratory investigations, field investigations, and technology transfer.

CHL personnel under the general direction of Mr. Thomas W. Richardson, Director, CHL, and Dr. Rose M. Kress, Chief, Navigation Division, conducted this study. Mr. Dennis G. Markle, former Chief, Harbors, Entrances and Structures Branch, CHL, provided direct guidance. Mr. John E. Evans and Mr. William G. Henderson, Civil Engineering Technicians, conducted the experiments under the direction of Mr. Seabergh, all of the Harbors, Entrances and Structures Branch. Messrs. Tim E. Nisley and David A. Daily of the ERDC Information Technology Laboratory provided instrumentation support. Mr. Seabergh, Dr. Lihwa Lin, Coastal Engineering Branch, and Dr. Zeki Demirbilek, Harbors, Entrances, and Structures Branch, prepared this report. Ms. J. Holley Messing, Coastal Engineering Branch, completed word processing and formatting. Ms. Julie D. Rosati and Mr. Ernest R. Smith, Coastal Processes Branch, provided helpful review comments.

At the time of publication of this report, COL James R. Rowan, EN, was Commander and Executive Director of ERDC. Dr. James R. Houston was Director. 


\section{Introduction}

Waves approaching a tidal inlet refract, diffract, shoal, and interact with tidal currents as they travel from deeper water toward the vicinity of the inlet. The transforming waves eventually break along the shore, creating wave-driven currents at the inlet. These currents are of concern to operation and maintenance of the channel. Wave processes adjacent to and inside the inlet, especially near the navigation channel, move sediment around causing channel erosion and accretion and loss of depth to navigation. In particular, waves, where they encounter a jetty, breakwater, or other discontinuity, can create complex circulation patterns. Controlled measurements of wave and currents on a sloping beach near jetties are lacking, yet this combined wave transformation is driving processes at coastal inlets that determine navigational reliability, channel performance, and morphology change.

\section{Objectives}

In this report, wave-generated currents and wave heights were examined through physical-model measurements made in an idealized physical model inlet. The primary objective of the study was to provide laboratory data to develop and validate numerical models for representing hydrodynamic processes (waves and currents) at an inlet. A second objective of these experiments was to improve understanding of the water circulation patterns developing near the beach-jetty intersection region.

\section{Background}

Jetties are built at inlets to reduce wave height for improved navigability and minimizing sedimentation in the navigation channel. These structures provide protection from the waves, align tidal currents, and reduce sedimentation of the navigation channel. On the seaside of the jetties, wave breaking generates a current that typically flows along the shore until it is diverted seaward by irregular bathymetry or a coastal structure such as a jetty. A longshore current may carry sediment towards the navigation channel and possibly create a strong crosscurrent that reduces channel reliability. Longshore current and tidegenerated current entering Grays Harbor, WA, are illustrated in Figure 1. If waves are high, the surf zone width increases, and the waves and wave-induced currents may strongly alter the inlet environment and activities therein. 


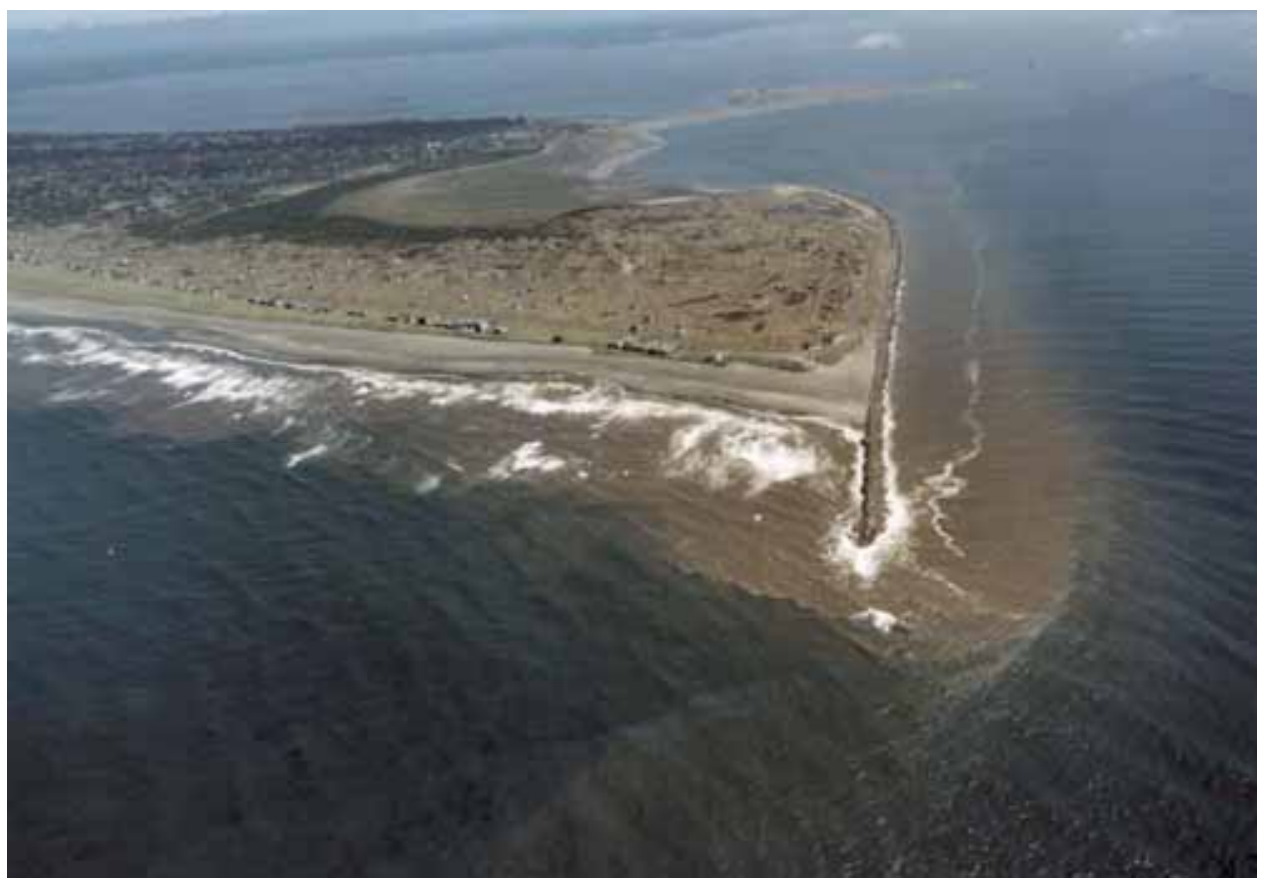

Figure 1. Wave-generated longshore currents entering Grays Harbor, WA, during flood tide

In the past, physical models have been used to study inlets and develop solutions to problems associated with their use, such as channel alignment, high waves detrimental to navigation, and channel shoaling (e.g., Seabergh and Lane 1977; Seabergh 1983, 1988; Bottin et al. 1995 and many other physical model U.S. Army Engineer Research and Development Center (ERDC) reports). Today (2005), numerical models are being applied to study a variety of issues at inlets. However, data are needed to calibrate and verify numerical wave and circulation models developed for inlets.

Advanced numerical models have been developed for modeling flow, wave, and morphodynamics of coastal inlets. These process-based models can be applied to hindcast the morphological development of a coastal inlet and adjacent shoreface beaches. The U.S. Army Corps of Engineers' (USACE) Inlet Modeling System (IMS) (Zundel et al. 2002) is a state-of-the-art toolbox that presently consists of several two-dimensional (2D) horizontal hydrodynamic flow models, wave models, and sediment transport models specifically developed for coastal inlets. Details of the IMS and other aspects of the Coastal Inlets Research Program (CIRP) are available at http://cirp.wes.army.mil/cirp/cirp.html. The physical modeling experiments described in this report have been conducted primarily in support of the CIRP's model testing, validation, and enhancement.

Recent progress in coastal modeling has made sophisticated hydrodynamic and morphodynamic process-based models increasingly valuable tools for coastal engineers and managers. In particular, 2D horizontal (2DH) models have been widely applied in engineering studies for modeling spatial changes in bathymetry and wave climate, although this class of models rely on depth-averaged estimates that ignore vertical variation in the flow and wave characteristics that are 
important to inlet processes. Cialone and Kraus (2001), Cialone et al. (2003), and Cialone (2003) present applications of the IMS at structured inlets. Grunnet et al. (2004) discuss these issues and describe a systematic approach to be used in the validation of the 2D and three-dimensional (3D) numerical models for shoreface nourishment. They also critique the lack of proper data used in some previous studies conducted for measuring nearshore data aimed at validation of nearshore zone hydrodynamic evolution in time and space.

The CIRP experiments were performed in two phases. Initial experiments, conducted as the first phase of the study, have been described in Seabergh et al. (2002). Phase I experiments focused on wave height and direction measurements of waves behind a breakwater, a dogleg jetty, and propagation of waves into the inlet bay through an idealized inlet. Data from this study have been used in the evaluation and validation of two steady-state spectral wave models (Lin and Demirbilek 2005).

In this Phase II study, experiments were conducted to obtain high-resolution measurements of waves and currents around jetties and within an idealized inlet. In the field, jetty structure composition may vary from porous rock rubble to strongly reflecting vertical sheet piles. The extreme structural conditions of a nearly fully wave absorbing jetty and a fully reflective jetty were examined in this study to provide information to numerical modelers. Waves breaking along the shore create a longshore current that is deflected seaward by a jetty. The circulation created by such currents interacts with the wave field that is propagating from the sea and may be reflected off the jetty. Wave and current measurements were made in the direct vicinity of these. Measurement stations were placed on a grid consisting of cross-shore and alongshore transects on the incident-wave side of the jetties that extended in the cross-shore direction. Measurements within the inlet were obtained on three transects, one at the channel centerline and the other two positioned near the side boundaries of inlet parallel to the channel centerline. Gauge layout and experimental arrangement are depicted in Chapter 3.

Previous work on data collection in the beach-jetty region has been limited due to its energetic wave environment. Seabergh (1988) discussed flow patterns at inlets based on physical, analytical, and numerical models. Even in physical model studies, data collection was limited to using dye to measure the current field, as the inertia of mechanical current meters precluded accurate measurements. With the advent of acoustic-Doppler type current meters in the laboratory (Kraus et al. 1994), collection of accurate measurements has been greatly enhanced (Seabergh and Smith 2001). This also is true for field measurements. Osborne (2003) and Sherwood et al. (2001) obtained data sets in the high-energy environment adjacent to Grays Harbor, WA. Sherwood et al. (2001) describe measuring currents on the ebb shoal and adjacent regions at Grays Harbor. Helicopters have been used by Pollock (1995) to insert instruments into the energetic hydrodynamic environment near jetties at Siuslaw River, OR, and by Osborne et al. (2002) at the north jetty at Grays Harbor, WA. 


\section{Motivation}

The experiments in this study were designed to provide an extreme range of reflection coefficients for numerical modeling of waves and currents near inlet structures. Not only is this a severe test of numerical modeling capability, but it is also important in the representation of actual field conditions, where there are a variety of structures that may be modeled. Reflectivity depends primarily on the structure type and to some degree on water elevation and depth near jetty structure, and currents in the vicinity of the jetty.

Examples of the many jetty structures that need proper representation in numerical models are shown in Figure 2. In general, structures with high reflectivity include those with vertical sheet-metal or wood piles such as those seen in Figure 2a-2c. Lower reflectivity structures can be characterized by gentle side slopes and higher transmissibility such as large rubble-mound or preformed concrete unit structures (Figures 2d and 2e).

A “pier” type structure, composed of vertical wood pilings at White Lake Harbor, MI, is shown in Figure 2a. Interesting to note from Figure 2a is the high degree of wave reflection occurring for this structure. Figure $2 b$ shows complex configuration of rubble mound plus stone filled vertical sheet pile at the lakeside end at Charlievoix Harbor, MI. Another multi-component jetty at Big Bay Harbor, MI, with filled cellular construction at the lake end of rubble mound is shown in Figure 2c. These vertical sheet pile jetty elements are highly reflective. A more typical rubble mound jetty at San Marino Inlet, Guatemala, is shown in Figure 2d. At many locations in the United States, there are a variety of rubblemound jetties with stone size in proportion to the wave climate. Some rubblemound jetties may be more transmissive to wave energy at higher elevations in the structure, due to relatively large stone that have large voids. At lower levels of the structure, smaller core stone makes them impermeable to wave penetration. Figure 2e is a rubble-mound jetty that is being rehabbed at the seaward end with concrete Core-Loc armor at Manasquan Inlet, NJ. A jetty at Puerto Quetzal, Guatemala, with a solid concrete core that serves as a pier, flanked by armor units is shown in Figure 2f. All these examples indicate the large range of jetty types the modeler may encounter.

\section{Scope}

Following this introduction are descriptions of the laboratory facility and equipment used. Experiment basin bathymetry and scaling relationships are discussed in Chapter 2. The inlet structures studied, gauge layouts for various setups, and experimental wave conditions are discussed in Chapter 3. Examples of data collected, including velocity, wave height, wave direction, and dye current patterns are discussed in Chapter 4. Chapter 5 summarizes the report and presents conclusions. A CD containing the data collected is included with this report. 


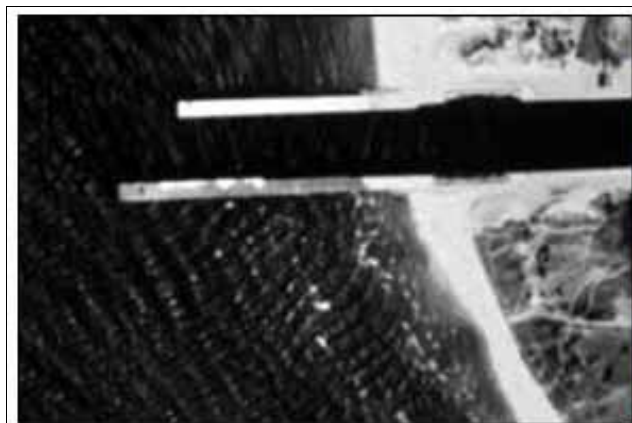

(a)

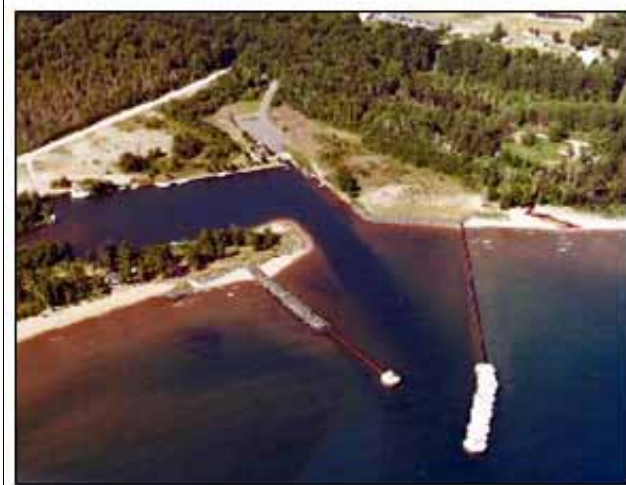

(c)

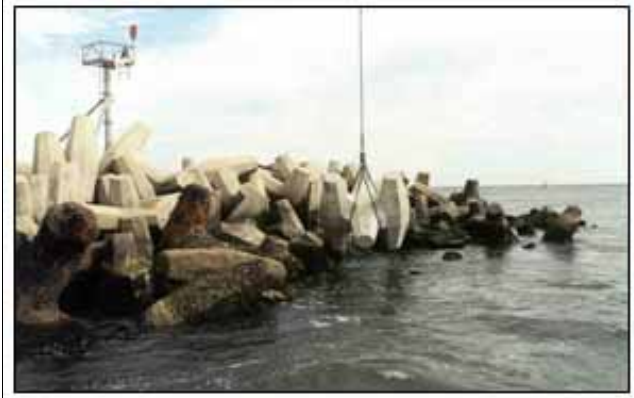

(e)

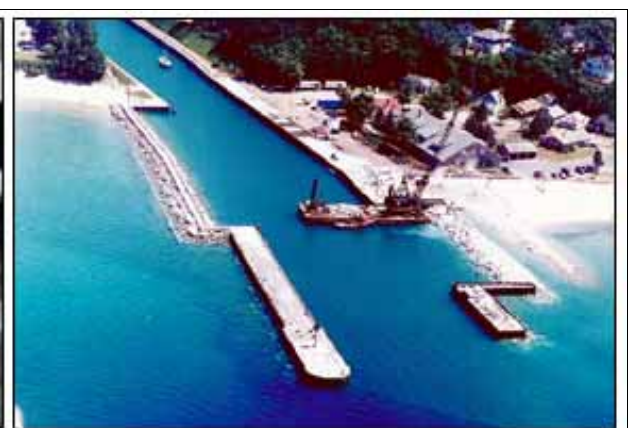

(b)

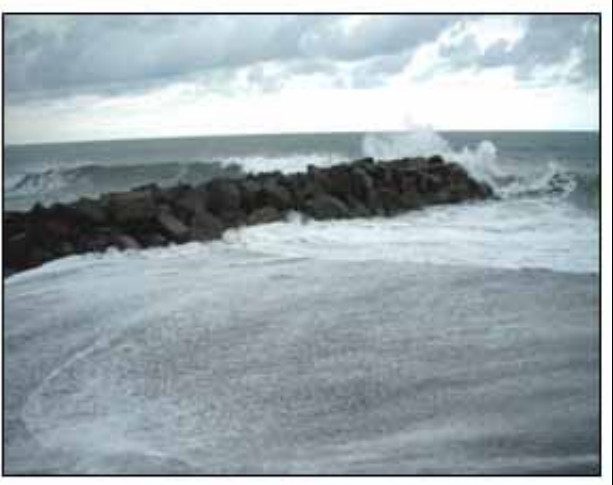

(d)

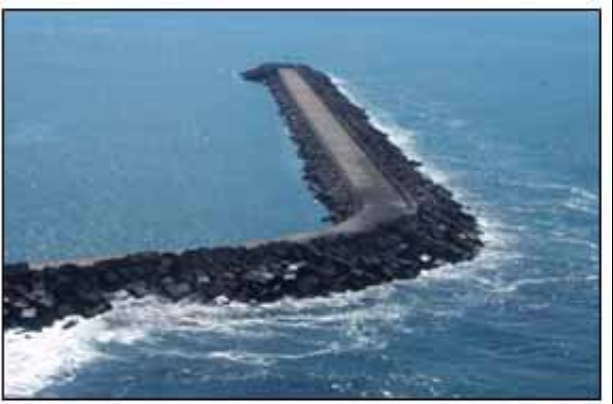

(f)

Figure 2. Jetty examples of varying wave reflectivity discussed in text 


\section{Laboratory Facility and Equipment}

As part of the CIRP, a physical model facility was created to address research and field problems of tidal inlets (Seabergh 1999). The model and appurtenances necessary to the study and procedures and analysis of data are discussed in this chapter.

\section{Idealized Inlet Facility}

An idealized inlet was designed within a $46 \mathrm{~m}(150 \mathrm{ft})$ wide by $99 \mathrm{~m}(325 \mathrm{ft})$ long concrete basin with $0.6-\mathrm{m}(2 \mathrm{ft})$ high walls. The approach was to design an inlet with simplified bathymetry and relatively steep beach slopes so additional features (such as an ebb shoal) could easily be added. Plans included using fine sand as both a tracer and as a fully mobile bed that could be placed over the concrete bottom in a thick veneer. A 1:50 undistorted scale was specified to determine reasonable inlet dimensions to model; however, other scales can easily be assumed to accommodate studies of specific processes with the simplified bathymetry.

The idealized inlet facility (Figure 3) is connected to a large sump (not shown), with volume of $1.98 \times 10^{6} \mathrm{~L}$ (523,000 gal) for water exchange. A tide may be produced in the facility's "ocean" to drive tidal currents into and out of the inlet bay. A constant inflow is introduced from the sump into the basin's ocean, and a rolling gate either reduces or increases flow area over an exit pipe into the sump that causes ocean rise or fall, respectively. The two cylinders in Figure 3 are storage tanks, each tank holding 182,000 L (48,000 gal) water. The tanks can be activated to simulate a much larger bay area by storing flood tide water and releasing it back to the bay to flow to the ocean during ebb flow. Pumps and control valves associated with this procedure are located adjacent to the storage tanks.

The piping system shown in Figure 3 can establish a steady-state flow for simulating ebbing or flooding currents. Water is either collected (flood flow) or distributed (ebb flow) through a system of manifolds in the bay that may be adjusted for one, two, or three bay channels or a uniform flow across the bay. Water is either released (flood flow) or taken from (ebb flow) the ocean headbay to complete the circulation energized by the pumps located in the upper right side of Figure 3. 


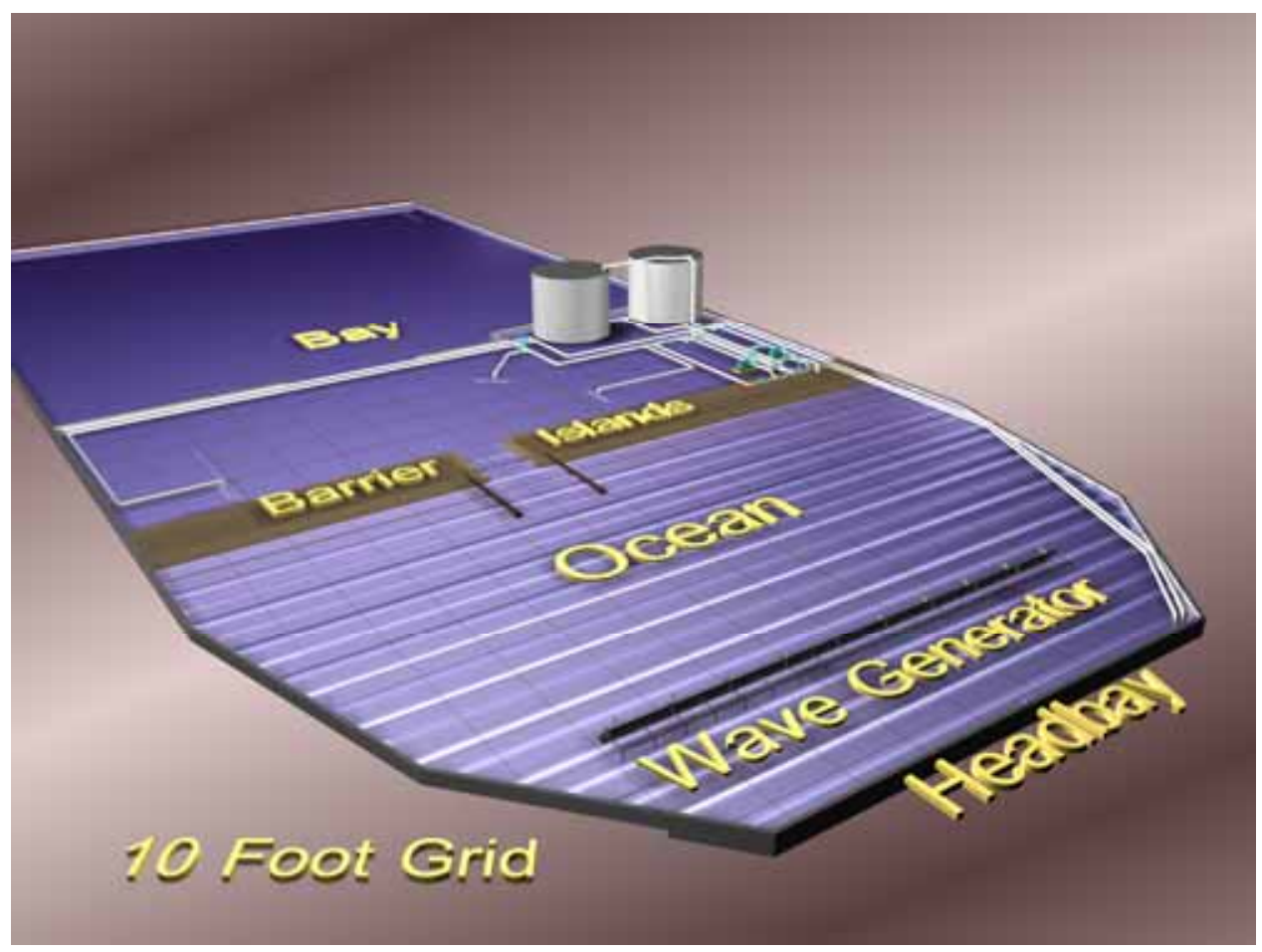

Figure 3. Idealized inlet model research facility

The ocean-side parallel contours (Figure 4) were specified by applying an equilibrium profile equation from Dean (1977).

$$
d=A x^{0.67}
$$

where

$d=$ still-water depth

$x=$ distance offshore from the shoreline

and $A$ is determined by sediment characteristics. A value of $A=0.24 \mathrm{ft}^{1 / 3}$ was specified to represent a relatively steep beach. The contoured beach slope extends

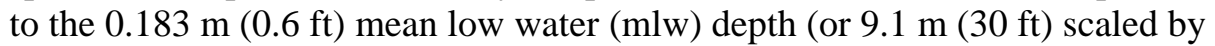
$1: 50)$.

The inlet throat region converges to a depth of $0.152 \mathrm{~m}$ (or if scaled to 1:50, to a depth of $7.6 \mathrm{~m}(25 \mathrm{ft})$ ) relative to a mlw datum. The minimum width is

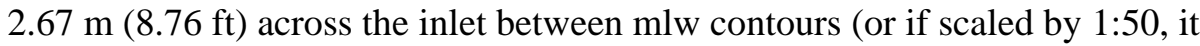
represents a width of $133.4 \mathrm{~m}(438 \mathrm{ft})$ ). The inlet with a parallel jetty configuration is shown in Figure 5.

Based on Froude's model law (Hughes 1993) and the linear scale of 1:50, the model-prototype relations in Table 1 were derived. Dimensions are in terms of length $(\ell)$ and time $(\mathrm{t})$. Figure 4 shows the model inlet during testing. As mentioned previously, other scales may be assumed for the bathymetric contours, so different scaling relationships would apply than those listed in Table 1. 


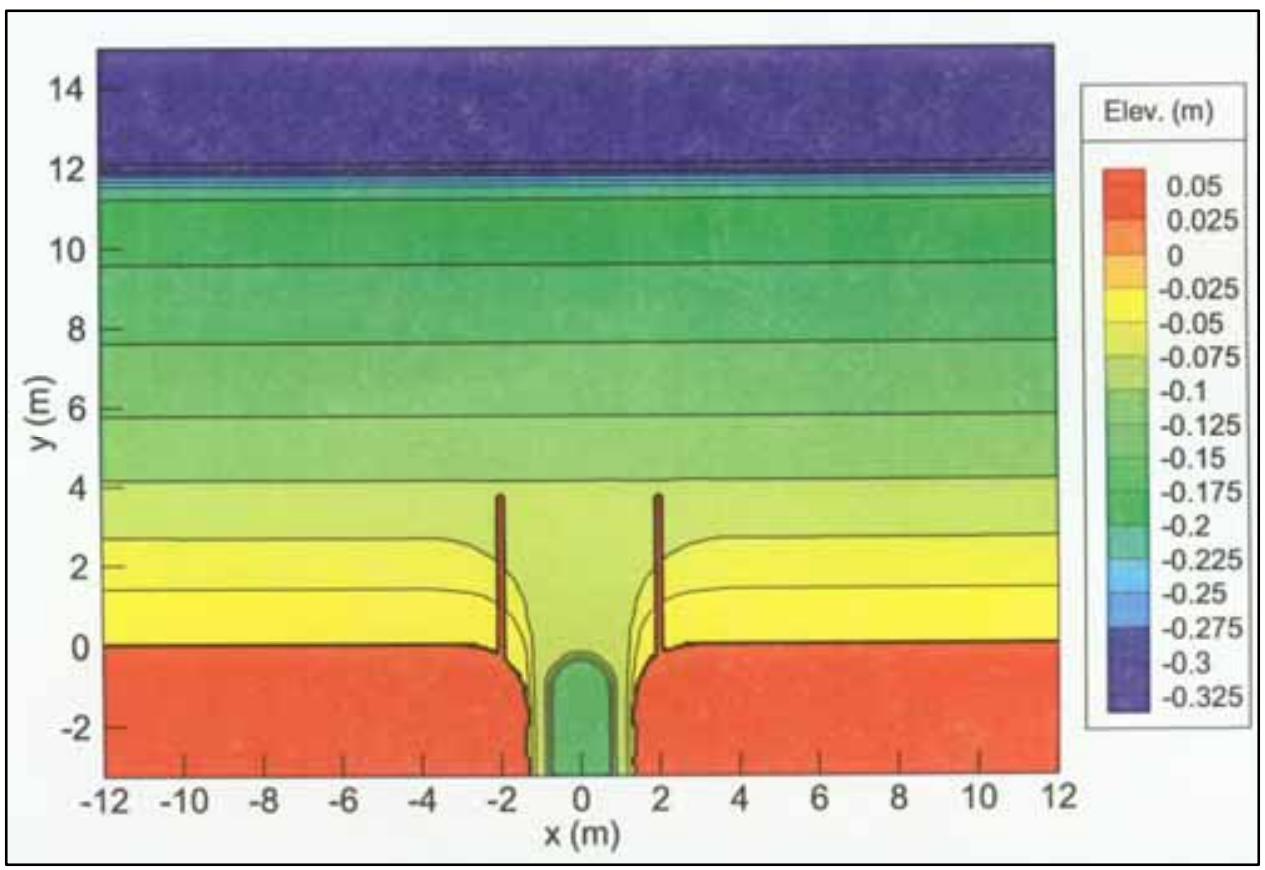

Figure 4. Contours in model units in idealized inlet

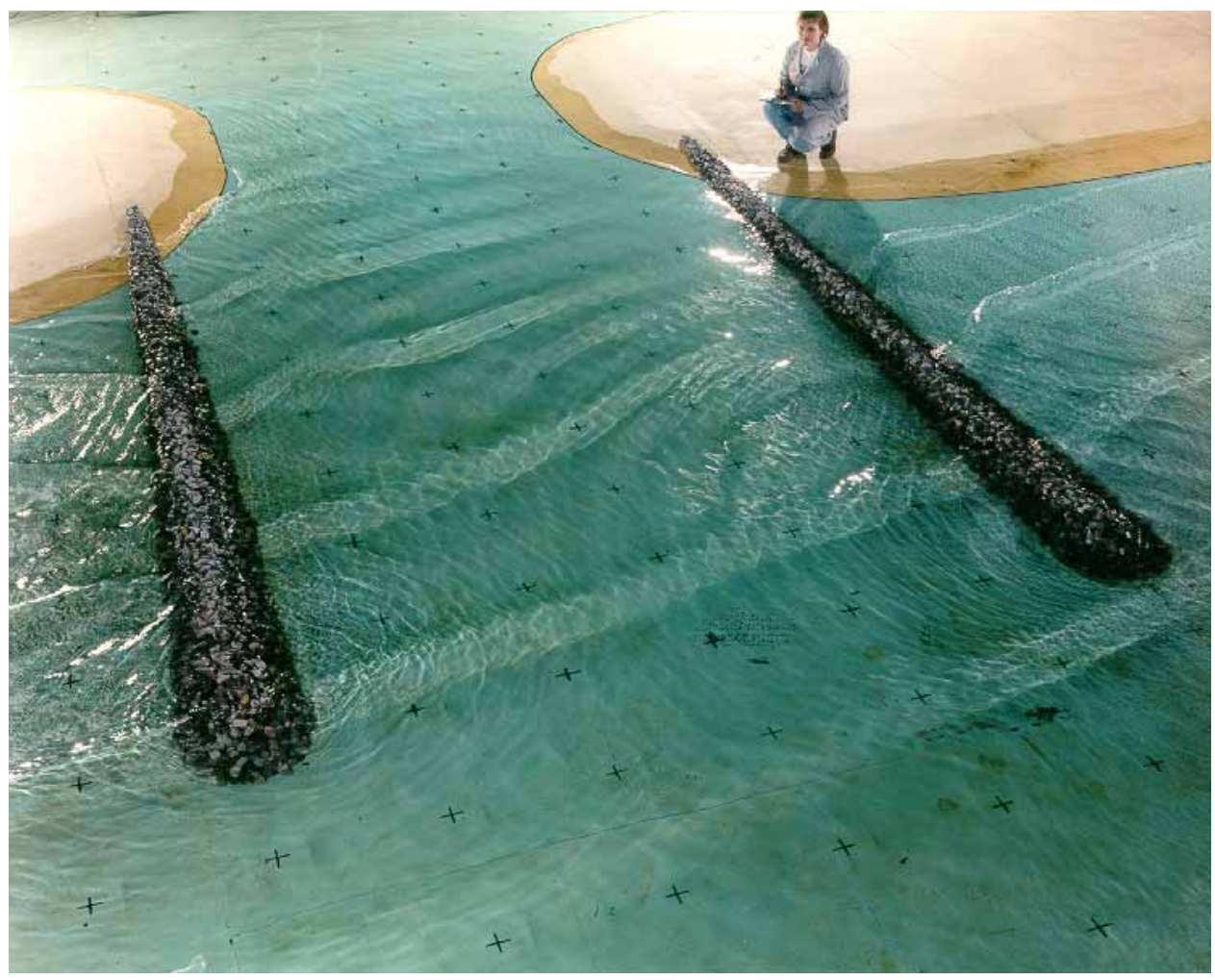

Figure 5. Idealized inlet entrance channel with obligue wave approaching inlet (spacing $0.62 \mathrm{~m}$ between "+" marking on research facility basin floor) 


\begin{tabular}{||l|l|l||}
\hline \hline $\begin{array}{l}\text { Table 1 } \\
\text { Model-Prototype Scale Relations at 1:50 Undistorted Scale }\end{array}$ \\
\hline \hline Characteristic & Dimension & Model-Prototype Scale Relation \\
\hline \hline Length & $\ell$ & $\ell_{r}=1: 50$ \\
\hline Area & $\ell^{2}$ & $\mathrm{Ar}=\ell_{r}^{2}=1: 2,500$ \\
\hline Volume & $\ell^{3}$ & $\mathrm{Vr}=\ell_{r}^{3}=1: 125,000$ \\
\hline Time & $\mathrm{t}$ & $\mathrm{Tr}=\sqrt{\ell_{r}}=1: 7.07$ \\
\hline Velocity & $\mathrm{Ur}=\ell_{r} / t_{r}=1: 7.07$ \\
\hline
\end{tabular}

A movable, 24-m-long (80-ft-long) unidirectional-wave generator (Figure 3) was located on the ocean side of the facility to produce either irregular or monochromatic waves. Unscaled wave periods can be varied from 0.5 to about $3 \mathrm{sec}$ and wave heights to $0.1 \mathrm{~m}$ (at the generator location and for this model configuration). Wave angle can be varied for specific tests by moving the generator on its castors.

\section{Instrumentation and Calibration}

Wave height and period data were collected on electrical capacitance wave gauges (Figure 6) that were calibrated daily with a computer-controlled procedure. The calibration procedure incorporated a least square fit of measurements at 11 steps that were determined by moving the wave rod incrementally through still water. This averaging technique, using 21 voltage samples per gauge, minimizes the errors of slack in the gear drives and hysteresis in the sensors. Typical wave height calibration errors are less than 1 percent of full scale for the capacitance wave gauges. Wave signal generation and data acquisition were controlled by a personal computer.

Velocity data were collected with SonTek 2D Acoustic Doppler Velocimeters (ADV) with a side-looking probe (Figure 7) that was oriented to collect $\mathrm{x}-$ $y$ horizontal velocity information in a

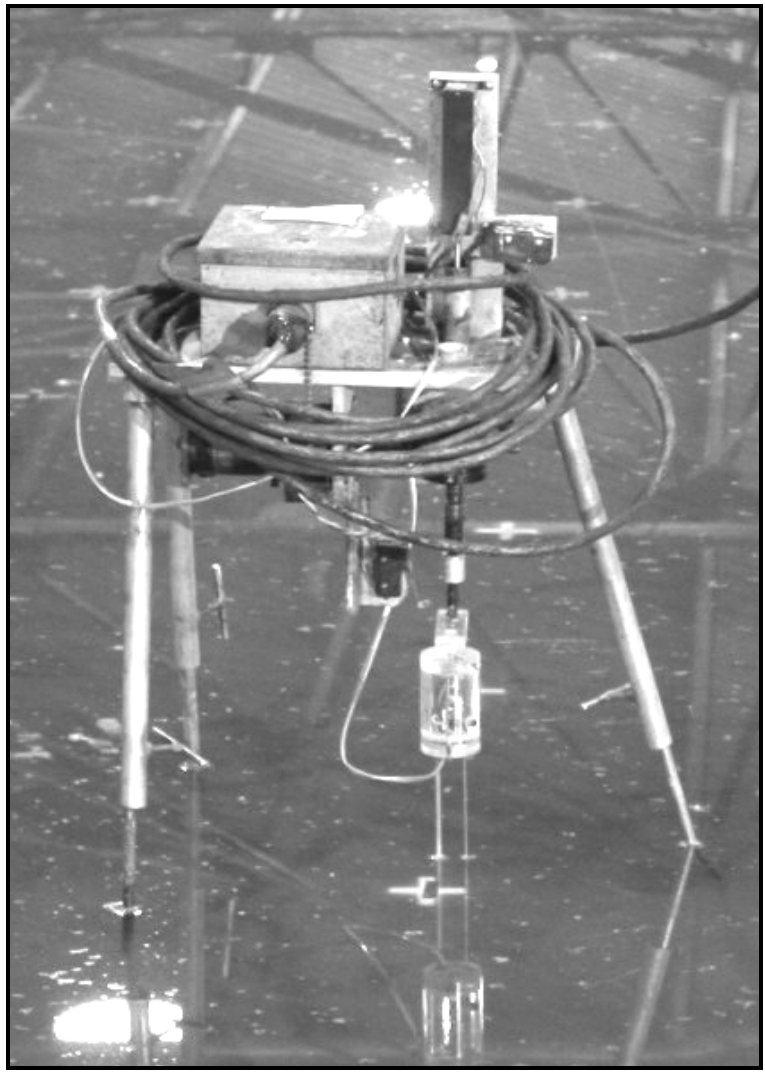

Figure 6. Capacitance wave gauge horizontal plane. Samples were collected at $20 \mathrm{~Hz}$, though the instrument makes 250 pings/sec and averages for each output sample. Accuracy is 0.5 percent of the measured velocity, with resolution of $0.1 \mathrm{~mm} / \mathrm{sec}$ and threshold of $0.1 \mathrm{~cm} / \mathrm{sec}$. The probe samples a $0.25 \mathrm{cu} \mathrm{cm}$ 


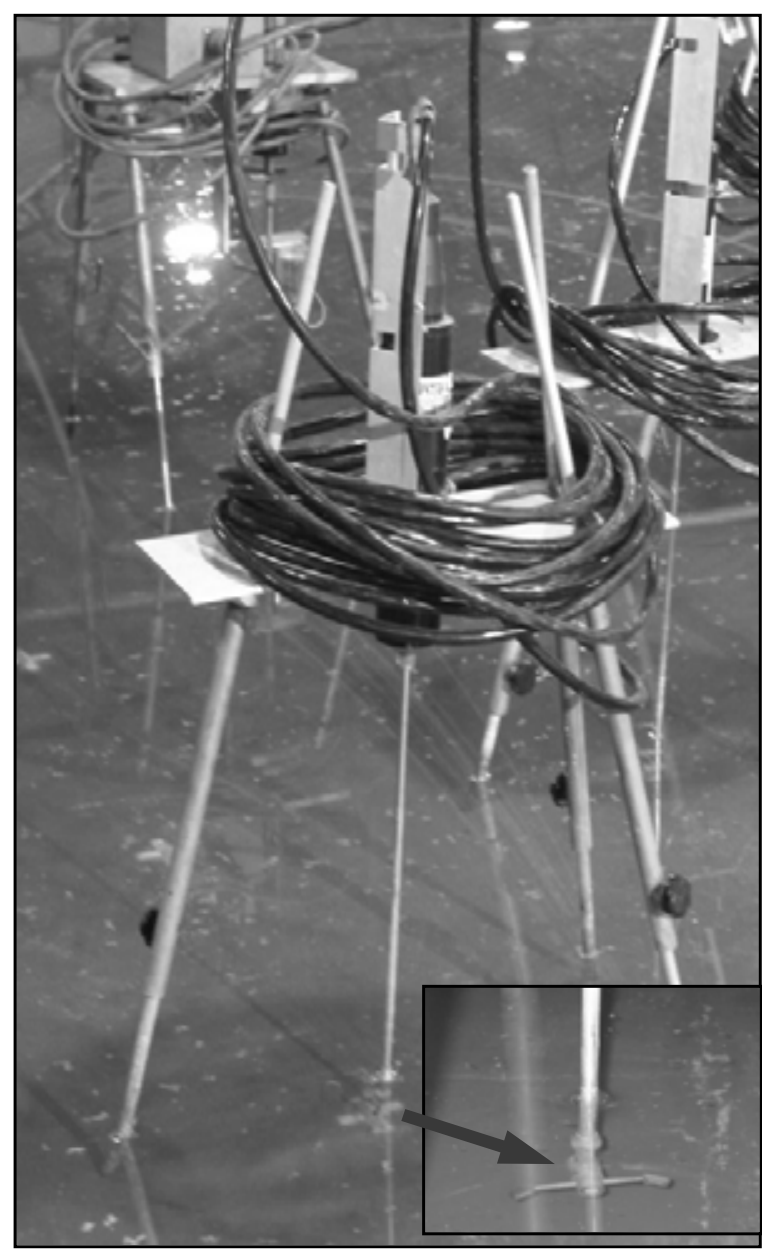

Figure 7. Acoustic Doppler Velocimeter
(0.015 cu in.) volume located $5 \mathrm{~cm}$ ( 2 in.) from the sensor heads. The velocity data also were analyzed for wave direction.

The sensor placement locations are discussed in Chapter 3. A gauge rack was designed to hold the velocity sensors in a co-linear manner, with a $0.61 \mathrm{~m}$ $(2.0 \mathrm{ft})$ separation between gauges. The rack could be moved to other locations for various test runs as described in Chapter 3.

\section{Data Sampling and Wave Generation}

Following daily calibration of the wave gauges and incident wave conditions, the experiments began and either current or wave data were collected. The wave generator was operated for $600 \mathrm{sec}$ with a 10-sec ramp-up and ramp-down time. The wave gauge-sampling rate was $20 \mathrm{~Hz}$, and 12,000 water elevation data points were collected at each gauge. Velocity data samples (a $20-\mathrm{Hz}$ sampling rate) for each sensor were usually of slightly shorter duration, as data collection was not initiated until a short time after waves began.

All wave tests were monochromatic, and no flood or ebb currents were generated in the model. This was done to establish a more consistent circulation pattern that would be easier to interpret and compare to the numerical model results.

\section{Data Analysis}

Wave data included with this report were analyzed by simple averaging of the middle one-third of the $20-\mathrm{Hz}$ water-level measurements. These data are tabulated in Appendix B. The raw data are included as an ASCII text file in units of meters on a compact disk (CD) included with this report. Each record has 12,000 data points with time interval $\Delta \mathrm{t}=0.05 \mathrm{sec}$.

The velocity data are collected in a special format that must be interpreted by a program specific to the Sontek current meter. Such a program has been written by Mr. Tony Wahl (U.S. Bureau of Reclamation). This program may be downloaded from the web at: 
http://www.usbr.gov/pmts/hydraulics lab/twahl/winadv/index.html. The raw data files are included on the CD, and the analyzed resultant data are included in Excel spreadsheet format. Plots of the data are contained within the spreadsheet. The current meters have an internal coordinate convention with respect to flow direction. Five of the six meters had the same x-y convention (Probes 1 thru 5, Figure 8 ) with the sixth (Probe 0 ) having the positive $x$-axis opposite to that of the others. Outside the jetties, the raw velocity data had a $\left(\mathrm{x}^{\prime}, \mathrm{y}^{\prime}\right)$ coordinate system (Figure 8) and inside the jetties a $\left(\mathrm{x}^{\prime \prime}, \mathrm{y}^{\prime \prime}\right)$ coordinate system (Figure 8). The current measurements were all adjusted to a common $(\mathrm{x}, \mathrm{y})$ convention used by many modelers, with positive $\mathrm{x}$-axis shoreward and positive $\mathrm{y}$-axis along the coast as shown in Figure 8. Final velocity components also followed this system (Figure 8). If the user would like to start with the raw data, the user's resultant data should be compared with the final data set included on the CD to ensure the correct coordinate directions are achieved. Also, there is a text file in the CD explaining the directional convention of each velocity probe and its orientation relative to the coordinate system.

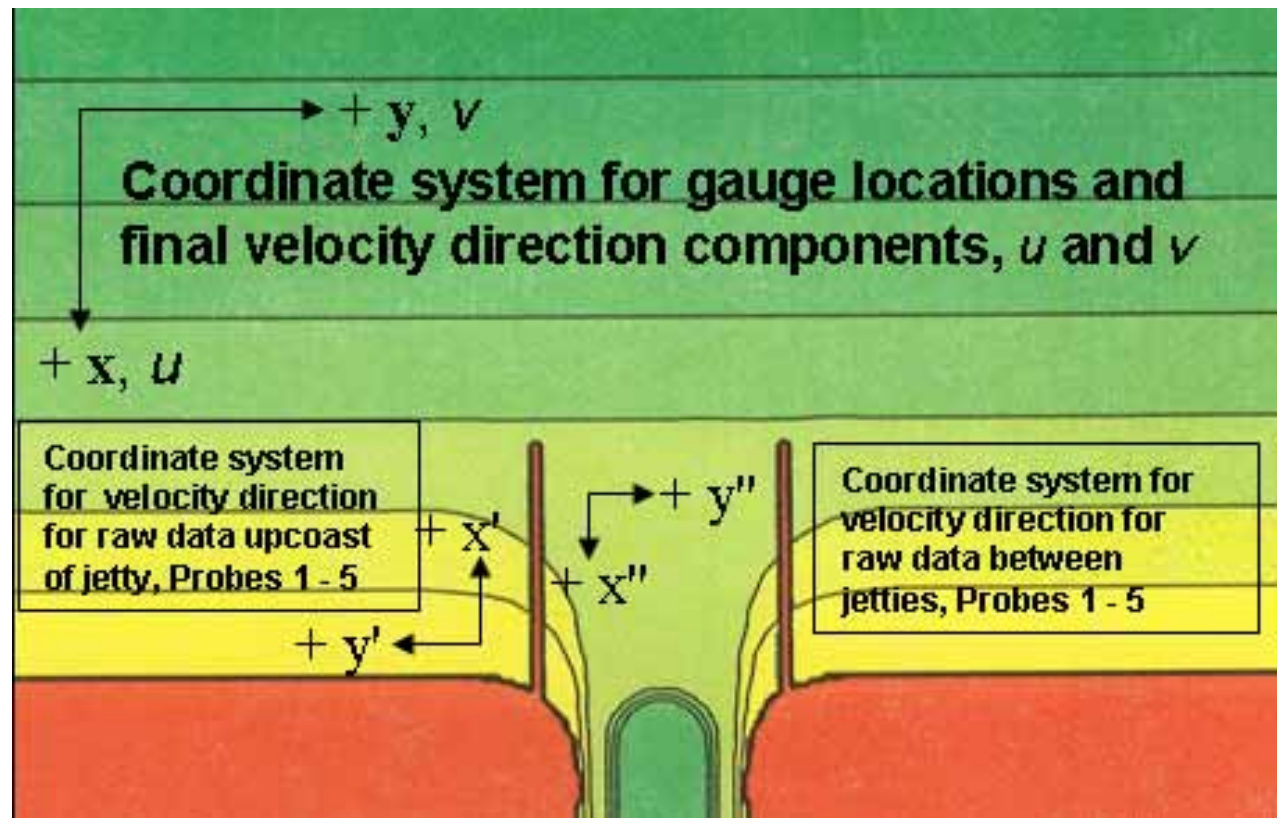

Figure 8. Coordinate system convention for data. Upper left $(x, y)$ coordinate system for gauge locations and final velocity data. Lower $(x, y)$ coordinate system for raw velocity data upcoast of jetties

Wave direction was calculated as follows. Based on a standard stochastic method, the wave propagation direction was determined from velocity component measurements in the two orthogonal directions (Cartwright 1963; Long 1980). For instance, if $u$ and $v$ represent time series of wave orbital velocity components measured in the easting and westing directions, respectively, the wave direction $\theta$ associated with a frequency, $f$, can be computed as: 


$$
\theta(f)=\frac{1}{2} \tan ^{-1}\left\{\frac{2 R_{u v}(f)}{R_{u u}(f)-R_{v v}(f)}\right\}
$$

where $R_{u u}(f)$ and $R_{v v}(f)$ are spectra of u and v signals, respectively, and $R_{u v}(f)$ is the co-spectrum of $\mathrm{u}$ and $\mathrm{v}$ signals. The direction for waves was measured counter-clockwise from the positive $\mathrm{x}$-axis and is given as the direction the wave is propagating towards. 


\section{Experiment Gauge Setup, Layout, and Conditions}

This chapter provides information on the experiment setup, locations of data collected, and data collection procedure and analysis. Selected example plots of data are also shown.

\section{Jetty Description}

The initial jetty setup was designed to be of a nonreflecting nature. This was achieved by lining the up-shore face of an impermeable rock jetty with a fibrous material used for wave absorption at the boundaries of physical models. Wire mesh held the absorber in place. A photograph of the jetty is shown in Figure 9. The second jetty setup was designed for a totally reflecting type. A plywood face (Figure 10) was placed at the edge of the fibrous material so that the same location was maintained for the edge of the jetty as the nonreflecting type.

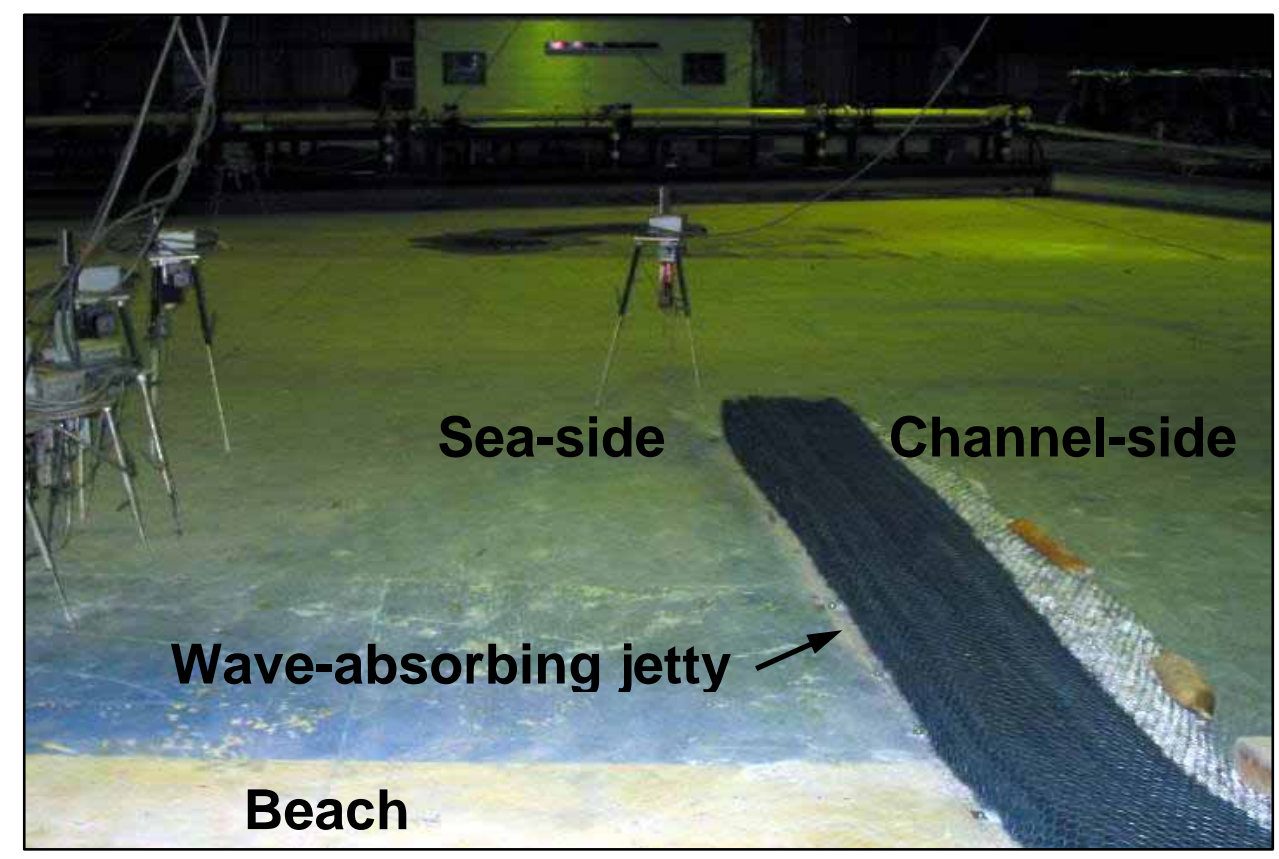

Figure 9. Wave-absorbing jetty perpendicular to shore in physical model 


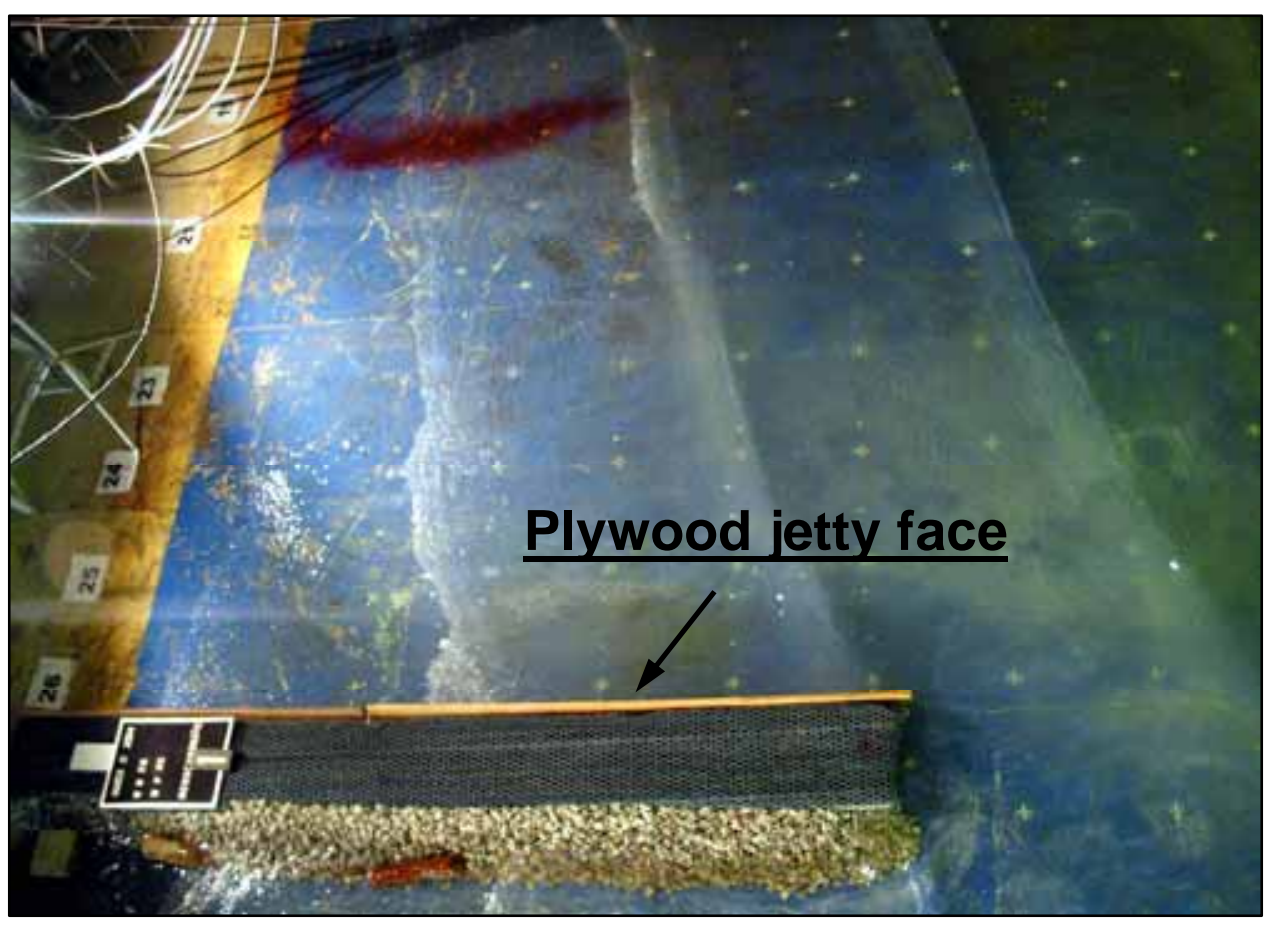

Figure 10. Plywood reflecting jetty face

\section{Data Sampling Locations}

The main objective of these experiments was to collect velocity and current data for numerical model calibration in the region upcoast (or upwave) of an inlet jetty system, as comprehensive data sets have not been available for model calibration in this part of an inlet system. As the experiments progressed, the addition of wave and current data in the region between the jetties was added. Even though tidal currents were not being reproduced for these experiments, circulation currents normally are generated by wave activity in the channel area between the jetties. Wave heights also were measured in this region. Photographs of wave gauges during data collection and ADV meters are shown in Figures 11 and 12. When wave and current measurements were collected in the region between the jetties, a six-position gauge rack was used to hold the gauges. Figure 13 shows the rack with six current meters.

Schematic diagrams of gauge location for the wave gauges and current meters for the region upcoast of the jetty are shown in Figures 14 and 15. Figure 16 shows wave gauge locations inside the jetty region. The complete set of data locations is shown in Appendix A. The location of gauges defined by $\mathrm{x}, \mathrm{y}, \mathrm{z}$ coordinates (see Figure A1 for orientation of axis) are listed in tables in Appendix A. Wave gauges were organized by "transect" numbers. Each transect had eight gauges, with Channel 1 gauge always being the incident wave gauge near the wave generator (see Figure 14). Channels 2 through 8 progressed shoreward along the transect. Current meters were identified by probe number and organized in "range" numbers (Figure 15). 


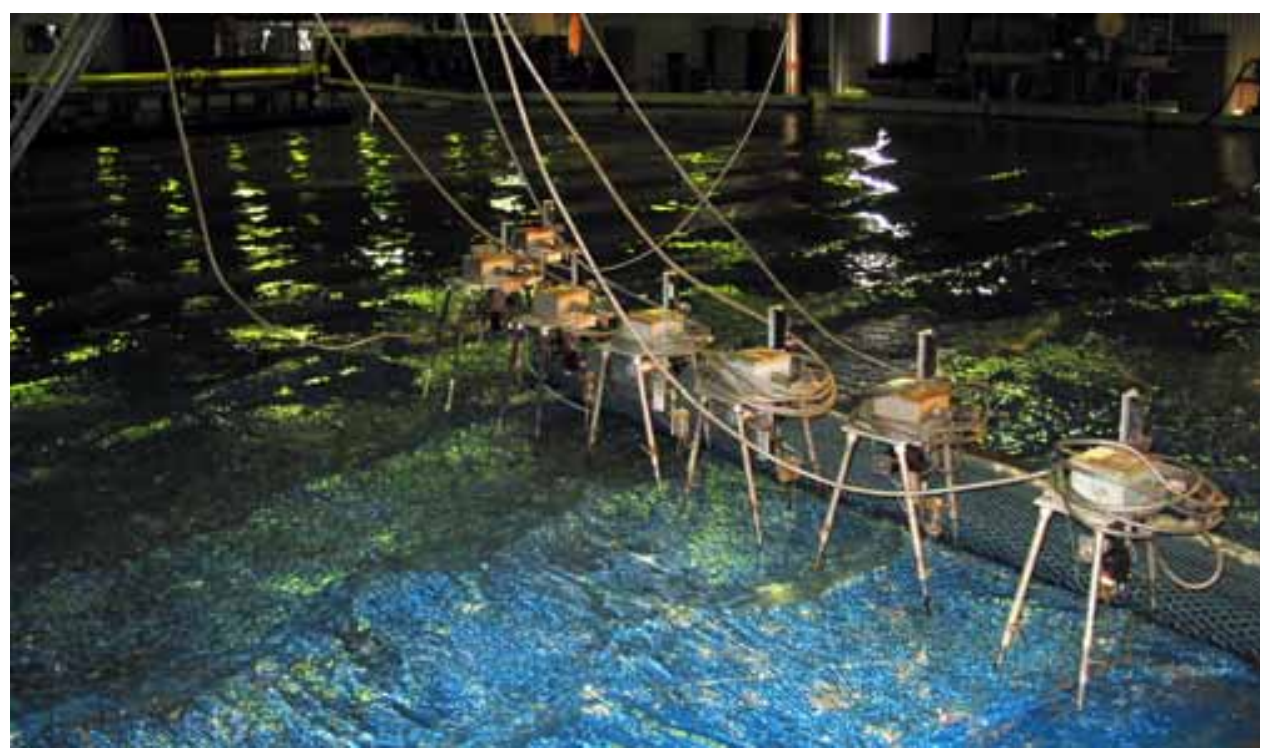

Figure 11. Wave gauges near jetty

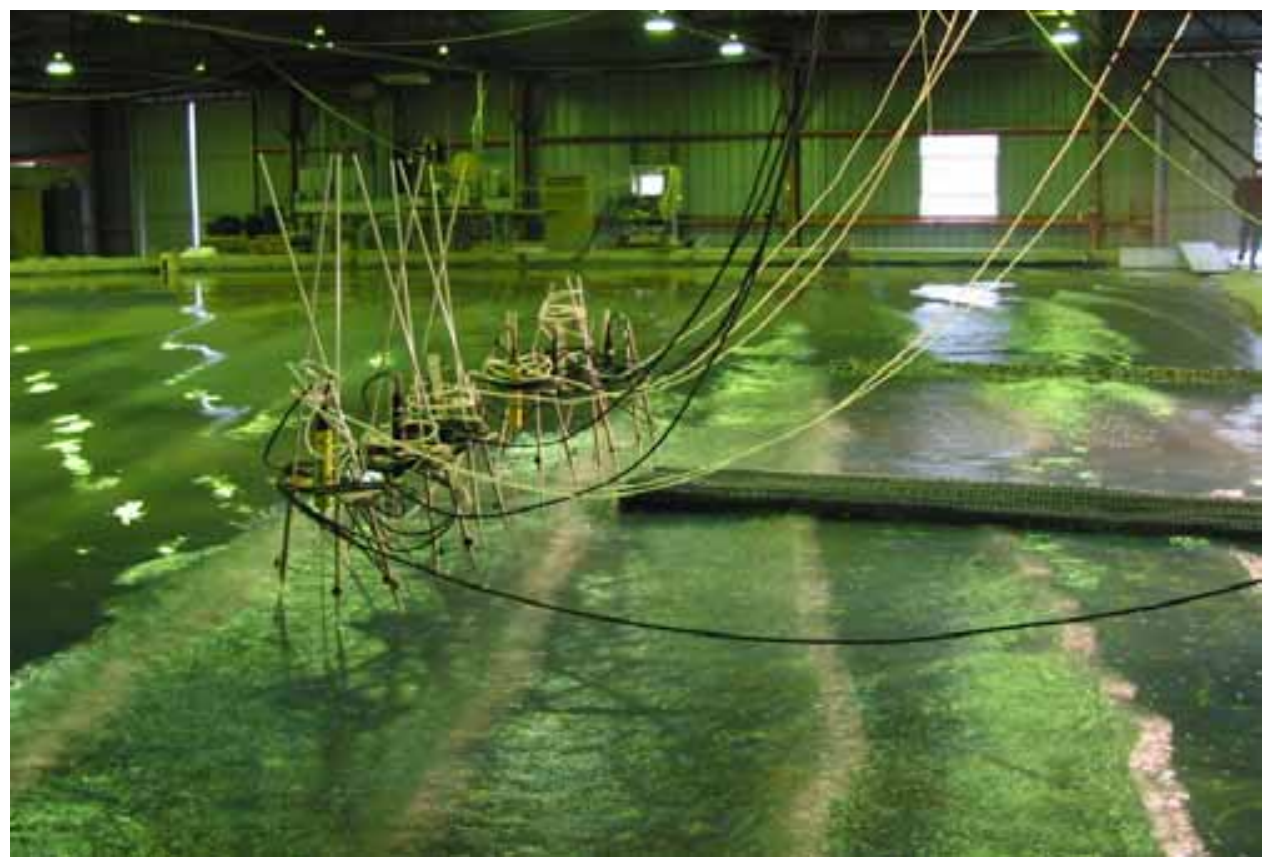

Figure 12. Current meters seaward of jetty 


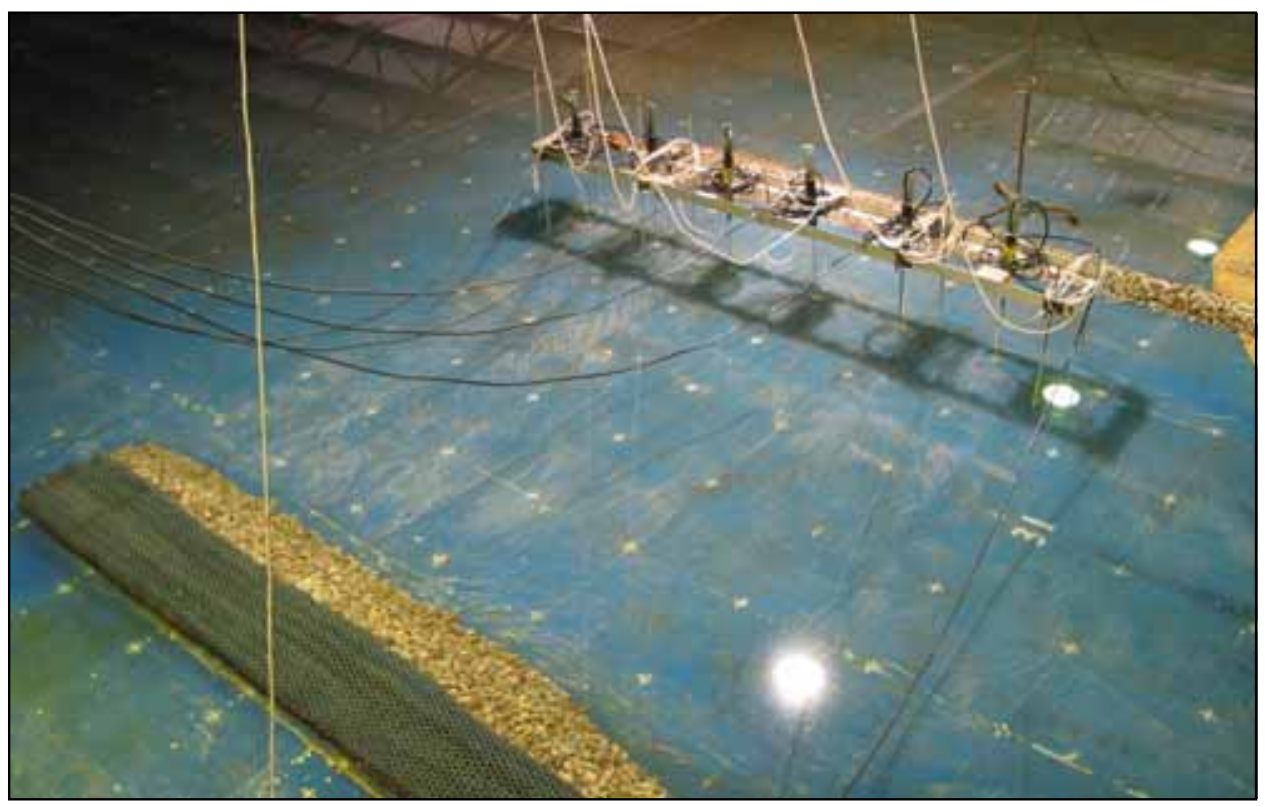

Figure 13. Rack holding six current meters in entrance channel

\section{Spur Jetty Experiment}

The last experiment setup was designed for a three-spur jetty structure (Figure 17). Current and wave height measurements were collected at many of the same locations discussed for earlier experiments. The structure in this case was composed entirely of rock and had an impermeable core. A detailed gauge location for this experiment is described in Appendix A.

\section{Experiment Conditions}

\section{Waves}

The experiments were conducted with only waves being reproduced in the model basin. All currents measured were derived from the waves. Some current measurements were purely oscillatory under the wave motion, whereas in a region of breaking waves a net current is measured. The incident waves at the seaward channel boundary were always monochromatic for these experiments and initial wave crest was 20 deg with respect to the shore (Figure 15) or 20 deg counter-clockwise from the x-axis. Table 2 presents wave heights and periods reproduced in the present study.

As noted in Table 2, only the first three experiment conditions were run for data in the channel. The in-channel data should be similar for both the absorbing and reflective conditions as the change was only for the outside part of the jetty. Inside the channel, both jetties were rock with an impermeable core. 


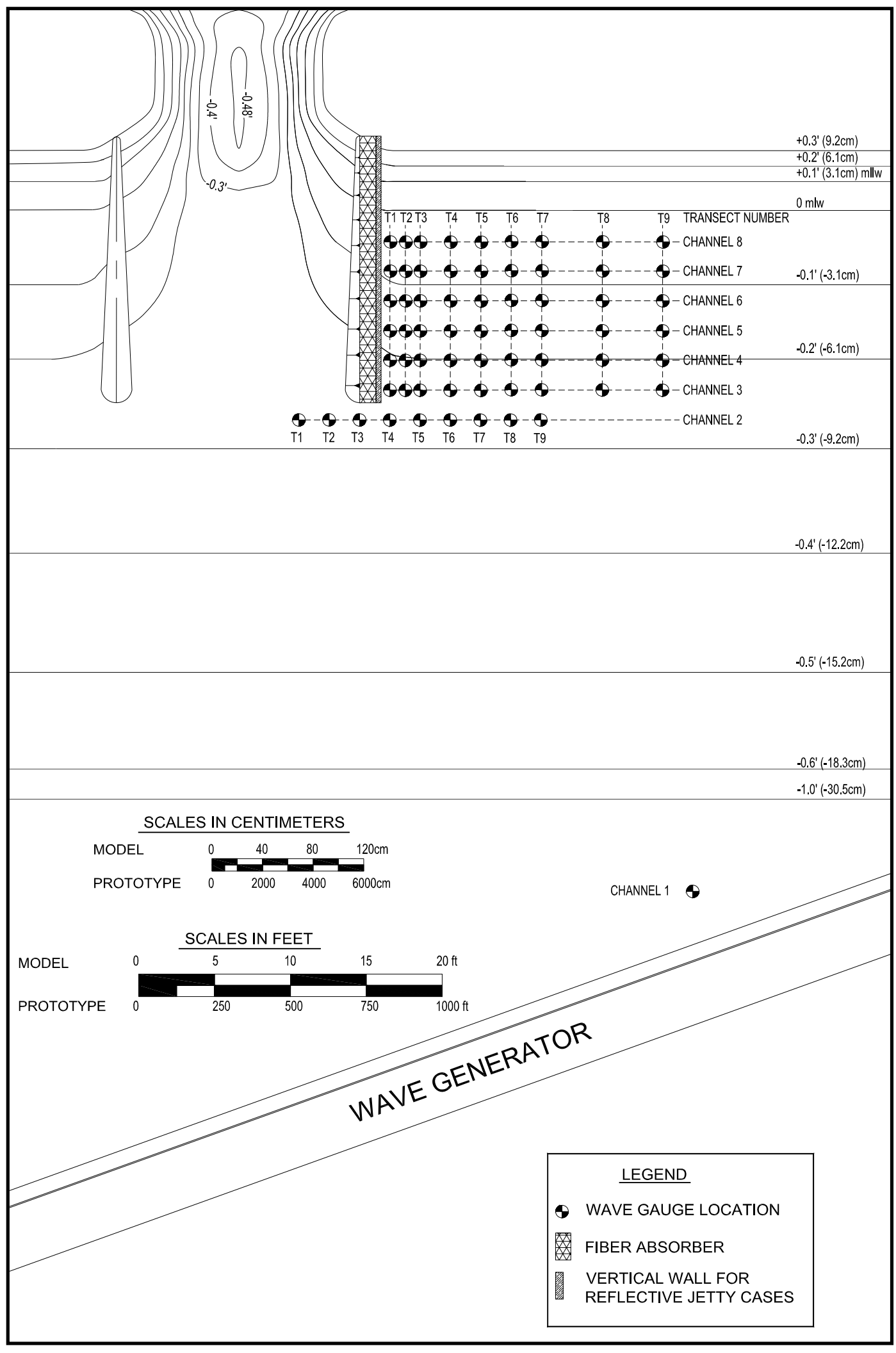

Figure 14. Wave gauge locations upcoast of jetties 


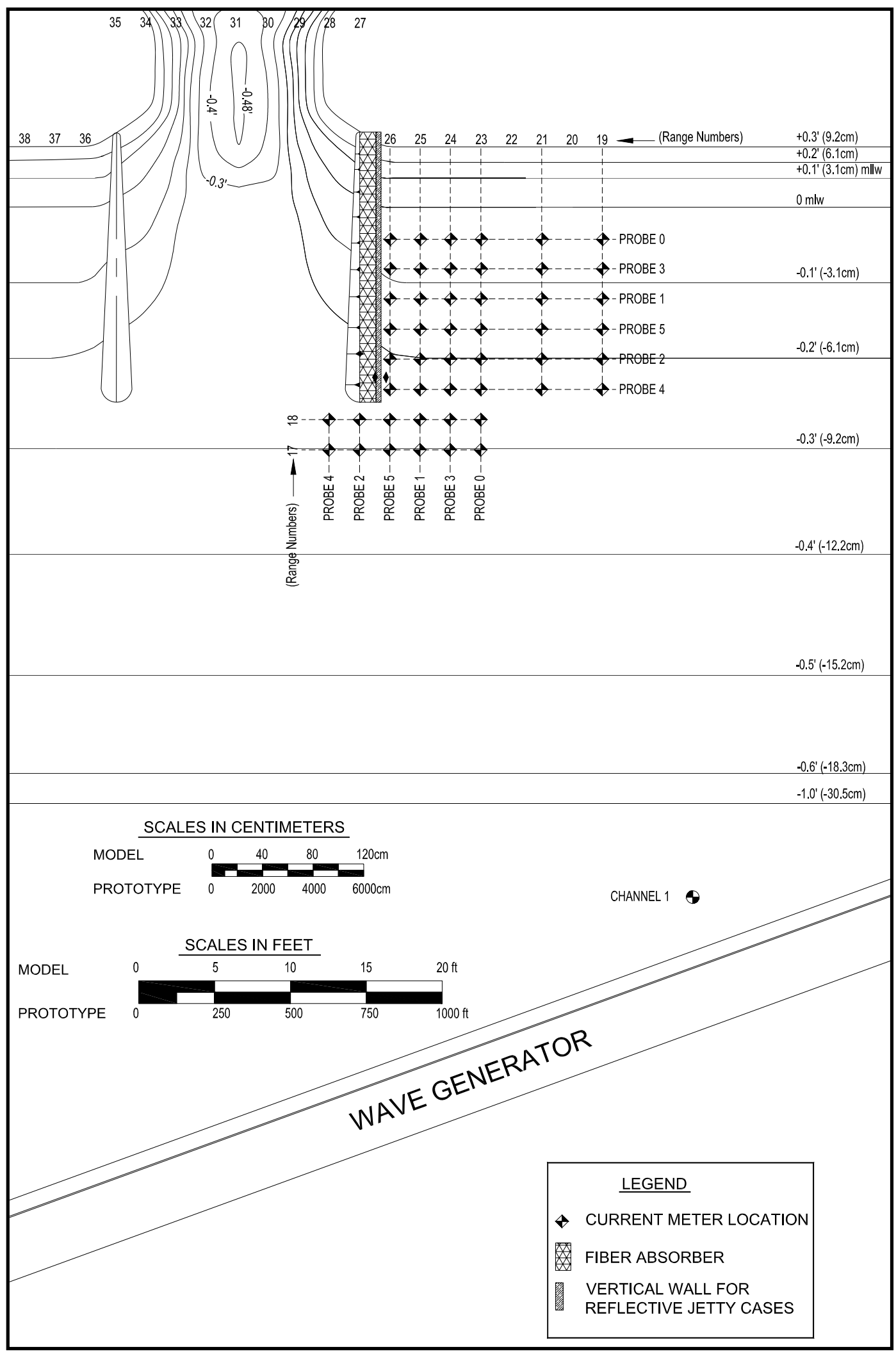

Figure 15. Current meter locations upcoast of jetties with probe number shown for various range numbers. Unscaled contours shown in feet and centimeters 


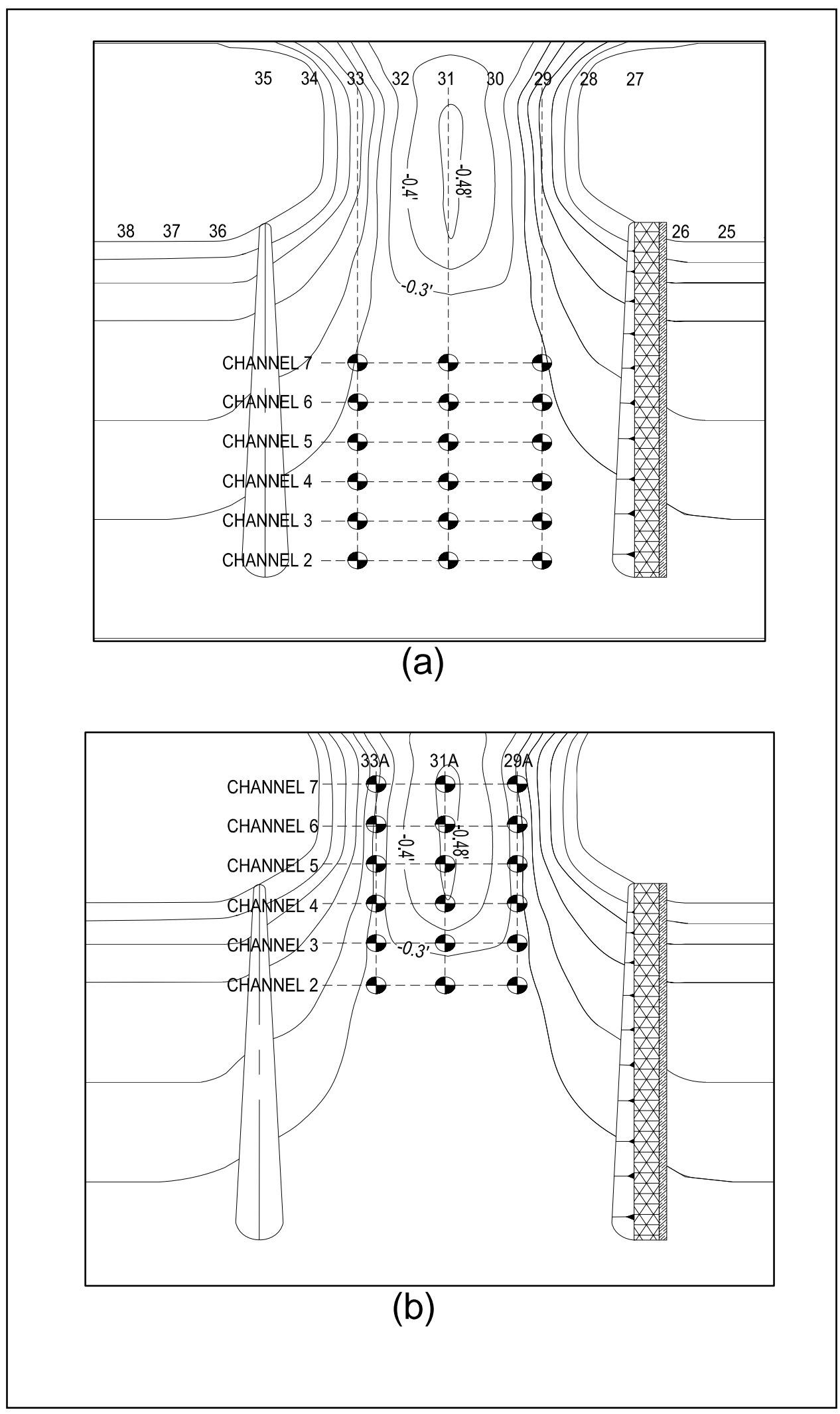

Figure 16. Wave gauge locations (a) in outer portion of channel and (b) inside portion. Range numbers shown at top of figure 


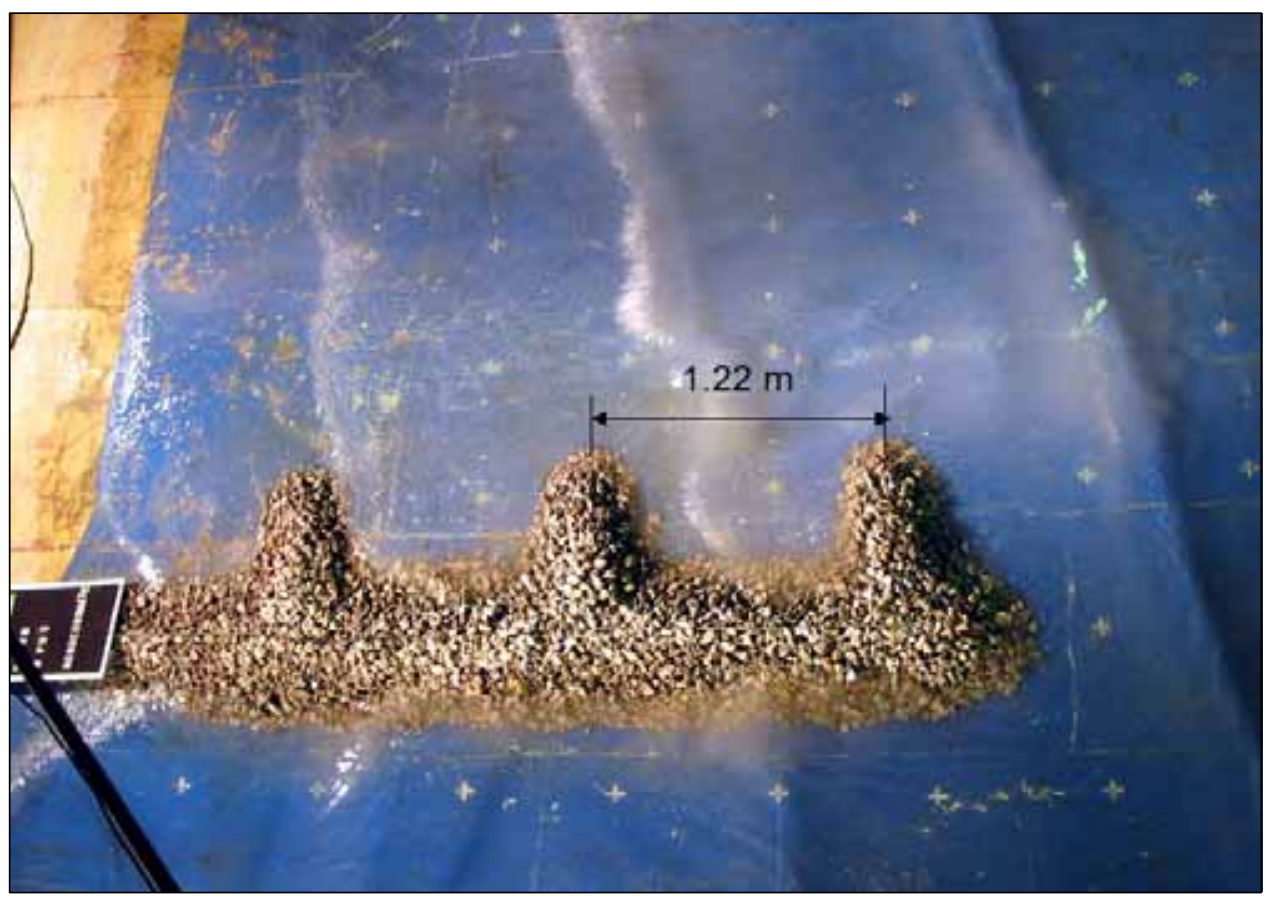

Figure 17. Spur jetty

\begin{tabular}{|c|c|c|}
\hline Jetty Type & $\begin{array}{l}\text { Incident Wave Height, } \mathrm{m} \\
\text { (Prototype Scale, 1:50, m) }\end{array}$ & $\begin{array}{l}\text { Wave Period, sec } \\
\text { (Prototype Scale, 1:7.07, sec) }\end{array}$ \\
\hline Absorbing & $0.02(1.0)$ & $1.56(11)$ \\
\hline Absorbing & $0.04(2.0)$ & $1.56(11)$ \\
\hline Absorbing & $0.07(3.4)$ & $1.13(8)$ \\
\hline Absorbing & $0.02(1.0)$ & $1.13(8)$ \\
\hline Absorbing & $0.033(1.65)$ & $1.56(11)$ \\
\hline Reflecting & $0.02(1.0)$ & $1.56(11)$ \\
\hline Reflecting & $0.04(2.0)$ & $1.56(11)$ \\
\hline Reflecting & $0.02(1.0)$ & $1.13(8)$ \\
\hline Reflecting & $0.07(3.4)$ & $1.13(8)$ \\
\hline Reflecting & $0.015(0.75)$ & $1.13(8)$ \\
\hline Spur & $0.02(1.0)$ & $1.56(11)$ \\
\hline Spur & $0.04(2.0)$ & $1.56(11)$ \\
\hline Spur & $0.07(3.4)$ & $1.13(8)$ \\
\hline
\end{tabular}




\section{Water level}

The experiments were conducted with a constant water level. The water surface elevation was at $0.33 \mathrm{~m}$ (1.52 m prototype) above the low water datum.

\section{Additional Information}

The contoured region of the experimental facility is molded to templates with concrete mortar. The surface has a smooth troweled finish and has been painted. An estimated Manning's n for this surface is 0.015 .

The absorbing jetty (Figure 9) was composed of fibrous rubberized hair filter material. Keulegan (1972) examined this material in a laboratory study. From his data it may be estimated that the coefficient of reflection for the jetty ranges from 0.10 to 0.25 . The reflective jetty was constructed of smooth, 3/4-in. marine plywood. The spur jetty was constructed of rock with a typical diameter in the range of 1- to 2.5-in.

Other data collected included dye visualization, documented with still and video photography. These data are discussed in Chapter 4. 


\section{Discussion of Results}

This chapter provides a discussion of the data and how to interpret the data. Also discussed are the differences noted in response between the wave-absorbing jetty, the fully reflecting jetty and a spur jetty.

\section{Steady-State Data Segments}

The raw wave height and velocity data included with this report are the entire time series, from initiation of wave generation to its conclusion. Therefore, transient conditions also are captured. This section is provided to guide the user in choosing appropriate windows of the data, if desired. If the forcing conditions are near steady-state in an experiment, a more or less steady-state condition is reached after a period of time. The user may be interested in the initial transient event, but most likely will analyze or model the near steady-state portion of the data. Examination of wave height measurements shows that for the smaller wave heights (0.02 m height, $1.56 \mathrm{sec}$ period), about $100 \mathrm{sec}$ is required to reach steady-state. The total time of data recording is $600 \mathrm{sec}$. The steady-state time also is dependent on location of the measurement, and can be less (farther away from the jetty) where wave-current interaction is less. Larger waves (e.g., $0.04 \mathrm{~m}$ height, $1.56 \mathrm{sec}$ period) may require up to $200 \mathrm{sec}$ for relatively steady-state conditions. Figure 18 shows wave height measurements at the wave generator (channel 1) and along the jetty at Transect 1, channel 6 (see Figure 14) for the 0.04-m, 1.56-sec wave (absorbing jetty). Gauge locations are shown in Figure 14.

Current measurements have about the same steady-state setup time as for wave measurements. Figure 19 shows an example of current data for a location near the absorbing jetty (see Figure 15 for location). Current speeds represent the wave orbital velocity, and the net current for the $\mathrm{x}$ and $\mathrm{y}$ components can be seen to be greater than zero. Current is near-steady-state from 200 to $500 \mathrm{sec}$.

Figure 20 shows a 10-sec segment of the record seen in Figure 19.

\section{Results}

This section provides examples and examination of the data collected. Sample contour plots of currents and wave heights are shown. Illustrative plots of current direction and wave direction are also presented. 


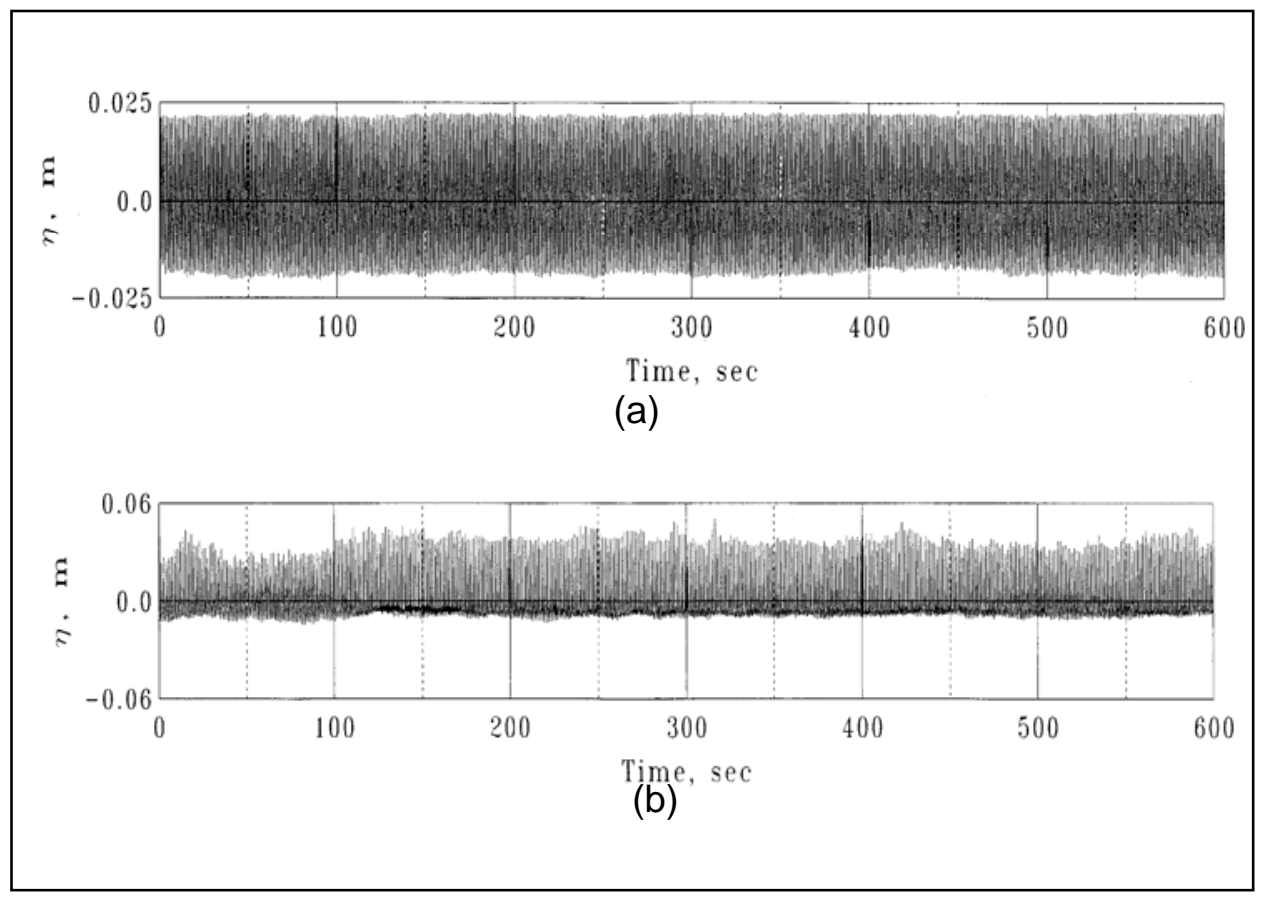

Figure 18. Wave height measurements (in meters) showing (a) waves at generator and (b) waves along Transect 1, channel 6

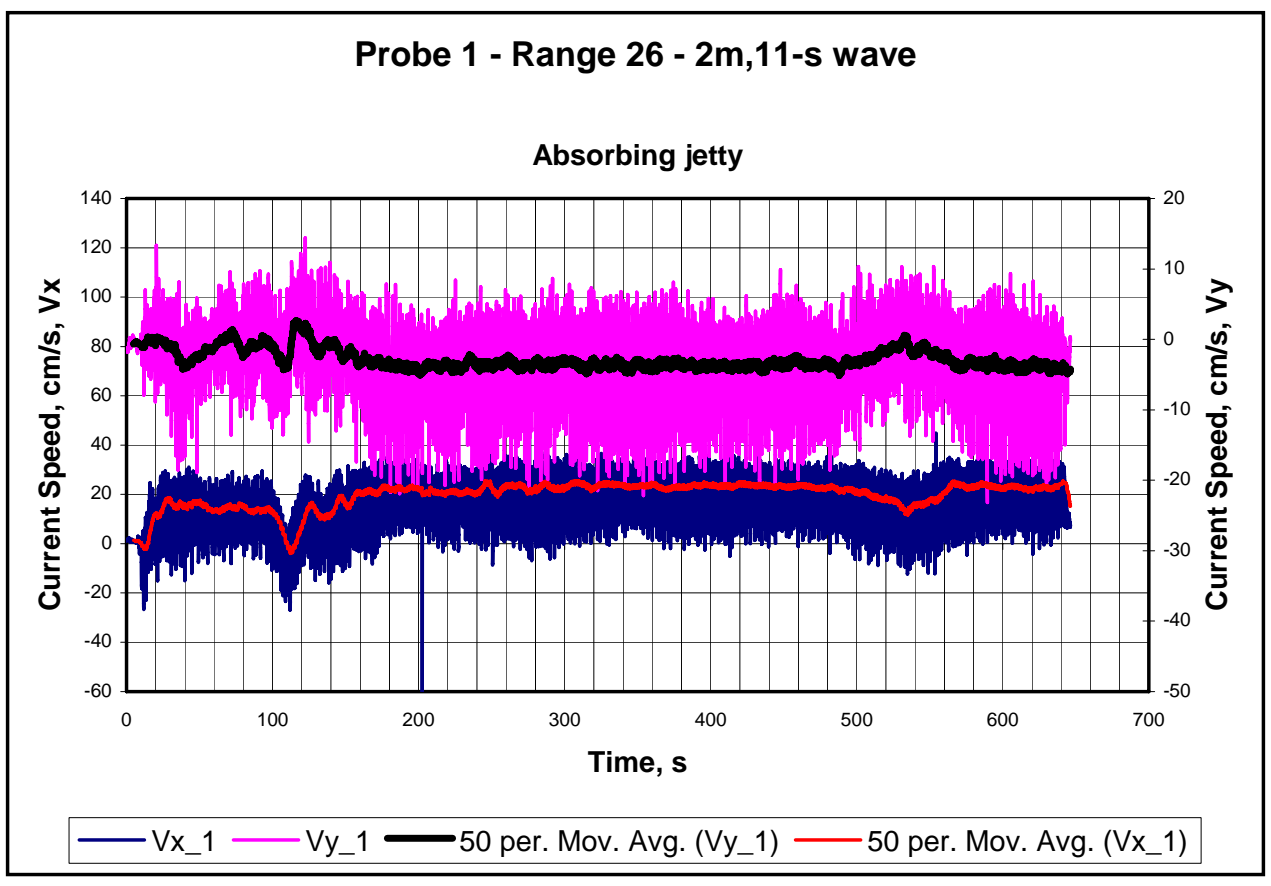

Figure 19. Current speed at Range 26, probe 0 


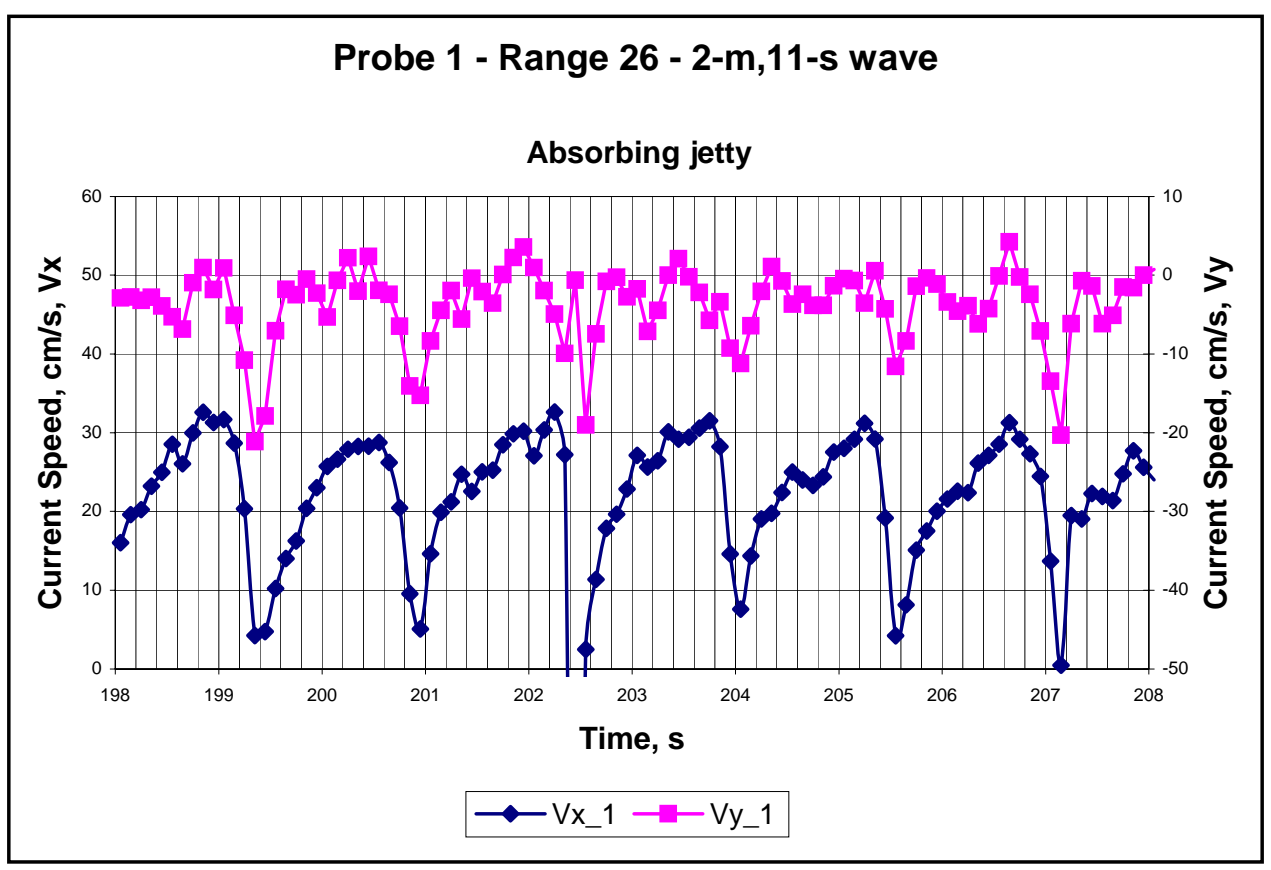

Figure 20. Current speed at Range 26, probe 0, for time 198 to $208 \mathrm{sec}$ of Figure 17

\section{Wave height}

Wave height contours for the 2-m, 11-sec offshore wave (prototype units, 0.04-m, 1.56-sec in model units) with the absorbing jetty are shown in Figure 21. On the seaward side of the absorbing jetty (lower jetty in Figure 21), the contours generally move seaward, indicating reduction in wave height shoreward. Wave height contours in the channel indicate the 20-deg wave approach, with the greater wave heights located toward the top of the figure inside the channel and penetrating farther bayward.

Results of the 2-m, 11-sec wave for the reflective jetty are shown in Figure 22. An increase in wave height can be seen in the region of the jetty due to reflection from the jetty. The largest wave results (3.5-m, 8-sec wave, prototype units, 0.07-m, 1.13-sec in model units) are presented in Figure 23.

\section{Currents due to waves}

Figure 24 shows wave-generated currents in the region upcoast of the absorbing jetty (bottom jetty in Figure 22). The wave condition with the absorbing jetty was the 2-m, 11-sec wave (prototype units, 0.02-m, 1.56-sec in model units) and was the same as that used for Figure 21. The maximum current along the jetty is $1.6 \mathrm{~m} / \mathrm{sec}$, greater than the longshore current along the beach. Current direction may also be noted in Figure 24. Typically, all vectors have a component toward the jetty (except those closest to jetty), indicating no significant circulation cells in the region of the jetty. 


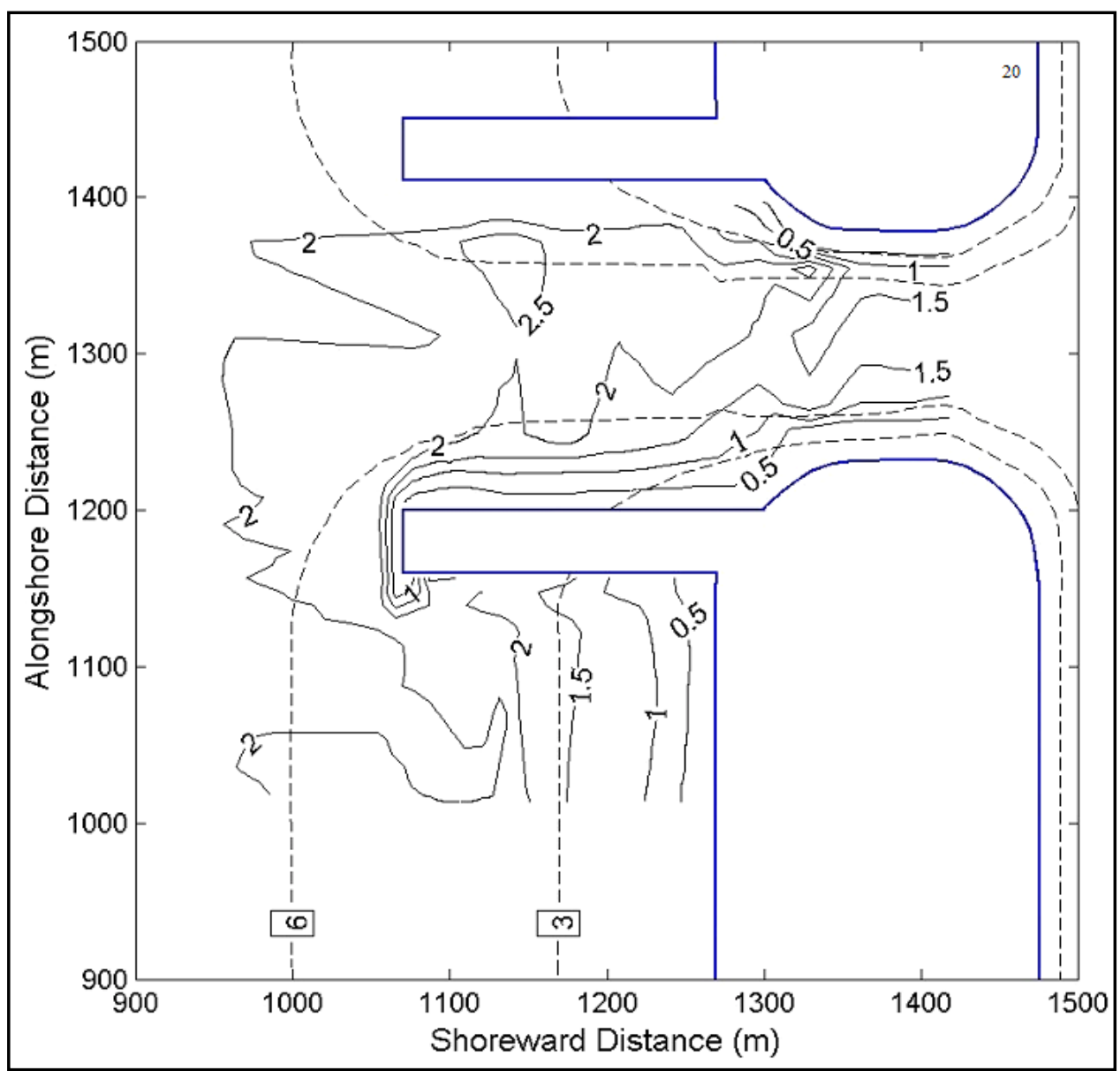

Figure 21. Contours of wave height for 2-m, 11-sec wave, absorbing jetty setup

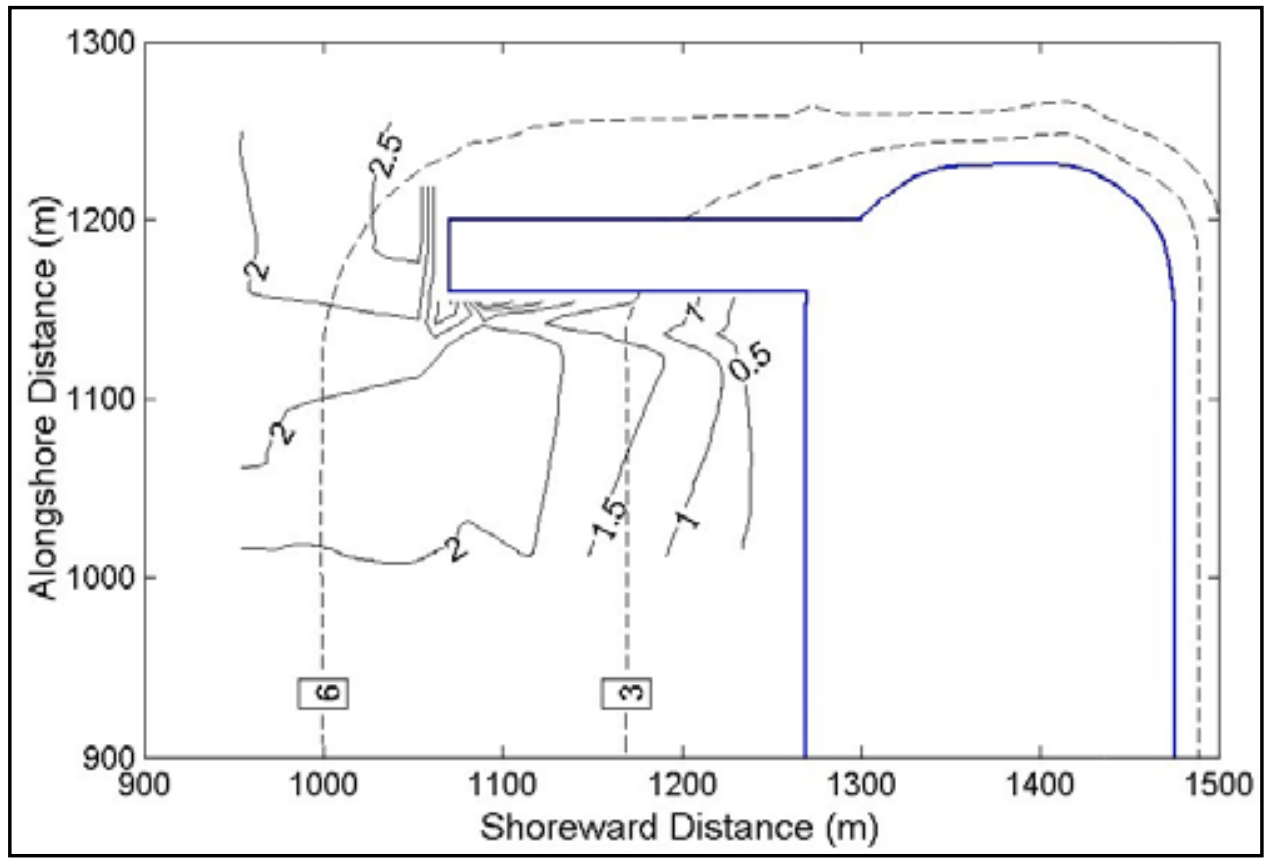

Figure 22. Contours of wave height for 2-m, 11-sec wave, reflecting jetty setup 


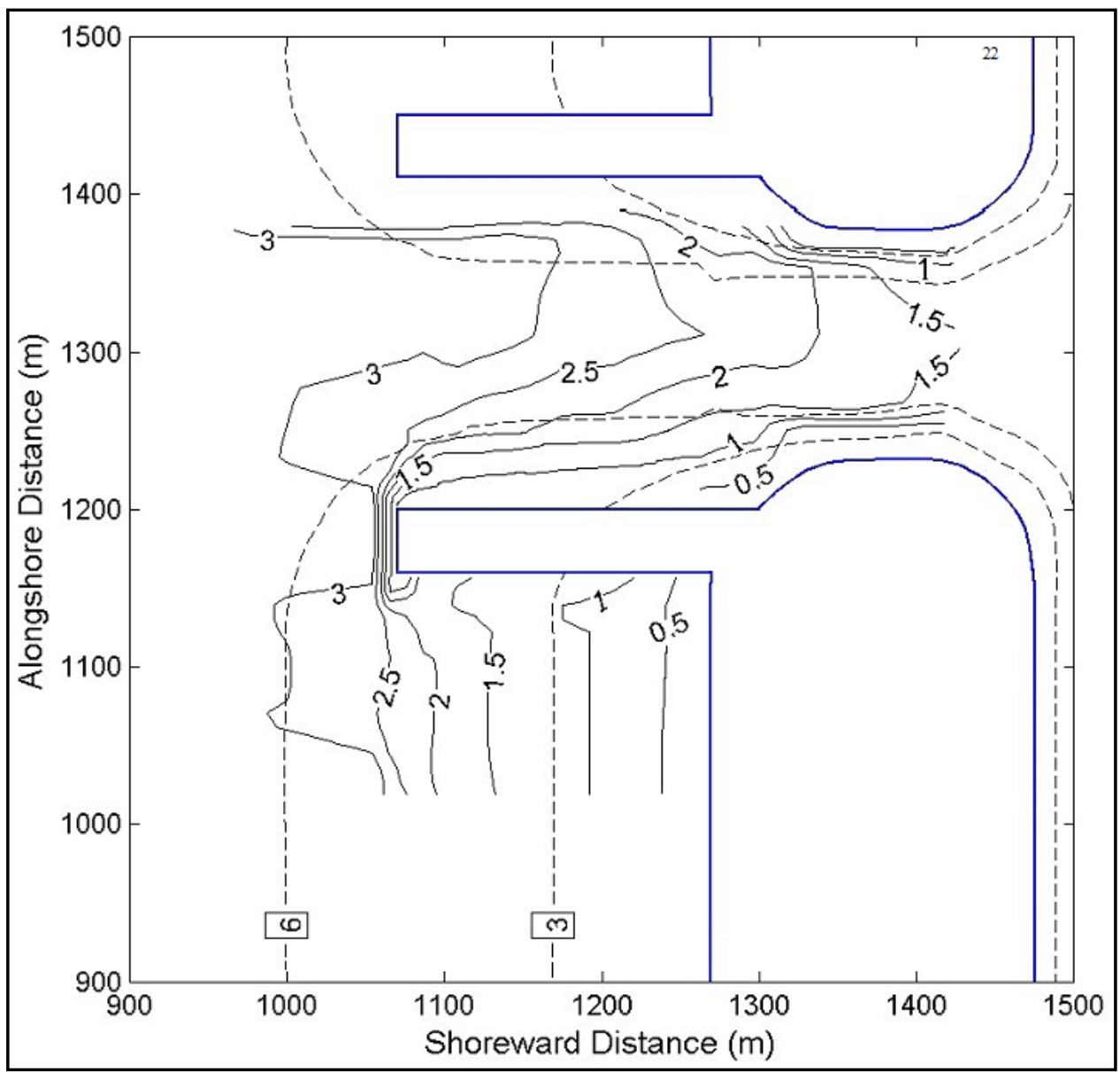

Figure 23. Contours of wave height for 3-m, 8-sec wave, absorbing jetty setup

\section{Wave direction}

Wave direction for three conditions is shown in Figure 25. Figure 25a shows wave direction approaching the jetty is unchanged as the wave enters the absorbing jetty. Figure 25b indicates the effect of the reflective jetty by the vectors being parallel to the jetty. It should be noted that wave direction in this region was affected by the current that was moving alongshore then seaward as the current approached the jetty.

\section{Circulation Near Reflective and Wave-Absorbing Jetties}

The above examination of the sample data indicated there are distinct differences in waves and circulation between the reflective and absorbing jetties. This section examines dye photographs that illustrate differences in the circulation pattern. Figures 26 and 27 show the differences in the circulation pattern upcoast of the absorbing and reflecting jetties respectively. For the absorbing jetty 


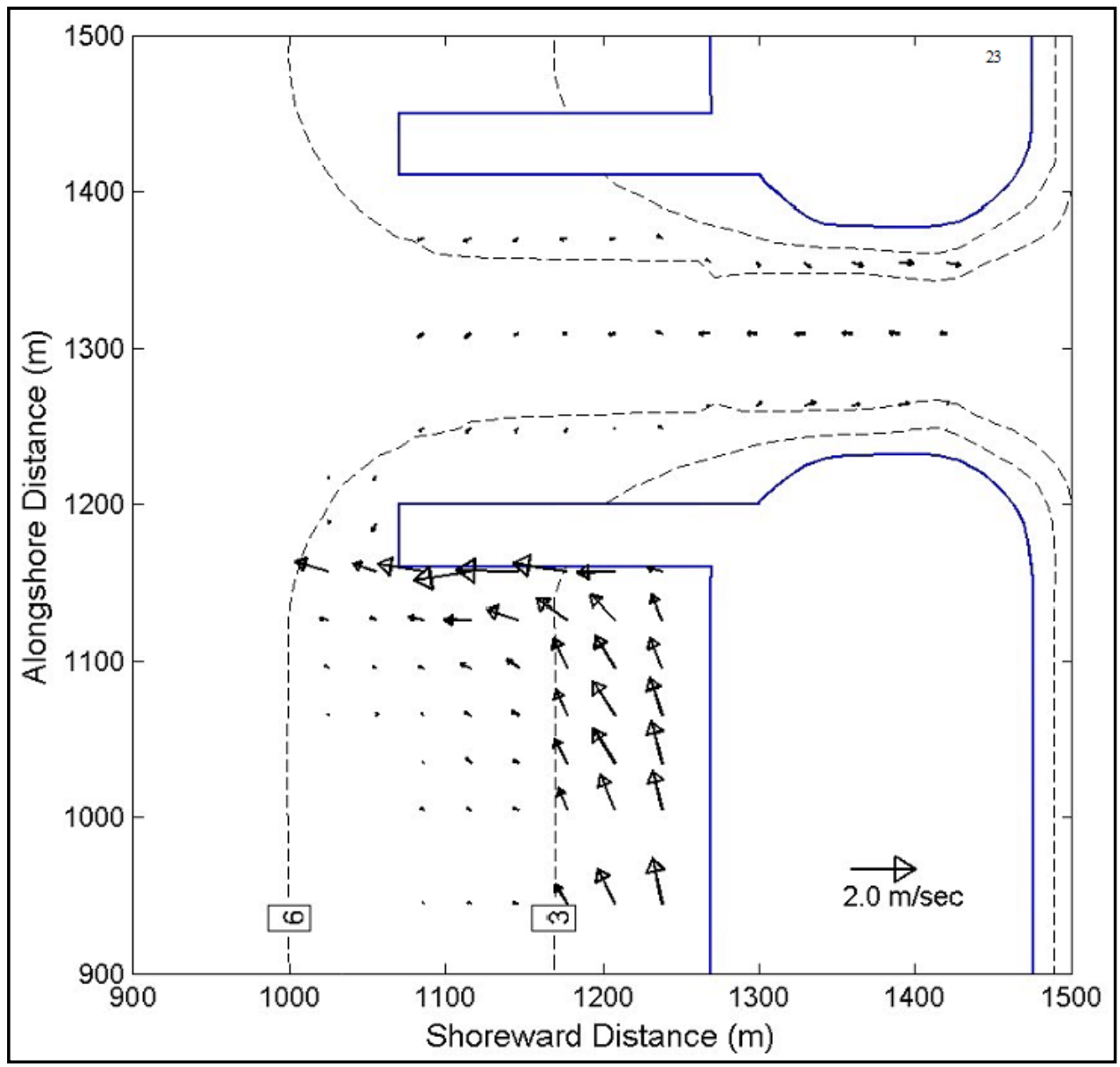

Figure 24. Wave-generated current for 2-m, 11-sec wave, absorbing jetty setup

(Figure 26), the dye patch is inserted in model as shown in the first photograph (1), and the sequential movement is followed in frames (2) to (7). The dye usually moves towards the jetty and is deflected seaward. The breaker location is roughly along a line that passes through the middle of the jetty. For the reflecting jetty (Figure 27), the dye patch begins to move seaward in (2), and further seaward in the following photograph frames (3) to (5). The waves for the reflecting jetty experiment have created a clockwise circulation along the shoreward half of the jetty that deflects the incoming longshore current seaward further up-drift than for the absorbing jetty.

The circulation difference between the two jetty types also can be seen in plots of velocities. Figures 28-30 show current patterns and magnitudes for a small wave (1-m, 11-sec), a moderate wave (2-m, 11-sec), and a larger wave (3.5-m, 8-sec). These figures compare the absorbing-jetty current velocity with the reflecting-jetty velocity. Note the velocity scale on each figure. The reflected wave energy drives a shoreward circulation along the vertical plywood-faced jetty. 


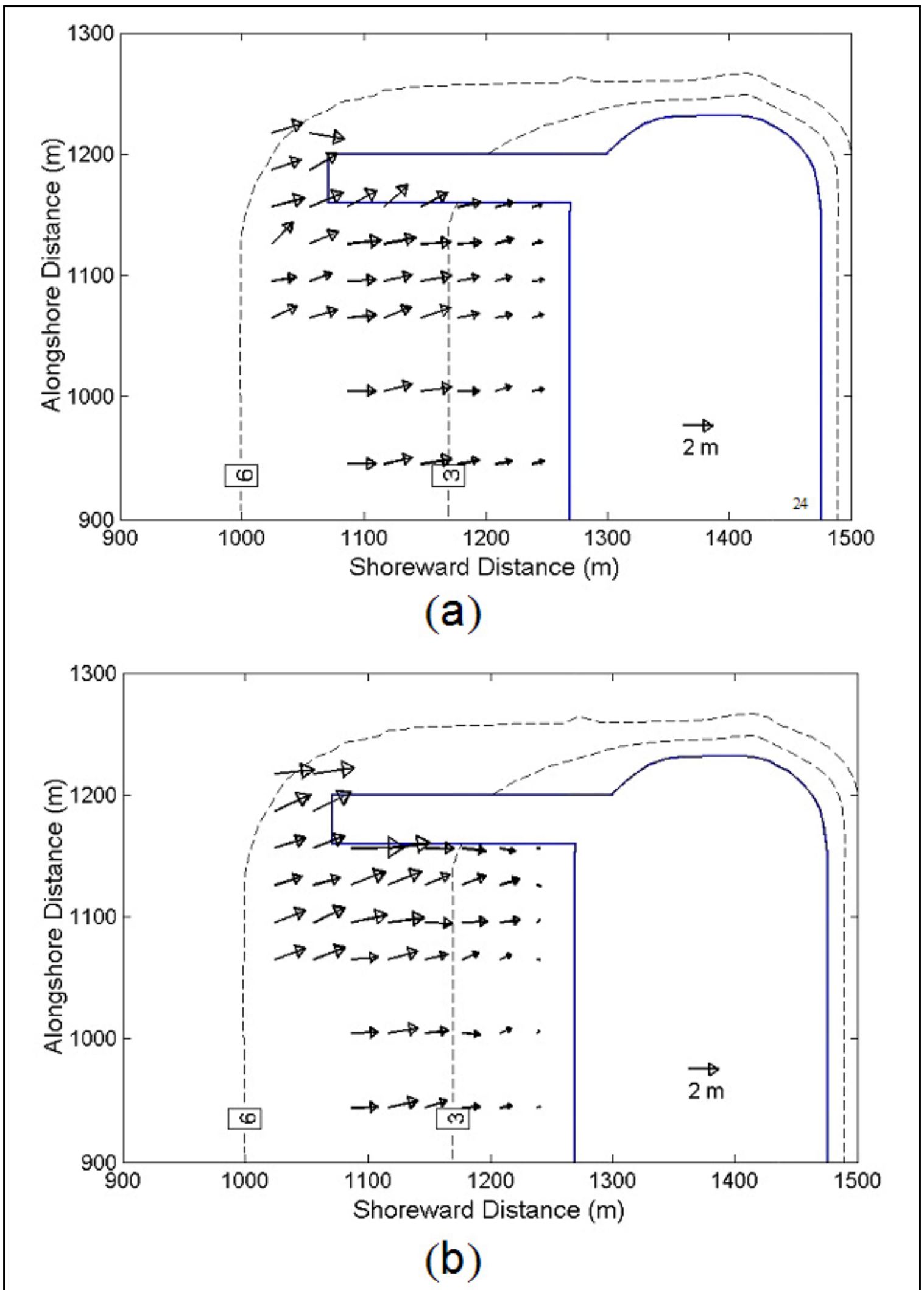

Figure 25. Wave direction vectors and scaled wave height for (a) wave absorbing jetty and (b) reflective jetty 


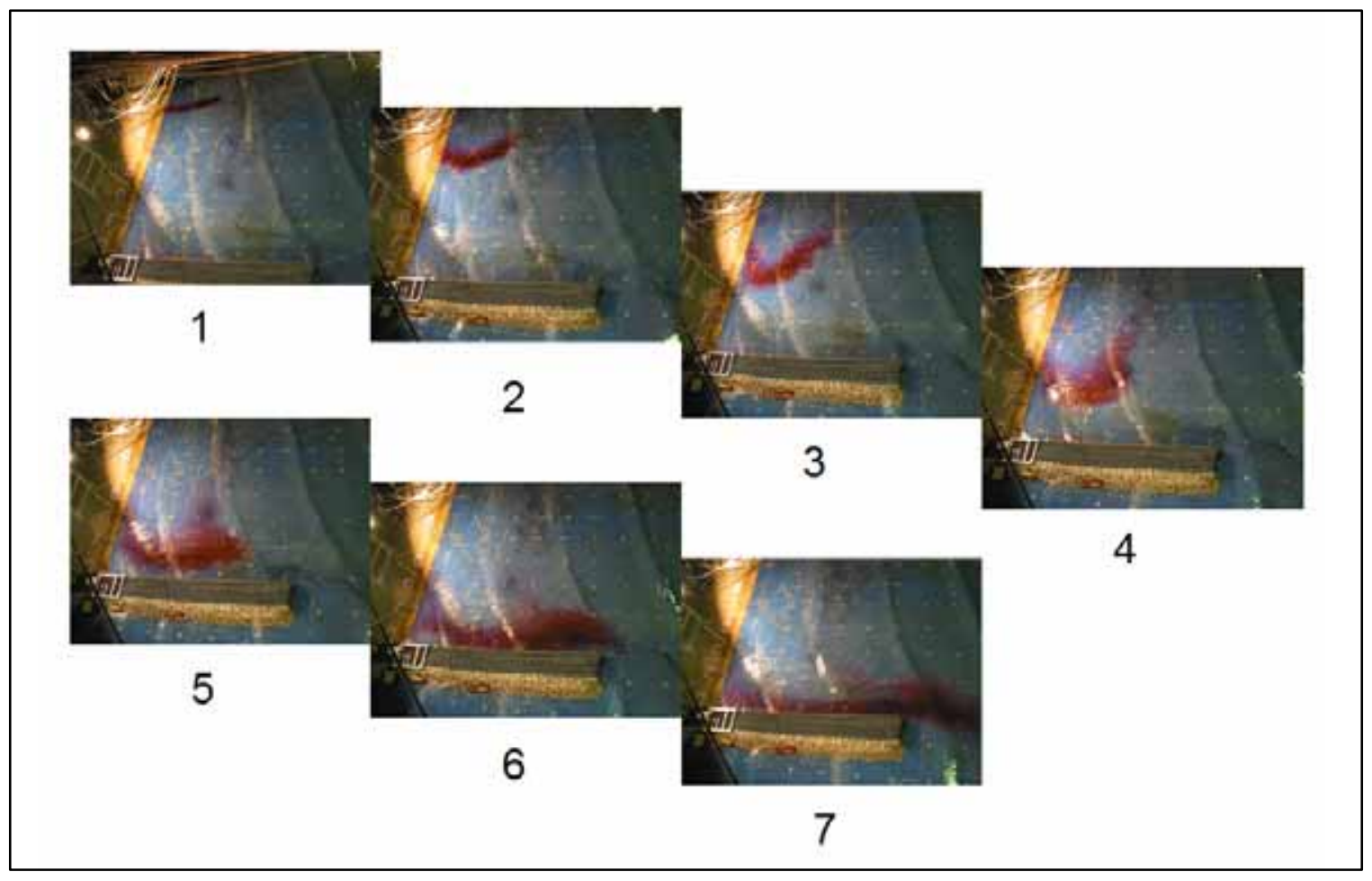

Figure 26. Sequence of photographs (1-7) of dye patch approaching absorbing jetty (2-m, 11-sec wave)

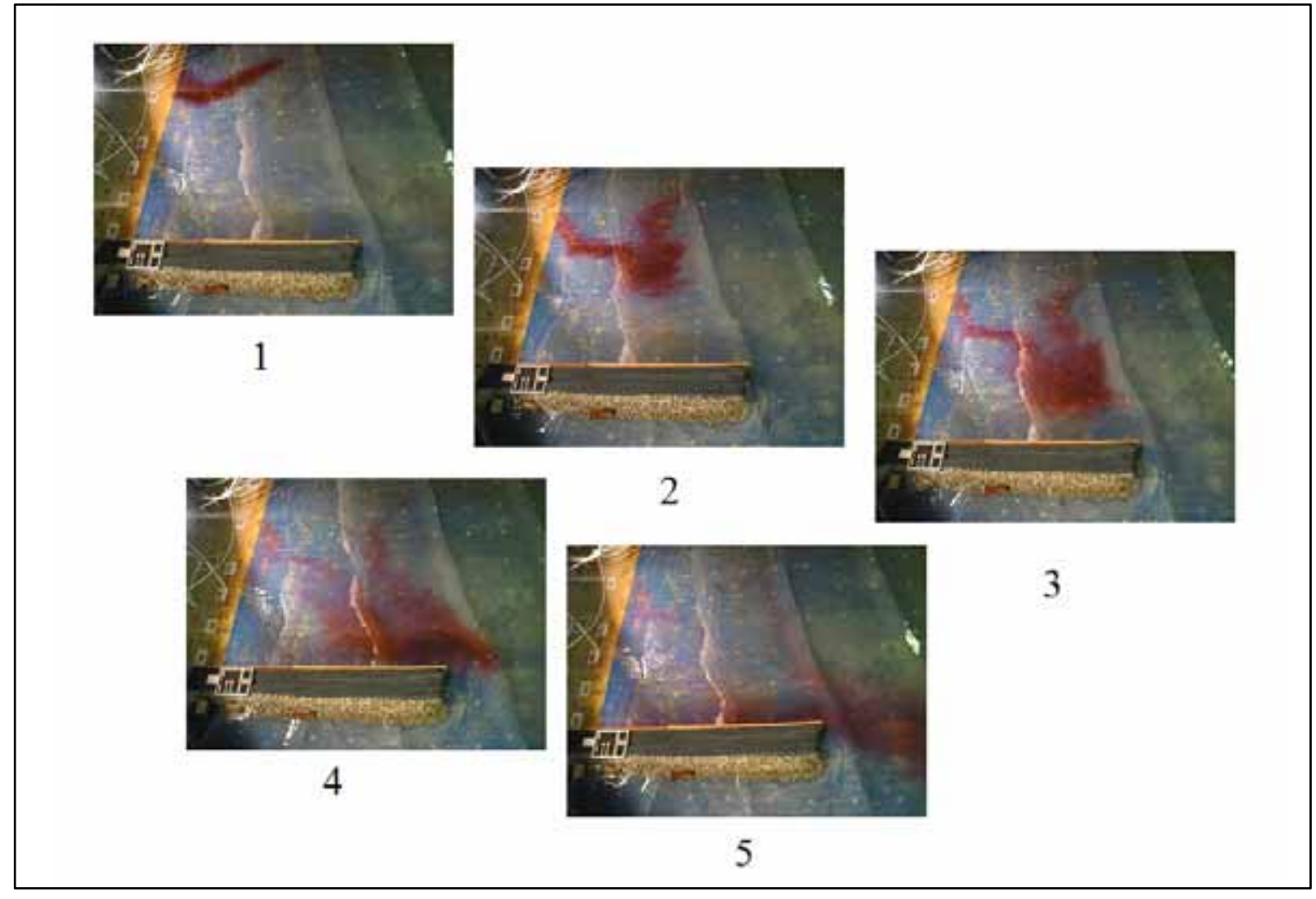

Figure 27. Sequence of photographs (1-5) of dye patch approaching reflecting jetty (2-m, 11-sec wave) 


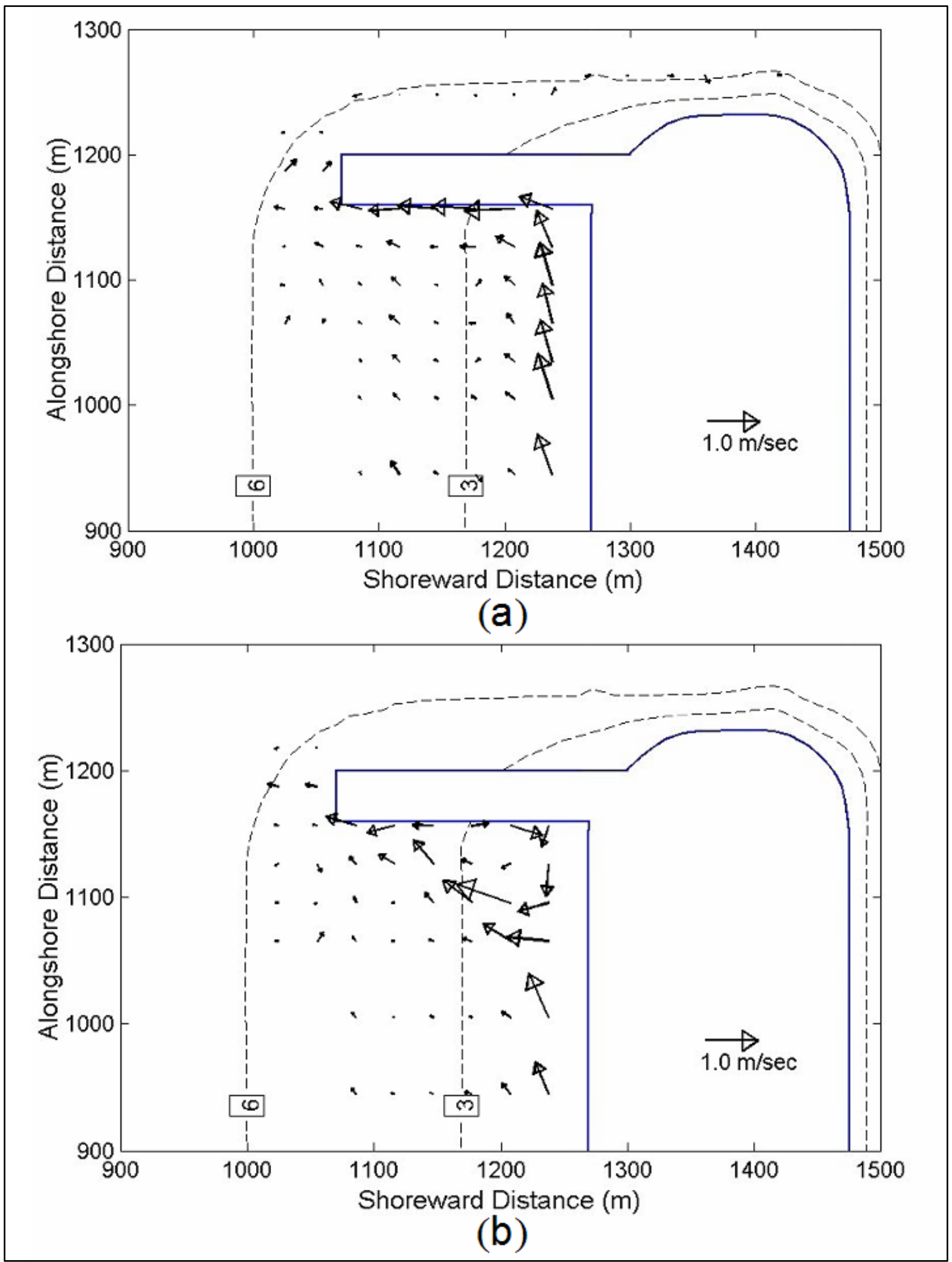

Figure 28. Comparison of (a) absorbing jetty and (b) reflecting jetty for 1-m, 11-sec wave 


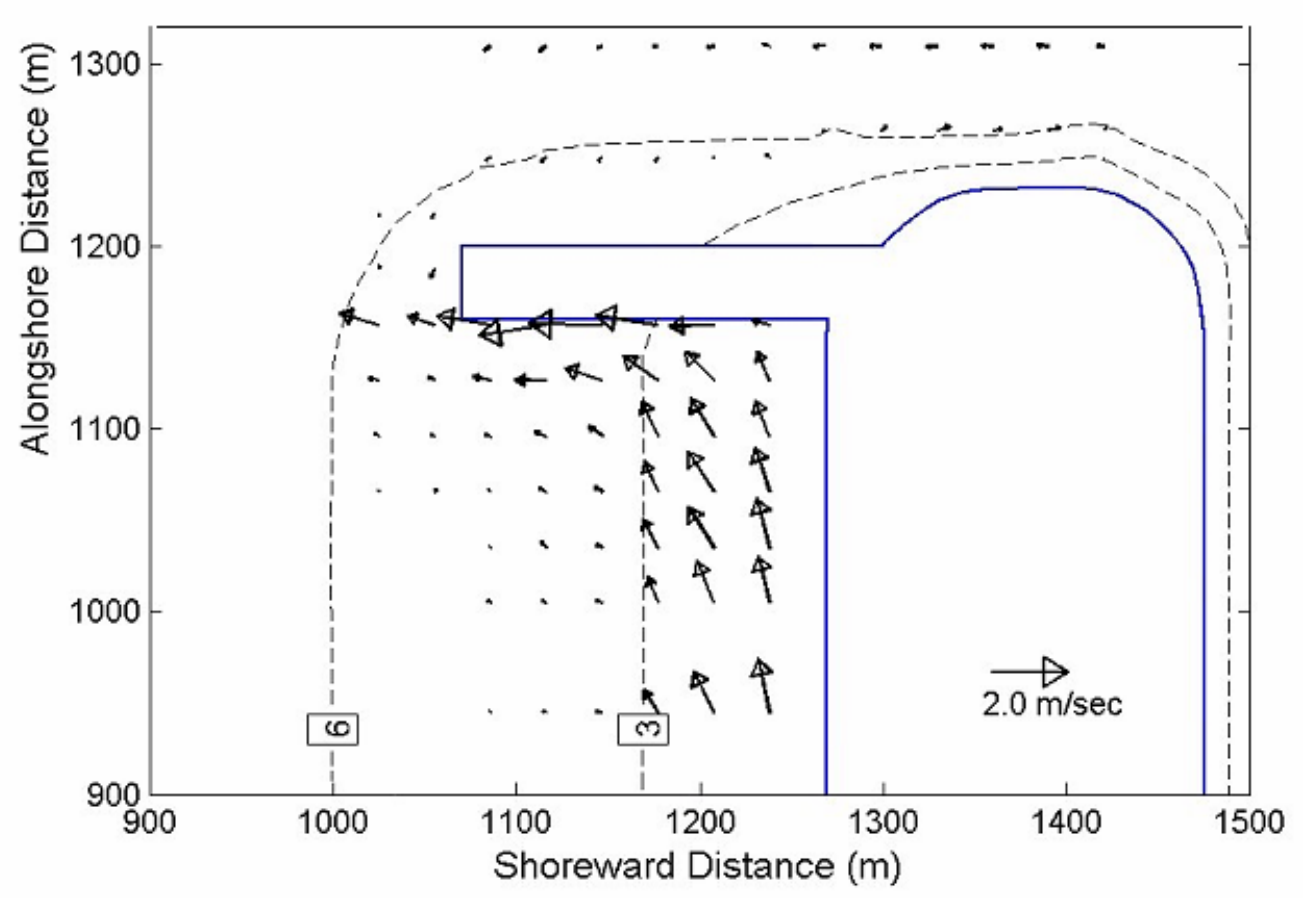

(a)

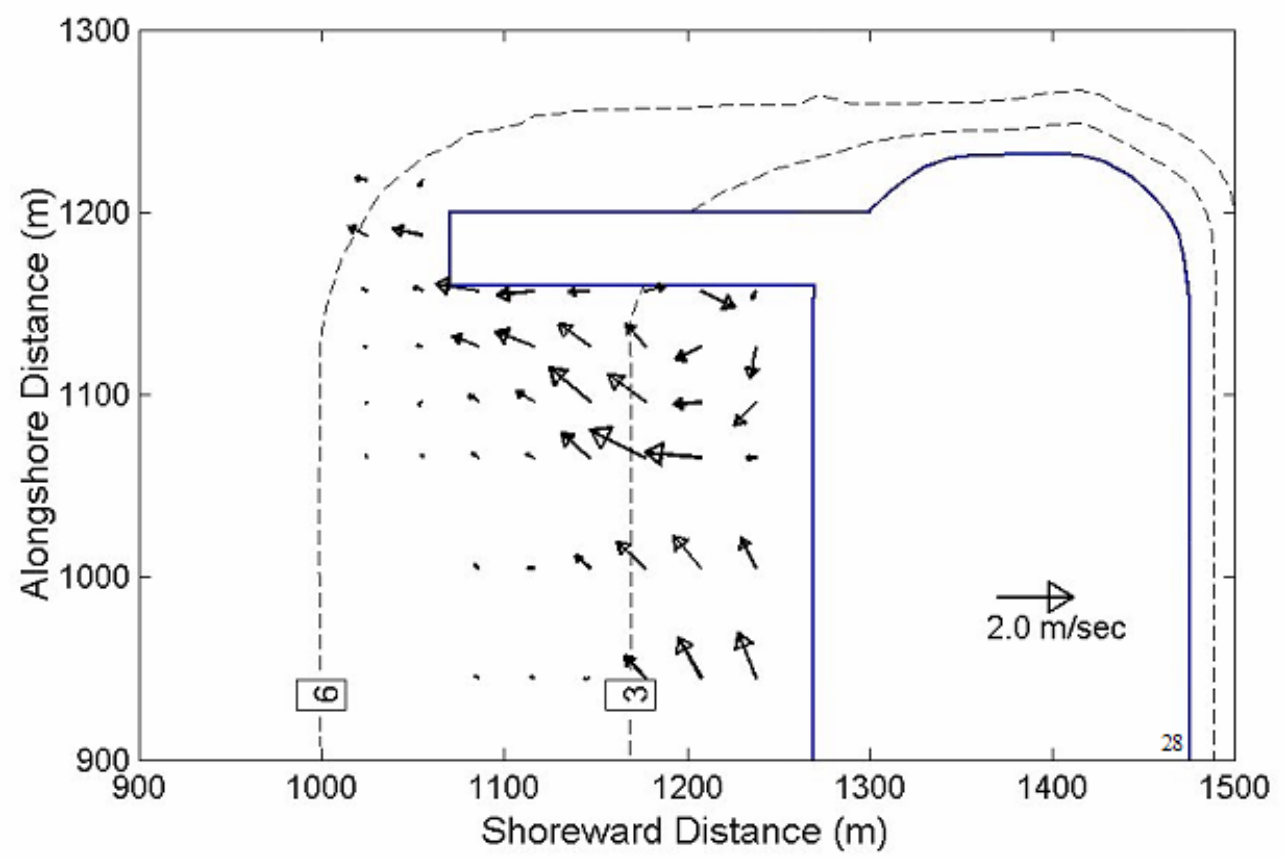

(b)

Figure 29. Comparison of (a) absorbing jetty and (b) reflecting jetty for 2-m, 11-sec wave 


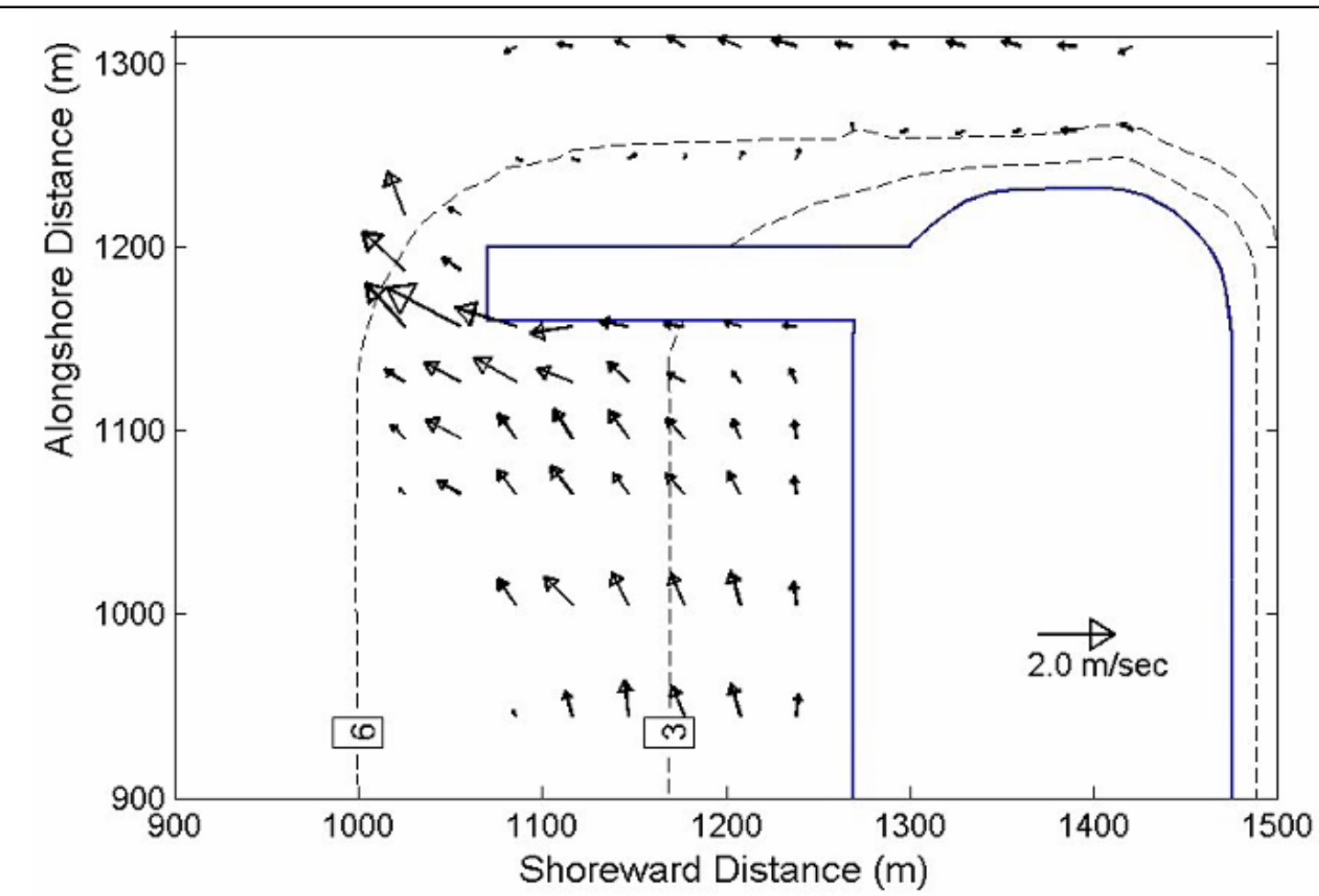

(a)

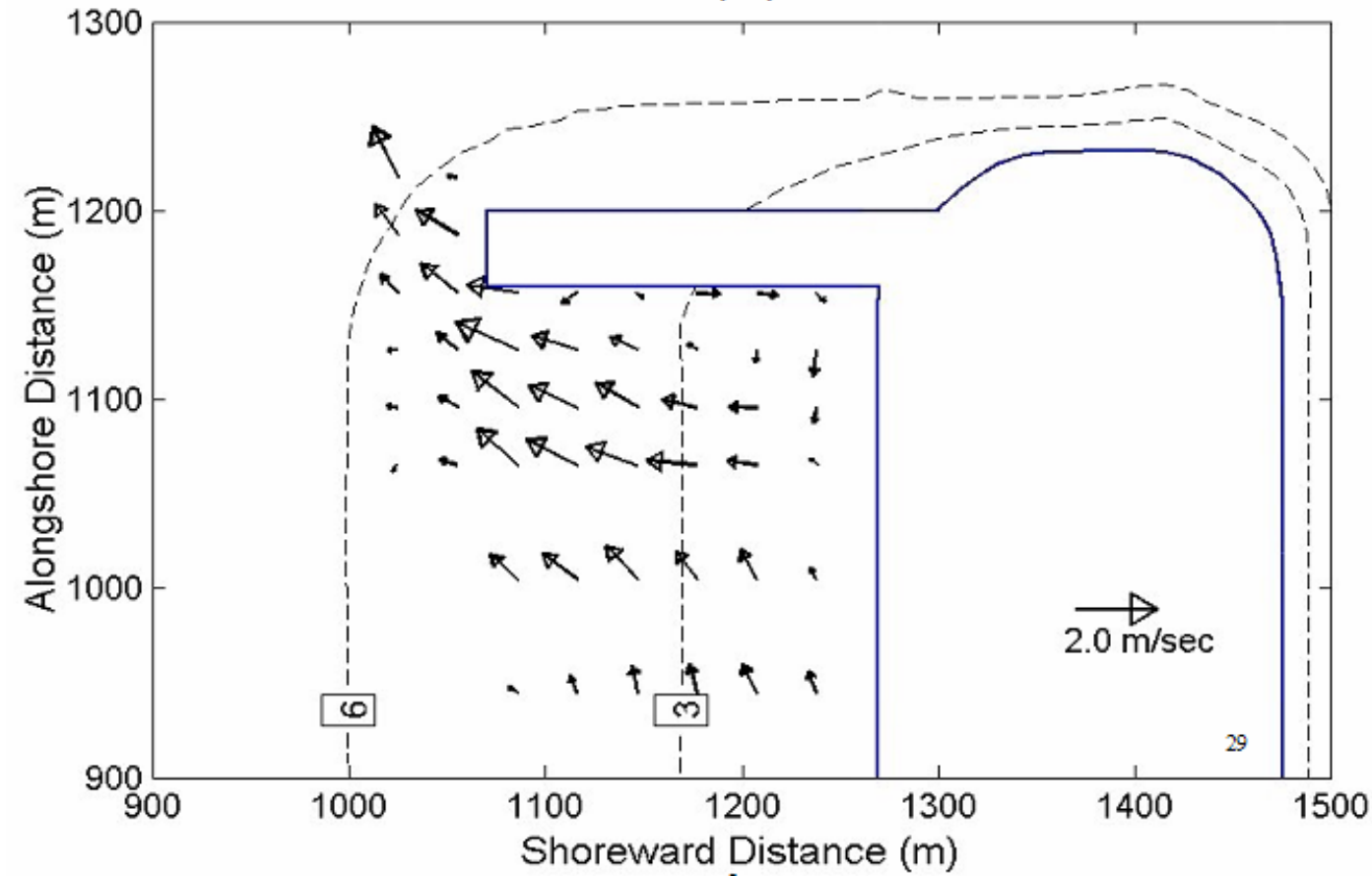

(b)

Figure 30. Comparison of (a) absorbing jetty and (b) reflecting jetty for 3.4-m, 8-sec wave 


\section{Spur Jetty Velocity Examples}

The spatially dense spur jetty velocity data indicated small circulation cells between the spur segments. Plots of velocity data for the $2.0-\mathrm{m}, 11-\mathrm{sec}$ wave and the 3.4-m, 8-sec wave are shown in Figure 31. Of interest with respect to current patterns, the three-spur configuration does not produce a deflected current. The current pattern is similar to the wave-absorbing jetty, i.e., it is deflected seaward, parallel to the basic jetty alignment though there are small circulation cells formed between spurs.

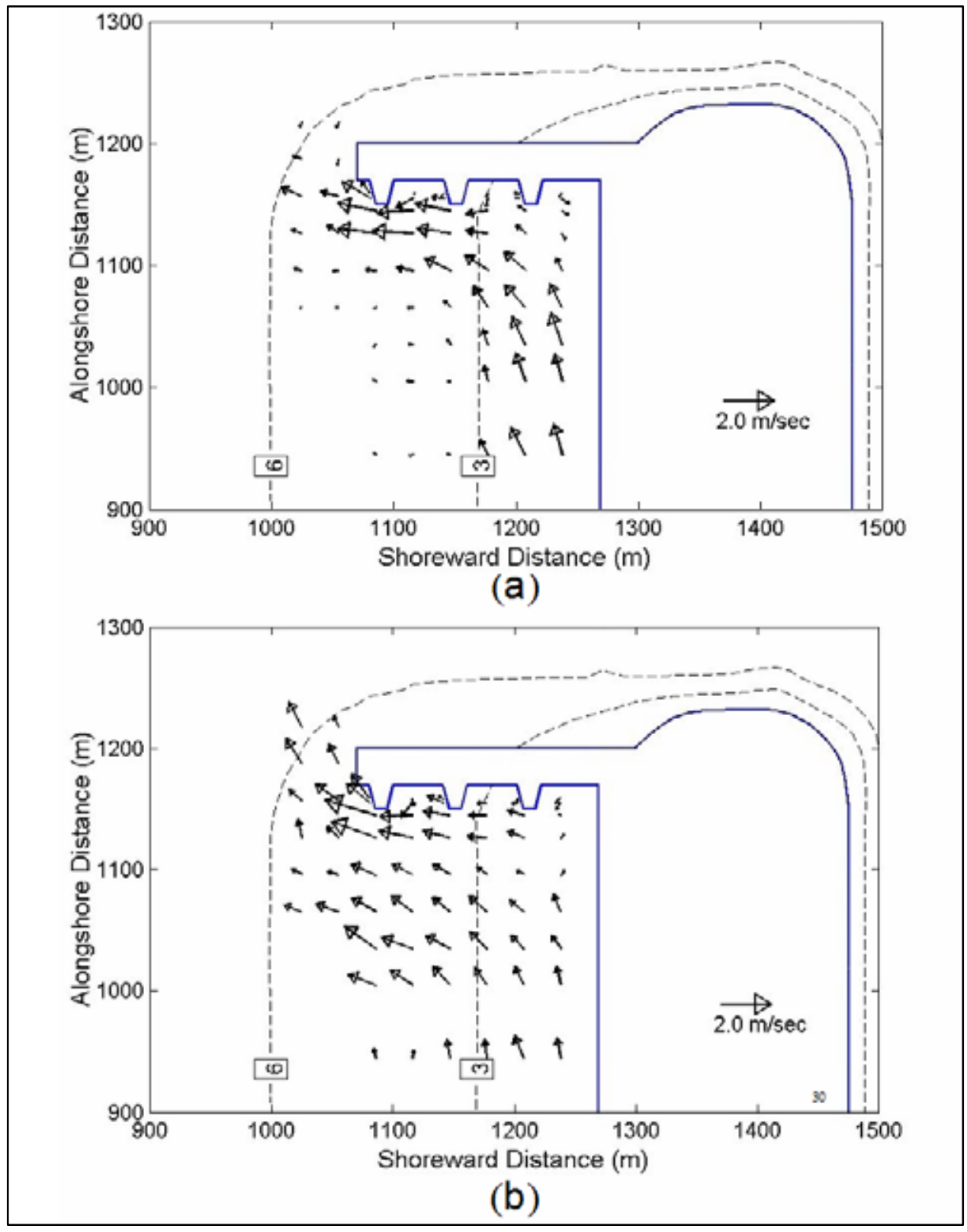

Figure 31. Spur jetty velocities for (a) 2.0-m, 11-sec wave and (b) 3.4-m, 8-sec wave 


\section{Data on CD}

The CD with this report contains data on measured waves, current velocity, and bathymetry. The data are tied to a coordinate system established for a numerical model grid that is included on the CD. Figure 32 shows this bathymetry. The $\mathrm{x}$-axis is aligned along shore-normal, and the $\mathrm{y}$-axis is alongshore. The files on CD are ASCII format time series of water elevation collected at $20 \mathrm{~Hz}$ for 600 sec and tables of analyzed mean wave height and wave direction. The velocity measurements are provided in raw data files. These may be analyzed as discussed in Chapter 2. The measurements also are provided in a spreadsheet format and in summary tables. These velocities have been reduced and are in $\mathrm{x}$ and $\mathrm{y}$ component form. These measurements have not been filtered for spikes or time periods when the signal to noise level is below a certain threshold. The occurrences of spikes are rare. The coordinates of $\mathrm{x}$ and $\mathrm{y}$ velocity components of the raw velocity data are relative to the meter's coordinate system as noted in Figure 8 and discussed in Chapter 2. Current velocity data in spreadsheets and tables have been converted to the common coordinate system.

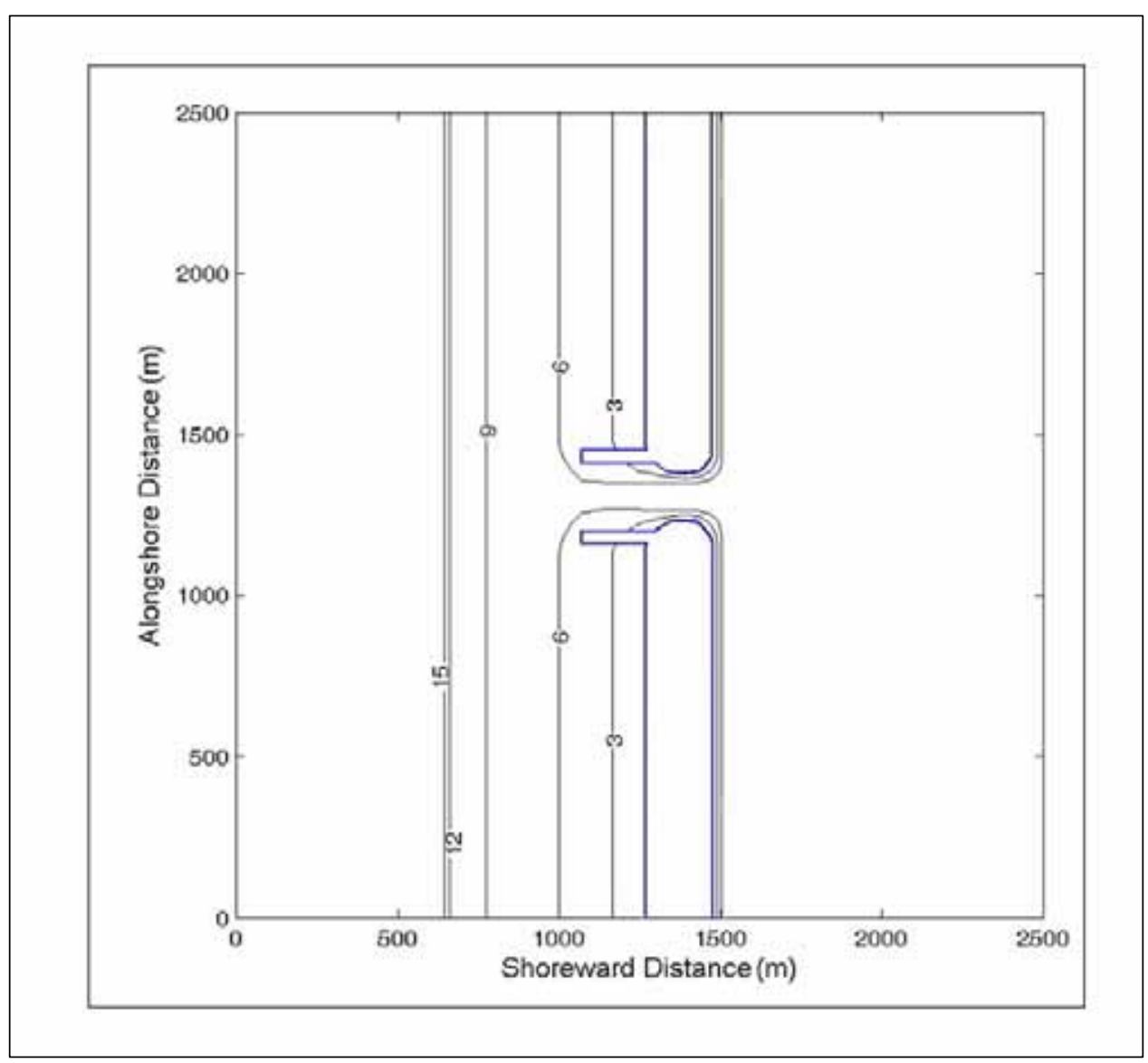

Figure 32. Contours of bathymetry in prototype meters relative to water level 
The file structure of the data CD has been constructed in the following manner:

a. Raw data.

(1) Wave heights

(2) Current velocities

b. Analyzed data.

(1) Wave heights

(2) Wave direction (from velocity data)

(3) Current velocities

c. Gauge location coordinates.

d. Summary tables of wave height and interpolated wave direction at the location of wave height measurement.

e. Summary tables of velocity, wave direction, and interpolated wave height at the location of velocity measurement.

Items c, d, and e in the above list are presented in Appendices A through C, respectively. A help text file is included on the CD. 


\section{Conclusions}

Water-level fluctuation, wave-height variation, wave direction, and velocity data were collected at numerous locations for situations typical of jetties at coastal inlets. The primary region of measurements was upcoast of a jettied inlet. In this region, the longshore current is deflected seaward by the jetty system. The main objective in this study was to supply laboratory data sets for numerical modeling that contain wave height and current information near an inlet where waves are breaking, which generate currents that interact with waves and jetties and cause circulation and sedimentation. The data obtained in this study may be used in the development of numerical models that simulate field conditions.

The measurements were made at an idealized inlet with smooth contours. Wave height and velocity measurements were made both upcoast of a jetty protecting the inlet and between two parallel jetties on both sides of an inlet. Measurements were performed for a number of wave conditions representative of tidal inlets. Three inlet/jetty configurations were examined:

a. An inlet protected by absorbing jetty perpendicular to the beach. The absorbing jetty was composed of a material that minimized reflection of wave energy.

$b$. An inlet that had a jetty with reflective face along the beach side. The jetty in this case was fully reflective of incident wave energy.

c. A spur jetty with three short spurs, equally spaced along the jetty length.

Differences in the response of the wave-generated currents for the reflected versus the wave absorbing jetties were observed. The composition of the jetty was designed to portray the extremes of an inlet jetty - a jetty that fully reflects the incident waves toward the upcoast shoreline adjacent to the jetty, and an almost fully absorbing jetty, which reflects very little energy. These two extreme jetty structures created different circulation patterns. The nearly fully absorbing jetty configuration permitted the wave-generated longshore current to approach the jetty and essentially be deflected seaward 90 deg along the jetty. The waves fully reflecting from the jetty created a clockwise circulation cell, starting at the mid-section of jetty and reaching the shoreline. This cell was large enough to deflect the offshore movement of the longshore current a distance of approximately one wavelength upcoast. This was significantly different from the circulation for the absorbing jetty, where flow approached the base of the jetty before deflecting seaward. The spur jetty setup had small circulation cells between spurs. However, the cells did not deflect the longshore current, as the main body of the current deflected seaward parallel to the jetty. 


\section{References}

Bottin, R. R., Mize, M. G., and Demirbilek, Z. (1995). "Camp Ellis Beach, Maine, model study of beach erosion, coastal model investigation,” Coastal Engineering Research Center Technical Report CERC-95-11, U.S. Army Engineer Waterways Experiment Station, Vicksburg, MS.

Cartwright, D. E. (1963). "The use of directional spectra in studying output of a wave recorder on a moving ship.” Ocean Wave Spectra: Proceedings of a Conference. Prentice-Hall, Inc., Inglewood Cliffs, NJ, 203-218.

Cialone, M. A. (2003). "Chapter 7: Wave, circulation, and sediment transport modeling," in North Jetty Performance and Entrance Navigation Channel Maintenance, Grays Harbor, Washington, Vol. 1, N. C. Kraus and H. T. Arden, ed., Coastal and Hydraulics Laboratory Technical Report ERDC/CHL TR-03-12, U.S. Army Engineer Research and Development Center, Vicksburg, MS.

Cialone, M. A., and Kraus, N. C. (2001). "Engineering study of inlet entrance hydrodynamics: Grays Harbor, Washington, USA,” Proceedings Coastal Dynamics '01, American Society of Civil Engineers, 413-422.

Cialone, M. A., Militello, A., Brown, M. E., and Kraus, N. C. (2003). “Coupling of wave and circulation numerical models at Grays Harbor Entrance, Washington, USA," Proceedings $28^{\text {th }}$ International Coastal Engineering Conference, Vol. 2, World Scientific, J. M. Smith, ed., 1,279-1,291.

Dean, R. G. (1977). "Equilibrium beach profiles: U.S. Atlantic and Gulf Coasts,” Ocean Engineering Technical Report No. 12, Department of Civil Engineering and College of Marine Studies, University of Delaware, Newark, DE.

Grunnet, N. M., Walstra, D. R., and Ruessink, B. G. (2004). "Process-based modelling of a shoreface nourishment," Coastal Engineering 51(7), 581-607.

Hughes, S. A. (1993). Physical models and laboratory techniques in coastal engineering. World Scientific.

Keulegan, G. H. (1972). "Wave damping effects of fibrous screens, hydraulic model investigation,” Hydraulics Laboratory, Research Report H-72-2, U.S. Army Engineer Waterways Experiment Station, Vicksburg, MS. 
Kraus, N. C., Lohrmann, A., and Cabrera, R. (1994). "New acoustic meter for measuring 3-D laboratory flows,” Journal of Hydraulic Engineering 120(3), 406-412.

Lin, L., and Demirbilek, Z. (2005). "Evaluation of two numerical wave models with inlet physical model,” Journal of Waterway, Port, Coastal and Ocean Engineering 131(4), ASCE, 149-161.

Long, R. B. (1980). "The statistical evaluation of directional spectrum estimates derived from pitch/roll buoy data,” Journal of Physical Oceanography 10, 944-952.

Osborne, P. D. (2003). “Chapter 4: Oceanographic setting, field data collection, and analysis,” in North Jetty Performance and Entrance Navigation Channel Maintenance, Grays Harbor, Washington, Vol. 1, N. C. Kraus and H. T. Arden, ed., Coastal and Hydraulics Laboratory Technical Report ERDC/CHL TR-03-12, U.S. Army Engineer Research and Development Center, Vicksburg, MS.

Osborne, P. D., Herichs, D. B., and Kraus, N. C. (2002). "Deployment of oceanographic instruments in high-energy environments and near structures," Coastal and Hydraulics Laboratory Technical Note ERDC/CHL CHETN-IV46, U.S. Army Engineer Research and Development Center, Vicksburg, MS.

Pollock, C. E. (1995). "Effectiveness of spur jetties at Siuslaw River, Oregon; Report 2: Localized current flow patterns induced by spur jetties: Airborne current measurement system and prototype/physical model correlation,” Coastal Engineering Research Center Technical Report CERC-95-14, U.S. Army Engineer Waterways Experiment Station, Vicksburg, MS.

Seabergh, W. C. (1983). "Weir jetty performance model study,” Hydraulics Laboratory Technical Report HL-83-5, U.S. Army Engineer Waterways Experiment Station, Vicksburg, MS.

Seabergh, W. C. (1988). "Observations on inlet flow patterns derived from numerical and physical modeling studies," Larval Fish and Shellfish Transport through Inlets, Coastal Transport Workshop, American Fisheries Society Symposium 3.

Seabergh, W. C. (1999). "Physical model for coastal inlet entrance studies," Coastal Engineering Technical Note CETN-IV-19, U.S. Army Engineer Waterways Experiment Station, Vicksburg, MS.

Seabergh, W. C., Curtis, W. R., Thomas, L. J., and Hathaway, K. K. (2002). "Physical model study of wave diffraction-refraction at an idealized inlet," Coastal and Hydraulics Laboratory Technical Report ERDC/CHL TR-02-27, U.S. Army Engineer Research and Development Center, Vicksburg, MS.

Seabergh, W. C., and Lane, E. F. (1977). "Improvements for Little River Inlet, South Carolina,” Hydraulics Laboratory Technical Report H-77-21, U.S. Army Engineer Waterways Experiment Station, Vicksburg, MS. 
Seabergh, W. C., and Smith, J. M. (2001). "Wave scaling in tidal inlet physical models," $3^{\text {rd }}$ International Symposium on Ocean Wave Measurement and Analysis, ASCE, 1,228-1,237.

Sherwood, C. R., Gelfenbaum, G., Howd, P. A., and Palmsten, M. L. (2001). "Sediment transport on a high-energy ebb-tidal delta," Coastal Dynamics '01, Proceedings of Fourth Conference on Coastal Dynamics, ASCE, 473482.

Zundel, A. K., Cialone, M. A., and Moreland, T. J. (2002). "The SMS steering module for coupling waves and currents, 1: ADCIRC and STWAVE," Coastal and Hydraulics Laboratory Technical Note ERDC/CHL CHETN-IV41, U.S. Army Engineer Research and Development Center, Vicksburg, MS. 


\section{Appendix A Gauge Layouts and Locations}

The orientation of the $x-y$ coordinate system is shown in Figure A1. The origin is actually located beyond the figure's upper left corner. The gauge locations are shown in Figures A2 to A9. The $x-y-z$ coordinates for each gauge follow in Tables A1 to A5. The physical model was operated at the $+1.5 \mathrm{~m}$ $(+5.0 \mathrm{ft}) \mathrm{mlw}$ water level (prototype (1:50 scale)). The figure below shows the origin with the positive $\mathrm{x}$-axis running vertically down from the point located in the upper left corner, and the y-axis running horizontally, parallel to the shore.

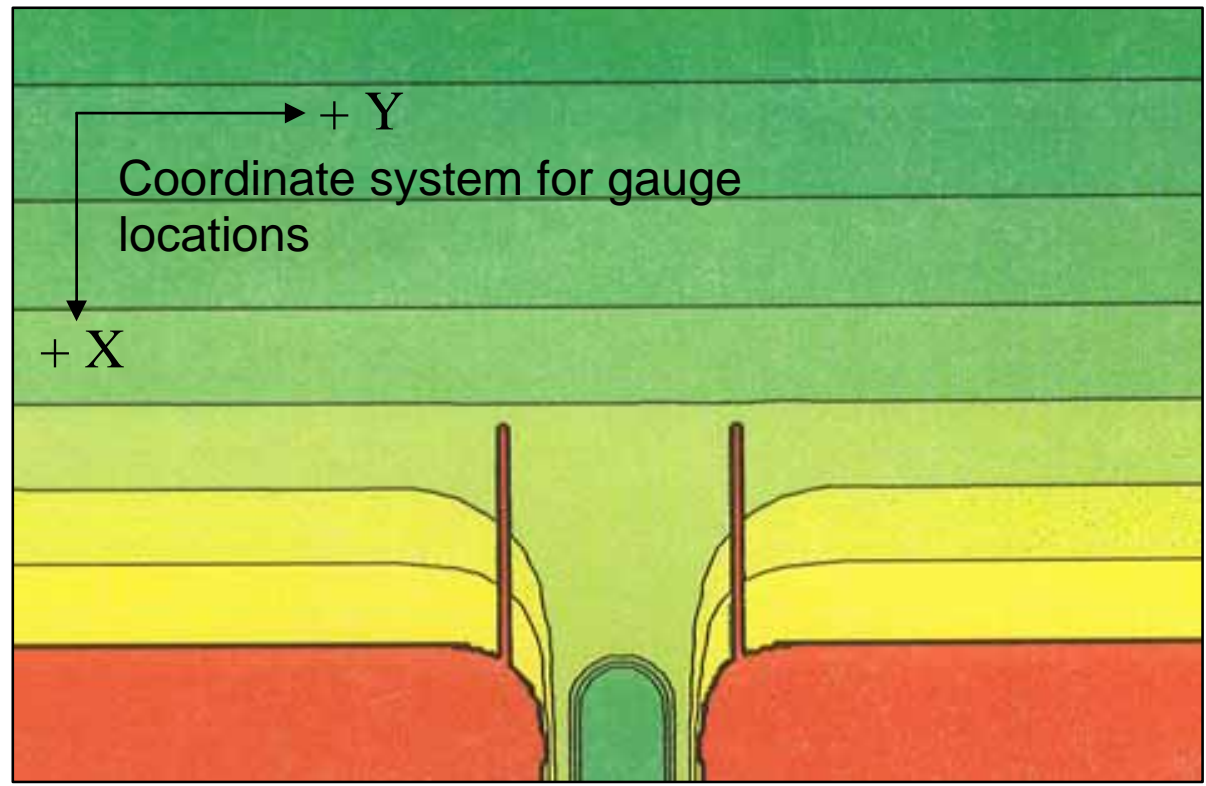

Figure A1. Orientation of axis system for describing gauge locations 


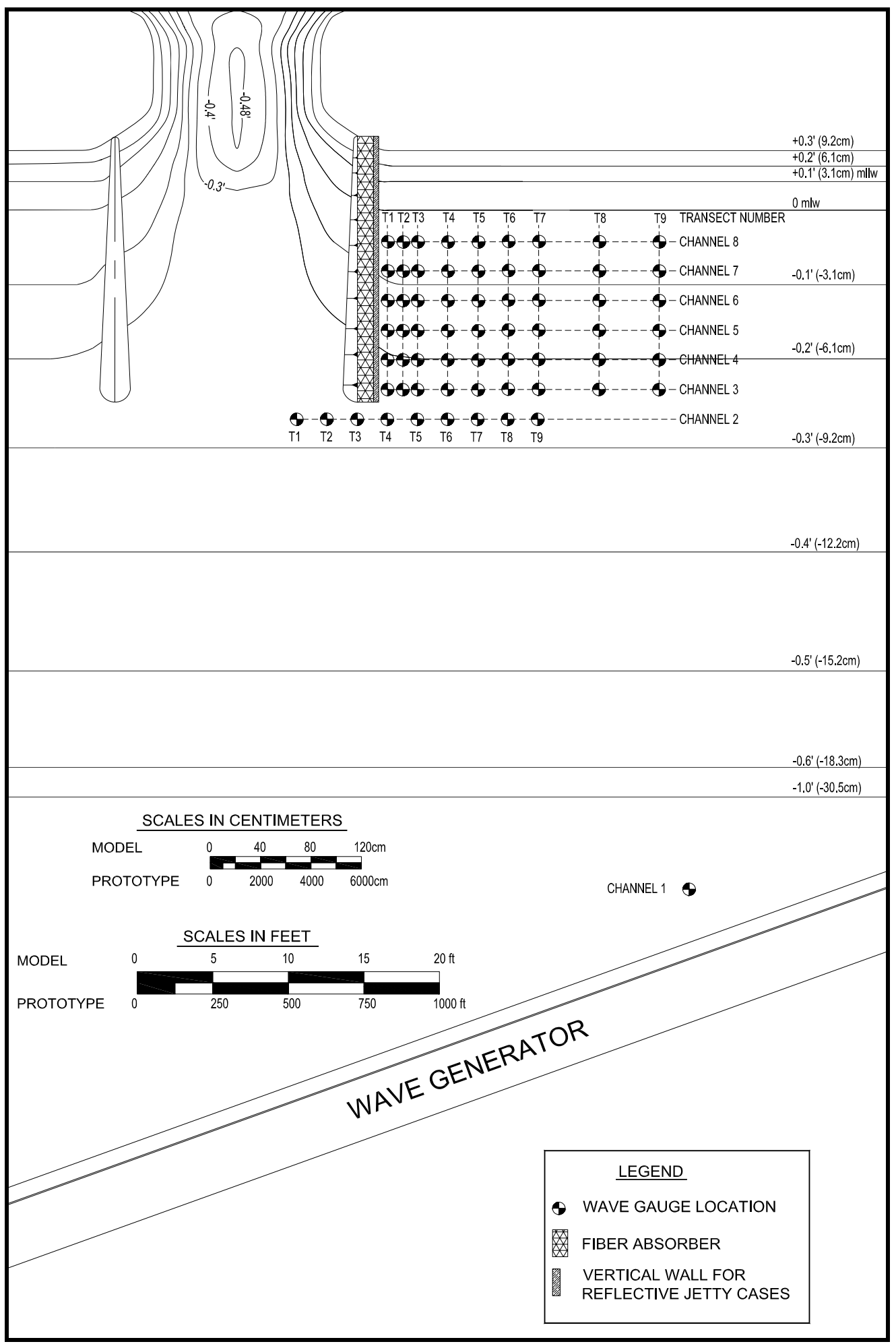

Figure A2. Wave gauge layout upcoast of jetty for measurements conducted outside the inlet. Depth contours are shown in model scale units in feet (centimeters) 


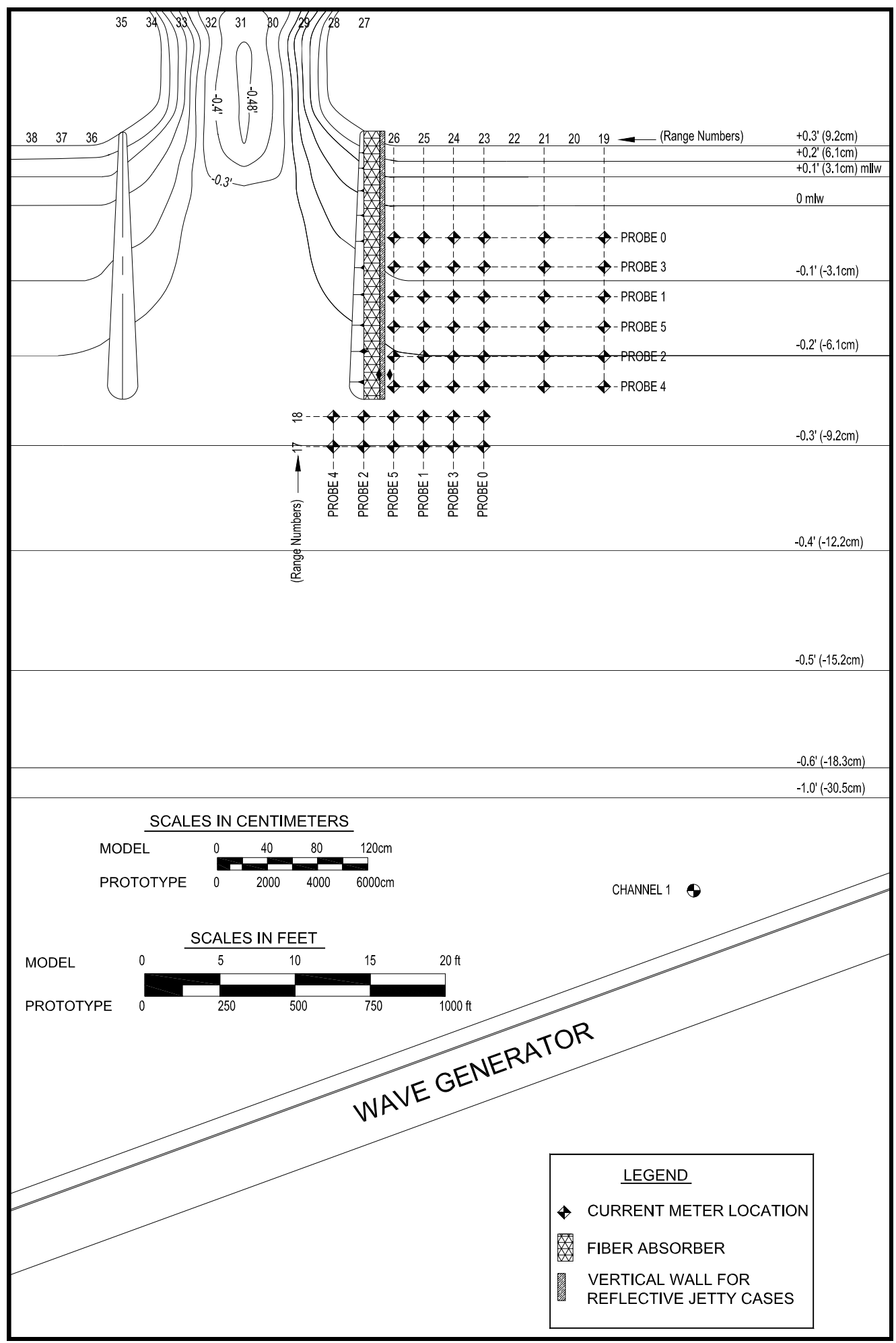

Figure A3. Current meter layout upcoast of jetty for measurements conducted outside the inlet. Depth contours are shown in model scale units in feet (centimeters) 


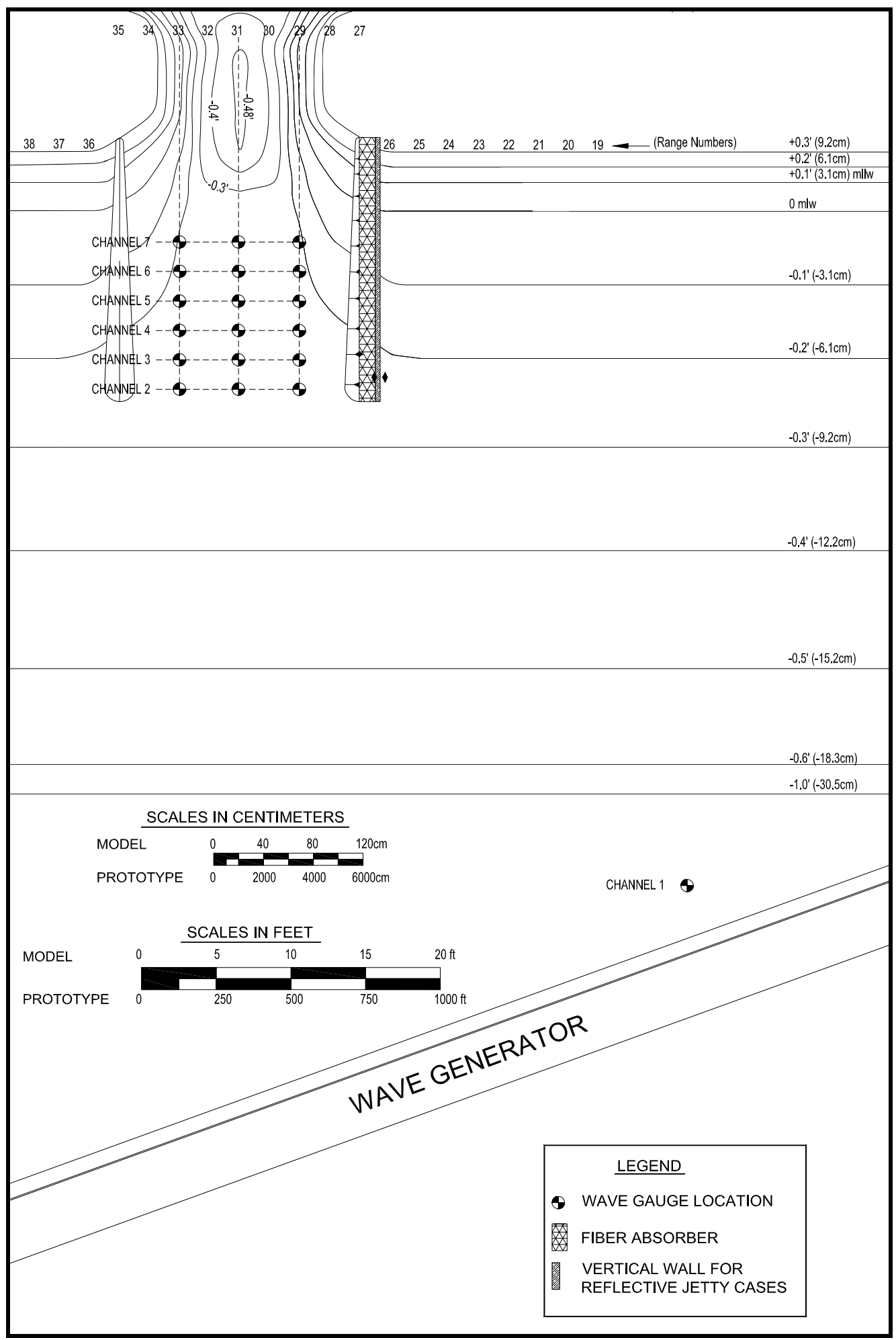

Figure A4. Wave gauge layout in outer channel for measurements conducted inside the inlet. Depth contours are shown in model scale units in feet (centimeters) 


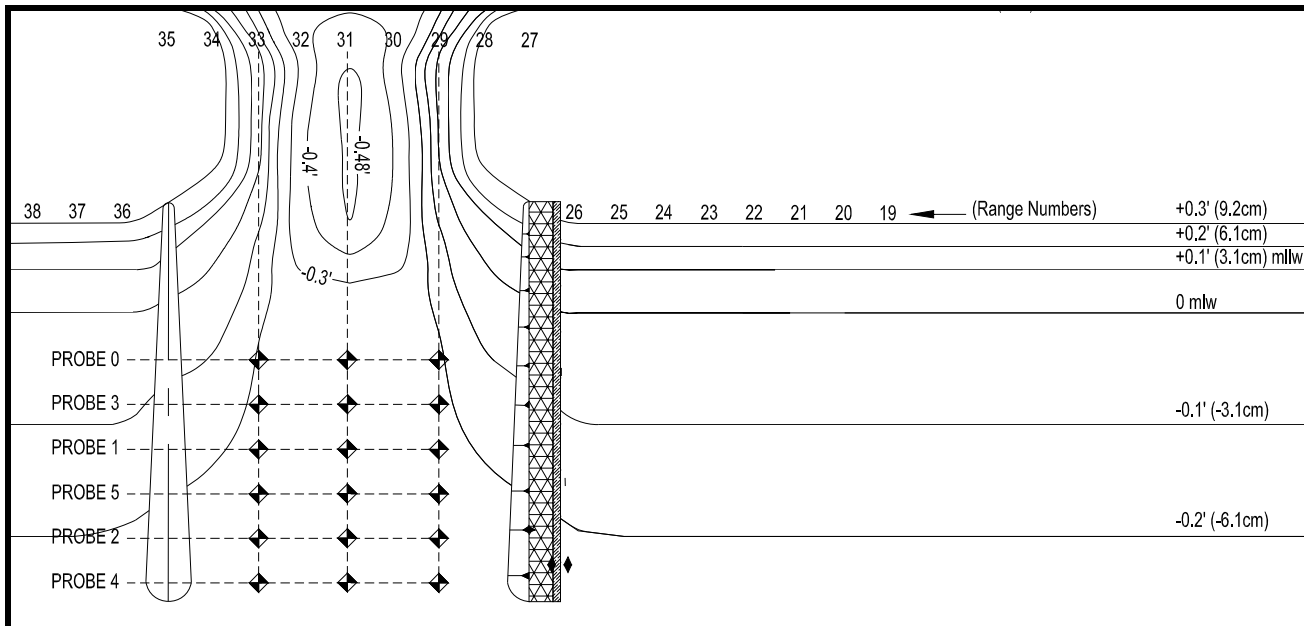

$-0.3^{\prime}(-9.2 \mathrm{~cm})$

SCALES IN CENTIMETERS

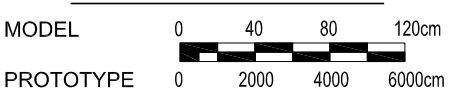

PROTOTYPE $\quad 0 \quad 2000 \quad 4000 \quad 6000 \mathrm{~cm}$

CHANNEL $1 \oplus$

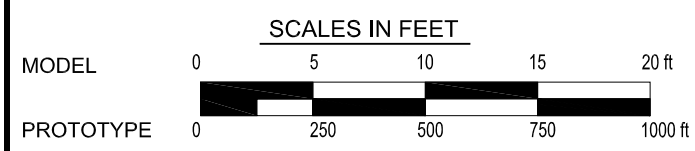

WANE GENERATOR

\begin{tabular}{|l} 
LEGEND \\
CURRENT METER LOCATION \\
FIBER ABSORBER \\
VERTICAL WALL FOR \\
REFLECTIVE JETTY CASES
\end{tabular}

Figure A5. Current meter layout in outer channel for measurements conducted inside the inlet. Depth contours are shown in model scale units in feet (centimeters) 


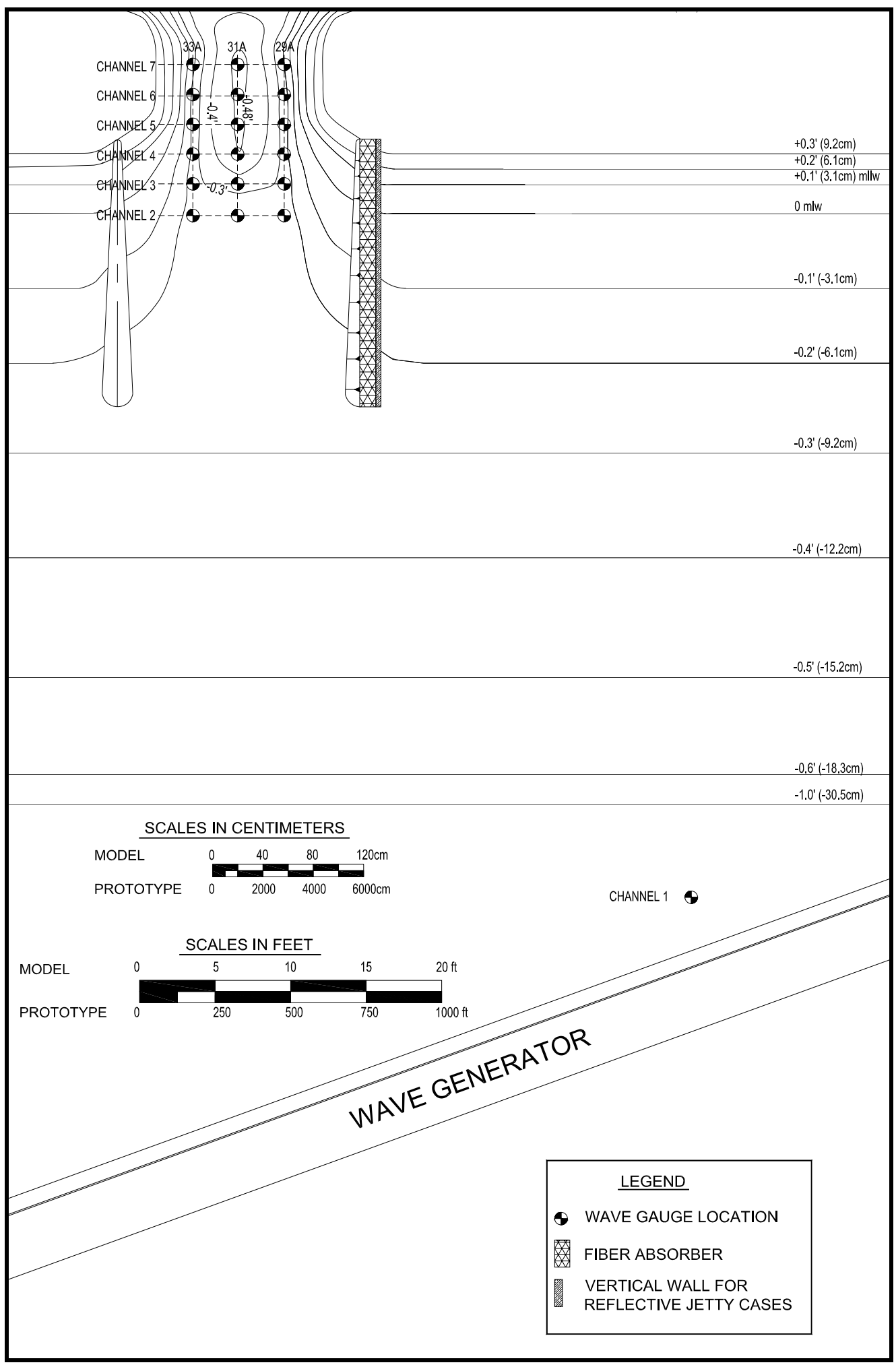

Figure A6. Wave gauge layout in inner channel for measurements conducted inside the inlet. Depth contours are shown in model scale units in feet (centimeters) 


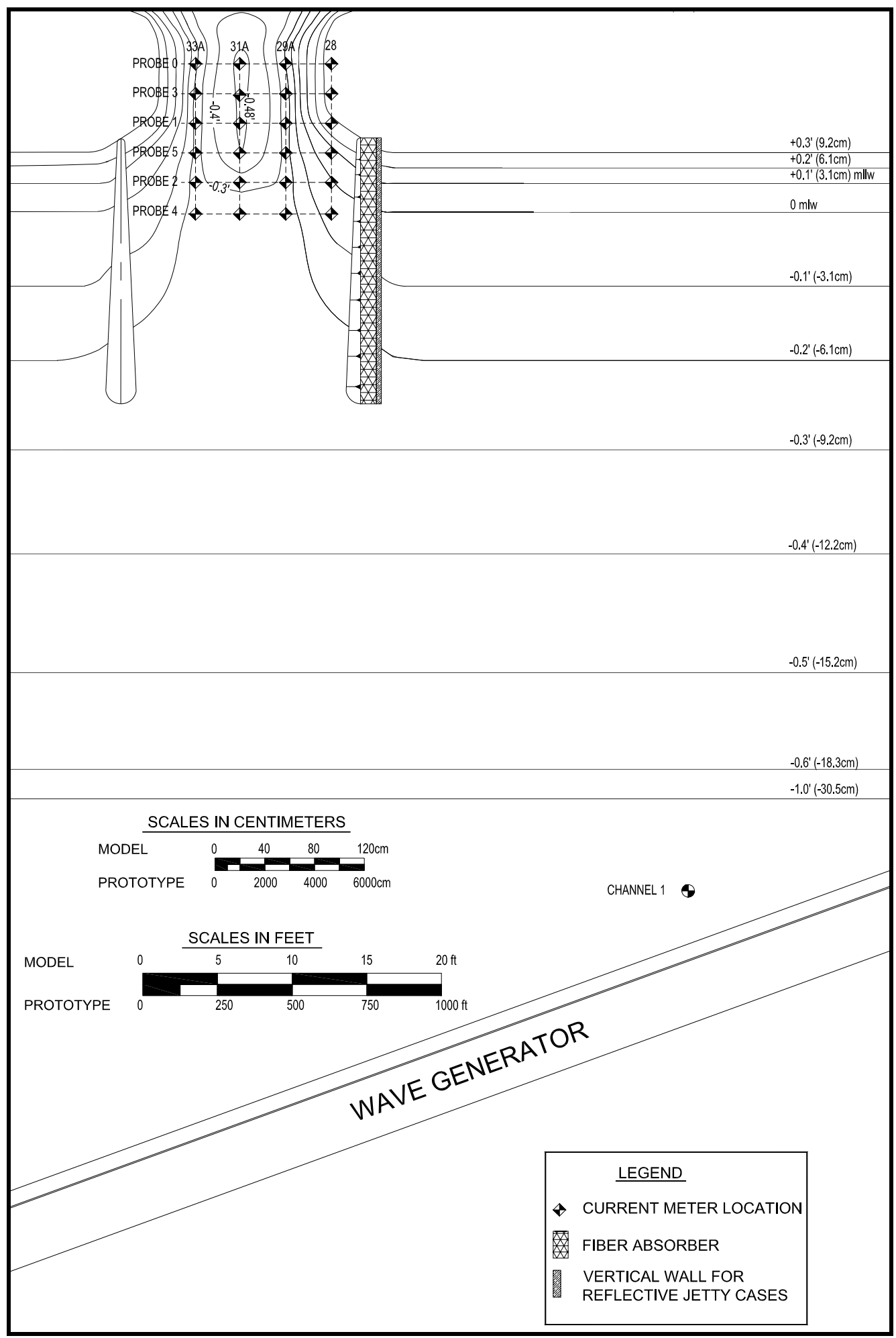

Figure A7. Current meter layout in inner channel for measurements conducted inside the inlet. Depth contours are shown in model scale units in feet (centimeters) 


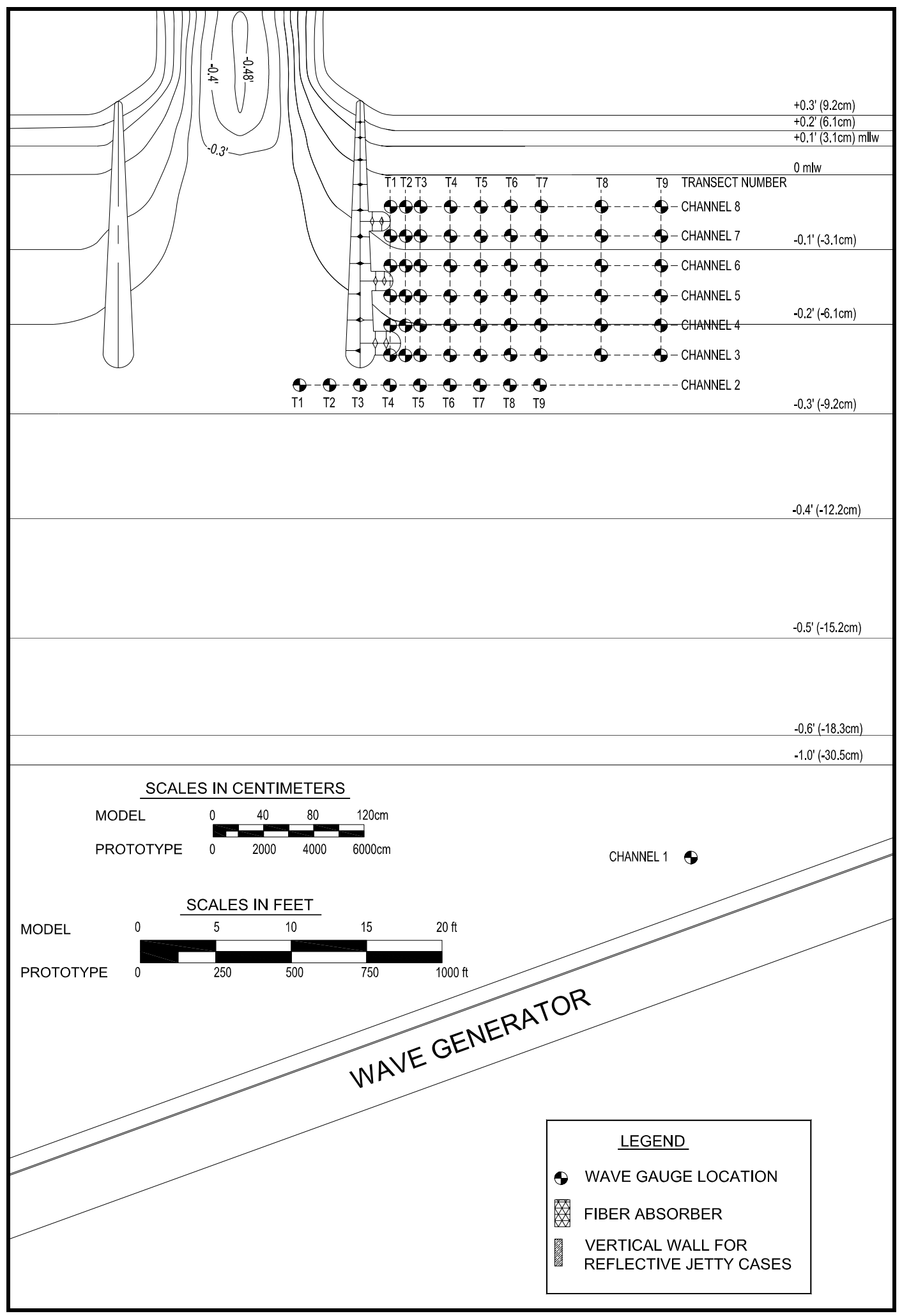

Figure A8. Wave gauge layout 1 for spur jetty for measurements conducted outside the inlet. Depth contours are shown in model scale units in feet (centimeters) 


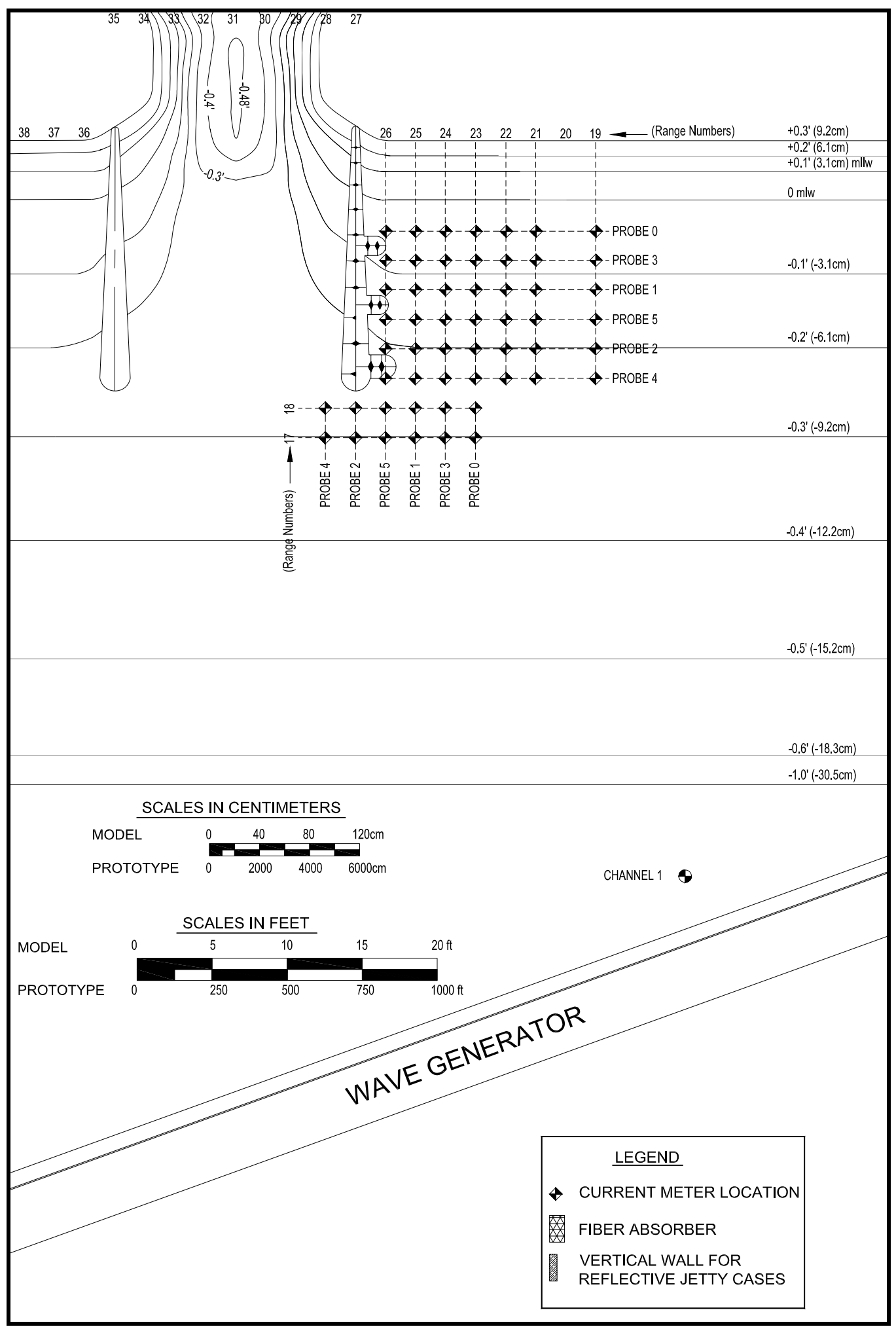

Figure A9. Current meter layout for spur jetty for measurements conducted outside the inlet. Depth contours are shown in model scale units in feet (centimeters) 


\section{Table A1 \\ Wave Gauge Locations Upcoast of Jetty, T1-T9}

\begin{tabular}{|c|c|c|c|c|c|c|}
\hline \multirow[b]{3}{*}{ Channel No. } & \multicolumn{6}{|c|}{ Gauge Location } \\
\hline & \multicolumn{3}{|c|}{ Prototype } & \multicolumn{3}{|c|}{ Laboratory } \\
\hline & $X(m)$ & $Y(m)$ & $Z(m)$ & $X(m)$ & $Y(m)$ & $Z(m)$ \\
\hline \multicolumn{7}{|c|}{ Transect T1 } \\
\hline 1 & 950.0 & $1,248.5$ & 6.94 & 19.0 & 24.97 & 0.139 \\
\hline 2 & $1,055.0$ & $1,248.5$ & 6.07 & 21.1 & 24.97 & 0.121 \\
\hline 3 & $1,085.5$ & $1,159.0$ & 4.7 & 21.71 & 23.18 & 0.094 \\
\hline 4 & $1,116.0$ & $1,159.0$ & 4.13 & 22.32 & 23.18 & 0.083 \\
\hline 5 & $1,146.5$ & $1,159.0$ & 3.57 & 22.93 & 23.18 & 0.071 \\
\hline 6 & $1,177.0$ & $1,159.0$ & 2.98 & 23.54 & 23.18 & 0.06 \\
\hline 7 & $1,207.5$ & $1,159.0$ & 2.33 & 24.15 & 23.18 & 0.047 \\
\hline 8 & $1,238.0$ & $1,159.0$ & 1.56 & 24.76 & 23.18 & 0.031 \\
\hline \multicolumn{7}{|c|}{ Transect T2 } \\
\hline 1 & 950.0 & 1,218 & 6.94 & 19.0 & 24.36 & 0.139 \\
\hline 2 & $1,055.0$ & 1,218 & 5.81 & 21.1 & 24.36 & 0.116 \\
\hline 3 & $1,085.5$ & 1,157 & 4.68 & 21.71 & 23.14 & 0.094 \\
\hline 4 & $1,116.0$ & 1,157 & 4.12 & 22.32 & 23.14 & 0.082 \\
\hline 5 & $1,146.5$ & 1,157 & 3.55 & 22.93 & 23.14 & 0.071 \\
\hline 6 & $1,177.0$ & 1,157 & 2.96 & 23.54 & 23.14 & 0.059 \\
\hline 7 & $1,207.5$ & 1,157 & 2.32 & 24.15 & 23.14 & 0.046 \\
\hline 8 & $1,238.0$ & 1,157 & 1.55 & 24.76 & 23.14 & 0.031 \\
\hline \multicolumn{7}{|c|}{ Transect T3 } \\
\hline 1 & 950.0 & $1,187.5$ & 6.9 & 19.0 & 23.75 & 0.138 \\
\hline 2 & $1,055.0$ & $1,187.5$ & 5.41 & 21.1 & 23.75 & 0.108 \\
\hline 3 & $1,085.5$ & $1,155.0$ & 4.67 & 21.71 & 23.1 & 0.093 \\
\hline 4 & $1,116.0$ & $1,155.0$ & 4.1 & 22.32 & 23.1 & 0.082 \\
\hline 5 & $1,146.5$ & $1,155.0$ & 3.53 & 22.93 & 23.1 & 0.071 \\
\hline 6 & $1,177.0$ & $1,155.0$ & 2.94 & 23.54 & 23.1 & 0.059 \\
\hline 7 & $1,207.5$ & $1,155.0$ & 2.3 & 24.15 & 23.1 & 0.046 \\
\hline 8 & $1,238.0$ & $1,155.0$ & 1.54 & 24.76 & 23.1 & 0.031 \\
\hline \multicolumn{7}{|c|}{ Transect T4 } \\
\hline 1 & 950.0 & 1,157 & 6.74 & 19.0 & 23.14 & 0.135 \\
\hline 2 & $1,055.0$ & 1,157 & 5.18 & 21.1 & 23.14 & 0.104 \\
\hline 3 & $1,085.5$ & 1,151 & 4.65 & 21.71 & 23.02 & 0.093 \\
\hline 4 & $1,116.0$ & 1,151 & 4.08 & 22.32 & 23.02 & 0.082 \\
\hline 5 & $1,146.5$ & 1,151 & 3.5 & 22.93 & 23.02 & 0.07 \\
\hline 6 & $1,177.0$ & 1,151 & 2.91 & 23.54 & 23.02 & 0.058 \\
\hline 7 & $1,207.5$ & 1,151 & 2.27 & 24.15 & 23.02 & 0.045 \\
\hline 8 & $1,238.0$ & 1,151 & 1.54 & 24.76 & 23.02 & 0.031 \\
\hline \multicolumn{7}{|c|}{ (Sheet 1 of 3} \\
\hline
\end{tabular}




\section{Table A1 (Continued)}

\begin{tabular}{|c|c|c|c|c|c|c|}
\hline \multirow[b]{3}{*}{ Channel No. } & \multicolumn{6}{|c|}{ Gauge Location } \\
\hline & \multicolumn{3}{|c|}{ Prototype } & \multicolumn{3}{|c|}{ Laboratory } \\
\hline & $X(m)$ & $Y(m)$ & $Z(m)$ & $X(m)$ & $Y(m)$ & $Z(m)$ \\
\hline \multicolumn{7}{|c|}{ Transect T5 } \\
\hline 1 & 950.0 & $1,126.5$ & 6.71 & 19.0 & 22.53 & 0.134 \\
\hline 2 & $1,055.0$ & $1,126.5$ & 5.07 & 21.1 & 22.53 & 0.101 \\
\hline 3 & $1,085.5$ & $1,147.0$ & 4.63 & 21.71 & 22.94 & 0.093 \\
\hline 4 & $1,116.0$ & $1,147.0$ & 4.05 & 22.32 & 22.94 & 0.081 \\
\hline 5 & $1,146.5$ & $1,147.0$ & 3.46 & 22.93 & 22.94 & 0.069 \\
\hline 6 & $1,177.0$ & $1,147.0$ & 2.87 & 23.54 & 22.94 & 0.057 \\
\hline 7 & $1,207.5$ & $1,147.0$ & 2.25 & 24.15 & 22.94 & 0.045 \\
\hline 8 & $1,238.0$ & $1,147.0$ & 1.54 & 24.76 & 22.94 & 0.031 \\
\hline \multicolumn{7}{|c|}{ Transect T6 } \\
\hline 1 & 950.0 & $1,096.0$ & 6.71 & 19.0 & 21.92 & 0.134 \\
\hline 2 & $1,055.0$ & $1,096.0$ & 5.07 & 21.1 & 21.92 & 0.101 \\
\hline 3 & $1,085.5$ & $1,141.0$ & 4.6 & 21.71 & 22.82 & 0.092 \\
\hline 4 & $1,116.0$ & $1,141.0$ & 4.02 & 22.32 & 22.82 & 0.08 \\
\hline 5 & $1,146.5$ & $1,141.0$ & 3.43 & 22.93 & 22.82 & 0.069 \\
\hline 6 & $1,177.0$ & $1,141.0$ & 2.84 & 23.54 & 22.82 & 0.057 \\
\hline 7 & $1,207.5$ & $1,141.0$ & 2.21 & 24.15 & 22.82 & 0.044 \\
\hline 8 & $1,238.0$ & $1,141.0$ & 1.53 & 24.76 & 22.82 & 0.031 \\
\hline \multicolumn{7}{|c|}{ Transect T7 } \\
\hline 1 & 950.0 & $1,065.5$ & 6.7 & 19.0 & 21.31 & 0.134 \\
\hline 2 & $1,055.0$ & $1,065.5$ & 5.07 & 21.1 & 21.31 & 0.101 \\
\hline 3 & $1,085.5$ & $1,135.0$ & 4.58 & 21.71 & 22.7 & 0.092 \\
\hline 4 & $1,116.0$ & $1,135.0$ & 4.01 & 22.32 & 22.7 & 0.08 \\
\hline 5 & $1,146.5$ & $1,135.0$ & 3.42 & 22.93 & 22.7 & 0.068 \\
\hline 6 & $1,177.0$ & $1,135.0$ & 2.83 & 23.54 & 22.7 & 0.057 \\
\hline 7 & $1,207.5$ & $1,135.0$ & 2.19 & 24.15 & 22.7 & 0.044 \\
\hline 8 & $1,238.0$ & $1,135.0$ & 1.53 & 24.76 & 22.7 & 0.031 \\
\hline \multicolumn{7}{|c|}{ Transect T8 } \\
\hline 1 & 950.0 & $1,035.0$ & 6.7 & 19.0 & 20.7 & 0.134 \\
\hline 2 & $1,055.0$ & $1,035.0$ & 5.07 & 21.1 & 20.7 & 0.101 \\
\hline 3 & $1,085.5$ & $1,123.0$ & 4.56 & 21.71 & 22.46 & 0.091 \\
\hline 4 & $1,116.0$ & $1,123.0$ & 3.99 & 22.32 & 22.46 & 0.08 \\
\hline 5 & $1,146.5$ & $1,123.0$ & 3.42 & 22.93 & 22.46 & 0.068 \\
\hline 6 & $1,177.0$ & $1,123.0$ & 2.83 & 23.54 & 22.46 & 0.057 \\
\hline 7 & $1,207.5$ & $1,123.0$ & 2.19 & 24.15 & 22.46 & 0.044 \\
\hline 8 & $1,238.0$ & $1,123.0$ & 1.53 & 24.76 & 22.46 & 0.031 \\
\hline
\end{tabular}

(Sheet 2 of 3) 


\begin{tabular}{|c|c|c|c|c|c|c|}
\hline \multicolumn{7}{|c|}{ Table A1 (Concluded) } \\
\hline \multirow[b]{3}{*}{ Channel No. } & \multicolumn{6}{|c|}{ Gauge Location } \\
\hline & \multicolumn{3}{|c|}{ Prototype } & \multicolumn{3}{|c|}{ Laboratory } \\
\hline & $X(m)$ & $Y(m)$ & $Z(m)$ & $X(m)$ & $Y(m)$ & $Z(m)$ \\
\hline \multicolumn{7}{|c|}{ Transect T9 } \\
\hline 1 & 950.0 & $1,010.5$ & 6.71 & 19.0 & 20.21 & 0.134 \\
\hline 2 & $1,055.0$ & $1,010.5$ & 5.07 & 21.1 & 20.21 & 0.101 \\
\hline 3 & $1,085.5$ & $1,010.5$ & 4.56 & 21.71 & 20.21 & 0.091 \\
\hline 4 & $1,116.0$ & $1,010.5$ & 4.0 & 22.32 & 20.21 & 0.08 \\
\hline 5 & $1,146.5$ & $1,010.5$ & 3.43 & 22.93 & 20.21 & 0.069 \\
\hline 6 & $1,177.0$ & $1,010.5$ & 2.84 & 23.54 & 20.21 & 0.057 \\
\hline 7 & $1,207.5$ & $1,010.5$ & 2.19 & 24.15 & 20.21 & 0.044 \\
\hline 8 & $1,238.0$ & $1,010.5$ & 1.53 & 24.76 & 20.21 & 0.031 \\
\hline
\end{tabular}




\section{Table A2 \\ Wave Gauge Locations Between Jetties, Transects C29, C29A, C31, C31A, C33, and C33A}

\begin{tabular}{|c|c|c|c|c|c|c|}
\hline \multirow[b]{3}{*}{ Channel No. } & \multicolumn{6}{|c|}{ Gauge Location } \\
\hline & \multicolumn{3}{|c|}{ Prototype } & \multicolumn{3}{|c|}{ Laboratory } \\
\hline & $X(m)$ & $Y(m)$ & $Z(m)$ & $X(m)$ & $Y(m)$ & $Z(m)$ \\
\hline \multicolumn{7}{|c|}{ Transect C29 } \\
\hline 1 & 950.0 & $1,248.5$ & 6.94 & 19.0 & 24.97 & 0.139 \\
\hline 2 & $1,085.5$ & $1,248.5$ & 6.05 & 21.71 & 24.97 & 0.121 \\
\hline 3 & $1,116.0$ & $1,248.5$ & 5.98 & 22.32 & 24.97 & 0.12 \\
\hline 4 & $1,146.5$ & $1,248.5$ & 5.88 & 22.93 & 24.97 & 0.118 \\
\hline 5 & $1,177.0$ & $1,248.5$ & 5.83 & 23.54 & 24.97 & 0.117 \\
\hline 6 & $1,207.5$ & $1,248.5$ & 5.71 & 24.15 & 24.97 & 0.114 \\
\hline 7 & $1,238.0$ & $1,248.5$ & 5.32 & 24.76 & 24.97 & 0.106 \\
\hline \multicolumn{7}{|c|}{ Transect C29A } \\
\hline 1 & 950.0 & $1,248.5$ & 6.94 & 19.0 & 24.97 & 0.139 \\
\hline 2 & $1,268.5$ & $1,263.75$ & 6.0 & 25.37 & 25.27 & 0.12 \\
\hline 3 & $1,299.0$ & $1,263.75$ & 6.38 & 25.98 & 25.27 & 0.128 \\
\hline 4 & $1,329.5$ & $1,263.75$ & 6.42 & 26.59 & 25.27 & 0.128 \\
\hline 5 & $1,360.0$ & $1,263.75$ & 6.35 & 27.2 & 25.27 & 0.127 \\
\hline 6 & $1,390.5$ & $1,263.75$ & 5.97 & 27.81 & 25.27 & 0.119 \\
\hline 7 & $1,421.0$ & $1,263.75$ & 5.75 & 28.42 & 25.27 & 0.115 \\
\hline \multicolumn{7}{|c|}{ Transect C31 } \\
\hline 1 & 950.0 & $1,309.5$ & 6.94 & 19.0 & 26.19 & 0.139 \\
\hline 2 & $1,085.5$ & $1,309.5$ & 6.07 & 21.71 & 26.19 & 0.121 \\
\hline 3 & $1,116.0$ & $1,309.5$ & 6.07 & 22.32 & 26.19 & 0.121 \\
\hline 4 & $1,146.5$ & $1,309.5$ & 6.07 & 22.93 & 26.19 & 0.121 \\
\hline 5 & $1,177.0$ & $1,309.5$ & 6.07 & 23.54 & 26.19 & 0.121 \\
\hline 6 & $1,207.5$ & $1,309.5$ & 6.07 & 24.15 & 26.19 & 0.121 \\
\hline 7 & $1,238.0$ & $1,309.5$ & 6.07 & 24.76 & 26.19 & 0.121 \\
\hline \multicolumn{7}{|c|}{ Transect C31A } \\
\hline 1 & 950.0 & $1,309.5$ & 6.94 & 19.0 & 26.19 & 0.139 \\
\hline 2 & $1,268.5$ & $1,309.5$ & 6.93 & 25.37 & 26.19 & 0.139 \\
\hline 3 & $1,299.0$ & $1,309.5$ & 8.5 & 25.98 & 26.19 & 0.17 \\
\hline 4 & $1,329.5$ & $1,309.5$ & 8.81 & 26.59 & 26.19 & 0.176 \\
\hline 5 & $1,360.0$ & $1,309.5$ & 8.86 & 27.2 & 26.19 & 0.177 \\
\hline 6 & $1,390.5$ & $1,309.5$ & 8.92 & 27.81 & 26.19 & 0.178 \\
\hline 7 & $1,421.0$ & $1,309.5$ & 8.54 & 28.42 & 26.19 & 0.171 \\
\hline
\end{tabular}




\begin{tabular}{|c|c|c|c|c|c|c|}
\hline \multicolumn{7}{|c|}{ Table A2 (Concluded) } \\
\hline \multirow[b]{3}{*}{ Channel No. } & \multicolumn{6}{|c|}{ Gauge Location } \\
\hline & \multicolumn{3}{|c|}{ Prototype } & \multicolumn{3}{|c|}{ Laboratory } \\
\hline & $X(m)$ & $Y(m)$ & $Z(m)$ & $X(m)$ & $Y(m)$ & $Z(m)$ \\
\hline \multicolumn{7}{|c|}{ Transect C33 } \\
\hline 1 & 950.0 & $1,370.5$ & 6.94 & 19.0 & 27.41 & 0.139 \\
\hline 2 & $1,085.5$ & $1,370.5$ & 5.9 & 21.71 & 27.41 & 0.118 \\
\hline 3 & $1,116.0$ & $1,370.5$ & 5.64 & 22.32 & 27.41 & 0.113 \\
\hline 4 & $1,146.5$ & $1,370.5$ & 5.42 & 22.93 & 27.41 & 0.108 \\
\hline 5 & $1,177.0$ & $1,370.5$ & 5.11 & 23.54 & 27.41 & 0.102 \\
\hline 6 & $1,207.5$ & $1,370.5$ & 4.8 & 24.15 & 27.41 & 0.096 \\
\hline 7 & $1,238.0$ & $1,370.5$ & 4.19 & 24.76 & 27.41 & 0.084 \\
\hline \multicolumn{7}{|c|}{ Transect C33A } \\
\hline 1 & 950.0 & $1,370.5$ & 6.94 & 19.0 & 27.41 & 0.139 \\
\hline 2 & $1,268.5$ & $1,355.25$ & 5.27 & 25.37 & 27.11 & 0.105 \\
\hline 3 & $1,299.0$ & $1,355.25$ & 5.13 & 25.98 & 27.11 & 0.103 \\
\hline 4 & $1,329.5$ & $1,355.25$ & 4.96 & 26.59 & 27.11 & 0.099 \\
\hline 5 & $1,360.0$ & $1,355.25$ & 4.91 & 27.2 & 27.11 & 0.098 \\
\hline 6 & $1,390.5$ & $1,355.25$ & 4.39 & 27.81 & 27.11 & 0.088 \\
\hline 7 & $1,421.0$ & $1,355.25$ & 4.24 & 28.42 & 27.11 & 0.085 \\
\hline
\end{tabular}




\section{Table A3 \\ Velocity Gauge Locations Upcoast of Jetty, Transects C17-C19 and C21-C26}

\begin{tabular}{|c|c|c|c|c|c|c|}
\hline \multirow[b]{3}{*}{ Probe No. } & \multicolumn{6}{|c|}{ Gauge Location } \\
\hline & \multicolumn{3}{|c|}{ Prototype } & \multicolumn{3}{|c|}{ Laboratory } \\
\hline & $X(m)$ & $Y(m)$ & $Z(m)$ & $X(m)$ & $Y(m)$ & $Z(m)$ \\
\hline \multicolumn{7}{|c|}{ Transect C17 } \\
\hline 4 & $1,024.5$ & $1,218.0$ & 6.16 & 20.49 & 24.36 & 0.123 \\
\hline 2 & $1,024.5$ & $1,187.5$ & 5.9 & 20.49 & 23.75 & 0.118 \\
\hline 5 & $1,024.5$ & $1,157.0$ & 5.68 & 20.49 & 23.14 & 0.114 \\
\hline 1 & $1,024.5$ & $1,126.5$ & 5.58 & 20.49 & 22.53 & 0.112 \\
\hline 3 & $1,024.5$ & $1,096.0$ & 5.58 & 20.49 & 21.92 & 0.112 \\
\hline 0 & $1,024.5$ & $1,065.5$ & 5.57 & 20.49 & 21.31 & 0.111 \\
\hline \multicolumn{7}{|c|}{ Transect C18 } \\
\hline 4 & 1,055 & $1,218.0$ & 5.81 & 21.1 & 24.36 & 0.116 \\
\hline 2 & 1,055 & $1,187.5$ & 5.41 & 21.1 & 23.75 & 0.108 \\
\hline 5 & 1,055 & $1,157.0$ & 5.19 & 21.1 & 23.14 & 0.104 \\
\hline 1 & 1,055 & $1,126.5$ & 5.07 & 21.1 & 22.53 & 0.101 \\
\hline 3 & 1,055 & $1,096.0$ & 5.07 & 21.1 & 21.92 & 0.101 \\
\hline 0 & 1,055 & $1,065.5$ & 5.07 & 21.1 & 21.31 & 0.101 \\
\hline \multicolumn{7}{|c|}{ Transect C19 } \\
\hline 4 & $1,085.5$ & 945 & 4.55 & 21.71 & 18.9 & 0.091 \\
\hline 2 & $1,116.0$ & 945 & 3.99 & 22.32 & 18.9 & 0.08 \\
\hline 5 & $1,146.5$ & 945 & 3.42 & 22.93 & 18.9 & 0.068 \\
\hline 1 & $1,177.0$ & 945 & 2.83 & 23.54 & 18.9 & 0.057 \\
\hline 3 & $1,207.5$ & 945 & 2.19 & 24.15 & 18.9 & 0.044 \\
\hline 0 & $1,238.0$ & 945 & 1.54 & 24.76 & 18.9 & 0.031 \\
\hline \multicolumn{7}{|c|}{ Transect C21 } \\
\hline 4 & $1,085.5$ & 1,005 & 4.55 & 21.71 & 20.1 & 0.091 \\
\hline 2 & $1,116.0$ & 1,005 & 3.99 & 22.32 & 20.1 & 0.08 \\
\hline 5 & $1,146.5$ & 1,005 & 3.43 & 22.93 & 20.1 & 0.069 \\
\hline 1 & $1,177.0$ & 1,005 & 2.84 & 23.54 & 20.1 & 0.057 \\
\hline 3 & $1,207.5$ & 1,005 & 2.19 & 24.15 & 20.1 & 0.044 \\
\hline 0 & $1,238.0$ & 1,005 & 1.54 & 24.76 & 20.1 & 0.031 \\
\hline \multicolumn{7}{|c|}{ Transect C22 } \\
\hline 4 & $1,085.5$ & 1,035 & 4.56 & 21.71 & 20.7 & 0.091 \\
\hline 2 & $1,116.0$ & 1,035 & 4.0 & 22.32 & 20.7 & 0.08 \\
\hline 5 & $1,146.5$ & 1,035 & 3.43 & 22.93 & 20.7 & 0.069 \\
\hline 1 & $1,177.0$ & 1,035 & 2.84 & 23.54 & 20.7 & 0.057 \\
\hline 3 & $1,207.5$ & 1,035 & 2.19 & 24.15 & 20.7 & 0.044 \\
\hline 0 & $1,238.0$ & 1,035 & 1.54 & 24.76 & 20.7 & 0.031 \\
\hline \multicolumn{7}{|c|}{ (Continued) } \\
\hline
\end{tabular}




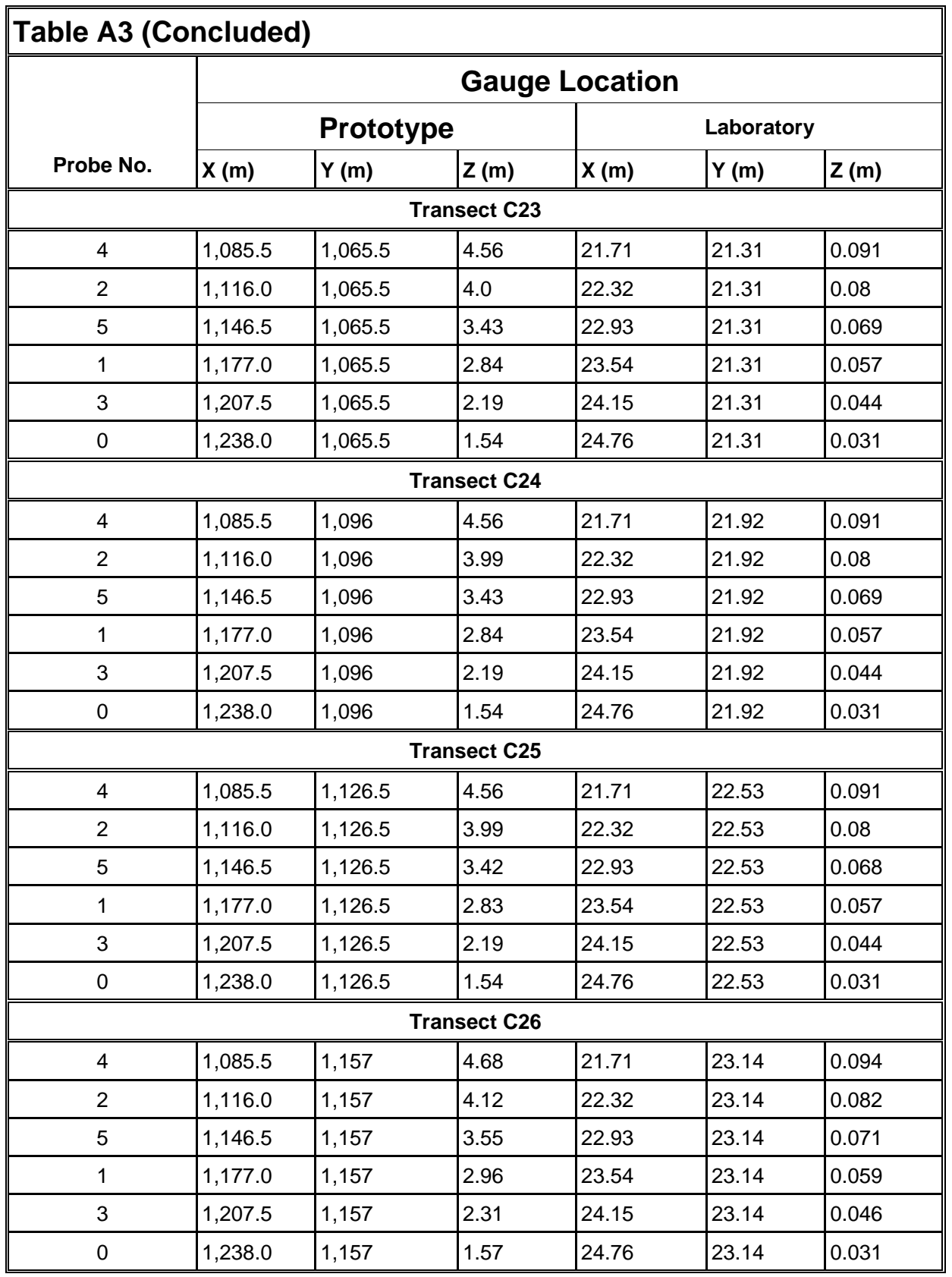




\section{Table A4 \\ Velocity Gauge Locations Between Jetties, Transects C27-C29, C29A, C31, C31A, C33, and C33A}

\begin{tabular}{|c|c|c|c|c|c|c|}
\hline \multirow[b]{3}{*}{ Probe No. } & \multicolumn{6}{|c|}{ Gauge Location } \\
\hline & \multicolumn{3}{|c|}{ Prototype } & \multicolumn{3}{|c|}{ Laboratory } \\
\hline & $x(m)$ & $Y(m)$ & $z(m)$ & $X(m)$ & $Y(m)$ & $z(m)$ \\
\hline \multicolumn{7}{|c|}{ Transect C27 } \\
\hline 4 & $1,085.5$ & 1,203 & 5.16 & 21.71 & 24.06 & 0.103 \\
\hline 2 & $1,116.0$ & 1,203 & 4.64 & 22.32 & 24.06 & 0.093 \\
\hline 5 & $1,146.5$ & 1,203 & 4.15 & 22.93 & 24.06 & 0.083 \\
\hline 1 & $1,177.0$ & 1,203 & 3.64 & 23.54 & 24.06 & 0.073 \\
\hline 3 & $1,207.5$ & 1,203 & 2.97 & 24.15 & 24.06 & 0.059 \\
\hline 0 & $1,238.0$ & 1,203 & 2.37 & 24.76 & 24.06 & 0.047 \\
\hline \multicolumn{7}{|c|}{ Transect C28 } \\
\hline 4 & $1,268.5$ & 1,240 & 3.88 & 25.37 & 24.8 & 0.078 \\
\hline 2 & $1,299.0$ & 1,240 & 3.14 & 25.98 & 24.8 & 0.063 \\
\hline 5 & $1,329.5$ & 1,240 & 2.39 & 26.59 & 24.8 & 0.048 \\
\hline 1 & $1,360.0$ & 1,240 & 1.71 & 27.2 & 24.8 & 0.034 \\
\hline 3 & $1,390.5$ & 1,240 & 1.42 & 27.81 & 24.8 & 0.028 \\
\hline 0 & $1,421.0$ & 1,240 & 1.57 & 28.42 & 24.8 & 0.031 \\
\hline \multicolumn{7}{|c|}{ Transect C29 } \\
\hline 4 & $1,085.5$ & $1,248.5$ & 6.05 & 21.71 & 24.97 & 0.121 \\
\hline 2 & $1,116.0$ & $1,248.5$ & 5.98 & 22.32 & 24.97 & 0.12 \\
\hline 5 & $1,146.5$ & $1,248.5$ & 5.88 & 22.93 & 24.97 & 0.118 \\
\hline 1 & $1,177.0$ & $1,248.5$ & 5.83 & 23.54 & 24.97 & 0.117 \\
\hline 3 & $1,207.5$ & $1,248.5$ & 5.71 & 24.15 & 24.97 & 0.114 \\
\hline 0 & $1,238.0$ & $1,248.5$ & 5.32 & 24.76 & 24.97 & 0.106 \\
\hline \multicolumn{7}{|c|}{ Transect C29A } \\
\hline 4 & $1,268.5$ & $1,263.75$ & 6.0 & 25.37 & 25.27 & 0.12 \\
\hline 2 & $1,299.0$ & $1,263.75$ & 6.38 & 25.98 & 25.27 & 0.128 \\
\hline 5 & $1,329.5$ & $1,263.75$ & 6.42 & 26.59 & 25.27 & 0.128 \\
\hline 1 & $1,360.0$ & $1,263.75$ & 6.35 & 27.2 & 25.27 & 0.127 \\
\hline 3 & $1,390.5$ & $1,263.75$ & 5.97 & 27.81 & 25.27 & 0.119 \\
\hline 0 & $1,421.0$ & $1,263.75$ & 5.75 & 28.42 & 25.27 & 0.115 \\
\hline \multicolumn{7}{|c|}{ Transect C31 } \\
\hline 4 & $1,085.5$ & $1,309.5$ & 6.07 & 21.71 & 26.19 & 0.121 \\
\hline 2 & $1,116.0$ & $1,309.5$ & 6.07 & 22.32 & 26.19 & 0.121 \\
\hline 5 & $1,146.5$ & $1,309.5$ & 6.07 & 22.93 & 26.19 & 0.121 \\
\hline 1 & $1,177.0$ & $1,309.5$ & 6.07 & 23.54 & 26.19 & 0.121 \\
\hline 3 & $1,207.5$ & $1,309.5$ & 6.07 & 24.15 & 26.19 & 0.121 \\
\hline 0 & $1,238.0$ & $1,309.5$ & 6.07 & 24.76 & 26.19 & 0.121 \\
\hline \multicolumn{7}{|c|}{ (Continued) } \\
\hline
\end{tabular}




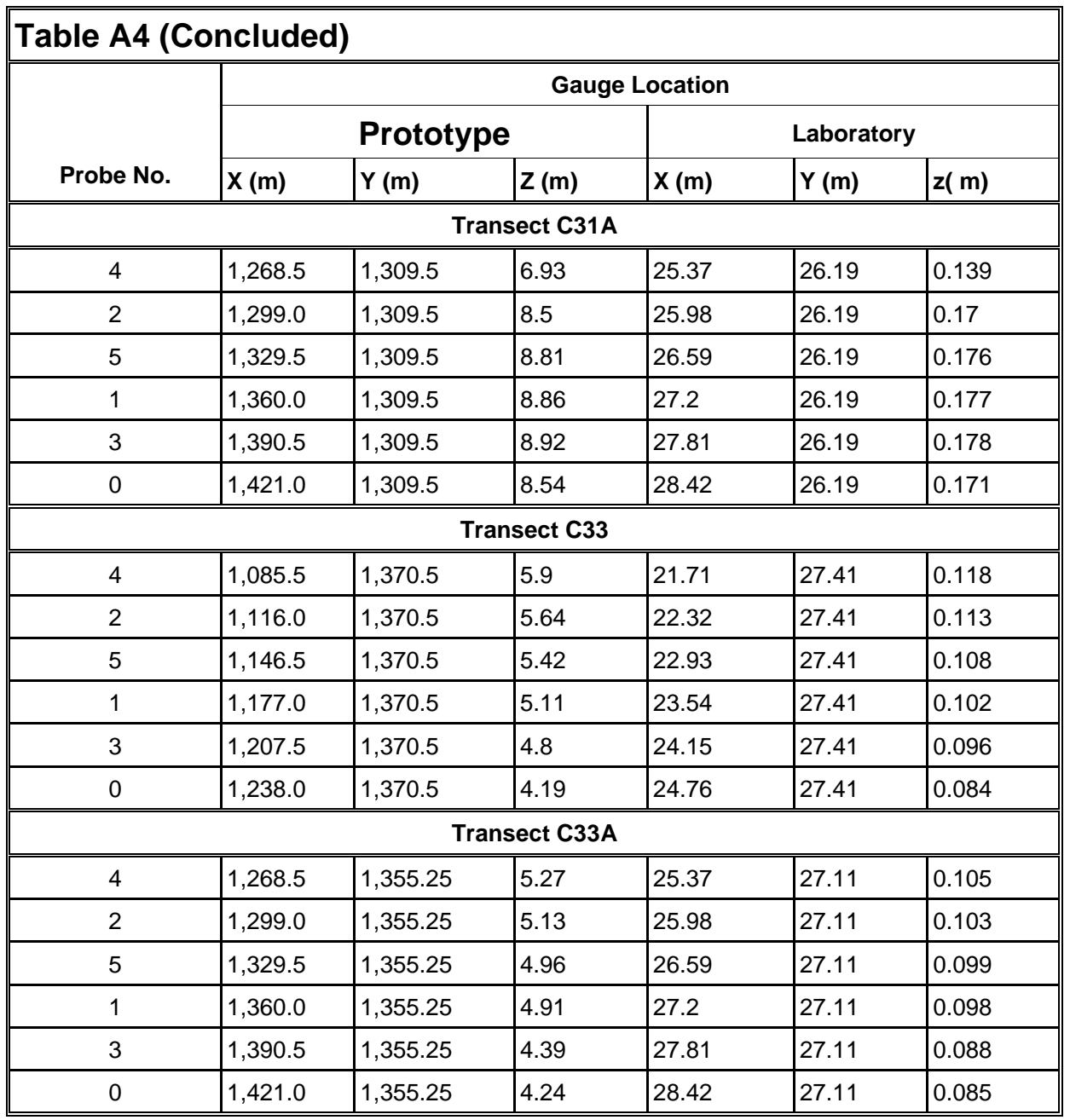




\begin{tabular}{|c|c|c|c|c|c|c|}
\hline \multicolumn{7}{|c|}{$\begin{array}{l}\text { Table A5 } \\
\text { Velocity Gauge Locations, } \\
\text { C19, C21-C26, T1, and T3 }\end{array}$} \\
\hline \multirow[b]{3}{*}{ Probe No. } & \multicolumn{6}{|c|}{ Gauge Location } \\
\hline & \multicolumn{3}{|c|}{ Prototype } & \multicolumn{3}{|c|}{ Laboratory } \\
\hline & $X(m)$ & $Y(m)$ & $Z(m)$ & $X(m)$ & $Y(m)$ & $Z(m)$ \\
\hline \multicolumn{7}{|c|}{ Transect C17 } \\
\hline 4 & $1,024.5$ & $1,218.0$ & 6.15 & 20.49 & 24.36 & 0.123 \\
\hline 2 & $1,024.5$ & $1,187.5$ & 5.9 & 20.49 & 23.75 & 0.118 \\
\hline 5 & $1,024.5$ & $1,157.0$ & 5.68 & 20.49 & 23.14 & 0.114 \\
\hline 1 & $1,024.5$ & $1,126.5$ & 5.58 & 20.49 & 22.53 & 0.112 \\
\hline 3 & $1,024.5$ & $1,096.0$ & 5.58 & 20.49 & 21.92 & 0.112 \\
\hline 0 & $1,024.5$ & $1,065.5$ & 5.57 & 20.49 & 21.31 & 0.111 \\
\hline \multicolumn{7}{|c|}{ Transect C18 } \\
\hline 4 & 1,055 & $1,218.0$ & 5.81 & 21.1 & 24.36 & 0.116 \\
\hline 2 & 1,055 & $1,187.5$ & 5.41 & 21.1 & 23.75 & 0.108 \\
\hline 5 & 1,055 & $1,157.0$ & 5.19 & 21.1 & 23.14 & 0.104 \\
\hline 1 & 1,055 & $1,126.5$ & 5.07 & 21.1 & 22.53 & 0.101 \\
\hline 3 & 1,055 & $1,096.0$ & 5.07 & 21.1 & 21.92 & 0.101 \\
\hline 0 & 1,055 & $1,065.5$ & 5.07 & 21.1 & 21.31 & 0.101 \\
\hline \multicolumn{7}{|c|}{ Transect C19 } \\
\hline 4 & $1,085.5$ & 945 & 4.55 & 21.71 & 18.9 & 0.091 \\
\hline 2 & $1,116.0$ & 945 & 3.99 & 22.32 & 18.9 & 0.08 \\
\hline 5 & $1,146.5$ & 945 & 3.42 & 22.93 & 18.9 & 0.068 \\
\hline 1 & $1,177.0$ & 945 & 2.83 & 23.54 & 18.9 & 0.057 \\
\hline 3 & $1,207.5$ & 945 & 2.19 & 24.15 & 18.9 & 0.044 \\
\hline 0 & $1,238.0$ & 945 & 1.52 & 24.76 & 18.9 & 0.03 \\
\hline \multicolumn{7}{|c|}{ Transect C21 } \\
\hline 4 & $1,085.5$ & 1,005 & 4.55 & 21.71 & 20.1 & 0.091 \\
\hline 2 & $1,116.0$ & 1,005 & 3.99 & 22.32 & 20.1 & 0.08 \\
\hline 5 & $1,146.5$ & 1,005 & 3.43 & 22.93 & 20.1 & 0.069 \\
\hline 1 & $1,177.0$ & 1,005 & 2.84 & 23.54 & 20.1 & 0.057 \\
\hline 3 & $1,207.5$ & 1,005 & 2.19 & 24.15 & 20.1 & 0.044 \\
\hline 0 & $1,238.0$ & 1,005 & 1.52 & 24.76 & 20.1 & 0.03 \\
\hline & & & & & & (Sheet 10 \\
\hline
\end{tabular}




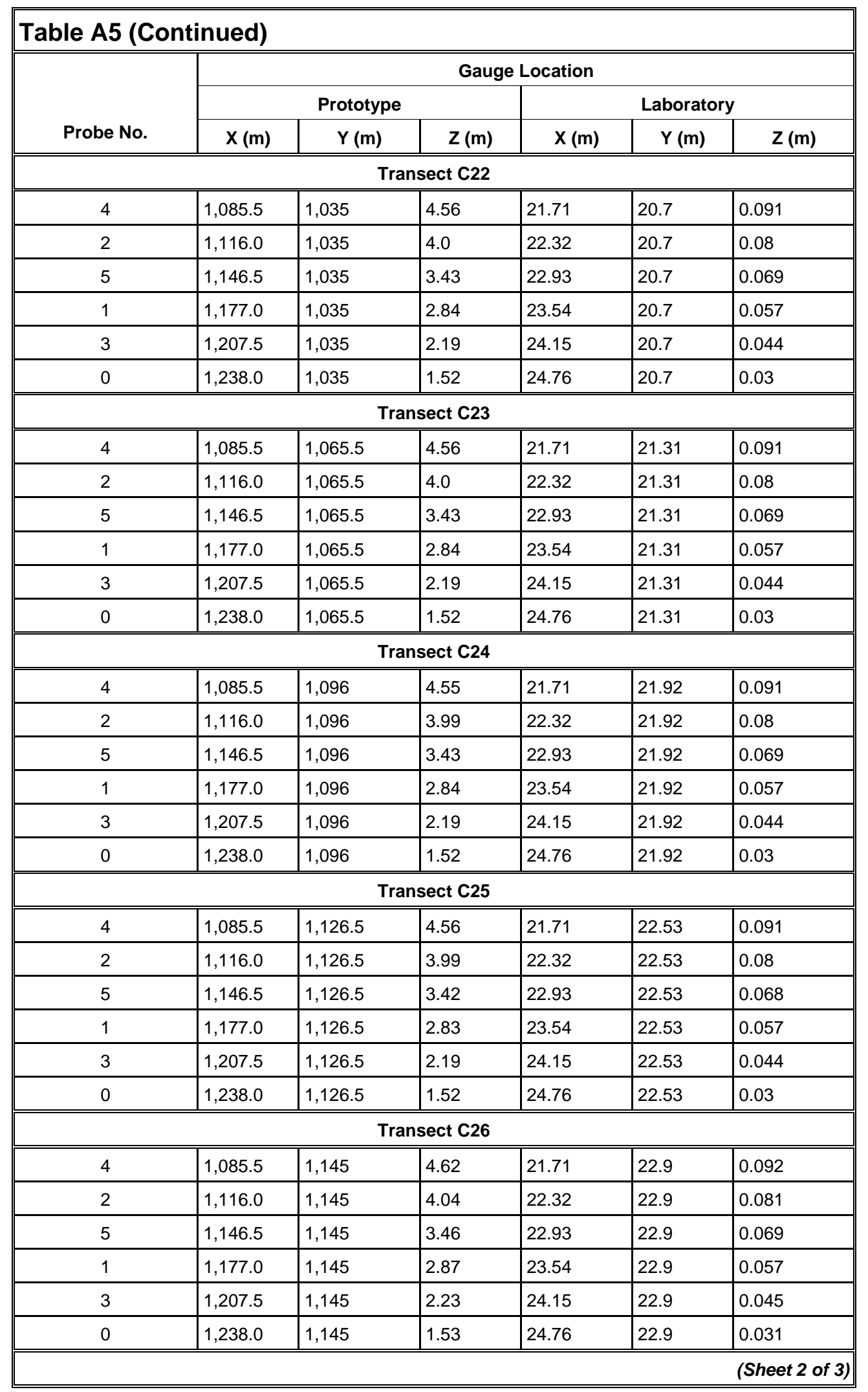




\begin{tabular}{|c|c|c|c|c|c|c|}
\hline \multicolumn{7}{|c|}{ Table A5 (Concluded) } \\
\hline \multirow[b]{3}{*}{ Probe No. } & \multicolumn{6}{|c|}{ Gauge Location } \\
\hline & \multicolumn{3}{|c|}{ Prototype } & \multicolumn{3}{|c|}{ Laboratory } \\
\hline & $X(m)$ & $Y(m)$ & $Z(m)$ & $X(m)$ & $Y(m)$ & $Z(m)$ \\
\hline \multicolumn{7}{|c|}{ Transect T1 } \\
\hline 4 & $1,080.5$ & 1,159 & 4.78 & 21.61 & 23.18 & 0.096 \\
\hline 2 & $1,116.0$ & 1,159 & 4.13 & 22.32 & 23.18 & 0.083 \\
\hline 5 & $1,141.5$ & 1,159 & 3.66 & 22.83 & 23.18 & 0.073 \\
\hline 1 & $1,177.0$ & 1,159 & 2.98 & 23.54 & 23.18 & 0.06 \\
\hline 3 & $1,202.5$ & 1,159 & 2.43 & 24.05 & 23.18 & 0.049 \\
\hline 0 & $1,238.0$ & 1,159 & 1.56 & 24.76 & 23.18 & 0.031 \\
\hline \multicolumn{7}{|c|}{ Transect T3 } \\
\hline 4 & $1,080.5$ & 1,155 & 4.76 & 21.61 & 23.1 & 0.095 \\
\hline 2 & $1,116.0$ & 1,155 & 4.1 & 22.32 & 23.1 & 0.082 \\
\hline 5 & $1,141.5$ & 1,155 & 3.62 & 22.83 & 23.1 & 0.072 \\
\hline 1 & 1,1770 & 1,155 & 2.94 & 23.54 & 23.1 & 0.059 \\
\hline 3 & $1,202.5$ & 1,155 & 2.4 & 24.05 & 23.1 & 0.048 \\
\hline 0 & $1,238.0$ & 1,155 & 1.55 & 24.76 & 23.1 & 0.031 \\
\hline & & & & & & (Sheet 3 o \\
\hline
\end{tabular}




\section{Appendix B Wave Height Data Tables}

Tables of the analyzed wave height and interpolated wave direction are included in this appendix (Tables B1-B15). These data also are included in the accompanying $\mathrm{CD}$, where the time series data also are provided. The interpolated value of the wave direction is the value of wave direction from the surrounding velocity gauge locations because velocity and wave height gauges were not usually collocated. At some locations an interpolated wave direction value is not provided when there is no velocity gauge nearby, or if there was a problem with the velocity data. The channel 1 gauge is located near the wave generator in an area of constant depth and the wave direction represents the incident wave direction (20 deg). Tables of the analyzed velocities and direction are included in Appendix C. These data are also included in the accompanying $\mathrm{CD}$, where the time series data may also be found. 
Table B1

Wave Height and Interpolated Wave Direction, Reflective Jetty, 3.4-m, 8-sec Wave, Transects T1-T9

\begin{tabular}{|c|c|c|c|c|}
\hline Channel & $X(m)$ & $Y(m)$ & Ht (m) & Int. Wave Dir (deg) \\
\hline \multicolumn{5}{|c|}{ Transect T1 } \\
\hline 1 & $9,50.0$ & $1,248.5$ & 3.4 & -- \\
\hline 2 & $1,055.0$ & $1,248.5$ & 2.9 & -- \\
\hline 3 & $1,085.5$ & $1,159.0$ & 1.95 & 352.5 \\
\hline 4 & $1,116.0$ & $1,159.0$ & 1.6 & 4.9 \\
\hline 5 & $1,146.5$ & $1,159.0$ & 1.15 & 2.6 \\
\hline 6 & $1,177.0$ & $1,159.0$ & 1.1 & 355.7 \\
\hline 7 & $1,207.5$ & $1,159.0$ & 0.75 & 1.3 \\
\hline 8 & $1,238.0$ & $1,159.0$ & 0.3 & 3.0 \\
\hline \multicolumn{5}{|c|}{ Transect T2 } \\
\hline 1 & 950.0 & 1,218 & 3.35 & -- \\
\hline 2 & $1,055.0$ & 1,218 & 2.5 & 10.7 \\
\hline 3 & $1,085.5$ & 1,157 & 1.9 & 352.5 \\
\hline 4 & $1,116.0$ & 1,157 & 1.55 & 4.9 \\
\hline 5 & $1,146.5$ & 1,157 & 1.25 & 2.6 \\
\hline 6 & $1,177.0$ & 1,157 & 1.15 & 355.7 \\
\hline 7 & $1,207.5$ & 1,157 & 0.7 & 1.3 \\
\hline 8 & $1,238.0$ & 1,157 & 0.35 & 3.0 \\
\hline \multicolumn{5}{|c|}{ Transect T3 } \\
\hline 1 & 950.0 & $1,187.5$ & 3.3 & -- \\
\hline 2 & $1,055.0$ & $1,187.5$ & 2.5 & 24.9 \\
\hline 3 & $1,085.5$ & $1,155.0$ & 2.25 & 353.7 \\
\hline 4 & $1,116.0$ & $1,155.0$ & 1.45 & 5.7 \\
\hline 5 & $1,146.5$ & $1,155.0$ & 1.35 & 3.2 \\
\hline 6 & $1,177.0$ & $1,155.0$ & 1.05 & 356.1 \\
\hline 7 & $1,207.5$ & $1,155.0$ & 0.65 & 0.9 \\
\hline 8 & $1,238.0$ & $1,155.0$ & 0.35 & 2.8 \\
\hline \multicolumn{5}{|c|}{ Transect T4 } \\
\hline 1 & 950.0 & 1,157 & 3.35 & -- \\
\hline 2 & $1,055.0$ & 1,157 & 2.3 & 19.1 \\
\hline 3 & $1,085.5$ & 1,151 & 2.2 & 356.0 \\
\hline 4 & $1,116.0$ & 1,151 & 1.9 & 7.2 \\
\hline 5 & $1,146.5$ & 1,151 & 1.45 & 4.5 \\
\hline 6 & $1,177.0$ & 1,151 & 1.0 & 356.8 \\
\hline 7 & $1,207.5$ & 1,151 & 0.7 & 0.1 \\
\hline 8 & $1,238.0$ & 1,151 & 0.35 & 2.5 \\
\hline & & & & (Sheet 1 of 3 ) \\
\hline
\end{tabular}




\section{Table B1 (Continued)}

\begin{tabular}{|c|c|c|c|c|}
\hline Channel & $X(m)$ & $Y(m)$ & $\mathrm{Ht}(\mathrm{m})$ & Int. Wave Dir (deg) \\
\hline \multicolumn{5}{|c|}{ Transect T5 } \\
\hline 1 & 950.0 & $1,126.5$ & 3.3 & -- \\
\hline 2 & $1,055.0$ & $1,126.5$ & 2.25 & 21.5 \\
\hline 3 & $1,085.5$ & $1,147.0$ & 1.35 & 358.4 \\
\hline 4 & $1,116.0$ & $1,147.0$ & 1.45 & 8.8 \\
\hline 5 & $1,146.5$ & $1,147.0$ & 1.35 & 5.8 \\
\hline 6 & $1,177.0$ & $1,147.0$ & 1.1 & 357.5 \\
\hline 7 & $1,207.5$ & $1,147.0$ & 0.85 & 359.4 \\
\hline 8 & $1,238.0$ & $1,147.0$ & 0.3 & 2.2 \\
\hline \multicolumn{5}{|c|}{ Transect T6 } \\
\hline 1 & 950.0 & 1,096 & 3.25 & -- \\
\hline 2 & $1,055.0$ & 1,096 & 2.25 & 17.7 \\
\hline 3 & $1,085.5$ & 1,141 & 1.8 & 1.9 \\
\hline 4 & $1,116.0$ & 1,141 & 1.5 & 11.1 \\
\hline 5 & $1,146.5$ & 1,141 & 0.8 & 7.7 \\
\hline 6 & $1,177.0$ & 1,141 & 1.2 & 358.5 \\
\hline 7 & $1,207.5$ & 1,141 & 0.95 & 358.2 \\
\hline 8 & $1,238.0$ & 1,141 & 0.3 & 1.7 \\
\hline \multicolumn{5}{|c|}{ Transect T7 } \\
\hline 1 & 950.0 & $1,065.5$ & 3.3 & -- \\
\hline 2 & $1,055.0$ & $1,065.5$ & 2.2 & 12.6 \\
\hline 3 & $1,085.5$ & 1,135 & 1.55 & 5.5 \\
\hline 4 & $1,116.0$ & 1,135 & 1.4 & 13.5 \\
\hline 5 & $1,146.5$ & 1,135 & 1.2 & 9.6 \\
\hline 6 & $1,177.0$ & 1,135 & 1.0 & 359.6 \\
\hline 7 & $1,207.5$ & 1,135 & 0.85 & 357.0 \\
\hline 8 & $1,238.0$ & 1,135 & 0.25 & 1.2 \\
\hline \multicolumn{5}{|c|}{ Transect T8 } \\
\hline 1 & 950.0 & 1,035 & 3.45 & -- \\
\hline 2 & $1,055.0$ & 1,035 & 2.9 & -- \\
\hline 3 & $1,085.5$ & 1,123 & 2.15 & 10.0 \\
\hline 4 & $1,116.0$ & 1,123 & 1.4 & 17.4 \\
\hline 5 & $1,146.5$ & 1,123 & 1.1 & 11.8 \\
\hline 6 & $1,177.0$ & 1,123 & 1.05 & 359.9 \\
\hline 7 & $1,207.5$ & 1,123 & 0.9 & 355.3 \\
\hline 8 & $1,238.0$ & 1,123 & 0.35 & 1.0 \\
\hline \multicolumn{5}{|c|}{ (Sheet 2 of 3 ) } \\
\hline
\end{tabular}




\section{Table B1 (Concluded)}

\begin{tabular}{|c|c|c|c|c|}
\hline Channel & $X(m)$ & $Y(m)$ & $\mathrm{Ht}(\mathrm{m})$ & Int. Wave Dir (deg) \\
\hline \multicolumn{5}{|c|}{ Transect T9 } \\
\hline 1 & 950.0 & $1,010.5$ & 3.25 & -- \\
\hline 2 & $1,055.0$ & $1,010.5$ & 2.25 & -- \\
\hline 3 & $1,085.5$ & $1,010.5$ & 1.8 & 18.6 \\
\hline 4 & $1,116.0$ & $1,010.5$ & 1.15 & 18.6 \\
\hline 5 & $1,146.5$ & $1,010.5$ & 1.1 & 2.5 \\
\hline 6 & $1,177.0$ & $1,010.5$ & 1.1 & 25.8 \\
\hline 7 & $1,207.5$ & $1,010.5$ & 0.85 & 27.2 \\
\hline 8 & $1,238.0$ & $1,010.5$ & 0.25 & 19.7 \\
\hline \multicolumn{5}{|c|}{ (Sheet 3 of 3) } \\
\hline
\end{tabular}




\begin{tabular}{|c|c|c|c|c|}
\hline \multicolumn{5}{|c|}{$\begin{array}{l}\text { Table B2 } \\
\text { Wave Height and Interpolated Wave Direction, } \\
\text { Reflective Jetty, 2.0-m, 11-sec Wave, Transects T1-T9 }\end{array}$} \\
\hline Channel & $X(m)$ & $Y(m)$ & Ht (m) & Int. Wave Dir (deg) \\
\hline \multicolumn{5}{|c|}{ Transect T1 } \\
\hline 1 & 950.0 & $1,248.5$ & 2.0 & -- \\
\hline 2 & $1,055.0$ & $1,248.5$ & 2.65 & -- \\
\hline 3 & $1,085.5$ & $1,159.0$ & 3.35 & 0.4 \\
\hline 4 & $1,116.0$ & $1,159.0$ & 2.75 & 6.6 \\
\hline 5 & $1,146.5$ & $1,159.0$ & 1.75 & 358.7 \\
\hline 6 & $1,177.0$ & $1,159.0$ & 1.4 & 351.6 \\
\hline 7 & $1,207.5$ & $1,159.0$ & 1.05 & 345.9 \\
\hline 8 & $1,238.0$ & $1,159.0$ & 0.2 & 357.4 \\
\hline \multicolumn{5}{|c|}{ Transect T2 } \\
\hline 1 & 950.0 & 1,218 & 1.95 & -- \\
\hline 2 & $1,055.0$ & 1,218 & 2.7 & 7.7 \\
\hline 3 & $1,085.5$ & 1,157 & 3.5 & 0.4 \\
\hline 4 & $1,116.0$ & 1,157 & 2.75 & 6.6 \\
\hline 5 & $1,146.5$ & 1,157 & 1.9 & 358.7 \\
\hline 6 & $1,177.0$ & 1,157 & 1.55 & 351.6 \\
\hline 7 & $1,207.5$ & 1,157 & 1.05 & 345.9 \\
\hline 8 & $1,238.0$ & 1,157 & 0.2 & 357.4 \\
\hline \multicolumn{5}{|c|}{ Transect T3 } \\
\hline 1 & 950.0 & $1,187.5$ & 1.9 & -- \\
\hline 2 & $1,055.0$ & $1,187.5$ & 2.7 & 26.1 \\
\hline 3 & $1,085.5$ & $1,155.0$ & 3.65 & 1.7 \\
\hline 4 & $1,116.0$ & $1,155.0$ & 2.65 & 7.6 \\
\hline 5 & $1,146.5$ & $1,155.0$ & 1.8 & 0.3 \\
\hline 6 & $1,177.0$ & $1,155.0$ & 1.5 & 353.5 \\
\hline 7 & $1,207.5$ & $1,155.0$ & 1.05 & 347.9 \\
\hline 8 & $1,238.0$ & $1,155.0$ & 0.25 & 356.8 \\
\hline \multicolumn{5}{|c|}{ Transect T4 } \\
\hline 1 & 950.0 & 1,157 & 1.95 & -- \\
\hline 2 & $1,055.0$ & 1,157 & 2.15 & 20.7 \\
\hline 3 & $1,085.5$ & 1,151 & 2.8 & 4.3 \\
\hline 4 & $1,116.0$ & 1,151 & 2.65 & 9.6 \\
\hline 5 & $1,146.5$ & 1,151 & 1.9 & 3.5 \\
\hline 6 & $1,177.0$ & 1,151 & 1.35 & 357.3 \\
\hline 7 & $1,207.5$ & 1,151 & 1.0 & 351.9 \\
\hline 8 & $1,238.0$ & 1,151 & 0.25 & 355.5 \\
\hline & & & & (Sheet 1 of 3 ) \\
\hline
\end{tabular}




\section{Table B2 (Continued)}

\begin{tabular}{|c|c|c|c|c|}
\hline Channel & $X(m)$ & $Y(m)$ & Ht (m) & Int. Wave Dir (deg) \\
\hline \multicolumn{5}{|c|}{ Transect T5 } \\
\hline 1 & 950.0 & $1,126.5$ & 1.95 & -- \\
\hline 2 & $1,055.0$ & $1,126.5$ & 1.8 & 15.9 \\
\hline 3 & $1,085.5$ & $1,147.0$ & 1.95 & 7.0 \\
\hline 4 & $1,116.0$ & $1,147.0$ & 1.55 & 11.7 \\
\hline 5 & $1,146.5$ & $1,147.0$ & 1.3 & 6.7 \\
\hline 6 & $1,177.0$ & $1,147.0$ & 1.35 & 1.2 \\
\hline 7 & $1,207.5$ & $1,147.0$ & 0.9 & 356.0 \\
\hline 8 & $1,238.0$ & $1,147.0$ & 0.2 & 354.2 \\
\hline \multicolumn{5}{|c|}{ Transect T6 } \\
\hline 1 & 950.0 & 1,096 & 1.9 & -- \\
\hline 2 & $1,055.0$ & 1,096 & 2.25 & 24.7 \\
\hline 3 & $1,085.5$ & 1,141 & 2.0 & 11.0 \\
\hline 4 & $1,116.0$ & 1,141 & 1.6 & 14.7 \\
\hline 5 & $1,146.5$ & 1,141 & 1.1 & 11.6 \\
\hline 6 & $1,177.0$ & 1,141 & 1.05 & 7.1 \\
\hline 7 & $1,207.5$ & 1,141 & 0.95 & 2.2 \\
\hline 8 & $1,238.0$ & 1,141 & 0.2 & 352.2 \\
\hline \multicolumn{5}{|c|}{ Transect T7 } \\
\hline 1 & 950.0 & $1,065.5$ & 1.95 & -- \\
\hline 2 & $1,055.0$ & $1,065.5$ & 2.2 & 20.1 \\
\hline 3 & $1,085.5$ & $1,135.0$ & 2.25 & 15 \\
\hline 4 & $1,116.0$ & $1,135.0$ & 2.1 & 17.8 \\
\hline 5 & $1,146.5$ & $1,135.0$ & 1.7 & 16.5 \\
\hline 6 & $1,177.0$ & $1,135.0$ & 1.4 & 13.1 \\
\hline 7 & $1,207.5$ & $1,135.0$ & 0.6 & 8.5 \\
\hline 8 & $1,238.0$ & $1,135.0$ & 0.2 & 350.3 \\
\hline \multicolumn{5}{|c|}{ Transect T8 } \\
\hline 1 & 950.0 & $1,035.0$ & 2.3 & -- \\
\hline 2 & $1,055.0$ & $1,035.0$ & 2.35 & -- \\
\hline 3 & $1,085.5$ & $1,123.0$ & 2.4 & 19.5 \\
\hline 4 & $1,116.0$ & $1,123.0$ & 2.35 & 20.4 \\
\hline 5 & $1,146.5$ & $1,123.0$ & 1.75 & 20.4 \\
\hline 6 & $1,177.0$ & $1,123.0$ & 1.65 & 19 \\
\hline 7 & $1,207.5$ & $1,123.0$ & 1.35 & 15.7 \\
\hline 8 & $1,238.0$ & $1,123.0$ & 0.25 & 352.7 \\
\hline
\end{tabular}

(Sheet 2 of 3) 


\section{Table B2 (Concluded)}

\begin{tabular}{|c|l|l|l|l||}
\hline \hline Channel & X (m) & $Y(m)$ & Ht (m) & Int. Wave Dir (deg) \\
\hline \hline \multicolumn{5}{|c||}{ Transect T9 } \\
\hline \hline 1 & 950.0 & $1,010.5$ & 1.9 & -- \\
\hline 2 & $1,055.0$ & $1,010.5$ & 1.95 & -- \\
\hline 3 & $1,085.5$ & $1,010.5$ & 1.8 & 1.6 \\
\hline 4 & $1,116.0$ & $1,010.5$ & 2.0 & 9.4 \\
\hline 5 & $1,146.5$ & $1,010.5$ & 1.5 & 6.3 \\
\hline 6 & $1,177.0$ & $1,010.5$ & 1.15 & 355.4 \\
\hline 7 & $1,207.5$ & $1,010.5$ & 0.8 & 20.3 \\
\hline 8 & $1,238.0$ & $1,010.5$ & 0.2 & 37.7 \\
\hline \hline \multicolumn{7}{|c|}{} \\
\hline \multicolumn{7}{|c|}{}
\end{tabular}


Table B3

Wave Height and Interpolated Wave Direction, Reflective Jetty, 1.0-m, 11-sec Wave, Transects T1-T9

\begin{tabular}{|c|c|c|c|c|}
\hline Channel & $X(m)$ & $\mathrm{Y}(\mathrm{m})$ & $\mathrm{Ht}(\mathrm{m})$ & Int. Wave Dir (deg) \\
\hline \multicolumn{5}{|c|}{ Transect T1 } \\
\hline 1 & 950.0 & $1,248.5$ & 0.95 & -- \\
\hline 2 & $1,055.0$ & $1,248.5$ & 1.4 & -- \\
\hline 3 & $1,085.5$ & $1,159.0$ & 1.5 & 351.9 \\
\hline 4 & $1,116.0$ & $1,159.0$ & 1.85 & 4.7 \\
\hline 5 & $1,146.5$ & $1,159.0$ & 1.6 & 0.3 \\
\hline 6 & $1,177.0$ & $1,159.0$ & 1.25 & 354.7 \\
\hline 7 & $1,207.5$ & $1,159.0$ & 0.8 & 356.0 \\
\hline 8 & $1,238.0$ & $1,159.0$ & 0.1 & 353.3 \\
\hline \multicolumn{5}{|c|}{ Transect T2 } \\
\hline 1 & 950.0 & 1,218 & 0.95 & -- \\
\hline 2 & $1,055.0$ & 1,218 & 1.35 & 7.5 \\
\hline 3 & $1,085.5$ & 1,157 & 1.6 & 351.9 \\
\hline 4 & $1,116.0$ & 1,157 & 1.85 & 4.7 \\
\hline 5 & $1,146.5$ & 1,157 & 1.65 & 0.3 \\
\hline 6 & $1,177.0$ & 1,157 & 1.25 & 354.7 \\
\hline 7 & $1,207.5$ & 1,157 & 0.85 & 356.0 \\
\hline 8 & $1,238.0$ & 1,157 & 0.1 & 353.3 \\
\hline \multicolumn{5}{|c|}{ Transect T3 } \\
\hline 1 & 950.0 & $1,187.5$ & 1.0 & -- \\
\hline 2 & $1,055.0$ & $1,187.5$ & 1.25 & 15.8 \\
\hline 3 & $1,085.5$ & $1,155.0$ & 1.7 & 352.8 \\
\hline 4 & $1,116.0$ & $1,155.0$ & 1.75 & 5.8 \\
\hline 5 & $1,146.5$ & $1,155.0$ & 1.6 & 1.3 \\
\hline 6 & $1,177.0$ & $1,155.0$ & 1.25 & 355.8 \\
\hline 7 & $1,207.5$ & $1,155.0$ & 0.8 & 356.4 \\
\hline 8 & $1,238.0$ & $1,155.0$ & 0.1 & 353.7 \\
\hline \multicolumn{5}{|c|}{ Transect T4 } \\
\hline 1 & 950.0 & 1,157 & 1.0 & -- \\
\hline 2 & $1,055.0$ & 1,157 & 1.05 & 17.7 \\
\hline 3 & $1,085.5$ & 1,151 & 1.55 & 354.6 \\
\hline 4 & $1,116.0$ & 1,151 & 1.55 & 8.0 \\
\hline 5 & $1,146.5$ & 1,151 & 1.45 & 3.4 \\
\hline 6 & $1,177.0$ & 1,151 & 1.4 & 357.9 \\
\hline 7 & $1,207.5$ & 1,151 & 0.75 & 357.3 \\
\hline 8 & $1,238.0$ & 1,151 & 0.1 & 354.6 \\
\hline & & & & (Sheet \\
\hline
\end{tabular}




\begin{tabular}{|c|c|c|c|c|}
\hline \multicolumn{5}{|c|}{ Table B3 (Continued) } \\
\hline Channel & $X(m)$ & $Y(m)$ & $\mathrm{Ht}(\mathrm{m})$ & Int. Wave Dir (deg) \\
\hline \multicolumn{5}{|c|}{ Transect T5 } \\
\hline 1 & 950.0 & $1,126.5$ & 1.0 & -- \\
\hline 2 & $1,055.0$ & $1,126.5$ & 0.95 & 9.3 \\
\hline 3 & $1,085.5$ & $1,147.0$ & 1.05 & 356.4 \\
\hline 4 & $1,116.0$ & $1,147.0$ & 1.2 & 10.2 \\
\hline 5 & $1,146.5$ & $1,147.0$ & 1.15 & 5.4 \\
\hline 6 & $1,177.0$ & $1,147.0$ & 1.15 & 360.0 \\
\hline 7 & $1,207.5$ & $1,147.0$ & 0.85 & 358.2 \\
\hline 8 & $1,238.0$ & $1,147.0$ & 0.1 & 355.5 \\
\hline \multicolumn{5}{|c|}{ Transect T6 } \\
\hline 1 & 950.0 & 1,096 & 0.95 & -- \\
\hline 2 & $1,055.0$ & 1,096 & 1.0 & 17.1 \\
\hline 3 & $1,085.5$ & 1,141 & 0.95 & 359.2 \\
\hline 4 & $1,116.0$ & 1,141 & 1.0 & 13.6 \\
\hline 5 & $1,146.5$ & 1,141 & 0.85 & 8.5 \\
\hline 6 & $1,177.0$ & 1,141 & 0.9 & 3.2 \\
\hline 7 & $1,207.5$ & 1,141 & 1.0 & 359.5 \\
\hline 8 & $1,238.0$ & 1,141 & 0.1 & 356.9 \\
\hline \multicolumn{5}{|c|}{ Transect T7 } \\
\hline 1 & 950.0 & $1,065.5$ & 0.95 & -- \\
\hline 2 & $1,055.0$ & $1,065.5$ & 1.1 & 17.8 \\
\hline 3 & $1,085.5$ & $1,135.0$ & 1.05 & 1.9 \\
\hline 4 & $1,116.0$ & $1,135.0$ & 1.0 & 16.9 \\
\hline 5 & $1,146.5$ & $1,135.0$ & 1.05 & 11.6 \\
\hline 6 & $1,177.0$ & $1,135.0$ & 1.4 & 6.4 \\
\hline 7 & $1,207.5$ & $1,135.0$ & 0.7 & 0.8 \\
\hline 8 & $1,238.0$ & $1,135.0$ & 0.1 & 358.2 \\
\hline \multicolumn{5}{|c|}{ Transect T8 } \\
\hline 1 & 950.0 & 1,035 & 0.9 & -- \\
\hline 2 & $1,055.0$ & 1,035 & 1.15 & -- \\
\hline 3 & $1,085.5$ & 1,123 & 1.15 & 6.8 \\
\hline 4 & $1,116.0$ & 1,123 & 1.2 & 21.0 \\
\hline 5 & $1,146.5$ & 1,123 & 1.2 & 15.5 \\
\hline 6 & $1,177.0$ & 1,123 & 1.65 & 10.5 \\
\hline 7 & $1,207.5$ & 1,123 & 1.0 & 5.4 \\
\hline 8 & $1,238.0$ & 1,123 & 0.15 & 1.4 \\
\hline
\end{tabular}




\section{Table B3 (Concluded)}

\begin{tabular}{|c|l|l|l|l||}
\hline \hline Channel & X (m) & $Y(m)$ & Ht (m) & Int. Wave Dir (deg) \\
\hline \hline \multicolumn{5}{|c||}{ Transect T9 } \\
\hline \hline 1 & 950.0 & $1,010.5$ & 0.95 & -- \\
\hline 2 & $1,055.0$ & $1,010.5$ & 0.95 & -- \\
\hline 3 & $1,085.5$ & $1,010.5$ & 0.95 & 1.8 \\
\hline 4 & $1,116.0$ & $1,010.5$ & 1.2 & 15.0 \\
\hline 5 & $1,146.5$ & $1,010.5$ & 1.3 & 7.6 \\
\hline 6 & $1,177.0$ & $1,010.5$ & 1.3 & 13.5 \\
\hline 7 & $1,207.5$ & $1,010.5$ & 0.7 & 10.3 \\
\hline 8 & $1,238.0$ & $1,010.5$ & 0.1 & 18.4 \\
\hline \hline \multicolumn{7}{|c|}{} \\
\hline \multicolumn{7}{|c|}{}
\end{tabular}




\begin{tabular}{|c|c|c|c|c|}
\hline \multicolumn{5}{|c|}{$\begin{array}{l}\text { Table B4 } \\
\text { Wave Height and Interpolated Wave Direction, } \\
\text { Reflective Jetty, 0.75-m, 11-sec Wave, Transects T1-T9 }\end{array}$} \\
\hline Channel & $X(m)$ & $Y(m)$ & Ht (m) & Int. Wave Dir (deg) \\
\hline \multicolumn{5}{|c|}{ Transect T1 } \\
\hline 1 & 950.0 & $1,248.5$ & 0.75 & -- \\
\hline 2 & $1,055.0$ & $1,248.5$ & 0.85 & -- \\
\hline 3 & $1,085.5$ & $1,159.0$ & 1.0 & 358.2 \\
\hline 4 & $1,116.0$ & $1,159.0$ & 1.1 & 5.1 \\
\hline 5 & $1,146.5$ & $1,159.0$ & 1.05 & 1.0 \\
\hline 6 & $1,177.0$ & $1,159.0$ & 1.1 & 359.9 \\
\hline 7 & $1,207.5$ & $1,159.0$ & 0.7 & 357.7 \\
\hline 8 & $1,238.0$ & $1,159.0$ & 0.1 & 1.1 \\
\hline \multicolumn{5}{|c|}{ Transect T2 } \\
\hline 1 & 950.0 & 1,218 & 0.7 & -- \\
\hline 2 & $1,055.0$ & 1,218 & 0.9 & 14.5 \\
\hline 3 & $1,085.5$ & 1,157 & 1.05 & 358.2 \\
\hline 4 & $1,116.0$ & 1,157 & 1.1 & 5.1 \\
\hline 5 & $1,146.5$ & 1,157 & 1.15 & 1.0 \\
\hline 6 & $1,177.0$ & 1,157 & 1.15 & 359.9 \\
\hline 7 & $1,207.5$ & 1,157 & 0.7 & 357.7 \\
\hline 8 & $1,238.0$ & 1,157 & 0.05 & 1.1 \\
\hline \multicolumn{5}{|c|}{ Transect T3 } \\
\hline 1 & 950.0 & $1,187.5$ & 0.7 & -- \\
\hline 2 & $1,055.0$ & $1,187.5$ & 0.85 & 28.2 \\
\hline 3 & $1,085.5$ & $1,155.0$ & 1.15 & 358.9 \\
\hline 4 & $1,116.0$ & $1,155.0$ & 1.05 & 5.6 \\
\hline 5 & $1,146.5$ & $1,155.0$ & 1.05 & 2.0 \\
\hline 6 & $1,177.0$ & $1,155.0$ & 1.05 & 0.6 \\
\hline 7 & $1,207.5$ & $1,155.0$ & 0.7 & 358.5 \\
\hline 8 & $1,238.0$ & $1,155.0$ & 0.05 & 1.0 \\
\hline \multicolumn{5}{|c|}{ Transect T4 } \\
\hline 1 & 950.0 & 1,157 & 0.75 & -- \\
\hline 2 & $1,055.0$ & 1,157 & 0.75 & 13.0 \\
\hline 3 & $1,085.5$ & 1,151 & 0.95 & 0.3 \\
\hline 4 & $1,116.0$ & 1,151 & 1.0 & 6.7 \\
\hline 5 & $1,146.5$ & 1,151 & 0.95 & 4.0 \\
\hline 6 & $1,177.0$ & 1,151 & 0.95 & 1.9 \\
\hline 7 & $1,207.5$ & 1,151 & 0.65 & 0.0 \\
\hline 8 & $1,238.0$ & 1,151 & 0.1 & 0.9 \\
\hline & & & & (Sheet 1 of 3) \\
\hline
\end{tabular}




\begin{tabular}{|c|c|c|c|c|}
\hline \multicolumn{5}{|c|}{ Table B4 (Continued) } \\
\hline Channel & $X(m)$ & $\mathrm{Y}(\mathrm{m})$ & $\mathrm{Ht}(\mathrm{m})$ & Int. Wave Dir (deg) \\
\hline \multicolumn{5}{|c|}{ Transect T5 } \\
\hline 1 & 950.0 & $1,126.5$ & 0.75 & -- \\
\hline 2 & $1,055.0$ & $1,126.5$ & 0.65 & 15.8 \\
\hline 3 & $1,085.5$ & $1,147.0$ & 0.65 & 1.7 \\
\hline 4 & $1,116.0$ & $1,147.0$ & 0.55 & 7.8 \\
\hline 5 & $1,146.5$ & $1,147.0$ & 0.4 & 6.0 \\
\hline 6 & $1,177.0$ & $1,147.0$ & 0.65 & 3.2 \\
\hline 7 & $1,207.5$ & $1,147.0$ & 0.9 & 1.6 \\
\hline 8 & $1,238.0$ & $1,147.0$ & 0.05 & 0.8 \\
\hline \multicolumn{5}{|c|}{ Transect T6 } \\
\hline 1 & 950.0 & 1,096 & 0.75 & -- \\
\hline 2 & $1,055.0$ & 1,096 & 0.65 & 17.7 \\
\hline 3 & $1,085.5$ & 1,141 & 0.65 & 3.9 \\
\hline 4 & $1,116.0$ & 1,141 & 0.6 & 9.3 \\
\hline 5 & $1,146.5$ & 1,141 & 0.45 & 9.0 \\
\hline 6 & $1,177.0$ & 1,141 & 0.6 & 5.1 \\
\hline 7 & $1,207.5$ & 1,141 & 0.85 & 3.9 \\
\hline 8 & $1,238.0$ & 1,141 & 0.05 & 0.7 \\
\hline \multicolumn{5}{|c|}{ Transect T7 } \\
\hline 1 & 950.0 & $1,065.5$ & 0.65 & -- \\
\hline 2 & $1,055.0$ & $1,065.5$ & 0.8 & 10.3 \\
\hline 3 & $1,085.5$ & $1,135.0$ & 0.7 & 6.0 \\
\hline 4 & $1,116.0$ & $1,135.0$ & 0.85 & 10.9 \\
\hline 5 & $1,146.5$ & $1,135.0$ & 0.7 & 12.0 \\
\hline 6 & $1,177.0$ & $1,135.0$ & 0.85 & 7.1 \\
\hline 7 & $1,207.5$ & $1,135.0$ & 0.8 & 6.3 \\
\hline 8 & $1,238.0$ & $1,135.0$ & 0.1 & 0.5 \\
\hline \multicolumn{5}{|c|}{ Transect T8 } \\
\hline 1 & 950.0 & 1,035 & 0.7 & -- \\
\hline 2 & $1,055.0$ & 1,035 & 0.75 & -- \\
\hline 3 & $1,085.5$ & 1,123 & 0.8 & 8.9 \\
\hline 4 & $1,116.0$ & 1,123 & 0.85 & 13.3 \\
\hline 5 & $1,146.5$ & 1,123 & 0.7 & 14.7 \\
\hline 6 & $1,177.0$ & 1,123 & 0.9 & 9.6 \\
\hline 7 & $1,207.5$ & 1,123 & 0.75 & 9.9 \\
\hline 8 & $1,238.0$ & 1,123 & 0.05 & 1.0 \\
\hline
\end{tabular}

(Sheet 2 of 3) 


\begin{tabular}{|c|c|c|c|c|}
\hline \multicolumn{5}{|c|}{ Table B4 (Concluded) } \\
\hline Channel & $X(m)$ & $Y(m)$ & $H t(m)$ & Int. Wave Dir (deg) \\
\hline \multicolumn{5}{|c|}{ Transect T9 } \\
\hline 1 & 950.0 & $1,010.5$ & 0.7 & -- \\
\hline 2 & $1,055.0$ & $1,010.5$ & 0.85 & -- \\
\hline 3 & $1,085.5$ & $1,010.5$ & 0.7 & 5.7 \\
\hline 4 & $1,116.0$ & $1,010.5$ & 0.85 & 5.8 \\
\hline 5 & $1,146.5$ & $1,010.5$ & 0.8 & 9.8 \\
\hline 6 & $1,177.0$ & $1,010.5$ & 0.85 & 6.6 \\
\hline 7 & $1,207.5$ & $1,010.5$ & 0.7 & 11.2 \\
\hline 8 & $1,238.0$ & $1,010.5$ & 0.05 & 8.0 \\
\hline
\end{tabular}


Table B5 Absorbing Jetty, 1.65-m, 11-sec Wave, Transects T1-T9

\begin{tabular}{|c|c|c|c|c|}
\hline Channel & $x(m)$ & $Y(m)$ & $\mathrm{Ht}(\mathrm{m})$ & Int. Wave Dir (deg) \\
\hline \multicolumn{5}{|c|}{ Transect T1 } \\
\hline 1 & 950.0 & $1,248.5$ & 1.65 & -- \\
\hline 2 & $1,055.0$ & $1,248.5$ & 1.8 & -- \\
\hline 3 & $1,085.5$ & 1,159 & 2.25 & 4.5 \\
\hline 4 & $1,116.0$ & 1,159 & 1.4 & 20.4 \\
\hline 5 & $1,146.5$ & 1,159 & 1.2 & 15.8 \\
\hline 6 & $1,177.0$ & 1,159 & 1.35 & 20.7 \\
\hline 7 & $1,207.5$ & 1,159 & 0.9 & 10.1 \\
\hline 8 & $1,238.0$ & 1,159 & 0.6 & 13.8 \\
\hline \multicolumn{5}{|c|}{ Transect T2 } \\
\hline 1 & 950.0 & 1,218 & 1.65 & -- \\
\hline 2 & $1,055.0$ & 1,218 & 1.8 & 17.0 \\
\hline 3 & $1,085.5$ & 1,157 & 2.25 & 4.5 \\
\hline 4 & $1,116.0$ & 1,157 & 1.55 & 20.4 \\
\hline 5 & $1,146.5$ & 1,157 & 1.2 & 15.8 \\
\hline 6 & $1,177.0$ & 1,157 & 1.45 & 20.7 \\
\hline 7 & $1,207.5$ & 1,157 & 0.95 & 10.1 \\
\hline 8 & $1,238.0$ & 1,157 & 0.6 & 13.8 \\
\hline \multicolumn{5}{|c|}{ Transect T3 } \\
\hline 1 & 950.0 & $1,187.5$ & 1.6 & -- \\
\hline 2 & $1,055.0$ & $1,187.5$ & 1.8 & 4.4 \\
\hline 3 & $1,085.5$ & $1,155.0$ & 2.0 & 5.0 \\
\hline 4 & $1,116.0$ & $1,155.0$ & 1.8 & 20.9 \\
\hline 5 & $1,146.5$ & $1,155.0$ & 1.55 & 16.2 \\
\hline 6 & $1,177.0$ & $1,155.0$ & 1.45 & 21.7 \\
\hline 7 & $1,207.5$ & $1,155.0$ & 1.0 & 10.4 \\
\hline 8 & $1,238.0$ & $1,155.0$ & 0.55 & 12.8 \\
\hline \multicolumn{5}{|c|}{ Transect T4 } \\
\hline 1 & 950.0 & 1,157 & 1.65 & -- \\
\hline 2 & $1,055.0$ & 1,157 & 2.15 & 8.4 \\
\hline 3 & $1,085.5$ & 1,151 & 1.75 & 6.1 \\
\hline 4 & $1,116.0$ & 1,151 & 1.55 & 22.0 \\
\hline 5 & $1,146.5$ & 1,151 & 1.35 & 17.1 \\
\hline 6 & $1,177.0$ & 1,151 & 1.3 & 23.8 \\
\hline 7 & $1,207.5$ & 1,151 & 0.85 & 11.0 \\
\hline 8 & $1,238.0$ & 1,151 & 0.45 & 10.8 \\
\hline
\end{tabular}

(Sheet 1 of 3) 


\section{Table B5 (Continued)}

\begin{tabular}{|c|c|c|c|c|}
\hline Channel & $X(m)$ & $Y(m)$ & Ht (m) & Int. Wave Dir (deg) \\
\hline \multicolumn{5}{|c|}{ Transect T5 } \\
\hline 1 & 950.0 & $1,126.5$ & 1.65 & -- \\
\hline 2 & $1,055.0$ & $1,126.5$ & 1.9 & 17.2 \\
\hline 3 & $1,085.5$ & $1,147.0$ & 1.4 & 7.2 \\
\hline 4 & $1,116.0$ & $1,147.0$ & 1.45 & 23.1 \\
\hline 5 & $1,146.5$ & $1,147.0$ & 1.65 & 18.0 \\
\hline 6 & $1,177.0$ & $1,147.0$ & 1.15 & 25.8 \\
\hline 7 & $1,207.5$ & $1,147.0$ & 0.9 & 11.6 \\
\hline 8 & $1,238.0$ & $1,147.0$ & 0.5 & 8.8 \\
\hline \multicolumn{5}{|c|}{ Transect T6 } \\
\hline 1 & 950.0 & 1,096 & 1.7 & -- \\
\hline 2 & $1,055.0$ & 1,096 & 1.95 & 0.0 \\
\hline 3 & $1,085.5$ & 1,141 & 1.6 & 8.9 \\
\hline 4 & $1,116.0$ & 1,141 & 1.5 & 24.6 \\
\hline 5 & $1,146.5$ & 1,141 & 1.4 & 19.3 \\
\hline 6 & $1,177.0$ & 1,141 & 1.35 & 28.9 \\
\hline 7 & $1,207.5$ & 1,141 & 0.9 & 12.6 \\
\hline 8 & $1,238.0$ & 1,141 & 0.55 & 5.8 \\
\hline \multicolumn{5}{|c|}{ Transect T7 } \\
\hline 1 & 950.0 & $1,065.5$ & 1.45 & -- \\
\hline 2 & $1,055.0$ & $1,065.5$ & 1.2 & 6.9 \\
\hline 3 & $1,085.5$ & $1,135.0$ & 1.5 & 10.5 \\
\hline 4 & $1,116.0$ & $1,135.0$ & 1.9 & 26.2 \\
\hline 5 & $1,146.5$ & $1,135.0$ & 1.75 & 20.6 \\
\hline 6 & $1,177.0$ & $1,135.0$ & 1.5 & 32.0 \\
\hline 7 & $1,207.5$ & $1,135.0$ & 1.1 & 13.5 \\
\hline 8 & $1,238.0$ & $1,135.0$ & 0.7 & 2.8 \\
\hline \multicolumn{5}{|c|}{ Transect T8 } \\
\hline 1 & 950.0 & 1,035 & 1.5 & -- \\
\hline 2 & $1,055.0$ & 1,035 & 1.5 & -- \\
\hline 3 & $1,085.5$ & 1,123 & 1.65 & 11.9 \\
\hline 4 & $1,116.0$ & 1,123 & 1.85 & 26.7 \\
\hline 5 & $1,146.5$ & 1,123 & 1.7 & 21.0 \\
\hline 6 & $1,177.0$ & 1,123 & 1.7 & 33.6 \\
\hline 7 & $1,207.5$ & 1,123 & 1.2 & 13.7 \\
\hline 8 & $1,238.0$ & 1,123 & 0.75 & 358.7 \\
\hline
\end{tabular}

(Sheet 2 of 3) 


\begin{tabular}{||c|l|l|l|l||}
\hline \multicolumn{7}{||c||}{ Table B5 (Concluded) } \\
\hline \hline \multicolumn{7}{|c||}{ Transect T9 } \\
\hline \hline \multicolumn{7}{|c|}{ Channel } & $\mathrm{X}(\mathrm{m})$ & $\mathrm{Y}(\mathrm{m})$ & $\mathrm{Ht}(\mathrm{m})$ & Int. Wave Dir (deg) \\
\hline \hline 1 & 950.0 & $1,010.5$ & 1.45 & -- \\
\hline 2 & $1,055.0$ & $1,010.5$ & 1.6 & -- \\
\hline 3 & $1,085.5$ & $1,010.5$ & 1.7 & 3.7 \\
\hline 4 & $1,116.0$ & $1,010.5$ & 1.65 & 14.1 \\
\hline 5 & $1,146.5$ & $1,010.5$ & 1.5 & 8.9 \\
\hline 6 & $1,177.0$ & $1,010.5$ & 1.45 & 10.0 \\
\hline 7 & $1,207.5$ & $1,010.5$ & 1.1 & 16.1 \\
\hline 8 & $1,238.0$ & $1,010.5$ & 0.75 & 4.5 \\
\hline \hline
\end{tabular}




\begin{tabular}{|c|c|c|c|c|}
\hline \multicolumn{5}{|c|}{$\begin{array}{l}\text { Table B6 } \\
\text { Wave Height and Interpolated Wave Direction, } \\
\text { Absorbing Jetty, 1.1-m, 11-sec Wave, Transects T1-T9 }\end{array}$} \\
\hline Channel & $X(m)$ & $Y(m)$ & Ht (m) & Int. Wave Dir (deg) \\
\hline \multicolumn{5}{|c|}{ Transect T1 } \\
\hline 1 & 950.0 & $1,248.5$ & 1.05 & -- \\
\hline 2 & $1,055.0$ & $1,248.5$ & 1.0 & -- \\
\hline 3 & $1,085.5$ & $1,159.0$ & 1.35 & 4.5 \\
\hline 4 & $1,116.0$ & $1,159.0$ & 0.95 & 20.4 \\
\hline 5 & $1,146.5$ & $1,159.0$ & 0.9 & 15.8 \\
\hline 6 & $1,177.0$ & $1,159.0$ & 0.95 & 20.7 \\
\hline 7 & $1,207.5$ & $1,159.0$ & 1.05 & 10.1 \\
\hline 8 & $1,238.0$ & $1,159.0$ & 0.55 & 13.8 \\
\hline \multicolumn{5}{|c|}{ Transect T2 } \\
\hline 1 & 950.0 & 1,218 & 1.1 & -- \\
\hline 2 & $1,055.0$ & 1,218 & 1.4 & 17.0 \\
\hline 3 & $1,085.5$ & 1,157 & 1.25 & 4.5 \\
\hline 4 & $1,116.0$ & 1,157 & 1.2 & 20.4 \\
\hline 5 & $1,146.5$ & 1,157 & 1.2 & 15.8 \\
\hline 6 & $1,177.0$ & 1,157 & 1.4 & 20.7 \\
\hline 7 & $1,207.5$ & 1,157 & 1.1 & 10.1 \\
\hline 8 & $1,238.0$ & 1,157 & 0.55 & 13.8 \\
\hline \multicolumn{5}{|c|}{ Transect T3 } \\
\hline 1 & 950.0 & $1,187.5$ & 1.15 & -- \\
\hline 2 & $1,055.0$ & $1,187.5$ & 1.25 & 4.4 \\
\hline 3 & $1,085.5$ & $1,155.0$ & 1.45 & 5.0 \\
\hline 4 & $1,116.0$ & $1,155.0$ & 1.4 & 20.9 \\
\hline 5 & $1,146.5$ & $1,155.0$ & 1.35 & 16.2 \\
\hline 6 & $1,177.0$ & $1,155.0$ & 1.45 & 21.7 \\
\hline 7 & $1,207.5$ & $1,155.0$ & 0.95 & 10.4 \\
\hline 8 & $1,238.0$ & $1,155.0$ & 0.6 & 12.8 \\
\hline \multicolumn{5}{|c|}{ Transect T4 } \\
\hline 1 & 950.0 & 1,157 & 1.05 & -- \\
\hline 2 & $1,055.0$ & 1,157 & 1.75 & 8.4 \\
\hline 3 & $1,085.5$ & 1,151 & 1.65 & 6.1 \\
\hline 4 & $1,116.0$ & 1,151 & 1.65 & 22.0 \\
\hline 5 & $1,146.5$ & 1,151 & 1.5 & 17.1 \\
\hline 6 & $1,177.0$ & 1,151 & 1.55 & 23.8 \\
\hline 7 & $1,207.5$ & 1,151 & 0.85 & 11.0 \\
\hline 8 & $1,238.0$ & 1,151 & 0.55 & 10.8 \\
\hline & & & & (Sheet 1 of 3 ) \\
\hline
\end{tabular}




\begin{tabular}{|c|c|c|c|c|}
\hline \multicolumn{5}{|c|}{ Table B6 (Continued) } \\
\hline Channel & $X(m)$ & $Y(m)$ & Ht (m) & Int. Wave Dir (deg) \\
\hline \multicolumn{5}{|c|}{ Transect T5 } \\
\hline 1 & 950.0 & $1,126.5$ & 1.15 & -- \\
\hline 2 & $1,055.0$ & $1,126.5$ & 1.2 & 17.2 \\
\hline 3 & $1,085.5$ & $1,147.0$ & 1.1 & 7.2 \\
\hline 4 & $1,116.0$ & $1,147.0$ & 1.25 & 23.1 \\
\hline 5 & $1,146.5$ & $1,147.0$ & 1.05 & 18.0 \\
\hline 6 & $1,177.0$ & $1,147.0$ & 0.9 & 25.8 \\
\hline 7 & $1,207.5$ & $1,147.0$ & 0.85 & 11.6 \\
\hline 8 & $1,238.0$ & $1,147.0$ & 0.55 & 8.8 \\
\hline \multicolumn{5}{|c|}{ Transect T6 } \\
\hline 1 & 950.0 & 1,096 & 1.1 & -- \\
\hline 2 & $1,055.0$ & 1,096 & 1.15 & 0.0 \\
\hline 3 & $1,085.5$ & 1,141 & 1.05 & 8.9 \\
\hline 4 & $1,116.0$ & 1,141 & 0.95 & 24.6 \\
\hline 5 & $1,146.5$ & 1,141 & 0.85 & 19.3 \\
\hline 6 & $1,177.0$ & 1,141 & 0.85 & 28.9 \\
\hline 7 & $1,207.5$ & 1,141 & 1.0 & 12.6 \\
\hline 8 & $1,238.0$ & 1,141 & 0.5 & 5.8 \\
\hline \multicolumn{5}{|c|}{ Transect T7 } \\
\hline 1 & 950.0 & $1,065.5$ & 0.9 & -- \\
\hline 2 & $1,055.0$ & $1,065.5$ & 1.0 & 6.9 \\
\hline 3 & $1,085.5$ & $1,135.0$ & 1.0 & 10.5 \\
\hline 4 & $1,116.0$ & $1,135.0$ & 0.95 & 26.2 \\
\hline 5 & $1,146.5$ & $1,135.0$ & 0.9 & 20.6 \\
\hline 6 & $1,177.0$ & $1,135.0$ & 0.95 & 32.0 \\
\hline 7 & $1,207.5$ & $1,135.0$ & 1.0 & 13.5 \\
\hline 8 & $1,238.0$ & $1,135.0$ & 0.55 & 2.8 \\
\hline \multicolumn{5}{|c|}{ Transect T8 } \\
\hline 1 & 950.0 & 1,035 & 0.95 & -- \\
\hline 2 & $1,055.0$ & 1,035 & 0.95 & -- \\
\hline 3 & $1,085.5$ & 1,123 & 0.85 & 11.9 \\
\hline 4 & $1,116.0$ & 1,123 & 0.85 & 26.7 \\
\hline 5 & $1,146.5$ & 1,123 & 1.05 & 21.0 \\
\hline 6 & $1,177.0$ & 1,123 & 1.1 & 33.6 \\
\hline 7 & $1,207.5$ & 1,123 & 1.0 & 13.7 \\
\hline 8 & $1,238.0$ & 1,123 & 0.55 & 358.7 \\
\hline
\end{tabular}

(Sheet 2 of 3) 


\begin{tabular}{|c|l|l|l|l||}
\hline \hline \multicolumn{7}{|c||}{ Table B6 (Concluded) } \\
\hline \hline \multicolumn{7}{|c||}{ Transect T9 } \\
\hline \hline 1 & 950.0 & $1,010.5$ & 0.9 & -- \\
\hline 2 & $1,055.0$ & $1,010.5$ & 1.0 & -- \\
\hline 3 & $1,085.5$ & $1,010.5$ & 1.1 & 3.7 \\
\hline 4 & $1,116.0$ & $1,010.5$ & 1.1 & 14.1 \\
\hline 5 & $1,146.5$ & $1,010.5$ & 1.05 & 8.9 \\
\hline 6 & $1,177.0$ & $1,010.5$ & 1.15 & 10.0 \\
\hline 7 & $1,207.5$ & $1,010.5$ & 1.05 & 16.1 \\
\hline 8 & $1,238.0$ & $1,010.5$ & 0.6 & 4.5 \\
\hline \hline
\end{tabular}




\begin{tabular}{|c|c|c|c|c|}
\hline \multicolumn{5}{|c|}{$\begin{array}{l}\text { Table B7 } \\
\text { Wave Height and Interpolated Wave Direction, } \\
\text { Absorbing Jetty, 3.4-m, 8-sec Wave, Transects T1-T9 }\end{array}$} \\
\hline Channel & $X(m)$ & $Y(m)$ & Ht (m) & Int. Wave Dir (deg) \\
\hline \multicolumn{5}{|c|}{ Transect T1 } \\
\hline 1 & 950.0 & 1248.5 & 3.3 & -- \\
\hline 2 & $1,055.0$ & 1248.5 & 2.65 & -- \\
\hline 3 & $1,085.5$ & 1159.0 & 2.05 & 8.5 \\
\hline 4 & $1,116.0$ & 1159.0 & 1.3 & 19.9 \\
\hline 5 & $1,146.5$ & 1159.0 & 1.1 & 4.8 \\
\hline 6 & $1,177.0$ & 1159.0 & 1.1 & 17.9 \\
\hline 7 & $1,207.5$ & 1159.0 & 1.15 & 4.1 \\
\hline 8 & $1,238.0$ & 1159.0 & 0.75 & 5.9 \\
\hline \multicolumn{5}{|c|}{ Transect T2 } \\
\hline 1 & 950.0 & 1,218 & 3.25 & -- \\
\hline 2 & $1,055.0$ & 1,218 & 2.95 & 10.8 \\
\hline 3 & $1,085.5$ & 1,157 & 1.9 & 8.5 \\
\hline 4 & $1,116.0$ & 1,157 & 1.45 & 19.9 \\
\hline 5 & $1,146.5$ & 1,157 & 1.25 & 4.8 \\
\hline 6 & $1,177.0$ & 1,157 & 1.25 & 17.9 \\
\hline 7 & $1,207.5$ & 1,157 & 1.2 & 4.1 \\
\hline 8 & $1,238.0$ & 1,157 & 0.8 & 5.9 \\
\hline \multicolumn{5}{|c|}{ Transect T3 } \\
\hline 1 & 950.0 & $1,187.5$ & 3.3 & -- \\
\hline 2 & $1,055.0$ & $1,187.5$ & 3.4 & 5.7 \\
\hline 3 & $1,085.5$ & $1,155.0$ & 1.75 & 9.1 \\
\hline 4 & $1,116.0$ & $1,155.0$ & 1.6 & 19.3 \\
\hline 5 & $1,146.5$ & $1,155.0$ & 1.35 & 5.4 \\
\hline 6 & $1,177.0$ & $1,155.0$ & 1.4 & 18.7 \\
\hline 7 & $1,207.5$ & $1,155.0$ & 1.2 & 5.2 \\
\hline 8 & $1,238.0$ & $1,155.0$ & 0.85 & 6.1 \\
\hline \multicolumn{5}{|c|}{ Transect T4 } \\
\hline 1 & 950.0 & 1,157 & 3.15 & -- \\
\hline 2 & $1,055.0$ & 1,157 & 3.05 & 15.3 \\
\hline 3 & $1,085.5$ & 1,151 & 1.85 & 10.2 \\
\hline 4 & $1,116.0$ & 1,151 & 1.55 & 18.2 \\
\hline 5 & $1,146.5$ & 1,151 & 1.25 & 6.7 \\
\hline 6 & $1,177.0$ & 1,151 & 1.5 & 20.4 \\
\hline 7 & $1,207.5$ & 1,151 & 1.15 & 7.5 \\
\hline 8 & $1,238.0$ & 1,151 & 0.75 & 6.6 \\
\hline
\end{tabular}




\begin{tabular}{|c|c|c|c|c|}
\hline \multicolumn{5}{|c|}{ Table B7 (Continued) } \\
\hline Channel & $X(m)$ & $Y(m)$ & $H t(m)$ & Int. Wave Dir (deg) \\
\hline \multicolumn{5}{|c|}{ Transect T5 } \\
\hline 1 & 950.0 & $1,126.5$ & 3.2 & -- \\
\hline 2 & $1,055.0$ & $1,126.5$ & 2.7 & 10.8 \\
\hline 3 & $1,085.5$ & $1,147.0$ & 1.95 & 11.3 \\
\hline 4 & $1,116.0$ & $1,147.0$ & 1.3 & 17.1 \\
\hline 5 & $1,146.5$ & $1,147.0$ & 1.25 & 7.9 \\
\hline 6 & $1,177.0$ & $1,147.0$ & 1.2 & 22.1 \\
\hline 7 & $1,207.5$ & $1,147.0$ & 0.95 & 9.8 \\
\hline 8 & $1,238.0$ & $1,147.0$ & 0.65 & 7.1 \\
\hline \multicolumn{5}{|c|}{ Transect T6 } \\
\hline 1 & 950.0 & 1096 & 3.2 & -- \\
\hline 2 & $1,055.0$ & 1,096 & 2.8 & 11.1 \\
\hline 3 & $1,085.5$ & 1,141 & 1.9 & 13.0 \\
\hline 4 & $1,116.0$ & 1,141 & 1.35 & 15.3 \\
\hline 5 & $1,146.5$ & 1,141 & 1.15 & 9.8 \\
\hline 6 & $1,177.0$ & 1,141 & 1.0 & 24.6 \\
\hline 7 & $1,207.5$ & 1,141 & 0.85 & 13.2 \\
\hline 8 & $1,238.0$ & 1,141 & 0.5 & 7.9 \\
\hline \multicolumn{5}{|c|}{ Transect T7 } \\
\hline 1 & 950.0 & $1,065.5$ & 3.2 & -- \\
\hline 2 & $1,055.0$ & $1,065.5$ & 2.45 & 4.9 \\
\hline 3 & $1,085.5$ & $1,135.0$ & 1.65 & 14.6 \\
\hline 4 & $1,116.0$ & $1,135.0$ & 1.5 & 13.6 \\
\hline 5 & $1,146.5$ & $1,135.0$ & 1.15 & 11.7 \\
\hline 6 & $1,177.0$ & $1,135.0$ & 0.95 & 27.1 \\
\hline 7 & $1,207.5$ & $1,135.0$ & 0.85 & 16.7 \\
\hline 8 & $1,238.0$ & $1,135.0$ & 0.55 & 8.6 \\
\hline \multicolumn{5}{|c|}{ Transect T8 } \\
\hline 1 & 950.0 & 1,035 & 3.2 & -- \\
\hline 2 & $1,055.0$ & 1,035 & 3.25 & -- \\
\hline 3 & $1,085.5$ & 1,123 & 1.9 & 17.4 \\
\hline 4 & $1,116.0$ & 1,123 & 1.75 & 12.8 \\
\hline 5 & $1,146.5$ & 1,123 & 1.2 & 14.3 \\
\hline 6 & $1,177.0$ & 1,123 & 1.05 & 28.8 \\
\hline 7 & $1,207.5$ & 1,123 & 0.95 & 19.8 \\
\hline 8 & $1,238.0$ & 1,123 & 0.55 & 8.9 \\
\hline
\end{tabular}




\begin{tabular}{|c|c|c|c|c|}
\hline \multicolumn{5}{|c|}{ Table B7 (Concluded) } \\
\hline Channel & $X(m)$ & $Y(m)$ & $\mathrm{Ht}(\mathrm{m})$ & Int. Wave Dir (deg) \\
\hline \multicolumn{5}{|c|}{ Transect T9 } \\
\hline 1 & 950.0 & $1,010.5$ & 3.2 & -- \\
\hline 2 & $1,055.0$ & $1,010.5$ & 3.2 & -- \\
\hline 3 & $1,085.5$ & $1,010.5$ & 2.2 & 29.5 \\
\hline 4 & $1,116.0$ & 1,010.5 & 1.65 & 22.9 \\
\hline 5 & $1,146.5$ & $1,010.5$ & 1.4 & 20.2 \\
\hline 6 & $1,177.0$ & $1,010.5$ & 1.05 & 16.9 \\
\hline 7 & $1,207.5$ & $1,010.5$ & 0.95 & 17.3 \\
\hline 8 & $1,238.0$ & $1,010.5$ & 0.55 & 14.8 \\
\hline
\end{tabular}




\begin{tabular}{|c|c|c|c|c|}
\hline \multicolumn{5}{|c|}{$\begin{array}{l}\text { Table B8 } \\
\text { Wave Height and Interpolated Wave Direction, } \\
\text { Absorbing Jetty, 1.0-m, 11-sec Wave, Transects T1-T9 }\end{array}$} \\
\hline Channel & $X(m)$ & $Y(m)$ & Ht (m) & Int. Wave Dir (deg) \\
\hline \multicolumn{5}{|c|}{ Transect T1 } \\
\hline 1 & 950.0 & $1,248.5$ & 0.95 & -- \\
\hline 2 & $1,055.0$ & $1,248.5$ & 1.05 & -- \\
\hline 3 & $1,085.5$ & $1,159.0$ & 1.25 & 5.9 \\
\hline 4 & $1,116.0$ & $1,159.0$ & 0.95 & 21.6 \\
\hline 5 & $1,146.5$ & $1,159.0$ & 0.95 & 24.1 \\
\hline 6 & $1,177.0$ & $1,159.0$ & 0.95 & 4.0 \\
\hline 7 & $1,207.5$ & $1,159.0$ & 1.05 & 27.8 \\
\hline 8 & $1,238.0$ & $1,159.0$ & 0.75 & 2.9 \\
\hline \multicolumn{5}{|c|}{ Transect T2 } \\
\hline 1 & 950.0 & 1,218 & 0.9 & -- \\
\hline 2 & $1,055.0$ & 1,218 & 0.85 & 355.2 \\
\hline 3 & $1,085.5$ & 1,157 & 1.4 & 5.9 \\
\hline 4 & $1,116.0$ & 1,157 & 1.15 & 21.6 \\
\hline 5 & $1,146.5$ & 1,157 & 1.15 & 24.1 \\
\hline 6 & $1,177.0$ & 1,157 & 1.25 & 4.0 \\
\hline 7 & $1,207.5$ & 1,157 & 1.25 & 27.8 \\
\hline 8 & $1,238.0$ & 1,157 & 0.8 & 2.9 \\
\hline \multicolumn{5}{|c|}{ Transect T3 } \\
\hline 1 & 950.0 & $1,187.5$ & 0.9 & -- \\
\hline 2 & $1,055.0$ & $1,187.5$ & 1.05 & 13.1 \\
\hline 3 & $1,085.5$ & $1,155.0$ & 1.4 & 5.9 \\
\hline 4 & $1,116.0$ & $1,155.0$ & 1.25 & 21.5 \\
\hline 5 & $1,146.5$ & $1,155.0$ & 1.25 & 23.0 \\
\hline 6 & $1,177.0$ & $1,155.0$ & 1.3 & 4.4 \\
\hline 7 & $1,207.5$ & $1,155.0$ & 1.2 & 26.8 \\
\hline 8 & $1,238.0$ & $1,155.0$ & 0.7 & 4.0 \\
\hline \multicolumn{5}{|c|}{ Transect T4 } \\
\hline 1 & 950.0 & 1,157 & 0.9 & -- \\
\hline 2 & $1,055.0$ & 1,157 & 1.4 & 15.8 \\
\hline 3 & $1,085.5$ & 1,151 & 1.25 & 5.8 \\
\hline 4 & $1,116.0$ & 1,151 & 1.35 & 21.4 \\
\hline 5 & $1,146.5$ & 1,151 & 1.25 & 20.9 \\
\hline 6 & $1,177.0$ & 1,151 & 1.2 & 5.3 \\
\hline 7 & $1,207.5$ & 1,151 & 1.1 & 24.7 \\
\hline 8 & $1,238.0$ & 1,151 & 0.6 & 6.1 \\
\hline & & & & (Sheet 1 of 3 ) \\
\hline
\end{tabular}




\section{Table B8 (Continued)}

\begin{tabular}{|c|c|c|c|c|}
\hline Channel & $X(m)$ & $\mathrm{Y}(\mathrm{m})$ & Ht (m) & Int. Wave Dir (deg) \\
\hline \multicolumn{5}{|c|}{ Transect T5 } \\
\hline 1 & 950.0 & $1,126.5$ & 0.85 & -- \\
\hline 2 & $1,055.0$ & $1,126.5$ & 1.55 & 12.8 \\
\hline 3 & $1,085.5$ & $1,147.0$ & 1.3 & 5.7 \\
\hline 4 & $1,116.0$ & $1,147.0$ & 1.35 & 21.2 \\
\hline 5 & $1,146.5$ & $1,147.0$ & 1.3 & 18.8 \\
\hline 6 & $1,177.0$ & $1,147.0$ & 1.25 & 6.1 \\
\hline 7 & $1,207.5$ & $1,147.0$ & 1.2 & 22.7 \\
\hline 8 & $1,238.0$ & $1,147.0$ & 0.6 & 8.2 \\
\hline \multicolumn{5}{|c|}{ Transect T6 } \\
\hline 1 & 950.0 & 1,096 & 0.95 & -- \\
\hline 2 & $1,055.0$ & 1,096 & 1.3 & 21.6 \\
\hline 3 & $1,085.5$ & 1,141 & 1.1 & 5.6 \\
\hline 4 & $1,116.0$ & 1,141 & 1.3 & 21.0 \\
\hline 5 & $1,146.5$ & 1,141 & 1.3 & 15.5 \\
\hline 6 & $1,177.0$ & 1,141 & 1.25 & 7.4 \\
\hline 7 & $1,207.5$ & 1,141 & 1.15 & 19.6 \\
\hline 8 & $1,238.0$ & 1,141 & 0.8 & 11.4 \\
\hline \multicolumn{5}{|c|}{ Transect T7 } \\
\hline 1 & 950.0 & $1,065.5$ & 0.9 & -- \\
\hline 2 & $1,055.0$ & $1,065.5$ & 1.05 & 21.1 \\
\hline 3 & $1,085.5$ & $1,135.0$ & 1.0 & 5.5 \\
\hline 4 & $1,116.0$ & $1,135.0$ & 0.95 & 20.7 \\
\hline 5 & $1,146.5$ & $1,135.0$ & 0.85 & 12.3 \\
\hline 6 & $1,177.0$ & $1,135.0$ & 0.9 & 8.7 \\
\hline 7 & $1,207.5$ & $1,135.0$ & 1.05 & 16.5 \\
\hline 8 & $1,238.0$ & $1,135.0$ & 0.65 & 14.6 \\
\hline \multicolumn{5}{|c|}{ Transect T8 } \\
\hline 1 & 950.0 & 1,035 & 0.9 & -- \\
\hline 2 & $1,055.0$ & 1,035 & 1.1 & -- \\
\hline 3 & $1,085.5$ & 1,123 & 1.0 & 6.2 \\
\hline 4 & $1,116.0$ & 1,123 & 1.05 & 20.6 \\
\hline 5 & $1,146.5$ & 1,123 & 1.0 & 8.3 \\
\hline 6 & $1,177.0$ & 1,123 & 1.0 & 11.4 \\
\hline 7 & $1,207.5$ & 1,123 & 1.1 & 11.8 \\
\hline 8 & $1,238.0$ & 1,123 & 0.55 & 16.7 \\
\hline
\end{tabular}




\begin{tabular}{|c|c|c|c|c|}
\hline \multicolumn{5}{|c|}{ Table B8 (Concluded) } \\
\hline Channel & $X(m)$ & $\mathrm{Y}(\mathrm{m})$ & Ht (m) & Int. Wave Dir (deg) \\
\hline \multicolumn{5}{|c|}{ Transect T9 } \\
\hline 1 & 950.0 & $1,010.5$ & 0.9 & -- \\
\hline 2 & $1,055.0$ & $1,010.5$ & 1.0 & -- \\
\hline 3 & $1,085.5$ & $1,010.5$ & 0.9 & 358.4 \\
\hline 4 & $1,116.0$ & $1,010.5$ & 1.0 & 18.0 \\
\hline 5 & $1,146.5$ & $1,010.5$ & 1.1 & 12.0 \\
\hline 6 & $1,177.0$ & $1,010.5$ & 1.3 & 11.9 \\
\hline 7 & $1,207.5$ & $1,010.5$ & 1.25 & 6.4 \\
\hline 8 & $1,238.0$ & $1,010.5$ & 0.7 & 12.5 \\
\hline
\end{tabular}




\begin{tabular}{|c|c|c|c|c|}
\hline \multicolumn{5}{|c|}{$\begin{array}{l}\text { Table B9 } \\
\text { Wave Height and Interpolated Wave Direction, } \\
\text { Absorbing Jetty, 2.0-m, 11-sec Wave, Transects T1-T9 }\end{array}$} \\
\hline Channel & $X(m)$ & $\mathrm{Y}(\mathrm{m})$ & Ht (m) & Int. Wave Dir (deg) \\
\hline \multicolumn{5}{|c|}{ Transect T1 } \\
\hline 1 & 950.0 & $1,248.5$ & 0.95 & -- \\
\hline 2 & $1,055.0$ & $1,248.5$ & 1.05 & -- \\
\hline 3 & $1,085.5$ & $1,159.0$ & 1.25 & 5.9 \\
\hline 4 & $1,116.0$ & $1,159.0$ & 0.95 & 21.6 \\
\hline 5 & $1,146.5$ & $1,159.0$ & 0.95 & 24.1 \\
\hline 6 & $1,177.0$ & $1,159.0$ & 0.95 & 4.0 \\
\hline 7 & $1,207.5$ & $1,159.0$ & 1.05 & 27.8 \\
\hline 8 & $1,238.0$ & $1,159.0$ & 0.75 & 2.9 \\
\hline \multicolumn{5}{|c|}{ Transect T2 } \\
\hline 1 & 950.0 & 1,218 & 0.9 & -- \\
\hline 2 & $1,055.0$ & 1,218 & 0.85 & 355.2 \\
\hline 3 & $1,085.5$ & 1,157 & 1.4 & 5.9 \\
\hline 4 & $1,116.0$ & 1,157 & 1.15 & 21.6 \\
\hline 5 & $1,146.5$ & 1,157 & 1.15 & 24.1 \\
\hline 6 & $1,177.0$ & 1,157 & 1.25 & 4.0 \\
\hline 7 & $1,207.5$ & 1,157 & 1.25 & 27.8 \\
\hline 8 & $1,238.0$ & 1,157 & 0.8 & 2.9 \\
\hline \multicolumn{5}{|c|}{ Transect T3 } \\
\hline 1 & 950.0 & $1,187.5$ & 0.9 & -- \\
\hline 2 & $1,055.0$ & $1,187.5$ & 1.05 & 13.1 \\
\hline 3 & $1,085.5$ & $1,155.0$ & 1.4 & 5.9 \\
\hline 4 & $1,116.0$ & $1,155.0$ & 1.25 & 21.5 \\
\hline 5 & $1,146.5$ & $1,155.0$ & 1.25 & 23.0 \\
\hline 6 & $1,177.0$ & $1,155.0$ & 1.3 & 4.4 \\
\hline 7 & $1,207.5$ & $1,155.0$ & 1.2 & 26.8 \\
\hline 8 & $1,238.0$ & $1,155.0$ & 0.7 & 4.0 \\
\hline \multicolumn{5}{|c|}{ Transect T4 } \\
\hline 1 & 950.0 & 1,157 & 0.9 & -- \\
\hline 2 & $1,055.0$ & 1,157 & 1.4 & 15.8 \\
\hline 3 & $1,085.5$ & 1,151 & 1.25 & 5.8 \\
\hline 4 & $1,116.0$ & 1,151 & 1.35 & 21.4 \\
\hline 5 & $1,146.5$ & 1,151 & 1.25 & 20.9 \\
\hline 6 & $1,177.0$ & 1,151 & 1.2 & 5.3 \\
\hline 7 & $1,207.5$ & 1,151 & 1.1 & 24.7 \\
\hline 8 & $1,238.0$ & 1,151 & 0.6 & 6.1 \\
\hline \multicolumn{5}{|r|}{ (Sheet 1 of 3 ) } \\
\hline
\end{tabular}




\section{Table B9 (Continued)}

\begin{tabular}{|c|c|c|c|c|}
\hline Channel & $X(m)$ & $Y(m)$ & $H t(m)$ & Int. Wave Dir (deg) \\
\hline \multicolumn{5}{|c|}{ Transect T5 } \\
\hline 1 & 950.0 & $1,126.5$ & 0.85 & -- \\
\hline 2 & $1,055.0$ & $1,126.5$ & 1.55 & 12.8 \\
\hline 3 & $1,085.5$ & $1,147.0$ & 1.3 & 5.7 \\
\hline 4 & $1,116.0$ & $1,147.0$ & 1.35 & 21.2 \\
\hline 5 & $1,146.5$ & $1,147.0$ & 1.3 & 18.8 \\
\hline 6 & $1,177.0$ & $1,147.0$ & 1.25 & 6.1 \\
\hline 7 & $1,207.5$ & $1,147.0$ & 1.2 & 22.7 \\
\hline 8 & $1,238.0$ & $1,147.0$ & 0.6 & 8.2 \\
\hline \multicolumn{5}{|c|}{ Transect T6 } \\
\hline 1 & 950.0 & 1,096 & 0.95 & -- \\
\hline 2 & $1,055.0$ & 1,096 & 1.3 & 21.6 \\
\hline 3 & $1,085.5$ & 1,141 & 1.1 & 5.6 \\
\hline 4 & $1,116.0$ & 1,141 & 1.3 & 21.0 \\
\hline 5 & $1,146.5$ & 1,141 & 1.3 & 15.5 \\
\hline 6 & $1,177.0$ & 1,141 & 1.25 & 7.4 \\
\hline 7 & $1,207.5$ & 1,141 & 1.15 & 19.6 \\
\hline 8 & $1,238.0$ & 1,141 & 0.8 & 11.4 \\
\hline \multicolumn{5}{|c|}{ Transect T7 } \\
\hline 1 & 950.0 & $1,065.5$ & 0.9 & -- \\
\hline 2 & $1,055.0$ & $1,065.5$ & 1.05 & 21.1 \\
\hline 3 & $1,085.5$ & $1,135.0$ & 1.0 & 5.5 \\
\hline 4 & $1,116.0$ & $1,135.0$ & 0.95 & 20.7 \\
\hline 5 & $1,146.5$ & $1,135.0$ & 0.85 & 12.3 \\
\hline 6 & $1,177.0$ & $1,135.0$ & 0.9 & 8.7 \\
\hline 7 & $1,207.5$ & $1,135.0$ & 1.05 & 16.5 \\
\hline 8 & $1,238.0$ & $1,135.0$ & 0.65 & 14.6 \\
\hline \multicolumn{5}{|c|}{ Transect T8 } \\
\hline 1 & 950.0 & 1,035 & 0.9 & -- \\
\hline 2 & $1,055.0$ & 1,035 & 1.1 & -- \\
\hline 3 & $1,085.5$ & 1,123 & 1.0 & 6.2 \\
\hline 4 & $1,116.0$ & 1,123 & 1.05 & 20.6 \\
\hline 5 & $1,146.5$ & 1,123 & 1.0 & 8.3 \\
\hline 6 & $1,177.0$ & 1,123 & 1.0 & 11.4 \\
\hline 7 & $1,207.5$ & 1,123 & 1.1 & 11.8 \\
\hline 8 & $1,238.0$ & 1,123 & 0.55 & 16.7 \\
\hline & & & & (Shee \\
\hline
\end{tabular}




\begin{tabular}{|c|c|c|c|c|}
\hline \multicolumn{5}{|c|}{ Table B9 (Concluded) } \\
\hline Channel & $X(m)$ & $Y(m)$ & $H t(m)$ & Int. Wave Dir (deg) \\
\hline \multicolumn{5}{|c|}{ Transect T9 } \\
\hline 1 & 950.0 & $1,010.5$ & 0.9 & -- \\
\hline 2 & $1,055.0$ & $1,010.5$ & 1.0 & -- \\
\hline 3 & $1,085.5$ & $1,010.5$ & 0.9 & 358.4 \\
\hline 4 & $1,116.0$ & $1,010.5$ & 1.0 & 18.0 \\
\hline 5 & $1,146.5$ & $1,010.5$ & 1.1 & 12.0 \\
\hline 6 & $1,177.0$ & $1,010.5$ & 1.3 & 11.9 \\
\hline 7 & $1,207.5$ & $1,010.5$ & 1.25 & 6.4 \\
\hline 8 & $1,238.0$ & $1,010.5$ & 0.7 & 12.5 \\
\hline
\end{tabular}




\begin{tabular}{|c|c|c|c|c|}
\hline \multicolumn{5}{|c|}{$\begin{array}{l}\text { Table B10 } \\
\text { Wave Height and Interpolated Wave Direction, } \\
\text { Channel, 1.0-m, 11-sec Wave, Transects T29, T29A, } \\
\text { T31, T31A, T33, and T33A }\end{array}$} \\
\hline Channel & $X(m)$ & $Y(m)$ & $\mathrm{Ht}(\mathrm{m})$ & Int. Wave Dir (deg) \\
\hline \multicolumn{5}{|c|}{ Transect T29 } \\
\hline 1 & 950.0 & $1,248.5$ & 0.95 & -- \\
\hline 2 & $1,085.5$ & $1,248.5$ & 0.9 & 3.0 \\
\hline 3 & $1,116.0$ & $1,248.5$ & 0.85 & 4.9 \\
\hline 4 & $1,146.5$ & $1,248.5$ & 1.0 & 2.4 \\
\hline 5 & $1,177.0$ & $1,248.5$ & 0.95 & 348.5 \\
\hline 6 & $1,207.5$ & $1,248.5$ & 0.75 & 4.2 \\
\hline 7 & $1,238.0$ & $1,248.5$ & 0.95 & 15.2 \\
\hline \multicolumn{5}{|c|}{ Transect T29A } \\
\hline 1 & 950.0 & $1,248.5$ & 0.9 & -- \\
\hline 2 & $1,268.5$ & $1,263.75$ & 0.8 & 341.2 \\
\hline 3 & $1,299.0$ & $1,263.75$ & 0.35 & 348.0 \\
\hline 4 & $1,329.5$ & $1,263.75$ & 1.0 & 304.6 \\
\hline 5 & $1,360.0$ & $1,263.75$ & 0.6 & 5.3 \\
\hline 6 & $1,390.5$ & $1,263.75$ & 0.4 & 0.3 \\
\hline 7 & $1,421.0$ & $1,263.75$ & 0.3 & 352.5 \\
\hline \multicolumn{5}{|c|}{ Transect T31 } \\
\hline 1 & 950.0 & $1,309.5$ & 0.9 & -- \\
\hline 2 & $1,085.5$ & $1,309.5$ & 1.05 & 12.3 \\
\hline 3 & $1,116.0$ & $1,309.5$ & 1.3 & 26.5 \\
\hline 4 & $1,146.5$ & $1,309.5$ & 0.9 & 15.9 \\
\hline 5 & $1,177.0$ & $1,309.5$ & 0.8 & 14.4 \\
\hline 6 & $1,207.5$ & $1,309.5$ & 1.1 & 13.2 \\
\hline 7 & $1,238.0$ & $1,309.5$ & 1.05 & 17.2 \\
\hline \multicolumn{5}{|c|}{ Transect T31A } \\
\hline 1 & 950.0 & $1,309.5$ & 0.95 & -- \\
\hline 2 & $1,268.5$ & $1,309.5$ & 0.55 & 4.2 \\
\hline 3 & $1,299.0$ & $1,309.5$ & 1.0 & 18.2 \\
\hline 4 & $1,329.5$ & $1,309.5$ & 0.6 & 350.3 \\
\hline 5 & $1,360.0$ & $1,309.5$ & 0.2 & 356.6 \\
\hline 6 & $1,390.5$ & $1,309.5$ & 0.6 & 7.8 \\
\hline 7 & $1,421.0$ & $1,309.5$ & 0.55 & 12.1 \\
\hline \multicolumn{5}{|c|}{ (Continued) } \\
\hline
\end{tabular}




\begin{tabular}{|l|l|l|l|l||}
\hline \hline \multicolumn{5}{||c||}{ Table B10 (Concluded) } \\
\hline \hline Channel & $\mathbf{X}(\mathbf{m})$ & $\mathbf{Y}(\mathbf{m})$ & Ht (m) & Int. Wave Dir (deg) \\
\hline \hline \multicolumn{5}{|c||}{ Transect T33 } \\
\hline \hline 1 & 950.0 & $1,370.5$ & 0.95 & -- \\
\hline 2 & $1,085.5$ & $1,370.5$ & 1.0 & 10.4 \\
\hline 3 & $1,116.0$ & $1,370.5$ & 1.2 & 17.3 \\
\hline 4 & $1,146.5$ & $1,370.5$ & 0.95 & 15.9 \\
\hline 5 & $1,177.0$ & $1,370.5$ & 0.8 & 6.6 \\
\hline 6 & $1,207.5$ & $1,370.5$ & 1.2 & 26.3 \\
\hline 7 & $1,238.0$ & $1,370.5$ & 1.0 & 34.6 \\
\hline \hline & & Transect T33A \\
\hline \hline 1 & 950.0 & $1,370.5$ & 0.9 & -- \\
\hline 2 & $1,268.5$ & $1,355.25$ & 0.8 & 37.2 \\
\hline 3 & $1,299.0$ & $1,355.25$ & 0.3 & 29.0 \\
\hline 4 & $1,329.5$ & $1,355.25$ & 1.2 & 58.6 \\
\hline 5 & $1,360.0$ & $1,355.25$ & 0.45 & 30.3 \\
\hline 6 & $1,390.5$ & $1,355.25$ & 0.25 & 38.8 \\
\hline 7 & $1,421.0$ & $1,355.25$ & 0.45 & 6.1 \\
\hline \hline
\end{tabular}




\section{Table B11 \\ Wave Height and Interpolated Wave Direction, Channel, 2.0-m, 11-sec Wave, Transects T29, T29A, T31, T31A, T33, and T33A}

\begin{tabular}{|c|c|c|c|c|}
\hline Channel & $X(m)$ & $Y(m)$ & $\mathrm{Ht}(\mathrm{m})$ & Int. Wave Dir (deg) \\
\hline \multicolumn{5}{|c|}{ Transect T29 } \\
\hline 1 & 950.0 & $1,248.5$ & 1.95 & -- \\
\hline 2 & $1,085.5$ & $1,248.5$ & 2.45 & 8.1 \\
\hline 3 & $1,116.0$ & $1,248.5$ & 2.5 & 10.5 \\
\hline 4 & $1,146.5$ & $1,248.5$ & 2.55 & 8.0 \\
\hline 5 & $1,177.0$ & $1,248.5$ & 2.1 & 5.9 \\
\hline 6 & $1,207.5$ & $1,248.5$ & 1.8 & 7.5 \\
\hline 7 & $1,238.0$ & $1,248.5$ & 1.7 & 4.2 \\
\hline \multicolumn{5}{|c|}{ Transect T29A } \\
\hline 1 & 950.0 & $1,248.5$ & 1.9 & -- \\
\hline 2 & $1,268.5$ & $1,263.75$ & 1.55 & 9.2 \\
\hline 3 & $1,299.0$ & $1,263.75$ & 1.2 & 355.3 \\
\hline 4 & $1,329.5$ & $1,263.75$ & 1.75 & 339.0 \\
\hline 5 & $1,360.0$ & $1,263.75$ & 0.9 & 305.5 \\
\hline 6 & $1,390.5$ & $1,263.75$ & 0.9 & 283.5 \\
\hline 7 & $1,421.0$ & $1,263.75$ & 0.75 & 288.2 \\
\hline \multicolumn{5}{|c|}{ Transect T31 } \\
\hline 1 & 950.0 & $1,309.5$ & 2.0 & -- \\
\hline 2 & $1,085.5$ & $1,309.5$ & 1.95 & 14.0 \\
\hline 3 & $1,116.0$ & $1,309.5$ & 2.1 & 17.9 \\
\hline 4 & $1,146.5$ & $1,309.5$ & 2.5 & 20.2 \\
\hline 5 & $1,177.0$ & $1,309.5$ & 2.2 & 11.5 \\
\hline 6 & $1,207.5$ & $1,309.5$ & 2.0 & 5.8 \\
\hline 7 & $1,238.0$ & $1,309.5$ & 2.5 & 7.7 \\
\hline \multicolumn{5}{|c|}{ Transect T31A } \\
\hline 1 & 950.0 & $1,309.5$ & 2.0 & -- \\
\hline 2 & $1,268.5$ & $1,309.5$ & 2.15 & 4.9 \\
\hline 3 & $1,299.0$ & $1,309.5$ & 1.95 & 3.2 \\
\hline 4 & $1,329.5$ & $1,309.5$ & 1.2 & 355.5 \\
\hline 5 & $1,360.0$ & $1,309.5$ & 1.85 & 356.2 \\
\hline 6 & $1,390.5$ & $1,309.5$ & 2.0 & 352.9 \\
\hline 7 & $1,421.0$ & $1,309.5$ & 1.95 & 354.8 \\
\hline
\end{tabular}




\begin{tabular}{|c|c|c|c|c|}
\hline \multicolumn{5}{|c|}{ Table B11 (Concluded) } \\
\hline Channel & $X(m)$ & $\mathrm{Y}(\mathrm{m})$ & $\mathrm{Ht}(\mathrm{m})$ & Int. Wave Dir (deg) \\
\hline \multicolumn{5}{|c|}{ Transect T33 } \\
\hline 1 & 950.0 & $1,370.5$ & 2.0 & -- \\
\hline 2 & $1,085.5$ & $1,370.5$ & 2.45 & 9.6 \\
\hline 3 & $1,116.0$ & $1,370.5$ & 2.6 & 10.6 \\
\hline 4 & $1,146.5$ & $1,370.5$ & 2.75 & 10.4 \\
\hline 5 & $1,177.0$ & $1,370.5$ & 2.2 & 358.4 \\
\hline 6 & $1,207.5$ & $1,370.5$ & 2.45 & 14.3 \\
\hline 7 & $1,238.0$ & $1,370.5$ & 2.45 & 21.2 \\
\hline \multicolumn{5}{|c|}{ Transect T33A } \\
\hline 1 & 950.0 & $1,370.5$ & 1.95 & -- \\
\hline 2 & $1,268.5$ & $1,355.25$ & 2.05 & 23.7 \\
\hline 3 & $1,299.0$ & $1,355.25$ & 2.2 & 21.2 \\
\hline 4 & $1,329.5$ & $1,355.25$ & 2.75 & 27.1 \\
\hline 5 & $1,360.0$ & $1,355.25$ & 1.2 & 45.3 \\
\hline 6 & $1,390.5$ & $1,355.25$ & 1.05 & 78.0 \\
\hline 7 & $1,421.0$ & $1,355.25$ & 1.1 & 69.7 \\
\hline
\end{tabular}




\begin{tabular}{|c|c|c|c|c|}
\hline \multicolumn{5}{|c|}{$\begin{array}{l}\text { Table B12 } \\
\text { Wave Height and Interpolated Wave Direction, } \\
\text { Channel, 3.4-m, 8-sec Wave, Transects T29, T29A } \\
\text { T31, T31A, T33, T33A }\end{array}$} \\
\hline Channel & $x(m)$ & $\mathrm{Y}(\mathrm{m})$ & $\mathrm{Ht}(\mathrm{m})$ & Int. Wave Dir (deg) \\
\hline \multicolumn{5}{|c|}{ Transect T29 } \\
\hline 1 & 950.0 & $1,248.5$ & 3.4 & -- \\
\hline 2 & $1,085.5$ & $1,248.5$ & 2.4 & 13.2 \\
\hline 3 & $1,116.0$ & $1,248.5$ & 2.1 & 18.9 \\
\hline 4 & $1,146.5$ & $1,248.5$ & 2.0 & 13.4 \\
\hline 5 & $1,177.0$ & $1,248.5$ & 1.8 & 7.1 \\
\hline 6 & $1,207.5$ & $1,248.5$ & 1.8 & 2.9 \\
\hline 7 & $1,238.0$ & $1,248.5$ & 1.5 & 356.7 \\
\hline \multicolumn{5}{|c|}{ Transect T29A } \\
\hline 1 & 950.0 & $1,248.5$ & 3.25 & -- \\
\hline 2 & $1,268.5$ & $1,263.75$ & 1.55 & 34.4 \\
\hline 3 & $1,299.0$ & $1,263.75$ & 1.5 & 341.5 \\
\hline 4 & $1,329.5$ & $1,263.75$ & 1.65 & 331.1 \\
\hline 5 & $1,360.0$ & $1,263.75$ & 1.75 & 342.6 \\
\hline 6 & $1,390.5$ & $1,263.75$ & 1.5 & 356.0 \\
\hline 7 & $1,421.0$ & $1,263.75$ & 1.2 & 33.3 \\
\hline \multicolumn{5}{|c|}{ Transect T31 } \\
\hline 1 & 950.0 & $1,309.5$ & 3.4 & -- \\
\hline 2 & $1,085.5$ & $1,309.5$ & 3.1 & 13.9 \\
\hline 3 & $1,116.0$ & $1,309.5$ & 3.3 & 16.3 \\
\hline 4 & $1,146.5$ & $1,309.5$ & 3.1 & 13.4 \\
\hline 5 & $1,177.0$ & $1,309.5$ & 2.8 & 10.6 \\
\hline 6 & $1,207.5$ & $1,309.5$ & 2.8 & 6.6 \\
\hline 7 & $1,238.0$ & $1,309.5$ & 2.6 & 8.2 \\
\hline \multicolumn{5}{|c|}{ Transect T31A } \\
\hline 1 & 950.0 & $1,309.5$ & 3.4 & -- \\
\hline 2 & $1,268.5$ & $1,309.5$ & 2.5 & 8.8 \\
\hline 3 & $1,299.0$ & $1,309.5$ & 2.3 & 7.4 \\
\hline 4 & $1,329.5$ & $1,309.5$ & 2.15 & 14.0 \\
\hline 5 & $1,360.0$ & $1,309.5$ & 1.6 & 16.1 \\
\hline 6 & $1,390.5$ & $1,309.5$ & 1.75 & 343.6 \\
\hline 7 & $1,421.0$ & $1,309.5$ & 1.6 & 341.4 \\
\hline
\end{tabular}




\begin{tabular}{|l|l|l|l|l||}
\hline \multicolumn{5}{|l|}{ Table B12 (Concluded) } \\
\hline \hline Channel & X (m) & Y (m) & Ht (m) & Int. Wave Dir (deg) \\
\hline \hline \multicolumn{5}{|c||}{ Transect T33 } \\
\hline \hline 1 & 950.0 & $1,370.5$ & 3.4 & -- \\
\hline 2 & $1,085.5$ & $1,370.5$ & 3.1 & 19.2 \\
\hline 3 & $1,116.0$ & $1,370.5$ & 3.1 & 14.1 \\
\hline 4 & $1,146.5$ & $1,370.5$ & 3.2 & 14.4 \\
\hline 5 & $1,177.0$ & $1,370.5$ & 3.0 & 10.4 \\
\hline 6 & $1,207.5$ & $1,370.5$ & 2.75 & 10.1 \\
\hline 7 & $1,238.0$ & $1,370.5$ & 2.35 & 20.9 \\
\hline \hline & & \multicolumn{5}{|c|}{ Transect T33A } \\
\hline \hline 1 & 950.0 & $1,370.5$ & 3.3 & -- \\
\hline 2 & $1,268.5$ & $1,355.25$ & 2.25 & 22.8 \\
\hline 3 & $1,299.0$ & $1,355.25$ & 2.4 & 16.2 \\
\hline 4 & $1,329.5$ & $1,355.25$ & 2.05 & 11.1 \\
\hline 5 & $1,360.0$ & $1,355.25$ & 1.6 & 36.7 \\
\hline 6 & $1,390.5$ & $1,355.25$ & 1.25 & 62.6 \\
\hline 7 & $1,421.0$ & $1,355.25$ & 1.05 & 305.2 \\
\hline \hline
\end{tabular}




\section{Table B13 \\ Wave Height and Interpolated Wave Direction, Spur Jetty, 2.0-m, 11-sec Wave, Transects C17-C19, C21- C26, T1, and T3}

\begin{tabular}{|c|c|c|c|c|}
\hline Channel & $x(m)$ & $Y(m)$ & Ht (m) & Int. Wave Dir (deg) \\
\hline \multicolumn{5}{|c|}{ Transect C17 } \\
\hline 1 & 950.0 & $1,248.5$ & 2.0 & -- \\
\hline 2 & $1,024.5$ & $1,218.0$ & 2.35 & 14.4 \\
\hline 3 & $1,024.5$ & $1,187.5$ & 2.75 & 10.5 \\
\hline 4 & $1,024.5$ & $1,157.0$ & 2.7 & 27.7 \\
\hline 5 & $1,024.5$ & $1,126.5$ & 2.55 & 20.2 \\
\hline 6 & $1,024.5$ & $1,096.0$ & 2.95 & 18.1 \\
\hline 7 & $1,024.5$ & $1,065.5$ & 2.65 & 30.2 \\
\hline \multicolumn{5}{|c|}{ Transect C18 } \\
\hline 1 & 950 & $1,218.0$ & 2.05 & -- \\
\hline 2 & 1,055 & $1,218.0$ & 2.7 & 22.1 \\
\hline 3 & 1,055 & $1,187.5$ & 2.75 & 23.9 \\
\hline 4 & 1,055 & $1,157.0$ & 3.4 & 7.4 \\
\hline 5 & 1,055 & $1,126.5$ & 2.2 & 46.1 \\
\hline 6 & 1,055 & $1,096.0$ & 3.15 & 10.9 \\
\hline 7 & 1,055 & $1,065.5$ & 2.75 & 33.0 \\
\hline \multicolumn{5}{|c|}{ Transect C19 } \\
\hline 1 & 950.0 & $1,187.5$ & 2.05 & -- \\
\hline 2 & $1,085.5$ & 945.0 & 2.7 & 1.3 \\
\hline 3 & $1,116.0$ & 945.0 & 2.2 & 20.6 \\
\hline 4 & $1,146.5$ & 945.0 & 3.2 & 12.6 \\
\hline 5 & $1,177.0$ & 945.0 & 1.95 & 356.5 \\
\hline 6 & $1,207.5$ & 945.0 & 1.75 & 1.9 \\
\hline 7 & $1,238.0$ & 945.0 & 1.1 & 7.9 \\
\hline \multicolumn{5}{|c|}{ Transect C21 } \\
\hline 1 & 950.0 & 1,157 & 2.1 & -- \\
\hline 2 & $1,085.5$ & 1,005 & 3.3 & 3.2 \\
\hline 3 & $1,116.0$ & 1,005 & 3.3 & 13.0 \\
\hline 4 & $1,146.5$ & 1,005 & 3.15 & 5.6 \\
\hline 5 & $1,177.0$ & 1,005 & 2.1 & 353.2 \\
\hline 6 & $1,207.5$ & 1,005 & 1.95 & 8.4 \\
\hline 7 & $1,238.0$ & 1,005 & 1.3 & 1.3 \\
\hline
\end{tabular}

(Sheet 1 of 3) 


\section{Table B13 (Continued)}

\begin{tabular}{|c|c|c|c|c|}
\hline Channel & $X(m)$ & $\mathrm{Y}(\mathrm{m})$ & $\mathrm{Ht}(\mathrm{m})$ & Int. Wave Dir (deg) \\
\hline \multicolumn{5}{|c|}{ Transect C22 } \\
\hline 1 & 950.0 & $1,126.5$ & 2.0 & -- \\
\hline 2 & $1,085.5$ & $1,035.0$ & 2.5 & 9.6 \\
\hline 3 & $1,116.0$ & $1,035.0$ & 2.8 & 4.9 \\
\hline 4 & $1,146.5$ & $1,035.0$ & 3.1 & 11.8 \\
\hline 5 & $1,177.0$ & $1,035.0$ & 2.0 & 33.4 \\
\hline 6 & $1,207.5$ & $1,035.0$ & 1.6 & 17.8 \\
\hline 7 & $1,238.0$ & $1,035.0$ & 1.0 & 358.3 \\
\hline \multicolumn{5}{|c|}{ Transect C23 } \\
\hline 1 & 950.0 & $1,096.0$ & 2.1 & -- \\
\hline 2 & $1,085.5$ & $1,065.5$ & 2.6 & 2.5 \\
\hline 3 & $1,116.0$ & $1,065.5$ & 2.45 & 21.0 \\
\hline 4 & $1,146.5$ & $1,065.5$ & 3.2 & 358.8 \\
\hline 5 & $1,177.0$ & $1,065.5$ & 2.3 & 8.3 \\
\hline 6 & $1,207.5$ & $1,065.5$ & 1.35 & 13.0 \\
\hline 7 & $1,238.0$ & $1,065.5$ & 0.95 & 7.9 \\
\hline \multicolumn{5}{|c|}{ Transect C24 } \\
\hline 1 & 950.0 & $1,065.5$ & 2.05 & -- \\
\hline 2 & $1,085.5$ & $1,096.0$ & 3.05 & 25.3 \\
\hline 3 & $1,116.0$ & $1,096.0$ & 3.05 & 7.3 \\
\hline 4 & $1,146.5$ & $1,096.0$ & 2.75 & 33.7 \\
\hline 5 & $1,177.0$ & $1,096.0$ & 2.45 & 16.1 \\
\hline 6 & $1,207.5$ & $1,096.0$ & 1.8 & 54.3 \\
\hline 7 & $1,238.0$ & $1,096.0$ & 1.0 & 11.8 \\
\hline \multicolumn{5}{|c|}{ Transect C25 } \\
\hline 1 & 950.0 & $1,035.0$ & 2.0 & -- \\
\hline 2 & $1,085.5$ & $1,126.5$ & 3.3 & 24.1 \\
\hline 3 & $1,116.0$ & $1,126.5$ & 3.4 & 17.4 \\
\hline 4 & $1,146.5$ & $1,126.5$ & 3.55 & 5.0 \\
\hline 5 & $1,177.0$ & $1,126.5$ & 2.25 & 2.3 \\
\hline 6 & $1,207.5$ & $1,126.5$ & 2.05 & 5.9 \\
\hline 7 & $1,238.0$ & $1,126.5$ & 1.2 & 3.4 \\
\hline
\end{tabular}

(Sheet 2 of 3) 


\section{Table B13 (Concluded)}

\begin{tabular}{|c|c|c|c|c|}
\hline Channel & $X(m)$ & $Y(m)$ & Ht (m) & Int. Wave Dir (deg) \\
\hline \multicolumn{5}{|c|}{ Transect C26 } \\
\hline 1 & 950.0 & $1,004.5$ & 2.1 & -- \\
\hline 2 & $1,085.5$ & $1,145.0$ & 2.85 & 22.8 \\
\hline 3 & $1,116.0$ & $1,145.0$ & 4.05 & 4.6 \\
\hline 4 & $1,146.5$ & $1,145.0$ & 3.3 & 23.9 \\
\hline 5 & $1,177.0$ & $1,145.0$ & 2.35 & 12.0 \\
\hline 6 & $1,207.5$ & $1,145.0$ & 1.7 & 18.2 \\
\hline 7 & $1,238.0$ & $1,145.0$ & 1.15 & 19.3 \\
\hline \multicolumn{5}{|c|}{ Transect T1 } \\
\hline 1 & 950.0 & 974 & 2.05 & -- \\
\hline 2 & $1,080.5$ & 1,159 & 2.55 & 10.5 \\
\hline 3 & $1,116.0$ & 1,159 & 2.0 & 56.5 \\
\hline 4 & $1,141.5$ & 1,159 & 2.0 & 31.3 \\
\hline 5 & $1,177.0$ & 1,159 & 1.4 & 76.7 \\
\hline 6 & $1,202.5$ & 1,159 & 1.2 & 34.1 \\
\hline 7 & $1,238.0$ & 1,159 & 0.5 & 72.3 \\
\hline \multicolumn{5}{|c|}{ Transect T3 } \\
\hline 1 & 950.0 & 945 & 2.05 & -- \\
\hline 2 & $1,080.5$ & 1,155 & 2.7 & 19.2 \\
\hline 3 & $1,116.0$ & 1,155 & 2.25 & 35.7 \\
\hline 4 & $1,141.5$ & 1,155 & 1.9 & 27.5 \\
\hline 5 & $1,177.0$ & 1,155 & 1.7 & 63.9 \\
\hline 6 & $1,202.5$ & 1,155 & 1.05 & 27.1 \\
\hline 7 & $1,238.0$ & 1,155 & 0.8 & 69.4 \\
\hline
\end{tabular}




\section{Table B14 \\ Wave Height and Interpolated Wave Direction, Spur Jetty, 1.0-m, 11-sec Wave, Transects C17-C19, C21- C26, T1, and T3}

\begin{tabular}{|c|c|c|c|c|}
\hline Channel & $X(m)$ & $\mathrm{Y}(\mathrm{m})$ & Ht (m) & Int. Wave Dir (deg) \\
\hline \multicolumn{5}{|c|}{ Transect C17 } \\
\hline 1 & 950.0 & $1,248.5$ & 1.05 & -- \\
\hline 2 & $1,024.5$ & $1,218.0$ & 0.8 & 18.4 \\
\hline 3 & $1,024.5$ & $1,187.5$ & 0.85 & 3.7 \\
\hline 4 & $1,024.5$ & $1,157.0$ & 1.0 & 5.1 \\
\hline 5 & $1,024.5$ & $1,126.5$ & 1.4 & 15.5 \\
\hline 6 & $1,024.5$ & $1,096.0$ & 1.6 & 18.1 \\
\hline 7 & $1,024.5$ & $1,065.5$ & 1.4 & 23.3 \\
\hline \multicolumn{5}{|c|}{ Transect C18 } \\
\hline 1 & 950 & $1,218.0$ & 1.05 & -- \\
\hline 2 & 1,055 & $1,218.0$ & 1.0 & 25.9 \\
\hline 3 & 1,055 & $1,187.5$ & 1.15 & 23.9 \\
\hline 4 & 1,055 & $1,157.0$ & 1.65 & 1.1 \\
\hline 5 & 1,055 & $1,126.5$ & 1.55 & 23.0 \\
\hline 6 & 1,055 & $1,096.0$ & 1.2 & 23.9 \\
\hline 7 & 1,055 & $1,065.5$ & 1.45 & 13.7 \\
\hline \multicolumn{5}{|c|}{ Transect C19 } \\
\hline 1 & 950.0 & $1,187.5$ & 1.05 & -- \\
\hline 2 & $1,085.5$ & 945.0 & 1.05 & 9.2 \\
\hline 3 & $1,116.0$ & 945.0 & 1.05 & 21.2 \\
\hline 4 & $1,146.5$ & 945.0 & 1.6 & 4.7 \\
\hline 5 & $1,177.0$ & 945.0 & 1.95 & 11.2 \\
\hline 6 & $1,207.5$ & 945.0 & 2.3 & 19.4 \\
\hline 7 & $1,238.0$ & 945.0 & 0.95 & 6.7 \\
\hline \multicolumn{5}{|c|}{ Transect C21 } \\
\hline 1 & 950.0 & 1,157 & 1.05 & -- \\
\hline 2 & $1,085.5$ & 1,005 & 1.15 & 7.8 \\
\hline 3 & $1,116.0$ & 1,005 & 1.35 & 18.6 \\
\hline 4 & $1,146.5$ & 1,005 & 1.8 & 2.2 \\
\hline 5 & $1,177.0$ & 1,005 & 1.7 & 12.6 \\
\hline 6 & $1,207.5$ & 1,005 & 2.15 & 13.7 \\
\hline 7 & $1,238.0$ & 1,005 & 1.15 & 13.1 \\
\hline & & & & (Sheet \\
\hline
\end{tabular}




\section{Table B14 (Continued)}

\begin{tabular}{|c|c|c|c|c|}
\hline Channel & $X(m)$ & $Y(m)$ & $\mathrm{Ht}(\mathrm{m})$ & Int. Wave Dir (deg) \\
\hline \multicolumn{5}{|c|}{ Transect C22 } \\
\hline 1 & 950.0 & $1,126.5$ & 1.05 & -- \\
\hline 2 & $1,085.5$ & $1,035.0$ & 1.1 & 5.4 \\
\hline 3 & $1,116.0$ & $1,035.0$ & 1.3 & 4.0 \\
\hline 4 & $1,146.5$ & $1,035.0$ & 1.35 & 18.3 \\
\hline 5 & $1,177.0$ & $1,035.0$ & 1.8 & 4.7 \\
\hline 6 & $1,207.5$ & $1,035.0$ & 2.2 & 8.4 \\
\hline 7 & $1,238.0$ & $1,035.0$ & 1.3 & 0.0 \\
\hline \multicolumn{5}{|c|}{ Transect C23 } \\
\hline 1 & 950.0 & $1,096.0$ & 1.05 & -- \\
\hline 2 & $1,085.5$ & $1,065.5$ & 1.2 & 8.5 \\
\hline 3 & $1,116.0$ & $1,065.5$ & 1.0 & 18.4 \\
\hline 4 & $1,146.5$ & $1,065.5$ & 1.45 & 358.2 \\
\hline 5 & $1,177.0$ & $1,065.5$ & 1.2 & 18.5 \\
\hline 6 & $1,207.5$ & $1,065.5$ & 1.7 & 19.5 \\
\hline 7 & $1,238.0$ & $1,065.5$ & 1.15 & 10.7 \\
\hline \multicolumn{5}{|c|}{ Transect C24 } \\
\hline 1 & 950.0 & $1,065.5$ & 1.0 & -- \\
\hline 2 & $1,085.5$ & $1,096.0$ & 1.4 & 20.6 \\
\hline 3 & $1,116.0$ & $1,096.0$ & 1.35 & 18.8 \\
\hline 4 & $1,146.5$ & $1,096.0$ & 1.35 & 22.4 \\
\hline 5 & $1,177.0$ & $1,096.0$ & 1.55 & 14.5 \\
\hline 6 & $1,207.5$ & $1,096.0$ & 1.65 & 8.2 \\
\hline 7 & $1,238.0$ & $1,096.0$ & 1.2 & 4.9 \\
\hline \multicolumn{5}{|c|}{ Transect C25 } \\
\hline 1 & 950.0 & $1,035.0$ & 1.0 & -- \\
\hline 2 & $1,085.5$ & $1,126.5$ & 1.65 & 18.5 \\
\hline 3 & $1,116.0$ & $1,126.5$ & 1.9 & 16.4 \\
\hline 4 & $1,146.5$ & $1,126.5$ & 1.85 & 17.7 \\
\hline 5 & $1,177.0$ & $1,126.5$ & 2.1 & 16.9 \\
\hline 6 & $1,207.5$ & $1,126.5$ & 2.25 & 5.1 \\
\hline 7 & $1,238.0$ & $1,126.5$ & 0.95 & 5.6 \\
\hline
\end{tabular}

(Sheet 2 of 3) 


\section{Table B14 (Concluded)}

\begin{tabular}{|c|c|c|c|c|}
\hline Channel & $X(m)$ & $Y(m)$ & $\mathrm{Ht}(\mathrm{m})$ & Int. Wave Dir (deg) \\
\hline \multicolumn{5}{|c|}{ Transect C26 } \\
\hline 1 & 950.0 & $1,004.5$ & 1.0 & -- \\
\hline 2 & $1,085.5$ & $1,145.0$ & 1.35 & 23.7 \\
\hline 3 & $1,116.0$ & $1,145.0$ & 1.95 & 4.7 \\
\hline 4 & $1,146.5$ & $1,145.0$ & 1.95 & 26.6 \\
\hline 5 & $1,177.0$ & $1,145.0$ & 1.8 & 9.5 \\
\hline 6 & $1,207.5$ & $1,145.0$ & 1.65 & 25.8 \\
\hline 7 & $1,238.0$ & $1,145.0$ & 1.2 & 12.2 \\
\hline \multicolumn{5}{|c|}{ Transect T1 } \\
\hline 1 & 950.0 & 974 & 1.0 & -- \\
\hline 2 & $1,080.5$ & 1,159 & 1.1 & 14.1 \\
\hline 3 & $1,116.0$ & 1,159 & 0.85 & 66.9 \\
\hline 4 & $1,141.5$ & 1,159 & 1.0 & 24.8 \\
\hline 5 & $1,177.0$ & 1,159 & 1.3 & 83.3 \\
\hline 6 & $1,202.5$ & 1,159 & 0.95 & 22.4 \\
\hline 7 & $1,238.0$ & 1,159 & 0.55 & 66.9 \\
\hline \multicolumn{5}{|c|}{ Transect T3 } \\
\hline 1 & 950.0 & 945 & 1.05 & -- \\
\hline 2 & 1080.5 & 1155 & 1.15 & 15.8 \\
\hline 3 & 1116.0 & 1155 & 1.3 & 41.5 \\
\hline 4 & 1141.5 & 1155 & 0.85 & 25.2 \\
\hline 5 & 1177.0 & 1155 & 1.45 & 47.1 \\
\hline 6 & 1202.5 & 1155 & 0.8 & 23.8 \\
\hline 7 & 1238.0 & 1155 & 0.7 & 53.0 \\
\hline
\end{tabular}




\section{Table B15 \\ Wave Height and Interpolated Wave Direction, Spur Jetty, 3.4-m, 8-sec Wave, Transects C17-C19, C21- C26, T1, and T3}

\begin{tabular}{|c|c|c|c|c|}
\hline Channel & $X(m)$ & $\mathrm{Y}(\mathrm{m})$ & Ht (m) & Int. Wave Dir (deg) \\
\hline \multicolumn{5}{|c|}{ Transect C17 } \\
\hline 1 & 950.0 & $1,248.5$ & 3.4 & -- \\
\hline 2 & $1,024.5$ & $1,218.0$ & 4.0 & 15.5 \\
\hline 3 & $1,024.5$ & $1,187.5$ & 4.3 & 18.2 \\
\hline 4 & $1,024.5$ & $1,157.0$ & 4.3 & 12.6 \\
\hline 5 & $1,024.5$ & $1,126.5$ & 3.65 & 36.0 \\
\hline 6 & $1,024.5$ & $1,096.0$ & 4.0 & 22.7 \\
\hline 7 & $1,024.5$ & $1,065.5$ & 4.3 & 15.8 \\
\hline \multicolumn{5}{|c|}{ Transect C18 } \\
\hline 1 & 950 & $1,218.0$ & 3.35 & -- \\
\hline 2 & 1,055 & $1,218.0$ & 3.85 & 14.6 \\
\hline 3 & 1,055 & $1,187.5$ & 4.3 & 6.8 \\
\hline 4 & 1,055 & $1,157.0$ & 4.25 & 7.6 \\
\hline 5 & 1,055 & $1,126.5$ & 3.75 & 352.9 \\
\hline 6 & 1,055 & $1,096.0$ & 3.85 & 7.4 \\
\hline 7 & 1,055 & $1,065.5$ & 3.55 & 20.4 \\
\hline \multicolumn{5}{|c|}{ Transect C19 } \\
\hline 1 & 950.0 & $1,187.5$ & 3.5 & -- \\
\hline 2 & $1,085.5$ & 945.0 & 3.15 & 4.7 \\
\hline 3 & $1,116.0$ & 945.0 & 2.2 & 18.1 \\
\hline 4 & $1,146.5$ & 945.0 & 1.5 & 3.6 \\
\hline 5 & $1,177.0$ & 945.0 & 1.5 & 3.6 \\
\hline 6 & $1,207.5$ & 945.0 & 1.6 & 32.9 \\
\hline 7 & $1,238.0$ & 945.0 & 0.95 & 14.0 \\
\hline \multicolumn{5}{|c|}{ Transect C21 } \\
\hline 1 & 950.0 & 1,157 & 3.45 & -- \\
\hline 2 & $1,085.5$ & 1,005 & 3.25 & 31.8 \\
\hline 3 & $1,116.0$ & 1,005 & 3.3 & 51.9 \\
\hline 4 & $1,146.5$ & 1,005 & 1.75 & 15.8 \\
\hline 5 & $1,177.0$ & 1,005 & 1.85 & 13.2 \\
\hline 6 & $1,207.5$ & 1,005 & 1.7 & 19.6 \\
\hline 7 & $1,238.0$ & 1,005 & 1.4 & 10.4 \\
\hline & & & & (Sheet \\
\hline
\end{tabular}




\section{Table B15 (Continued)}

\begin{tabular}{|c|c|c|c|c|}
\hline Channel & $X(m)$ & $Y(m)$ & $\mathrm{Ht}(\mathrm{m})$ & Int. Wave Dir (deg) \\
\hline \multicolumn{5}{|c|}{ Transect C22 } \\
\hline 1 & 950.0 & $1,126.5$ & 3.45 & -- \\
\hline 2 & $1,085.5$ & $1,035.0$ & 3.45 & 10.7 \\
\hline 3 & $1,116.0$ & $1,035.0$ & 2.95 & 12.4 \\
\hline 4 & $1,146.5$ & $1,035.0$ & 2.1 & 17.9 \\
\hline 5 & $1,177.0$ & $1,035.0$ & 1.75 & 16.0 \\
\hline 6 & $1,207.5$ & $1,035.0$ & 2.05 & 13.8 \\
\hline 7 & $1,238.0$ & $1,035.0$ & 1.5 & 8.2 \\
\hline \multicolumn{5}{|c|}{ Transect C23 } \\
\hline 1 & 950.0 & $1,096.0$ & 3.45 & -- \\
\hline 2 & $1,085.5$ & $1,065.5$ & 3.1 & 24.2 \\
\hline 3 & $1,116.0$ & $1,065.5$ & 2.15 & 15.8 \\
\hline 4 & $1,146.5$ & $1,065.5$ & 2.05 & 356.9 \\
\hline 5 & $1,177.0$ & $1,065.5$ & 1.55 & 39.8 \\
\hline 6 & $1,207.5$ & $1,065.5$ & 1.8 & 28.5 \\
\hline 7 & $1,238.0$ & $1,065.5$ & 1.5 & 16.1 \\
\hline \multicolumn{5}{|c|}{ Transect C24 } \\
\hline 1 & 950.0 & $1,065.5$ & 3.35 & -- \\
\hline 2 & $1,085.5$ & $1,096.0$ & 2.35 & 7.4 \\
\hline 3 & $1,116.0$ & $1,096.0$ & 2.1 & 14.1 \\
\hline 4 & $1,146.5$ & $1,096.0$ & 1.95 & 4.3 \\
\hline 5 & $1,177.0$ & $1,096.0$ & 1.8 & 35.3 \\
\hline 6 & $1,207.5$ & $1,096.0$ & 1.55 & 0.0 \\
\hline 7 & $1,238.0$ & $1,096.0$ & 1.0 & 22.5 \\
\hline \multicolumn{5}{|c|}{ Transect C25 } \\
\hline 1 & 950.0 & $1,035.0$ & 3.45 & -- \\
\hline 2 & $1,085.5$ & $1,126.5$ & 2.4 & 22.6 \\
\hline 3 & $1,116.0$ & $1,126.5$ & 2.0 & 18.3 \\
\hline 4 & $1,146.5$ & $1,126.5$ & 2.15 & 15.5 \\
\hline 5 & $1,177.0$ & $1,126.5$ & 1.75 & 12.9 \\
\hline 6 & $1,207.5$ & $1,126.5$ & 1.95 & 12.4 \\
\hline 7 & $1,238.0$ & $1,126.5$ & 1.15 & 11.0 \\
\hline
\end{tabular}

(Sheet 2 of 3) 


\section{Table B15 (Concluded)}

\begin{tabular}{|c|c|c|c|c|}
\hline Channel & $X(m)$ & $Y(m)$ & Ht (m) & Int. Wave Dir (deg) \\
\hline \multicolumn{5}{|c|}{ Transect C26 } \\
\hline 1 & 950.0 & $1,004.5$ & 3.35 & -- \\
\hline 2 & $1,085.5$ & $1,145.0$ & 2.8 & 10.8 \\
\hline 3 & $1,116.0$ & $1,145.0$ & 2.15 & 3.7 \\
\hline 4 & $1,146.5$ & $1,145.0$ & 2.3 & 18.3 \\
\hline 5 & $1,177.0$ & $1,145.0$ & 1.75 & 14.8 \\
\hline 6 & $1,207.5$ & $1,145.0$ & 1.6 & 19.8 \\
\hline 7 & $1,238.0$ & $1,145.0$ & 1.25 & 9.2 \\
\hline \multicolumn{5}{|c|}{ Transect T1 } \\
\hline 1 & 950.0 & 974 & 3.4 & -- \\
\hline 2 & $1,080.5$ & 1,159 & 3.05 & 3.5 \\
\hline 3 & $1,116.0$ & 1,159 & 1.3 & 5.5 \\
\hline 4 & $1,141.5$ & 1,159 & 0.9 & 12.9 \\
\hline 5 & $1,177.0$ & 1,159 & 0.9 & 45.6 \\
\hline 6 & $1,202.5$ & 1,159 & 0.85 & 26.1 \\
\hline 7 & $1,238.0$ & 1,159 & 0.6 & 54.0 \\
\hline \multicolumn{5}{|c|}{ Transect T3 } \\
\hline 1 & 950.0 & 945 & 3.4 & -- \\
\hline 2 & $1,080.5$ & 1,155 & 2.9 & 0.9 \\
\hline 3 & $1,116.0$ & 1,155 & 1.65 & 7.7 \\
\hline 4 & $1,141.5$ & 1,155 & 1.2 & 18.1 \\
\hline 5 & $1,177.0$ & 1,155 & 1.35 & 31.4 \\
\hline 6 & $1,202.5$ & 1,155 & 1.15 & 20.4 \\
\hline 7 & $1,238.0$ & 1,155 & 0.95 & 35.8 \\
\hline
\end{tabular}

(Sheet 3 of 3) 


\section{Appendix C Velocity Data Tables}

Tables of the analyzed velocity and wave height and direction are included in this appendix (Tables C1-C14). These data also are included in the accompanying $\mathrm{CD}$, where the time series data also may be found. Additionally, the tables include an interpolated value of the wave height at the velocity gauge location, as velocity and wave height gauges are not usually collocated. 


\begin{tabular}{|c|c|c|c|c|c|c|}
\hline \multicolumn{7}{|c|}{$\begin{array}{l}\text { Table C1 } \\
\text { Velocities, Wave Direction, and Interpolated Wave Height, } \\
\text { Reflective Jetty, 0.75-m, 11-sec Wave, Ranges C17-C19, } \\
\text { C21, and C23-C26 }\end{array}$} \\
\hline Probe & $X(m)$ & $Y(m)$ & $\mathrm{U}(\mathrm{m} / \mathrm{sec})$ & $\mathrm{V}$ (m/sec) & Int. Ht (m) & Wave Dir (deg) \\
\hline \multicolumn{7}{|c|}{ Range C17 } \\
\hline 4 & $1,024.5$ & $1,218.0$ & 0.11 & 0.04 & 0.84 & 18.2 \\
\hline 2 & $1,024.5$ & $1,187.5$ & 0.18 & 0.3 & 0.81 & 4.4 \\
\hline 5 & $1,024.5$ & $1,157.0$ & -0.08 & 0.05 & 0.75 & 18.1 \\
\hline 1 & $1,024.5$ & 1,126.5 & 0.13 & -0.14 & 0.68 & 15.7 \\
\hline 3 & $1,024.5$ & $1,096.0$ & -0.04 & -0.02 & 0.68 & 13.8 \\
\hline 0 & $1,024.5$ & $1,065.5$ & 0.08 & 0.13 & 0.76 & 18.2 \\
\hline \multicolumn{7}{|c|}{ Range C18 } \\
\hline 4 & 1,055 & $1,218.0$ & 0.11 & 0.04 & 0.9 & 14.5 \\
\hline 2 & 1,055 & $1,187.5$ & 0.25 & 0.2 & 0.85 & 28.2 \\
\hline 5 & 1,055 & $1,157.0$ & -0.08 & 0.05 & 0.75 & 13.0 \\
\hline 1 & 1,055 & $1,126.5$ & -0.02 & -0.01 & 0.65 & 15.8 \\
\hline 3 & 1,055 & $1,096.0$ & -0.03 & -0.01 & 0.65 & 17.7 \\
\hline 0 & 1,055 & $1,065.5$ & -0.04 & 0.01 & 0.8 & 10.3 \\
\hline \multicolumn{7}{|c|}{ Range C19 } \\
\hline 4 & $1,085.5$ & 945 & -0.06 & 0.18 & 0.7 & 6.9 \\
\hline 2 & $1,116.0$ & 945 & -0.05 & 0.05 & 0.85 & 8.0 \\
\hline 5 & $1,146.5$ & 945 & -0.04 & 0.03 & 0.8 & 8.9 \\
\hline 1 & $1,177.0$ & 945 & -0.02 & 0.06 & 0.85 & 7.6 \\
\hline 3 & $1,207.5$ & 945 & -0.11 & 0.13 & 0.7 & 8.0 \\
\hline 0 & $1,238.0$ & 945 & -0.19 & 0.37 & 0.05 & 7.0 \\
\hline \multicolumn{7}{|c|}{ Range C21 } \\
\hline 4 & $1,085.5$ & 1,005 & -0.04 & 0.11 & 0.7 & 5.7 \\
\hline 2 & $1,116.0$ & 1,005 & -0.02 & 0.02 & 0.85 & 5.8 \\
\hline 5 & $1,146.5$ & 1,005 & -0.02 & 0.03 & 0.8 & 9.8 \\
\hline 1 & $1,177.0$ & 1,005 & 0.05 & 0.06 & 0.85 & 6.6 \\
\hline 3 & $1,207.5$ & 1,005 & -0.08 & 0.08 & 0.7 & 11.2 \\
\hline 0 & $1,238.0$ & 1,005 & -0.21 & 0.23 & 0.05 & 8.0 \\
\hline \multicolumn{7}{|c|}{ Range C23 } \\
\hline 4 & $1,085.5$ & $1,065.5$ & -0.06 & 0.18 & 0.7 & 5.4 \\
\hline 2 & $1,116.0$ & $1,065.5$ & -0.04 & 0 & 0.85 & 12.5 \\
\hline 5 & $1,146.5$ & $1,065.5$ & -0.04 & 0.03 & 0.8 & 13.5 \\
\hline 1 & $1,177.0$ & $1,065.5$ & 0.1 & 0.05 & 0.85 & 8.5 \\
\hline 3 & $1,207.5$ & $1,065.5$ & -0.12 & 0.05 & 0.7 & 3.5 \\
\hline 0 & $1,238.0$ & $1,065.5$ & -0.17 & 0.09 & 0.05 & 10.3 \\
\hline
\end{tabular}




\begin{tabular}{|c|c|c|c|c|c|c|}
\hline \multicolumn{7}{|c|}{ Table C1 (Concluded) } \\
\hline Probe & $X(m)$ & $Y(m)$ & $\mathrm{U}(\mathrm{m} / \mathrm{sec})$ & $\mathrm{V}(\mathrm{m} / \mathrm{sec})$ & Int. Ht (m) & Wave Dir (deg) \\
\hline \multicolumn{7}{|c|}{ Range C24 } \\
\hline 4 & $1,085.5$ & 1,096 & -0.04 & 0.07 & 0.8 & 8.5 \\
\hline 2 & $1,116.0$ & 1,096 & -0.02 & -0.01 & 0.85 & 14.2 \\
\hline 5 & $1,146.5$ & 1,096 & -0.08 & 0.05 & 0.7 & 2.8 \\
\hline 1 & $1,177.0$ & 1,096 & -0.34 & 0.18 & 0.9 & 7.5 \\
\hline 3 & $1,207.5$ & 1,096 & -0.64 & 0.14 & 0.75 & 11.8 \\
\hline 0 & $1,238.0$ & 1,096 & -0.94 & 0.05 & 0.05 & 6.1 \\
\hline \multicolumn{7}{|c|}{ Range C25 } \\
\hline 4 & $1,085.5$ & $1,126.5$ & -0.07 & 0.12 & 0.8 & 9.0 \\
\hline 2 & $1,116.0$ & $1,126.5$ & -0.08 & -0.03 & 0.85 & 13.2 \\
\hline 5 & $1,146.5$ & $1,126.5$ & -0.15 & 0.08 & 0.7 & 16.2 \\
\hline 1 & $1,177.0$ & $1,126.5$ & -0.32 & 0.22 & 0.9 & 9.9 \\
\hline 3 & $1,207.5$ & $1,126.5$ & -0.27 & 0.04 & 0.75 & 9.6 \\
\hline 0 & $1,238.0$ & $1,126.5$ & -0.3 & -0.24 & 0.05 & 0.3 \\
\hline \multicolumn{7}{|c|}{ Range C26 } \\
\hline 4 & $1,085.5$ & 1,157 & -0.22 & 0.03 & 1.05 & 358.2 \\
\hline 2 & $1,116.0$ & 1,157 & -0.22 & -0.05 & 1.1 & 5.1 \\
\hline 5 & $1,146.5$ & 1,157 & -0.14 & 0.04 & 1.15 & 1.0 \\
\hline 1 & $1,177.0$ & 1,157 & 0.16 & -0.02 & 1.15 & 359.9 \\
\hline 3 & $1,207.5$ & 1,157 & 0.19 & -0.04 & 0.7 & 357.7 \\
\hline 0 & $1,238.0$ & 1,157 & 0.01 & -0.07 & 0.05 & 1.1 \\
\hline
\end{tabular}




\begin{tabular}{|c|c|c|c|c|c|c|}
\hline \multicolumn{7}{|c|}{$\begin{array}{l}\text { Table C2 } \\
\text { Velocities, Wave Direction, and Interpolated Wave Height, } \\
\text { Reflective Jetty, 3.4-m, 8-sec Wave, Ranges C17-C19, C21, } \\
\text { and C23-C26 }\end{array}$} \\
\hline Probe & $x(m)$ & $Y(m)$ & $\mathrm{U}(\mathrm{m} / \mathrm{sec})$ & $\mathrm{V}(\mathrm{m} / \mathrm{sec})$ & Int. Ht (m) & Wave Dir (deg) \\
\hline \multicolumn{7}{|c|}{ Range C17 } \\
\hline 4 & $1,024.5$ & $1,218.0$ & -0.61 & 1.32 & 2.75 & 16.6 \\
\hline 2 & $1,024.5$ & $1,187.5$ & -0.55 & 0.8 & 2.73 & 14.2 \\
\hline 5 & $1,024.5$ & $1,157.0$ & -0.41 & 0.46 & 2.61 & 19.2 \\
\hline 1 & $1,024.5$ & $1,126.5$ & -0.25 & 0.0 & 2.55 & 24.4 \\
\hline 3 & $1,024.5$ & $1,096.0$ & -0.26 & 0.05 & 2.54 & 12.1 \\
\hline 0 & $1,024.5$ & $1,065.5$ & -0.13 & -0.15 & 2.52 & 20.3 \\
\hline \multicolumn{7}{|c|}{ Range C18 } \\
\hline 4 & 1,055 & $1,218.0$ & -0.27 & 0.02 & 2.5 & 10.7 \\
\hline 2 & 1,055 & $1,187.5$ & -1.02 & 0.64 & 2.5 & 24.9 \\
\hline 5 & 1,055 & $1,157.0$ & -0.89 & 0.73 & 2.3 & 19.1 \\
\hline 1 & 1,055 & $1,126.5$ & -0.52 & 0.43 & 2.25 & 21.5 \\
\hline 3 & 1,055 & $1,096.0$ & -0.46 & 0.29 & 2.25 & 17.7 \\
\hline 0 & 1,055 & $1,065.5$ & -0.44 & 0.13 & 2.2 & 12.6 \\
\hline \multicolumn{7}{|c|}{ Range C19 } \\
\hline 4 & $1,085.5$ & 945 & -0.22 & 0.14 & 1.8 & 0.2 \\
\hline 2 & $1,116.0$ & 945 & -0.18 & 0.43 & 1.15 & 7.8 \\
\hline 5 & $1,146.5$ & 945 & -0.12 & 0.71 & 1.1 & 2.8 \\
\hline 1 & $1,177.0$ & 945 & -0.18 & 0.73 & 1.1 & 3.3 \\
\hline 3 & $1,207.5$ & 945 & -0.35 & 0.73 & 0.85 & 19.7 \\
\hline 0 & $1,238.0$ & 945 & -0.21 & 0.55 & 0.25 & 4.8 \\
\hline \multicolumn{7}{|c|}{ Range C21 } \\
\hline 4 & $1,085.5$ & 1,005 & -0.66 & 0.64 & 1.8 & 18.6 \\
\hline 2 & $1,116.0$ & 1,005 & -0.86 & 0.65 & 1.15 & 18.6 \\
\hline 5 & $1,146.5$ & 1,005 & -0.76 & 0.86 & 1.1 & 2.5 \\
\hline 1 & $1,177.0$ & 1,005 & -0.51 & 0.72 & 1.1 & 25.8 \\
\hline 3 & $1,207.5$ & 1,005 & -0.4 & 0.77 & 0.85 & 27.2 \\
\hline 0 & $1,238.0$ & 1,005 & -0.16 & 0.3 & 0.25 & 19.7 \\
\hline \multicolumn{7}{|c|}{ Range C23 } \\
\hline 4 & $1,085.5$ & $1,065.5$ & -0.99 & 0.93 & 1.8 & 13.7 \\
\hline 2 & $1,116.0$ & $1,065.5$ & -1.26 & 0.65 & 1.15 & 21.8 \\
\hline 5 & $1,146.5$ & $1,065.5$ & -1.28 & 0.48 & 1.1 & 4.7 \\
\hline 1 & $1,177.0$ & $1,065.5$ & -1.25 & 0.12 & 1.1 & 27.7 \\
\hline 3 & $1,207.5$ & $1,065.5$ & -0.76 & 0.1 & 0.85 & 22.2 \\
\hline 0 & $1,238.0$ & $1,065.5$ & -0.16 & 0.17 & 0.25 & 25.5 \\
\hline
\end{tabular}




\begin{tabular}{|c|c|c|c|c|c|c|}
\hline \multicolumn{7}{|c|}{ Table C2 (Concluded) } \\
\hline Probe & $X(m)$ & $\mathrm{Y}(\mathrm{m})$ & $\mathrm{U}(\mathrm{m} / \mathrm{sec})$ & $\mathrm{V}(\mathrm{m} / \mathrm{sec})$ & Int. Ht (m) & Wave Dir (deg) \\
\hline \multicolumn{7}{|c|}{ Range C24 } \\
\hline 4 & $1,085.5$ & 1,096 & -1.13 & 0.93 & 2.15 & 6.5 \\
\hline 2 & $1,116.0$ & 1,096 & -1.2 & 0.57 & 1.4 & 22.4 \\
\hline 5 & $1,146.5$ & 1,096 & -1.0 & 0.62 & 1.1 & 8.3 \\
\hline 1 & $1,177.0$ & 1,096 & -0.86 & 0.21 & 1.05 & 350.5 \\
\hline 3 & $1,207.5$ & 1,096 & -0.71 & 0.02 & 0.9 & 354.2 \\
\hline 0 & $1,238.0$ & 1,096 & -0.07 & -0.4 & 0.35 & 4.8 \\
\hline \multicolumn{7}{|c|}{ Range C25 } \\
\hline 4 & $1,085.5$ & $1,126.5$ & -1.54 & 0.72 & 2.15 & 10.5 \\
\hline 2 & $1,116.0$ & $1,126.5$ & -1.12 & 0.36 & 1.4 & 16.8 \\
\hline 5 & $1,146.5$ & $1,126.5$ & -0.65 & 0.34 & 1.1 & 12.3 \\
\hline 1 & $1,177.0$ & $1,126.5$ & -0.23 & 0.17 & 1.05 & 1.1 \\
\hline 3 & $1,207.5$ & $1,126.5$ & -0.04 & -0.32 & 0.9 & 355.4 \\
\hline 0 & $1,238.0$ & $1,126.5$ & -0.08 & -0.69 & 0.35 & 0.5 \\
\hline \multicolumn{7}{|c|}{ Range C26 } \\
\hline 4 & $1,085.5$ & 1,157 & -1.24 & 0.2 & 1.9 & 352.5 \\
\hline 2 & $1,116.0$ & 1,157 & -0.37 & -0.28 & 1.55 & 4.9 \\
\hline 5 & $1,146.5$ & 1,157 & 0.14 & -0.14 & 1.25 & 2.6 \\
\hline 1 & $1,177.0$ & 1,157 & 0.57 & -0.03 & 1.15 & 355.7 \\
\hline 3 & $1,207.5$ & 1,157 & 0.53 & -0.07 & 0.7 & 1.3 \\
\hline 0 & $1,238.0$ & 1,157 & 0.2 & -0.24 & 0.35 & 3.0 \\
\hline
\end{tabular}




\begin{tabular}{|c|c|c|c|c|c|c|}
\hline \multicolumn{7}{|c|}{$\begin{array}{l}\text { Table C3 } \\
\text { Velocities, Wave Direction, and Interpolated Wave Height, } \\
\text { Reflective Jetty, } 2.0-\mathrm{m}, 11-\text { sec Wave, Ranges C17-C19, } \\
\text { C21, and C23-C26 }\end{array}$} \\
\hline Probe & $x(m)$ & $Y(m)$ & $\mathrm{U}(\mathrm{m} / \mathrm{sec})$ & $\mathrm{V}$ (m/sec) & Int. Ht (m) & Wave Dir (deg) \\
\hline \multicolumn{7}{|c|}{ Range C17 } \\
\hline 4 & $1,024.5$ & $1,218.0$ & -0.3 & 0.05 & 2.48 & 5.3 \\
\hline 2 & $1,024.5$ & $1,187.5$ & -0.49 & 0.24 & 2.47 & 25.1 \\
\hline 5 & $1,024.5$ & $1,157.0$ & -0.11 & 0.05 & 2.09 & 17.4 \\
\hline 1 & $1,024.5$ & $1,126.5$ & -0.07 & 0.0 & 1.84 & 17.1 \\
\hline 3 & $1,024.5$ & $1,096.0$ & -0.01 & -0.04 & 2.15 & 21.3 \\
\hline 0 & $1,024.5$ & $1,065.5$ & -0.04 & 0.08 & 2.13 & 20.1 \\
\hline \multicolumn{7}{|c|}{ Range C18 } \\
\hline 4 & 1,055 & $1,218.0$ & -0.1 & -0.17 & 2.7 & 7.7 \\
\hline 2 & 1,055 & $1,187.5$ & -0.79 & 0.17 & 2.7 & 26.1 \\
\hline 5 & 1,055 & $1,157.0$ & -0.22 & 0.11 & 2.15 & 20.7 \\
\hline 1 & 1,055 & $1,126.5$ & -0.14 & 0.02 & 1.8 & 15.9 \\
\hline 3 & 1,055 & $1,096.0$ & -0.1 & -0.07 & 2.25 & 24.7 \\
\hline 0 & 1,055 & $1,065.5$ & -0.02 & 0.07 & 2.2 & 20.1 \\
\hline \multicolumn{7}{|c|}{ Range C19 } \\
\hline 4 & $1,085.5$ & 945 & -0.08 & 0.06 & 1.8 & 1.0 \\
\hline 2 & $1,116.0$ & 945 & -0.08 & 0.02 & 2.0 & 12.8 \\
\hline 5 & $1,146.5$ & 945 & -0.13 & -0.04 & 1.5 & 17.3 \\
\hline 1 & $1,177.0$ & 945 & -0.54 & 0.59 & 1.15 & 3.0 \\
\hline 3 & $1,207.5$ & 945 & -0.61 & 1.05 & 0.8 & 8.6 \\
\hline 0 & $1,238.0$ & 945 & -0.48 & 1.19 & 0.2 & 20.7 \\
\hline \multicolumn{7}{|c|}{ Range C21 } \\
\hline 4 & $1,085.5$ & 1,005 & -0.09 & 0.07 & 1.8 & 1.6 \\
\hline 2 & $1,116.0$ & 1,005 & -0.16 & -0.01 & 2.0 & 9.4 \\
\hline 5 & $1,146.5$ & 1,005 & -0.36 & 0.33 & 1.5 & 6.3 \\
\hline 1 & $1,177.0$ & 1,005 & -0.74 & 0.7 & 1.15 & 355.4 \\
\hline 3 & $1,207.5$ & 1,005 & -0.73 & 0.87 & 0.8 & 20.3 \\
\hline 0 & $1,238.0$ & 1,005 & -0.43 & 0.82 & 0.2 & 37.7 \\
\hline \multicolumn{7}{|c|}{ Range C23 } \\
\hline 4 & $1,085.5$ & $1,065.5$ & -0.16 & 0.13 & 1.8 & 4.8 \\
\hline 2 & $1,116.0$ & $1,065.5$ & -0.21 & 0.11 & 2.0 & 14.7 \\
\hline 5 & $1,146.5$ & $1,065.5$ & -0.76 & 0.65 & 1.5 & 12.7 \\
\hline 1 & $1,177.0$ & $1,065.5$ & -1.46 & 0.75 & 1.15 & 22.0 \\
\hline 3 & $1,207.5$ & $1,065.5$ & -1.48 & 0.15 & 0.8 & 20.8 \\
\hline 0 & $1,238.0$ & $1,065.5$ & -0.27 & 0.01 & 0.2 & 358.2 \\
\hline & & & & & & (Continue \\
\hline
\end{tabular}




\begin{tabular}{|c|c|c|c|c|c|c|}
\hline \multicolumn{7}{|c|}{ Table C3 (Concluded) } \\
\hline Probe & $X(m)$ & $Y(m)$ & $\mathrm{U}(\mathrm{m} / \mathrm{sec})$ & $\mathrm{V}$ (m/sec) & Int. Ht (m) & Wave Dir (deg) \\
\hline \multicolumn{7}{|c|}{ Range C24 } \\
\hline 4 & $1,085.5$ & 1,096 & -0.25 & 0.2 & 2.4 & 11.4 \\
\hline 2 & $1,116.0$ & 1,096 & -0.47 & 0.28 & 2.35 & 7.1 \\
\hline 5 & $1,146.5$ & 1,096 & -1.06 & 0.92 & 1.75 & 357.4 \\
\hline 1 & $1,177.0$ & 1,096 & -0.98 & 0.74 & 1.65 & 1.7 \\
\hline 3 & $1,207.5$ & 1,096 & -0.73 & -0.07 & 1.35 & 6.0 \\
\hline 0 & $1,238.0$ & 1,096 & -0.59 & -0.61 & 0.25 & 36.6 \\
\hline \multicolumn{7}{|c|}{ Range C25 } \\
\hline 4 & $1,085.5$ & $1,126.5$ & -0.68 & 0.28 & 2.4 & 20.6 \\
\hline 2 & $1,116.0$ & $1,126.5$ & -1.02 & 0.39 & 2.35 & 22.1 \\
\hline 5 & $1,146.5$ & $1,126.5$ & -0.8 & 0.6 & 1.75 & 23.3 \\
\hline 1 & $1,177.0$ & $1,126.5$ & -0.52 & 0.62 & 1.65 & 21.2 \\
\hline 3 & $1,207.5$ & $1,126.5$ & -0.67 & -0.33 & 1.35 & 17.0 \\
\hline 0 & $1,238.0$ & $1,126.5$ & -0.16 & -0.84 & 0.25 & 347.5 \\
\hline \multicolumn{7}{|c|}{ Range C26 } \\
\hline 4 & $1,085.5$ & 1,157 & -1.14 & 0.19 & 3.5 & 0.4 \\
\hline 2 & $1,116.0$ & 1,157 & -0.97 & -0.1 & 2.75 & 6.6 \\
\hline 5 & $1,146.5$ & 1,157 & -0.58 & -0.02 & 1.9 & 358.7 \\
\hline 1 & $1,177.0$ & 1,157 & 0.52 & 0.13 & 1.55 & 351.6 \\
\hline 3 & $1,207.5$ & 1,157 & 0.9 & -0.42 & 1.05 & 345.9 \\
\hline 0 & $1,238.0$ & 1,157 & -0.13 & -0.2 & 0.2 & 357.4 \\
\hline
\end{tabular}




\begin{tabular}{|c|c|c|c|c|c|c|}
\hline \multicolumn{7}{|c|}{$\begin{array}{l}\text { Table C4 } \\
\text { Velocities, Wave Direction, and Interpolated Wave Height, } \\
\text { Reflective Jetty, 1.0-m, 11-sec Wave, Ranges C17-C19, } \\
\text { C21, and C23-C26 }\end{array}$} \\
\hline Probe & $X(m)$ & $Y(m)$ & $\mathrm{U}(\mathrm{m} / \mathrm{sec})$ & $\mathrm{V}(\mathrm{m} / \mathrm{sec})$ & Int. Ht (m) & Wave Dir (deg) \\
\hline \multicolumn{7}{|c|}{ Range C17 } \\
\hline 4 & $1,024.5$ & $1,218.0$ & -0.07 & -0.02 & 1.23 & 3.2 \\
\hline 2 & $1,024.5$ & $1,187.5$ & -0.21 & 0.05 & 1.18 & 15.3 \\
\hline 5 & $1,024.5$ & $1,157.0$ & -0.08 & 0.01 & 1.04 & 17.2 \\
\hline 1 & $1,024.5$ & $1,126.5$ & -0.07 & -0.02 & 0.96 & 13.3 \\
\hline 3 & $1,024.5$ & $1,096.0$ & -0.07 & 0.0 & 0.99 & 13.9 \\
\hline 0 & $1,024.5$ & $1,065.5$ & -0.06 & 0.0 & 1.06 & 21.8 \\
\hline \multicolumn{7}{|c|}{ Range C18 } \\
\hline 4 & 1,055 & $1,218.0$ & -0.03 & 0.0 & 1.35 & 7.5 \\
\hline 2 & 1,055 & $1,187.5$ & -0.22 & 0.04 & 1.25 & 15.8 \\
\hline 5 & 1,055 & $1,157.0$ & -0.09 & 0.01 & 1.05 & 17.7 \\
\hline 1 & 1,055 & $1,126.5$ & 0.07 & -0.15 & 0.95 & 9.3 \\
\hline 3 & 1,055 & $1,096.0$ & -0.05 & -0.02 & 1.0 & 17.1 \\
\hline 0 & 1,055 & $1,065.5$ & 0.11 & 0.17 & 1.1 & 17.8 \\
\hline \multicolumn{7}{|c|}{ Range C19 } \\
\hline 4 & $1,085.5$ & 945 & -0.09 & 0.11 & 0.95 & 3.3 \\
\hline 2 & $1,116.0$ & 945 & -0.06 & 0.01 & 1.2 & 14.2 \\
\hline 5 & $1,146.5$ & 945 & -0.06 & 0.01 & 1.3 & 10.9 \\
\hline 1 & $1,177.0$ & 945 & -0.13 & 0.03 & 1.3 & 13.2 \\
\hline 3 & $1,207.5$ & 945 & -0.17 & 0.2 & 0.7 & 11.7 \\
\hline 0 & $1,238.0$ & 945 & -0.26 & 0.61 & 0.1 & 17.2 \\
\hline \multicolumn{7}{|c|}{ Range C21 } \\
\hline 4 & $1,085.5$ & 1,005 & -0.07 & 0.1 & 0.95 & 1.8 \\
\hline 2 & $1,116.0$ & 1,005 & -0.01 & 0.02 & 1.2 & 15.0 \\
\hline 5 & $1,146.5$ & 1,005 & -0.06 & 0.04 & 1.3 & 7.6 \\
\hline 1 & $1,177.0$ & 1,005 & -0.04 & 0.03 & 1.3 & 13.5 \\
\hline 3 & $1,207.5$ & 1,005 & -0.17 & 0.12 & 0.7 & 10.3 \\
\hline 0 & $1,238.0$ & 1,005 & -0.38 & 0.85 & 0.1 & 18.4 \\
\hline \multicolumn{7}{|c|}{ Range C23 } \\
\hline 4 & 1085.5 & 1065.5 & -0.06 & 0.09 & 0.95 & 3.6 \\
\hline 2 & 1116.0 & 1065.5 & -0.06 & 0.01 & 1.2 & 12.9 \\
\hline 5 & 1146.5 & 1065.5 & -0.08 & 0.04 & 1.3 & 5.9 \\
\hline 1 & 1177.0 & 1065.5 & -0.17 & 0.06 & 1.3 & 10.8 \\
\hline 3 & 1207.5 & 1065.5 & -0.52 & 0.33 & 0.7 & 9.6 \\
\hline 0 & 1238.0 & 1065.5 & -0.81 & 0.08 & 0.1 & 15.7 \\
\hline & & & & & & (Continued \\
\hline
\end{tabular}




\begin{tabular}{|c|c|c|c|c|c|c|}
\hline \multicolumn{7}{|c|}{ Table C4 (Concluded) } \\
\hline Probe & $X(m)$ & $\mathrm{Y}(\mathrm{m})$ & $\mathrm{U}(\mathrm{m} / \mathrm{sec})$ & $\mathrm{V}$ (m/sec) & Int. Ht (m) & Wave Dir (deg) \\
\hline \multicolumn{7}{|c|}{ Range C24 } \\
\hline 4 & $1,085.5$ & 1,096 & -0.04 & 0.12 & 1.15 & 14.3 \\
\hline 2 & $1,116.0$ & 1,096 & -0.04 & -0.01 & 1.2 & 16.3 \\
\hline 5 & $1,146.5$ & 1,096 & -0.16 & 0.19 & 1.2 & 11.7 \\
\hline 1 & $1,177.0$ & 1,096 & -0.55 & 0.42 & 1.65 & 7.8 \\
\hline 3 & $1,207.5$ & 1,096 & -1.03 & 0.35 & 1.0 & 27.8 \\
\hline 0 & $1,238.0$ & 1,096 & -0.6 & -0.17 & 0.15 & 11.1 \\
\hline \multicolumn{7}{|c|}{ Range C25 } \\
\hline 4 & $1,085.5$ & $1,126.5$ & -0.12 & 0.14 & 1.15 & 5.8 \\
\hline 2 & $1,116.0$ & $1,126.5$ & -0.3 & 0.18 & 1.2 & 21.6 \\
\hline 5 & $1,146.5$ & $1,126.5$ & -0.37 & 0.46 & 1.2 & 16.0 \\
\hline 1 & $1,177.0$ & $1,126.5$ & -0.2 & 0.08 & 1.65 & 10.9 \\
\hline 3 & $1,207.5$ & $1,126.5$ & -0.17 & -0.08 & 1.0 & 2.6 \\
\hline 0 & $1,238.0$ & $1,126.5$ & -0.05 & -0.61 & 0.15 & 0.1 \\
\hline \multicolumn{7}{|c|}{ Range C26 } \\
\hline 4 & $1,085.5$ & 1,157 & -0.57 & 0.17 & 1.6 & 351.9 \\
\hline 2 & $1,116.0$ & 1,157 & -0.53 & -0.14 & 1.85 & 4.7 \\
\hline 5 & $1,146.5$ & 1,157 & -0.4 & 0.01 & 1.65 & 0.3 \\
\hline 1 & $1,177.0$ & 1,157 & 0.33 & 0.05 & 1.25 & 354.7 \\
\hline 3 & $1,207.5$ & 1,157 & 0.61 & -0.2 & 0.85 & 356.0 \\
\hline 0 & $1,238.0$ & 1,157 & -0.13 & -0.41 & 0.1 & 353.3 \\
\hline
\end{tabular}




\begin{tabular}{|c|c|c|c|c|c|c|}
\hline \multicolumn{7}{|c|}{$\begin{array}{l}\text { Table C5 } \\
\text { Velocities, Wave Direction, and Interpolated Wave Height, } \\
\text { Absorbing Jetty, 1.65-m, 11-sec Wave, Ranges C17-C19, } \\
\text { C21, and C23-C26 }\end{array}$} \\
\hline Probe & $X(m)$ & $Y(m)$ & $\mathrm{U}(\mathrm{m} / \mathrm{sec})$ & $\mathrm{V}(\mathrm{m} / \mathrm{sec})$ & Int. Ht (m) & Wave Dir (deg) \\
\hline \multicolumn{7}{|c|}{ Range C17 } \\
\hline 4 & $1,024.5$ & $1,218.0$ & -0.09 & -0.01 & 1.76 & 350.0 \\
\hline 2 & $1,024.5$ & $1,187.5$ & -0.27 & -0.01 & 1.74 & 11.4 \\
\hline 5 & $1,024.5$ & $1,157.0$ & -0.24 & 0.15 & 2.0 & 17.1 \\
\hline 1 & $1,024.5$ & $1,126.5$ & -0.09 & 0.05 & 1.83 & 13.0 \\
\hline 3 & $1,024.5$ & $1,096.0$ & -0.04 & 0.05 & 1.88 & 8.4 \\
\hline 0 & $1,024.5$ & $1,065.5$ & -0.01 & 0.07 & 1.27 & 4.3 \\
\hline \multicolumn{7}{|c|}{ Range C18 } \\
\hline 4 & 1,055 & $1,218.0$ & -0.04 & -0.03 & 1.8 & 17.0 \\
\hline 2 & 1,055 & $1,187.5$ & -0.02 & -0.05 & 1.8 & 4.4 \\
\hline 5 & 1,055 & $1,157.0$ & -0.44 & 0.16 & 2.15 & 8.4 \\
\hline 1 & 1,055 & $1,126.5$ & -0.11 & 0.05 & 1.9 & 17.2 \\
\hline 3 & 1,055 & $1,096.0$ & -0.04 & 0.03 & 1.95 & 0.0 \\
\hline 0 & 1,055 & $1,065.5$ & -0.02 & 0.05 & 1.2 & 6.9 \\
\hline \multicolumn{7}{|c|}{ Range C19 } \\
\hline 4 & $1,085.5$ & 945 & -0.04 & 0.07 & 1.7 & 12.2 \\
\hline 2 & $1,116.0$ & 945 & -0.38 & -0.17 & 1.65 & 9.0 \\
\hline 5 & $1,146.5$ & 945 & -0.1 & 0.13 & 1.5 & 1.7 \\
\hline 1 & $1,177.0$ & 945 & -0.17 & 0.19 & 1.45 & 12.8 \\
\hline 3 & $1,207.5$ & 945 & -0.21 & 0.75 & 1.1 & 12.2 \\
\hline 0 & $1,238.0$ & 945 & -0.08 & 0.78 & 0.75 & 352.4 \\
\hline \multicolumn{7}{|c|}{ Range C21 } \\
\hline 4 & $1,085.5$ & 1,005 & -0.02 & 0.03 & 1.7 & 3.7 \\
\hline 2 & $1,116.0$ & 1,005 & -0.1 & 0.06 & 1.65 & 14.1 \\
\hline 5 & $1,146.5$ & 1,005 & -0.18 & 0.05 & 1.5 & 8.9 \\
\hline 1 & $1,177.0$ & 1,005 & -0.14 & 0.08 & 1.45 & 10.0 \\
\hline 3 & $1,207.5$ & 1,005 & -0.3 & 0.77 & 1.1 & 16.1 \\
\hline 0 & $1,238.0$ & 1,005 & -0.17 & 0.97 & 0.75 & 4.5 \\
\hline \multicolumn{7}{|c|}{ Range C23 } \\
\hline 4 & $1,085.5$ & $1,065.5$ & -0.14 & -0.01 & 1.7 & 15.7 \\
\hline 2 & $1,116.0$ & $1,065.5$ & -0.15 & 0.07 & 1.65 & 12.8 \\
\hline 5 & $1,146.5$ & $1,065.5$ & -0.19 & 0.06 & 1.5 & 4.3 \\
\hline 1 & $1,177.0$ & $1,065.5$ & -0.2 & 0.17 & 1.45 & 5.2 \\
\hline 3 & $1,207.5$ & $1,065.5$ & -0.2 & 0.82 & 1.1 & 4.8 \\
\hline 0 & $1,238.0$ & $1,065.5$ & -0.13 & 0.87 & 0.75 & 356.1 \\
\hline & & & & & & (Continued \\
\hline
\end{tabular}




\begin{tabular}{|c|c|c|c|c|c|c|}
\hline \multicolumn{7}{|c|}{ Table C5 (Concluded) } \\
\hline Probe & $X(m)$ & $\mathrm{Y}(\mathrm{m})$ & $\mathrm{U}(\mathrm{m} / \mathrm{sec})$ & $\mathrm{V}$ (m/sec) & Int. Ht (m) & Wave Dir (deg) \\
\hline \multicolumn{7}{|c|}{ Range C24 } \\
\hline 4 & $1,085.5$ & 1,096 & -0.12 & 0.02 & 1.65 & 4.6 \\
\hline 2 & $1,116.0$ & 1,096 & -0.18 & 0.07 & 1.85 & 12.7 \\
\hline 5 & $1,146.5$ & 1,096 & -0.23 & 0.06 & 1.7 & 9.9 \\
\hline 1 & $1,177.0$ & 1,096 & -0.17 & 0.25 & 1.7 & 12.0 \\
\hline 3 & $1,207.5$ & 1,096 & -0.08 & 0.75 & 1.2 & 5.0 \\
\hline 0 & $1,238.0$ & 1,096 & -0.02 & 0.9 & 0.75 & 359.5 \\
\hline \multicolumn{7}{|c|}{ Range C25 } \\
\hline 4 & $1,085.5$ & $1,126.5$ & -0.16 & 0.02 & 1.65 & 12.8 \\
\hline 2 & $1,116.0$ & $1,126.5$ & -0.18 & 0.01 & 1.85 & 28.5 \\
\hline 5 & $1,146.5$ & $1,126.5$ & -0.29 & 0.07 & 1.7 & 22.4 \\
\hline 1 & $1,177.0$ & $1,126.5$ & -0.48 & 0.18 & 1.7 & 36.3 \\
\hline 3 & $1,207.5$ & $1,126.5$ & -0.52 & 0.72 & 1.2 & 14.8 \\
\hline 0 & $1,238.0$ & $1,126.5$ & -0.26 & 0.78 & 0.75 & 358.6 \\
\hline \multicolumn{7}{|c|}{ Range C26 } \\
\hline 4 & $1,085.5$ & 1,157 & -0.71 & 0.07 & 2.25 & 4.5 \\
\hline 2 & $1,116.0$ & 1,157 & -0.75 & -0.12 & 1.55 & 20.4 \\
\hline 5 & $1,146.5$ & 1,157 & -0.84 & 0.08 & 1.2 & 15.8 \\
\hline 1 & $1,177.0$ & 1,157 & -0.89 & -0.05 & 1.45 & 20.7 \\
\hline 3 & $1,207.5$ & 1,157 & -0.64 & 0.43 & 0.95 & 10.1 \\
\hline 0 & $1,238.0$ & 1,157 & -0.33 & 0.0 & 0.6 & 13.8 \\
\hline
\end{tabular}




\begin{tabular}{|c|c|c|c|c|c|c|}
\hline \multicolumn{7}{|c|}{$\begin{array}{l}\text { Table C6 } \\
\text { Velocities, Wave Direction, and Interpolated Wave Height, } \\
\text { Absorbing Jetty, 3.25-m, 8-sec Wave, Ranges C17-C19, } \\
\text { C21, and C23-C26 }\end{array}$} \\
\hline Probe & $x(m)$ & $Y(m)$ & $\mathrm{U}(\mathrm{m} / \mathrm{sec})$ & $\mathrm{V}$ (m/sec) & Int. Ht (m) & Wave Dir (deg) \\
\hline \multicolumn{7}{|c|}{ Range C17 } \\
\hline 4 & $1,024.5$ & $1,218.0$ & -0.44 & 1.16 & 3.04 & 9.9 \\
\hline 2 & $1,024.5$ & $1,187.5$ & -1.09 & 1.04 & 3.37 & 18.3 \\
\hline 5 & $1,024.5$ & $1,157.0$ & -1.02 & 1.16 & 3.08 & 5.6 \\
\hline 1 & $1,024.5$ & $1,126.5$ & -0.52 & 0.34 & 2.85 & 21.0 \\
\hline 3 & $1,024.5$ & $1,096.0$ & -0.33 & 0.36 & 2.92 & 14.9 \\
\hline 0 & $1,024.5$ & $1,065.5$ & -0.12 & 0.14 & 2.67 & 4.7 \\
\hline \multicolumn{7}{|c|}{ Range C18 } \\
\hline 4 & 1,055 & $1,218.0$ & -0.31 & 0.17 & 2.95 & 10.8 \\
\hline 2 & 1,055 & $1,187.5$ & -0.47 & 0.33 & 3.4 & 5.7 \\
\hline 5 & 1,055 & $1,157.0$ & -1.98 & 1.05 & 3.05 & 15.3 \\
\hline 1 & 1,055 & $1,126.5$ & -0.95 & 0.52 & 2.7 & 10.8 \\
\hline 3 & 1,055 & $1,096.0$ & -0.91 & 0.5 & 2.8 & 11.1 \\
\hline 0 & 1,055 & $1,065.5$ & -0.59 & 0.36 & 2.45 & 4.9 \\
\hline \multicolumn{7}{|c|}{ Range C19 } \\
\hline 4 & $1,085.5$ & 945 & -0.09 & 0.13 & 2.2 & 7.5 \\
\hline 2 & $1,116.0$ & 945 & -0.18 & 0.67 & 1.65 & 14.6 \\
\hline 5 & $1,146.5$ & 945 & -0.09 & 0.94 & 1.4 & 9.7 \\
\hline 1 & $1,177.0$ & 945 & -0.32 & 0.79 & 1.05 & 9.8 \\
\hline 3 & $1,207.5$ & 945 & -0.25 & 0.86 & 0.95 & 12.9 \\
\hline 0 & $1,238.0$ & 945 & 0.06 & 0.59 & 0.55 & 11.5 \\
\hline \multicolumn{7}{|c|}{ Range C21 } \\
\hline 4 & $1,085.5$ & 1,005 & -0.48 & 0.7 & 2.2 & 29.5 \\
\hline 2 & $1,116.0$ & 1,005 & -0.73 & 0.77 & 1.65 & 22.9 \\
\hline 5 & $1,146.5$ & 1,005 & -0.45 & 0.88 & 1.4 & 20.2 \\
\hline 1 & $1,177.0$ & 1,005 & -0.36 & 0.86 & 1.05 & 16.9 \\
\hline 3 & $1,207.5$ & 1,005 & -0.25 & 0.92 & 0.95 & 17.3 \\
\hline 0 & $1,238.0$ & 1,005 & -0.08 & 0.65 & 0.55 & 14.8 \\
\hline \multicolumn{7}{|c|}{ Range C23 } \\
\hline 4 & $1,085.5$ & $1,065.5$ & -0.48 & 0.65 & 2.2 & 20.1 \\
\hline 2 & $1,116.0$ & $1,065.5$ & -0.56 & 0.75 & 1.65 & 24.3 \\
\hline 5 & $1,146.5$ & $1,065.5$ & -0.4 & 0.56 & 1.4 & 11.2 \\
\hline 1 & $1,177.0$ & $1,065.5$ & -0.48 & 0.55 & 1.05 & 15.0 \\
\hline 3 & $1,207.5$ & $1,065.5$ & -0.31 & 0.62 & 0.95 & 4.3 \\
\hline 0 & $1,238.0$ & $1,065.5$ & -0.06 & 0.48 & 0.55 & 2.9 \\
\hline & & & & & & (Continued \\
\hline
\end{tabular}




\begin{tabular}{|c|c|c|c|c|c|c|}
\hline \multicolumn{7}{|c|}{ Table C6 (Concluded) } \\
\hline Probe & $X(m)$ & $Y(m)$ & $U(\mathrm{~m} / \mathrm{sec})$ & $\mathrm{V}$ (m/sec) & Int. Ht (m) & Wave Dir (deg) \\
\hline \multicolumn{7}{|c|}{ Range C24 } \\
\hline 4 & $1,085.5$ & 1,096 & -0.48 & 0.65 & 1.9 & 20.6 \\
\hline 2 & $1,116.0$ & 1,096 & -0.49 & 0.77 & 1.75 & 24.8 \\
\hline 5 & $1,146.5$ & 1,096 & -0.52 & 0.73 & 1.2 & 13.3 \\
\hline 1 & $1,177.0$ & 1,096 & -0.48 & 0.54 & 1.05 & 15.2 \\
\hline 3 & $1,207.5$ & 1,096 & -0.19 & 0.51 & 0.95 & 6.6 \\
\hline 0 & $1,238.0$ & 1,096 & -0.06 & 0.49 & 0.55 & 2.6 \\
\hline \multicolumn{7}{|c|}{ Range C25 } \\
\hline 4 & $1,085.5$ & $1,126.5$ & -1.12 & 0.64 & 1.9 & 17.0 \\
\hline 2 & $1,116.0$ & $1,126.5$ & -0.93 & 0.35 & 1.75 & 11.2 \\
\hline 5 & $1,146.5$ & $1,126.5$ & -0.55 & 0.54 & 1.2 & 14.4 \\
\hline 1 & $1,177.0$ & $1,126.5$ & -0.46 & 0.25 & 1.05 & 30.6 \\
\hline 3 & $1,207.5$ & $1,126.5$ & -0.21 & 0.28 & 0.95 & 21.5 \\
\hline 0 & $1,238.0$ & $1,126.5$ & -0.16 & 0.37 & 0.55 & 9.7 \\
\hline \multicolumn{7}{|c|}{ Range C26 } \\
\hline 4 & $1,085.5$ & 1,157 & -1.62 & 0.49 & 1.9 & 8.5 \\
\hline 2 & $1,116.0$ & 1,157 & -1.11 & -0.2 & 1.45 & 19.9 \\
\hline 5 & $1,146.5$ & 1,157 & -0.76 & 0.13 & 1.25 & 4.8 \\
\hline 1 & $1,177.0$ & 1,157 & -0.54 & 0.05 & 1.25 & 17.9 \\
\hline 3 & $1,207.5$ & 1,157 & -0.42 & 0.12 & 1.2 & 4.1 \\
\hline 0 & $1,238.0$ & 1,157 & -0.35 & 0.02 & 0.8 & 5.9 \\
\hline
\end{tabular}




\begin{tabular}{|c|c|c|c|c|c|c|}
\hline \multicolumn{7}{|c|}{$\begin{array}{l}\text { Table C7 } \\
\text { Velocities, Wave Direction, and Interpolated Wave Height, } \\
\text { Absorbing Jetty, 1.0-m, 11-sec Wave, Ranges C17-C19, } \\
\text { and C21-C26 }\end{array}$} \\
\hline Probe & $X(m)$ & $Y(m)$ & $\mathrm{U}(\mathrm{m} / \mathrm{sec})$ & $\mathrm{V}(\mathrm{m} / \mathrm{sec})$ & Int. Ht (m) & Wave Dir (deg) \\
\hline \multicolumn{7}{|c|}{ Range C17 } \\
\hline 4 & $1,024.5$ & $1,218.0$ & -0.04 & 0.0 & 0.86 & 15.4 \\
\hline 2 & $1,024.5$ & $1,187.5$ & 0.22 & 0.22 & 1.01 & 17.6 \\
\hline 5 & $1,024.5$ & $1,157.0$ & -0.2 & 0.03 & 1.25 & 4.7 \\
\hline 1 & $1,024.5$ & $1,126.5$ & -0.03 & 0.01 & 1.35 & 22.3 \\
\hline 3 & $1,024.5$ & $1,096.0$ & -0.09 & 0.01 & 1.2 & 19.7 \\
\hline 0 & $1,024.5$ & $1,065.5$ & 0.09 & 0.13 & 1.01 & 15.7 \\
\hline \multicolumn{7}{|c|}{ Range C18 } \\
\hline 4 & 1,055 & $1,218.0$ & -0.05 & 0.0 & 0.85 & 355.2 \\
\hline 2 & 1,055 & $1,187.5$ & 0.16 & 0.17 & 1.05 & 13.1 \\
\hline 5 & 1,055 & $1,157.0$ & -0.17 & 0.01 & 1.4 & 15.8 \\
\hline 1 & 1,055 & $1,126.5$ & -0.15 & 0.08 & 1.55 & 12.8 \\
\hline 3 & 1,055 & $1,096.0$ & -0.06 & 0.11 & 1.3 & 21.6 \\
\hline 0 & $1,055.0$ & $1,065.5$ & 0.03 & 0.08 & 1.05 & 21.1 \\
\hline \multicolumn{7}{|c|}{ Range C19 } \\
\hline 4 & $1,085.5$ & 945.0 & -0.02 & 0.05 & 0.9 & 2.6 \\
\hline 2 & $1,116.0$ & 945.0 & -0.16 & 0.25 & 1.0 & 20.0 \\
\hline 5 & $1,146.5$ & 945.0 & -0.07 & 0.04 & 1.1 & 10.7 \\
\hline 1 & $1,177.0$ & 945.0 & 0.11 & -0.14 & 1.3 & 21.8 \\
\hline 3 & $1,207.5$ & 945.0 & -0.1 & 0.09 & 1.25 & 16.7 \\
\hline 0 & $1,238.0$ & 945.0 & -0.29 & 0.77 & 0.7 & 17.1 \\
\hline \multicolumn{7}{|c|}{ Range C21 } \\
\hline 4 & $1,085.5$ & 1,005 & -0.04 & 0.05 & 0.9 & 358.0 \\
\hline 2 & $1,116.0$ & 1,005 & -0.11 & 0.1 & 1.0 & 18.7 \\
\hline 5 & $1,146.5$ & 1,005 & -0.06 & 0.04 & 1.1 & 11.5 \\
\hline 1 & $1,177.0$ & 1,005 & -0.08 & 0.07 & 1.3 & 11.8 \\
\hline 3 & $1,207.5$ & 1,005 & -0.17 & 0.13 & 1.25 & 5.9 \\
\hline 0 & $1,238.0$ & 1,005 & -0.28 & 0.88 & 0.7 & 15.8 \\
\hline \multicolumn{7}{|c|}{ Range C22 } \\
\hline 4 & $1,085.5$ & 1,035 & -0.02 & 0.04 & 0.9 & 0.2 \\
\hline 2 & $1,116.0$ & 1,035 & -0.13 & 0.13 & 1.0 & 14.8 \\
\hline 5 & $1,146.5$ & 1,035 & -0.07 & 0.04 & 1.1 & 14.4 \\
\hline 1 & $1,177.0$ & 1,035 & 0.07 & 0.05 & 1.3 & 12.2 \\
\hline 3 & $1,207.5$ & 1,035 & -0.17 & 0.14 & 1.25 & 8.9 \\
\hline 0 & $1,238.0$ & 1,035 & -0.23 & 0.81 & 0.7 & 357.5 \\
\hline
\end{tabular}




\begin{tabular}{|c|c|c|c|c|c|c|}
\hline \multicolumn{7}{|c|}{ Table C7 (Concluded) } \\
\hline Probe & $X(m)$ & $\mathrm{Y}(\mathrm{m})$ & $\mathrm{U}(\mathrm{m} / \mathrm{sec})$ & $\mathrm{V}$ (m/sec) & Int. Ht (m) & Wave Dir (deg) \\
\hline \multicolumn{7}{|c|}{ Range C23 } \\
\hline 4 & $1,085.5$ & $1,065.5$ & -0.04 & 0.03 & 0.9 & 1.3 \\
\hline 2 & $1,116.0$ & $1,065.5$ & -0.19 & 0.15 & 1.0 & 9.3 \\
\hline 5 & $1,146.5$ & $1,065.5$ & -0.07 & 0.03 & 1.1 & 8.8 \\
\hline 1 & $1,177.0$ & $1,065.5$ & -0.12 & 0.0 & 1.3 & 8.6 \\
\hline 3 & $1,207.5$ & $1,065.5$ & -0.14 & 0.19 & 1.25 & 17.6 \\
\hline 0 & $1,238.0$ & $1,065.5$ & -0.19 & 0.78 & 0.7 & 14.1 \\
\hline \multicolumn{7}{|c|}{ Range C24 } \\
\hline 4 & $1,085.5$ & 1,096 & -0.05 & 0.03 & 1.0 & 12.3 \\
\hline 2 & $1,116.0$ & 1,096 & -0.14 & 0.15 & 1.05 & 22.2 \\
\hline 5 & $1,146.5$ & 1,096 & -0.05 & 0.0 & 1.0 & 12.5 \\
\hline 1 & $1,177.0$ & 1,096 & 0.1 & 0.1 & 1.0 & 18.7 \\
\hline 3 & $1,207.5$ & 1,096 & -0.18 & 0.17 & 1.1 & 8.8 \\
\hline 0 & $1,238.0$ & 1,096 & -0.24 & 0.83 & 0.55 & 357.6 \\
\hline \multicolumn{7}{|c|}{ Range C25 } \\
\hline 4 & $1,085.5$ & $1,126.5$ & -0.08 & 0.03 & 1.0 & 5.4 \\
\hline 2 & $1,116.0$ & $1,126.5$ & -0.24 & 0.11 & 1.05 & 20.4 \\
\hline 5 & $1,146.5$ & $1,126.5$ & -0.14 & 0.0 & 1.0 & 7.8 \\
\hline 1 & $1,177.0$ & $1,126.5$ & -0.3 & 0.01 & 1.0 & 10.5 \\
\hline 3 & $1,207.5$ & $1,126.5$ & -0.35 & 0.2 & 1.1 & 12.2 \\
\hline 0 & $1,238.0$ & $1,126.5$ & -0.3 & 0.7 & 0.55 & 19.1 \\
\hline \multicolumn{7}{|c|}{ Range C26 } \\
\hline 4 & $1,085.5$ & 1,157 & -0.59 & 0.13 & 1.4 & 5.9 \\
\hline 2 & $1,116.0$ & 1,157 & -0.59 & -0.03 & 1.15 & 21.6 \\
\hline 5 & $1,146.5$ & 1,157 & -0.76 & 0.07 & 1.15 & 24.1 \\
\hline 1 & $1,177.0$ & 1,157 & -0.85 & 0.05 & 1.25 & 4.0 \\
\hline 3 & $1,207.5$ & 1,157 & -0.96 & -0.03 & 1.25 & 27.8 \\
\hline 0 & $1,238.0$ & 1,157 & -0.63 & 0.23 & 0.8 & 2.9 \\
\hline
\end{tabular}




\section{Table C8}

Velocities, Wave Direction, and Interpolated Wave Height, Absorbing Jetty, 2.0-m, 11-sec Wave, Ranges C17-C19, and C21-C26

\begin{tabular}{|c|c|c|c|c|c|c|}
\hline Probe & $X(m)$ & $Y(m)$ & $\mathrm{U}(\mathrm{m} / \mathrm{sec})$ & $\mathrm{V}(\mathrm{m} / \mathrm{sec})$ & Int. Ht (m) & Wave Dir (deg) \\
\hline \multicolumn{7}{|c|}{ Range C17 } \\
\hline 4 & $1,024.5$ & $1,218.0$ & 0.02 & -0.04 & 2.23 & 17.2 \\
\hline 2 & $1,024.5$ & $1,187.5$ & 0.02 & 0.09 & 2.07 & 19.3 \\
\hline 5 & $1,024.5$ & $1,157.0$ & -1.03 & 0.32 & 2.29 & 15.1 \\
\hline 1 & $1,024.5$ & $1,126.5$ & -0.26 & 0.07 & 2.01 & 45.2 \\
\hline 3 & $1,024.5$ & $1,096.0$ & -0.09 & 0.1 & 1.65 & 7.6 \\
\hline 0 & $1,024.5$ & $1,065.5$ & 0.0 & 0.06 & 1.9 & 24.0 \\
\hline \multicolumn{7}{|c|}{ Range C18 } \\
\hline 4 & 1,055 & $1,218.0$ & -0.06 & -0.11 & 2.35 & 350.0 \\
\hline 2 & 1,055 & $1,187.5$ & -0.09 & -0.21 & 2.1 & 31.2 \\
\hline 5 & 1,055 & $1,157.0$ & -0.7 & 0.24 & 2.45 & 23.2 \\
\hline 1 & 1,055 & $1,126.5$ & -0.17 & 0.1 & 2.05 & 22.7 \\
\hline 3 & 1,055 & $1,096.0$ & -0.09 & 0.04 & 1.55 & 18.7 \\
\hline 0 & 1,055 & $1,065.5$ & 0.05 & 0.09 & 1.9 & 15.9 \\
\hline \multicolumn{7}{|c|}{ Range C19 } \\
\hline 4 & $1,085.5$ & 945 & -0.04 & 0.04 & 1.95 & 360.0 \\
\hline 2 & $1,116.0$ & 945 & -0.07 & 0.02 & 1.95 & 12.3 \\
\hline 5 & $1,146.5$ & 945 & -0.16 & 0.02 & 2.1 & 9.1 \\
\hline 1 & $1,177.0$ & 945 & -0.38 & 0.59 & 1.45 & 10.4 \\
\hline 3 & $1,207.5$ & 945 & -0.53 & 1.07 & 1.15 & 9.6 \\
\hline 0 & $1,238.0$ & 945 & -0.29 & 1.42 & 0.8 & 12.6 \\
\hline \multicolumn{7}{|c|}{ Range C21 } \\
\hline 4 & $1,085.5$ & 1,005 & -0.07 & 0.05 & 1.95 & 0.2 \\
\hline 2 & $1,116.0$ & 1,005 & -0.09 & 0.05 & 1.95 & 14.2 \\
\hline 5 & $1,146.5$ & 1,005 & -0.16 & 0.06 & 2.1 & 7.7 \\
\hline 1 & $1,177.0$ & 1,005 & -0.27 & 0.69 & 1.45 & 359.9 \\
\hline 3 & $1,207.5$ & 1,005 & -0.44 & 1.1 & 1.15 & 16.3 \\
\hline 0 & $1,238.0$ & 1,005 & -0.31 & 1.24 & 0.8 & 8.6 \\
\hline \multicolumn{7}{|c|}{ Range C22 } \\
\hline 4 & $1,085.5$ & 1,035 & -0.04 & 0.03 & 1.95 & 5.4 \\
\hline 2 & $1,116.0$ & 1,035 & -0.14 & 0.16 & 1.95 & 21.0 \\
\hline 5 & $1,146.5$ & 1,035 & -0.15 & 0.1 & 2.1 & 18.5 \\
\hline 1 & $1,177.0$ & 1,035 & -0.41 & 0.77 & 1.45 & 11.1 \\
\hline 3 & $1,207.5$ & 1,035 & -0.66 & 1.08 & 1.15 & 10.1 \\
\hline 0 & $1,238.0$ & 1,035 & -0.34 & 1.33 & 0.8 & 16.0 \\
\hline & & & & & & (Continue \\
\hline
\end{tabular}




\section{Table C8 (Concluded)}

\begin{tabular}{|c|c|c|c|c|c|c|}
\hline Probe & $X(m)$ & $Y(m)$ & $\mathrm{U}(\mathrm{m} / \mathrm{sec})$ & $\mathrm{V}(\mathrm{m} / \mathrm{sec})$ & Int. Ht (m) & Wave Dir (deg) \\
\hline \multicolumn{7}{|c|}{ Range C23 } \\
\hline 4 & $1,085.5$ & $1,065.5$ & -0.05 & 0.07 & 1.95 & 1.9 \\
\hline 2 & $1,116.0$ & $1,065.5$ & -0.18 & 0.1 & 1.95 & 11.8 \\
\hline 5 & $1,146.5$ & $1,065.5$ & -0.2 & 0.14 & 2.1 & 9.1 \\
\hline 1 & $1,177.0$ & $1,065.5$ & -0.37 & 0.81 & 1.45 & 10.8 \\
\hline 3 & $1,207.5$ & $1,065.5$ & -0.68 & 1.07 & 1.15 & 13.6 \\
\hline 0 & $1,238.0$ & $1,065.5$ & -0.39 & 1.19 & 0.8 & 4.9 \\
\hline \multicolumn{7}{|c|}{ Range C24 } \\
\hline 4 & $1,085.5$ & 1,096 & -0.14 & 0.07 & 2.3 & 5.8 \\
\hline 2 & $1,116.0$ & 1,096 & -0.3 & 0.12 & 2.15 & 10.6 \\
\hline 5 & $1,146.5$ & 1,096 & -0.35 & 0.27 & 2.0 & 2.9 \\
\hline 1 & $1,177.0$ & 1,096 & -0.42 & 0.92 & 1.55 & 3.3 \\
\hline 3 & $1,207.5$ & 1,096 & -0.61 & 1.01 & 1.3 & 14.7 \\
\hline 0 & $1,238.0$ & 1,096 & -0.37 & 0.94 & 0.7 & 12.1 \\
\hline \multicolumn{7}{|c|}{ Range C25 } \\
\hline 4 & $1,085.5$ & $1,126.5$ & -0.46 & 0.1 & 2.3 & 28.6 \\
\hline 2 & $1,116.0$ & $1,126.5$ & -0.82 & 0.03 & 2.15 & 42.2 \\
\hline 5 & $1,146.5$ & $1,126.5$ & -0.97 & 0.34 & 2.0 & 28.4 \\
\hline 1 & $1,177.0$ & $1,126.5$ & -0.92 & 0.65 & 1.55 & 11.4 \\
\hline 3 & $1,207.5$ & $1,126.5$ & -0.76 & 0.74 & 1.3 & 12.3 \\
\hline 0 & $1,238.0$ & $1,126.5$ & -0.32 & 0.78 & 0.7 & 11.0 \\
\hline \multicolumn{7}{|c|}{ Range C26 } \\
\hline 4 & $1,085.5$ & 1,157 & -1.41 & 0.23 & 2.6 & 17.8 \\
\hline 2 & $1,116.0$ & 1,157 & -1.77 & -0.28 & 2.4 & 35.1 \\
\hline 5 & $1,146.5$ & 1,157 & -1.93 & 0.04 & 1.95 & 25.7 \\
\hline 1 & $1,177.0$ & 1,157 & -1.64 & 0.25 & 1.65 & 24.1 \\
\hline 3 & $1,207.5$ & 1,157 & -1.17 & -0.03 & 0.9 & 23.1 \\
\hline 0 & $1,238.0$ & 1,157 & -0.47 & 0.11 & 0.6 & 30.0 \\
\hline
\end{tabular}




\begin{tabular}{|c|c|c|c|c|c|c|}
\hline \multicolumn{7}{|c|}{$\begin{array}{l}\text { Table C9 } \\
\text { Velocities, Wave Direction, and Interpolated Wave Height, in } \\
\text { Channel, 1.0-m, 11-sec Wave, Ranges C29, C29A, C31, } \\
\text { C31A, C33, and C33A }\end{array}$} \\
\hline Probe & $X(m)$ & $Y(m)$ & $\mathrm{U}(\mathrm{m} / \mathrm{sec})$ & $\mathrm{V}(\mathrm{m} / \mathrm{sec})$ & Int. Ht (m) & Wave Dir (deg) \\
\hline \multicolumn{7}{|c|}{ Range C29 } \\
\hline 4 & $1,085.5$ & $1,248.5$ & -0.16 & -0.04 & 0.9 & 3.0 \\
\hline 2 & $1,116.0$ & $1,248.5$ & 0.0 & 0.0 & 0.85 & 4.9 \\
\hline 5 & $1,146.5$ & $1,248.5$ & -0.01 & -0.03 & 1.0 & 2.4 \\
\hline 1 & $1,177.0$ & $1,248.5$ & 0.0 & -0.04 & 0.95 & 348.5 \\
\hline 3 & $1,207.5$ & $1,248.5$ & -0.01 & -0.01 & 0.75 & \begin{tabular}{|l|}
4.2 \\
\end{tabular} \\
\hline 0 & $1,238.0$ & $1,248.5$ & 0.06 & 0.13 & 0.95 & 15.2 \\
\hline \multicolumn{7}{|c|}{$\begin{array}{l}\text { Range C29A } \\
\end{array}$} \\
\hline 4 & $1,268.5$ & $1,263.75$ & -0.1 & -0.03 & 0.8 & 341.2 \\
\hline 2 & $1,299.0$ & $1,263.75$ & -0.03 & -0.02 & 0.35 & 348.0 \\
\hline 5 & $1,329.5$ & $1,263.75$ & 0.12 & -0.01 & 1.0 & 304.6 \\
\hline 1 & $1,360.0$ & $1,263.75$ & 0.07 & -0.16 & 0.6 & 5.3 \\
\hline 3 & $1,390.5$ & $1,263.75$ & -0.02 & -0.02 & 0.4 & 0.3 \\
\hline 0 & $1,421.0$ & $1,263.75$ & -0.09 & 0.01 & 0.3 & 352.5 \\
\hline \multicolumn{7}{|c|}{ Range C31 } \\
\hline 4 & $1,085.5$ & $1,309.5$ & -0.09 & -0.04 & 1.05 & 12.3 \\
\hline 2 & $1,116.0$ & $1,309.5$ & 0.01 & -0.04 & 1.3 & 26.5 \\
\hline 5 & $1,146.5$ & $1,309.5$ & 0.1 & -0.05 & 0.9 & 15.9 \\
\hline 1 & $1,177.0$ & $1,309.5$ & 0.07 & 0.0 & 0.8 & 14.4 \\
\hline 3 & $1,207.5$ & $1,309.5$ & 0.03 & 0.0 & 1.1 & 13.2 \\
\hline 0 & $1,238.0$ & $1,309.5$ & 0.03 & -0.01 & 1.05 & 17.2 \\
\hline \multicolumn{7}{|c|}{ Range C31A } \\
\hline 4 & $1,268.5$ & $1,309.5$ & -0.08 & 0.02 & 0.55 & 4.2 \\
\hline 2 & $1,299.0$ & $1,309.5$ & -0.03 & 0.0 & 1.0 & 18.2 \\
\hline 5 & $1,329.5$ & $1,309.5$ & 0.02 & -0.05 & 0.6 & 350.3 \\
\hline 1 & $1,360.0$ & $1,309.5$ & 0.03 & 0.03 & 0.2 & 356.6 \\
\hline 3 & $1,390.5$ & $1,309.5$ & -0.04 & 0.0 & 0.6 & 7.8 \\
\hline 0 & $1,421.0$ & $1,309.5$ & -0.1 & 0.0 & 0.55 & 12.1 \\
\hline \multicolumn{7}{|c|}{ Range C33 } \\
\hline 4 & $1,085.5$ & $1,370.5$ & -0.08 & -0.06 & 1.0 & 10.4 \\
\hline 2 & $1,116.0$ & $1,370.5$ & -0.03 & -0.03 & 1.2 & 17.3 \\
\hline 5 & $1,146.5$ & $1,370.5$ & 0.02 & -0.05 & 0.95 & 15.9 \\
\hline 1 & $1,177.0$ & $1,370.5$ & -0.03 & 0.0 & 0.8 & 6.6 \\
\hline 3 & $1,207.5$ & $1,370.5$ & 0.0 & -0.01 & 1.2 & 26.3 \\
\hline 0 & $1,238.0$ & $1,370.5$ & -0.14 & 0.0 & 1.0 & 34.6 \\
\hline \multicolumn{7}{|c|}{ Range C33A } \\
\hline 4 & $1,268.5$ & 1,355.25 & 0.01 & 0.02 & 0.8 & 37.2 \\
\hline 2 & $1,299.0$ & $1,355.25$ & 0.06 & -0.01 & 0.3 & 29.0 \\
\hline 5 & $1,329.5$ & $1,355.25$ & -0.04 & -0.04 & 1.2 & 58.6 \\
\hline 1 & $1,360.0$ & $1,355.25$ & -0.04 & 0.13 & 0.45 & 30.3 \\
\hline 3 & $1,390.5$ & $1,355.25$ & -0.04 & 0.0 & 0.25 & 38.8 \\
\hline 0 & $1,421.0$ & $1,355.25$ & -0.04 & -0.01 & 0.45 & 6.1 \\
\hline
\end{tabular}




\begin{tabular}{|c|c|c|c|c|c|c|}
\hline \multicolumn{7}{|c|}{$\begin{array}{l}\text { Table C10 } \\
\text { Velocities, Wave Direction, and Interpolated Wave Height, in } \\
\text { Channel, 2.0-m, 11-sec Wave, Ranges C29, C29A, C31, } \\
\text { C31A, C33, and C33A }\end{array}$} \\
\hline Probe & $X(m)$ & $Y(m)$ & $\mathrm{U}(\mathrm{m} / \mathrm{sec})$ & $\mathrm{V}(\mathrm{m} / \mathrm{sec})$ & Int. Ht (m) & Wave Dir (deg) \\
\hline \multicolumn{7}{|c|}{ Range C29 } \\
\hline 4 & $1,085.5$ & $1,248.5$ & -0.12 & -0.05 & 2.45 & 8.1 \\
\hline 2 & $1,116.0$ & $1,248.5$ & -0.14 & -0.09 & 2.5 & 10.5 \\
\hline 5 & $1,146.5$ & $1,248.5$ & -0.1 & -0.08 & 2.55 & 8.0 \\
\hline 1 & $1,177.0$ & $1,248.5$ & -0.07 & -0.08 & 2.1 & 5.9 \\
\hline 3 & $1,207.5$ & $1,248.5$ & -0.01 & 0.03 & 1.8 & 7.5 \\
\hline 0 & $1,238.0$ & $1,248.5$ & -0.12 & 0.1 & 1.7 & 4.2 \\
\hline \multicolumn{7}{|c|}{ Range C29A } \\
\hline 4 & $1,268.5$ & $1,263.75$ & -0.05 & -0.03 & 1.55 & 9.2 \\
\hline 2 & $1,299.0$ & $1,263.75$ & 0.13 & 0.09 & 1.2 & 355.3 \\
\hline 5 & $1,329.5$ & $1,263.75$ & 0.34 & 0.1 & 1.75 & 339.0 \\
\hline 1 & $1,360.0$ & $1,263.75$ & 0.22 & 0.03 & 0.9 & 305.5 \\
\hline 3 & $1,390.5$ & $1,263.75$ & 0.29 & 0.07 & 0.9 & 283.5 \\
\hline 0 & $1,421.0$ & $1,263.75$ & 0.03 & 0.11 & 0.75 & 288.2 \\
\hline \multicolumn{7}{|c|}{ Range C31 } \\
\hline 4 & $1,085.5$ & $1,309.5$ & -0.15 & -0.11 & 1.95 & 14.0 \\
\hline 2 & $1,116.0$ & $1,309.5$ & -0.18 & -0.12 & 2.1 & 17.9 \\
\hline 5 & $1,146.5$ & $1,309.5$ & -0.11 & -0.07 & 2.5 & 20.2 \\
\hline 1 & $1,177.0$ & $1,309.5$ & -0.12 & -0.01 & 2.2 & 11.5 \\
\hline 3 & $1,207.5$ & $1,309.5$ & -0.17 & -0.02 & 2.0 & 5.8 \\
\hline 0 & $1,238.0$ & $1,309.5$ & -0.17 & 0.07 & 2.5 & 7.7 \\
\hline \multicolumn{7}{|c|}{ Range C31A } \\
\hline 4 & $1,268.5$ & $1,309.5$ & -0.31 & 0.0 & 2.15 & 4.9 \\
\hline 2 & $1,299.0$ & $1,309.5$ & -0.31 & 0.01 & 1.95 & 3.2 \\
\hline 5 & $1,329.5$ & $1,309.5$ & -0.3 & -0.02 & 1.2 & 355.5 \\
\hline 1 & $1,360.0$ & $1,309.5$ & -0.3 & 0.03 & 1.85 & 356.2 \\
\hline 3 & $1,390.5$ & $1,309.5$ & -0.32 & 0.03 & 2.0 & 352.9 \\
\hline 0 & $1,421.0$ & $1,309.5$ & -0.23 & 0.02 & 1.95 & 354.8 \\
\hline \multicolumn{7}{|c|}{ Range C33 } \\
\hline 4 & $1,085.5$ & $1,370.5$ & -0.16 & -0.06 & 2.45 & 9.6 \\
\hline 2 & $1,116.0$ & $1,370.5$ & -0.21 & -0.08 & 2.6 & 10.6 \\
\hline 5 & $1,146.5$ & $1,370.5$ & -0.13 & -0.07 & 2.75 & 10.4 \\
\hline 1 & $1,177.0$ & $1,370.5$ & -0.2 & -0.02 & 2.2 & 358.4 \\
\hline 3 & $1,207.5$ & $1,370.5$ & -0.15 & -0.01 & 2.45 & 14.3 \\
\hline 0 & $1,238.0$ & $1,370.5$ & -0.15 & 0.1 & 2.45 & 21.2 \\
\hline \multicolumn{7}{|c|}{ Range C33A } \\
\hline 4 & $1,268.5$ & $1,355.25$ & -0.1 & 0.1 & 2.05 & 23.7 \\
\hline 2 & $1,299.0$ & $1,355.25$ & 0.07 & -0.11 & 2.2 & 21.2 \\
\hline 5 & $1,329.5$ & $1,355.25$ & 0.17 & -0.15 & 2.75 & 27.1 \\
\hline 1 & $1,360.0$ & $1,355.25$ & 0.34 & -0.1 & 1.2 & 45.3 \\
\hline 3 & $1,390.5$ & $1,355.25$ & 0.43 & -0.01 & 1.05 & 78.0 \\
\hline 0 & $1,421.0$ & $1,355.25$ & 0.37 & -0.08 & 1.1 & 69.7 \\
\hline
\end{tabular}




\begin{tabular}{|c|c|c|c|c|c|c|}
\hline \multicolumn{7}{|c|}{$\begin{array}{l}\text { Table C11 } \\
\text { Velocities, Wave Direction, and Interpolated Wave Height, in } \\
\text { Channel, 3.4-m, 8-sec Wave, Ranges C29, C29A, C31, C31A, } \\
\text { C33, and C33A }\end{array}$} \\
\hline Probe & $X(m)$ & $Y(m)$ & $\mathrm{U}(\mathrm{m} / \mathrm{sec})$ & $\mathrm{V}(\mathrm{m} / \mathrm{sec})$ & Int. Ht (m) & Wave Dir (deg) \\
\hline \multicolumn{7}{|c|}{$\mathrm{C} 29$} \\
\hline 4 & $1,085.5$ & $1,248.5$ & 0.17 & -0.06 & 2.4 & 13.2 \\
\hline 2 & $1,116.0$ & $1,248.5$ & 0.2 & -0.06 & 2.1 & 18.9 \\
\hline 5 & $1,146.5$ & $1,248.5$ & 0.23 & 0.1 & 2.0 & 13.4 \\
\hline 1 & $1,177.0$ & $1,248.5$ & 0.06 & 0.1 & 1.8 & 7.1 \\
\hline 3 & $1,207.5$ & $1,248.5$ & 0.09 & 0.19 & 1.8 & 2.9 \\
\hline 0 & $1,238.0$ & $1,248.5$ & 0.1 & 0.25 & 1.5 & 356.7 \\
\hline \multicolumn{7}{|c|}{ C29A } \\
\hline 4 & $1,268.5$ & $1,263.75$ & -0.01 & 0.19 & 1.55 & 34.4 \\
\hline 2 & $1,299.0$ & $1,263.75$ & -0.2 & -0.04 & 1.5 & 341.5 \\
\hline 5 & $1,329.5$ & $1,263.75$ & -0.22 & -0.09 & 1.65 & 331.1 \\
\hline 1 & $1,360.0$ & $1,263.75$ & -0.18 & -0.05 & 1.75 & 342.6 \\
\hline 3 & $1,390.5$ & $1,263.75$ & -0.4 & 0.0 & 1.5 & 356.0 \\
\hline 0 & $1,421.0$ & $1,263.75$ & -0.3 & 0.18 & 1.2 & 33.3 \\
\hline \multicolumn{7}{|c|}{ C31 } \\
\hline 4 & $1,085.5$ & $1,309.5$ & -0.3 & \begin{tabular}{|l|}
-0.16 \\
\end{tabular} & 3.1 & 13.9 \\
\hline 2 & $1,116.0$ & $1,309.5$ & -0.4 & 0.07 & 3.3 & 16.3 \\
\hline 5 & $1,146.5$ & $1,309.5$ & -0.34 & 0.16 & 3.1 & 13.4 \\
\hline 1 & $1,177.0$ & $1,309.5$ & -0.45 & 0.26 & 2.8 & 10.6 \\
\hline 3 & $1,207.5$ & $1,309.5$ & -0.59 & 0.22 & 2.8 & 6.6 \\
\hline 0 & $1,238.0$ & $1,309.5$ & -0.65 & 0.18 & 2.6 & 8.2 \\
\hline \multicolumn{7}{|c|}{ C31A } \\
\hline 4 & $1,268.5$ & $1,309.5$ & -0.47 & $\begin{array}{l}0.07 \\
\end{array}$ & 2.5 & 8.8 \\
\hline 2 & $1,299.0$ & $1,309.5$ & -0.5 & 0.07 & 2.3 & 7.4 \\
\hline 5 & $1,329.5$ & $1,309.5$ & \begin{tabular}{|l|}
-0.47 \\
\end{tabular} & 0.12 & 2.15 & 14.0 \\
\hline 1 & $1,360.0$ & $1,309.5$ & \begin{tabular}{|l|}
-0.49 \\
\end{tabular} & 0.14 & 1.6 & 16.1 \\
\hline 3 & $1,390.5$ & $1,309.5$ & -0.49 & 0.01 & 1.75 & 343.6 \\
\hline 0 & $1,421.0$ & $1,309.5$ & \begin{tabular}{|l|}
-0.38 \\
\end{tabular} & -0.18 & 1.6 & 341.4 \\
\hline \multicolumn{7}{|c|}{ C33 } \\
\hline 4 & $1,085.5$ & $1,370.5$ & -0.54 & 0.06 & 3.1 & 19.2 \\
\hline 2 & $1,116.0$ & $1,370.5$ & -0.67 & 0.12 & 3.1 & 14.1 \\
\hline 5 & $1,146.5$ & $1,370.5$ & -0.49 & 0.17 & 3.2 & 14.4 \\
\hline 1 & $1,177.0$ & $1,370.5$ & -0.37 & 0.24 & 3.0 & 10.4 \\
\hline 3 & $1,207.5$ & $1,370.5$ & \begin{tabular}{|l|}
-0.18 \\
\end{tabular} & 0.13 & 2.75 & 10.1 \\
\hline 0 & $1,238.0$ & $1,370.5$ & 0.11 & 0.0 & 2.35 & 20.9 \\
\hline \multicolumn{7}{|c|}{ C33A } \\
\hline 4 & $1,268.5$ & $1,355.25$ & 0.09 & -0.04 & 2.25 & 22.8 \\
\hline 2 & $1,299.0$ & $1,355.25$ & 0.42 & -0.19 & 2.4 & 16.2 \\
\hline 5 & $1,329.5$ & $1,355.25$ & 0.72 & -0.22 & 2.05 & 11.1 \\
\hline 1 & $1,360.0$ & $1,355.25$ & 1.14 & 0.02 & 1.6 & 36.7 \\
\hline 3 & $1,390.5$ & $1,355.25$ & 1.12 & 0.0 & 1.25 & 62.6 \\
\hline 0 & $1,421.0$ & $1,355.25$ & 1.1 & -0.22 & 1.05 & 305.2 \\
\hline
\end{tabular}


Table C12

Velocities, Wave Direction, and Interpolated Wave Height, Spur, 2.0-m, 11-sec Wave, Ranges C17-C19, C21-C26, T1, and T3

\begin{tabular}{|c|c|c|c|c|c|c|}
\hline Probe & $X(m)$ & $Y(m)$ & $\mathrm{U}(\mathrm{m} / \mathrm{sec})$ & $\mathrm{V}(\mathrm{m} / \mathrm{sec})$ & Int. Ht (m) & Wave Dir (deg) \\
\hline \multicolumn{7}{|c|}{ C17 } \\
\hline 4 & $1,024.5$ & $1,218.0$ & -0.08 & -0.21 & 2.35 & 14.4 \\
\hline 2 & $1,024.5$ & $1,187.5$ & -0.35 & 0.12 & 2.75 & 10.5 \\
\hline 5 & $1,024.5$ & $1,157.0$ & -0.83 & 0.34 & 2.7 & 27.7 \\
\hline 1 & $1,024.5$ & $1,126.5$ & -0.41 & 0.14 & 2.55 & 20.2 \\
\hline 3 & $1,024.5$ & $1,096.0$ & -0.3 & 0.08 & 2.95 & 18.1 \\
\hline 0 & $1,024.5$ & $1,065.5$ & -0.07 & -0.02 & 2.65 & 30.2 \\
\hline \multicolumn{7}{|c|}{ C18 } \\
\hline 4 & 1,055 & $1,218.0$ & -0.1 & -0.24 & 2.7 & 22.1 \\
\hline 2 & 1,055 & $1,187.5$ & -0.06 & -0.24 & 2.75 & 23.9 \\
\hline 5 & 1,055 & $1,157.0$ & -0.73 & 0.18 & 3.4 & 7.4 \\
\hline 1 & 1,055 & $1,126.5$ & -0.46 & 0.31 & 2.2 & 46.1 \\
\hline 3 & 1,055 & $1,096.0$ & -0.26 & -0.02 & 3.15 & 10.9 \\
\hline 0 & 1,055 & $1,065.5$ & -0.15 & 0.01 & 2.75 & 33.0 \\
\hline \multicolumn{7}{|c|}{ C19 } \\
\hline 4 & $1,085.5$ & 945 & -0.1 & 0.06 & 2.7 & 1.3 \\
\hline 2 & $1,116.0$ & 945 & -0.15 & -0.06 & 2.2 & 20.6 \\
\hline 5 & $1,146.5$ & 945 & -0.14 & 0.02 & 3.2 & 12.6 \\
\hline 1 & $1,177.0$ & 945 & -0.3 & 0.6 & 1.95 & 356.5 \\
\hline 3 & $1,207.5$ & 945 & -0.56 & 1.08 & 1.75 & 1.9 \\
\hline 0 & $1,238.0$ & 945 & -0.35 & 1.22 & 1.1 & 7.9 \\
\hline \multicolumn{7}{|c|}{$\mathrm{C} 21$} \\
\hline 4 & $1,085.5$ & 1,005 & -0.11 & 0.08 & 3.3 & 3.2 \\
\hline 2 & $1,116.0$ & 1,005 & -0.27 & 0.03 & 3.3 & 13.0 \\
\hline 5 & $1,146.5$ & 1,005 & -0.11 & -0.01 & 3.15 & 5.6 \\
\hline 1 & $1,177.0$ & 1,005 & -0.15 & 0.63 & 2.1 & 353.2 \\
\hline 3 & $1,207.5$ & 1,005 & -0.37 & 1.13 & 1.95 & 8.4 \\
\hline 0 & $1,238.0$ & 1,005 & -0.3 & 1.1 & 1.3 & 1.3 \\
\hline \multicolumn{7}{|c|}{$\mathrm{C} 22$} \\
\hline 4 & $1,085.5$ & 1,035 & -0.1 & -0.05 & 2.5 & 9.6 \\
\hline 2 & $1,116.0$ & 1,035 & -0.2 & 0.01 & 2.8 & 4.9 \\
\hline 5 & $1,146.5$ & 1,035 & -0.13 & 0.21 & 3.1 & 11.8 \\
\hline 1 & $1,177.0$ & 1,035 & -0.21 & 0.64 & 2.0 & 33.4 \\
\hline 3 & $1,207.5$ & 1,035 & -0.5 & 1.12 & 1.6 & 17.8 \\
\hline 0 & $1,238.0$ & 1,035 & -0.46 & 1.27 & 1.0 & 358.3 \\
\hline & & & & & & (Continued \\
\hline
\end{tabular}




\begin{tabular}{|c|c|c|c|c|c|c|}
\hline \multicolumn{7}{|c|}{ Table C12 (Concluded) } \\
\hline Probe & $X(m)$ & $Y(m)$ & $\mathrm{U}(\mathrm{m} / \mathrm{sec})$ & $\mathrm{V}(\mathrm{m} / \mathrm{sec})$ & Int. Ht (m) & Wave Dir (deg) \\
\hline \multicolumn{7}{|c|}{$\mathrm{C} 23$} \\
\hline 4 & $1,085.5$ & $1,065.5$ & -0.07 & -0.02 & 2.6 & 2.5 \\
\hline 2 & $1,116.0$ & $1,065.5$ & -0.25 & 0.0 & 2.45 & 21.0 \\
\hline 5 & $1,146.5$ & $1,065.5$ & -0.26 & 0.27 & 3.2 & 358.8 \\
\hline 1 & $1,177.0$ & $1,065.5$ & -0.58 & 0.86 & 2.3 & 8.3 \\
\hline 3 & $1,207.5$ & $1,065.5$ & -0.81 & 0.91 & 1.35 & 13.0 \\
\hline 0 & $1,238.0$ & $1,065.5$ & -0.51 & 0.94 & 0.95 & 7.9 \\
\hline \multicolumn{7}{|c|}{$\mathrm{C} 24$} \\
\hline 4 & $1,085.5$ & 1,096 & -0.43 & \begin{tabular}{|l|}
0.04 \\
\end{tabular} & 3.05 & 25.3 \\
\hline 2 & $1,116.0$ & 1,096 & -0.68 & 0.1 & 3.05 & 7.3 \\
\hline 5 & $1,146.5$ & 1,096 & -1.02 & 0.49 & 2.75 & 33.7 \\
\hline 1 & $1,177.0$ & 1,096 & -0.91 & 0.6 & 2.45 & 16.1 \\
\hline 3 & $1,207.5$ & 1,096 & -0.83 & 0.73 & 1.8 & 54.3 \\
\hline 0 & $1,238.0$ & 1,096 & -0.27 & 0.51 & 1.0 & 11.8 \\
\hline \multicolumn{7}{|c|}{$\mathrm{C} 25$} \\
\hline 4 & $1,085.5$ & $1,126.5$ & -1.54 & 0.18 & 3.3 & 24.1 \\
\hline 2 & $1,116.0$ & $1,126.5$ & -1.62 & 0.1 & 3.4 & 17.4 \\
\hline 5 & $1,146.5$ & $1,126.5$ & -1.34 & 0.19 & 3.55 & 5.0 \\
\hline 1 & $1,177.0$ & $1,126.5$ & -0.88 & 0.11 & 2.25 & 2.3 \\
\hline 3 & $1,207.5$ & $1,126.5$ & -0.36 & 0.32 & 2.05 & 5.9 \\
\hline 0 & $1,238.0$ & $1,126.5$ & 0.11 & -0.27 & 1.2 & 3.4 \\
\hline \multicolumn{7}{|c|}{$\mathrm{C} 26$} \\
\hline 4 & $1,085.5$ & 1,145 & -1.53 & 0.3 & 2.85 & 22.8 \\
\hline 2 & $1,116.0$ & 1,145 & -1.45 & -0.08 & 4.05 & 4.6 \\
\hline 5 & $1,146.5$ & 1,145 & -1.41 & 0.28 & 3.3 & 23.9 \\
\hline 1 & $1,177.0$ & 1,145 & -0.88 & -0.13 & 2.35 & 12.0 \\
\hline 3 & $1,207.5$ & 1,145 & -0.3 & 0.2 & 1.7 & 18.2 \\
\hline 0 & $1,238.0$ & 1,145 & 0.24 & -0.16 & 1.15 & 19.3 \\
\hline \multicolumn{7}{|c|}{ T1 } \\
\hline 4 & $1,080.5$ & 1,159 & -0.37 & 0.5 & 2.55 & 10.5 \\
\hline 2 & $1,116.0$ & 1,159 & 0.06 & 0.02 & 2.0 & 56.5 \\
\hline 5 & $1,141.5$ & 1,159 & -0.15 & -0.13 & 2.0 & 31.3 \\
\hline 1 & $1,177.0$ & 1,159 & -0.04 & -0.1 & 1.4 & 76.7 \\
\hline 3 & $1,202.5$ & 1,159 & -0.19 & 0.03 & 1.2 & 34.1 \\
\hline 0 & $1,238.0$ & 1,159 & -0.14 & -0.13 & 0.5 & 72.3 \\
\hline \multicolumn{7}{|c|}{ T3 } \\
\hline 4 & $1,080.5$ & 1,155 & -1.13 & 0.67 & 2.7 & 19.2 \\
\hline 2 & $1,116.0$ & 1,155 & -0.7 & -0.39 & 2.25 & 35.7 \\
\hline 5 & $1,141.5$ & 1,155 & -0.52 & 0.06 & 1.9 & 27.5 \\
\hline 1 & $1,177.0$ & 1,155 & -0.06 & -0.34 & 1.7 & 63.9 \\
\hline 3 & $1,202.5$ & 1,155 & -0.15 & 0.04 & 1.05 & 27.1 \\
\hline 0 & $1,238.0$ & 1,155 & 0.27 & -0.2 & 0.8 & 69.4 \\
\hline
\end{tabular}


Table C13

Velocities, Wave Direction, and Interpolated Wave Height, Spur, 1.0-m, 11-sec Wave, Ranges C17-C19, C21-C26, T1, and T3

\begin{tabular}{|c|c|c|c|c|c|c|}
\hline Probe & $X(m)$ & $Y(m)$ & $U(\mathrm{~m} / \mathrm{sec})$ & $\mathrm{V}(\mathrm{m} / \mathrm{sec})$ & Int. Ht (m) & Wave Dir (deg) \\
\hline \multicolumn{7}{|c|}{ C17 } \\
\hline 4 & $1,024.5$ & $1,218.0$ & 0.02 & -0.1 & 0.8 & 18.4 \\
\hline 2 & $1,024.5$ & $1,187.5$ & -0.05 & -0.04 & 0.85 & 3.7 \\
\hline 5 & $1,024.5$ & $1,157.0$ & -0.1 & -0.11 & 1.0 & 5.1 \\
\hline 1 & $1,024.5$ & $1,126.5$ & -0.17 & -0.01 & 1.4 & 15.5 \\
\hline 3 & $1,024.5$ & $1,096.0$ & -0.12 & 0.04 & 1.6 & 18.1 \\
\hline 0 & $1,024.5$ & $1,065.5$ & -0.13 & 0.12 & 1.4 & 23.3 \\
\hline \multicolumn{7}{|c|}{ C18 } \\
\hline 4 & 1,055 & $1,218.0$ & 0.04 & -0.13 & 1.0 & 25.9 \\
\hline 2 & 1,055 & $1,187.5$ & -0.01 & -0.05 & 1.15 & 23.9 \\
\hline 5 & 1,055 & $1,157.0$ & -0.11 & -0.07 & 1.65 & 1.1 \\
\hline 1 & 1,055 & $1,126.5$ & -0.22 & 0.06 & 1.55 & 23.0 \\
\hline 3 & 1,055 & $1,096.0$ & -0.05 & -0.15 & 1.2 & 23.9 \\
\hline 0 & 1,055 & $1,065.5$ & -0.12 & 0.05 & 1.45 & 13.7 \\
\hline \multicolumn{7}{|c|}{ C19 } \\
\hline 4 & $1,085.5$ & 945 & -0.07 & 0.19 & 1.05 & 9.2 \\
\hline 2 & $1,116.0$ & 945 & -0.02 & 0.0 & 1.05 & 21.2 \\
\hline 5 & $1,146.5$ & 945 & 0.06 & 0.03 & 1.6 & 4.7 \\
\hline 1 & $1,177.0$ & 945 & 0.05 & 0.02 & 1.95 & 11.2 \\
\hline 3 & $1,207.5$ & 945 & -0.17 & 0.15 & 2.3 & 19.4 \\
\hline 0 & $1,238.0$ & 945 & -0.5 & 1.07 & 0.95 & 6.7 \\
\hline \multicolumn{7}{|c|}{$\mathrm{C} 21$} \\
\hline 4 & $1,085.5$ & 1,005 & -0.07 & 0.0 & 1.15 & 7.8 \\
\hline 2 & $1,116.0$ & 1,005 & -0.09 & 0.0 & 1.35 & 18.6 \\
\hline 5 & $1,146.5$ & 1,005 & -0.06 & -0.01 & 1.8 & 2.2 \\
\hline 1 & $1,177.0$ & 1,005 & -0.1 & 0.01 & 1.7 & 12.6 \\
\hline 3 & $1,207.5$ & 1,005 & -0.14 & 0.2 & 2.15 & 13.7 \\
\hline 0 & $1,238.0$ & 1,005 & -0.31 & 0.84 & 1.15 & 13.1 \\
\hline \multicolumn{7}{|c|}{$\mathrm{C} 22$} \\
\hline 4 & $1,085.5$ & 1,035 & -0.04 & 0.01 & 1.1 & 5.4 \\
\hline 2 & $1,116.0$ & 1,035 & -0.08 & 0.0 & 1.3 & 4.0 \\
\hline 5 & $1,146.5$ & 1,035 & -0.03 & 0.03 & 1.35 & 18.3 \\
\hline 1 & $1,177.0$ & 1,035 & -0.11 & 0.05 & 1.8 & 4.7 \\
\hline 3 & $1,207.5$ & 1,035 & -0.16 & 0.17 & 2.2 & 8.4 \\
\hline 0 & $1,238.0$ & 1,035 & -0.26 & 0.79 & 1.3 & 0.0 \\
\hline & & & & & & (Continuec \\
\hline
\end{tabular}




\begin{tabular}{|c|c|c|c|c|c|c|}
\hline \multicolumn{7}{|c|}{ Table C13 (Concluded) } \\
\hline Probe & $X(m)$ & $Y(m)$ & $\mathrm{U}(\mathrm{m} / \mathrm{sec})$ & $\mathrm{V}(\mathrm{m} / \mathrm{sec})$ & Int. Ht (m) & Wave Dir (deg) \\
\hline \multicolumn{7}{|c|}{$\mathrm{C} 23$} \\
\hline & & & & & & \\
\hline 4 & $1,085.5$ & $1,065.5$ & 0.07 & 0.06 & 1.2 & 8.5 \\
\hline 2 & $1,116.0$ & $1,065.5$ & -0.07 & 0.05 & 1.0 & 18.4 \\
\hline 5 & $1,146.5$ & $1,065.5$ & 0.01 & 0.02 & 1.45 & 358.2 \\
\hline 1 & $1,177.0$ & $1,065.5$ & -0.04 & 0.15 & 1.2 & 18.5 \\
\hline 3 & $1,207.5$ & $1,065.5$ & -0.14 & 0.23 & 1.7 & 19.5 \\
\hline 0 & $1,238.0$ & $1,065.5$ & -0.28 & 0.81 & 1.15 & 10.7 \\
\hline \multicolumn{7}{|c|}{ C24 } \\
\hline 4 & $1,085.5$ & $1,096.0$ & -0.05 & -0.01 & 1.4 & 20.6 \\
\hline 2 & $1,116.0$ & $1,096.0$ & -0.08 & 0.0 & 1.35 & 18.8 \\
\hline 5 & $1,146.5$ & $1,096.0$ & -0.15 & 0.01 & 1.35 & 22.4 \\
\hline 1 & $1,177.0$ & $1,096.0$ & -0.2 & 0.04 & 1.55 & 14.5 \\
\hline 3 & $1,207.5$ & $1,096.0$ & -0.32 & 0.17 & 1.65 & 8.2 \\
\hline 0 & $1,238.0$ & $1,096.0$ & -0.41 & 0.65 & 1.2 & 4.9 \\
\hline \multicolumn{7}{|c|}{ C25 } \\
\hline 4 & $1,085.5$ & $1,126.5$ & -0.47 & 0.08 & 1.65 & 18.5 \\
\hline 2 & $1,116.0$ & $1,126.5$ & -0.45 & 0.02 & 1.9 & 16.4 \\
\hline 5 & $1,146.5$ & $1,126.5$ & -0.47 & 0.04 & 1.85 & 17.7 \\
\hline 1 & $1,177.0$ & $1,126.5$ & -0.54 & -0.07 & 2.1 & 16.9 \\
\hline 3 & $1,207.5$ & $1,126.5$ & -0.46 & 0.09 & 2.25 & 5.1 \\
\hline 0 & $1,238.0$ & $1,126.5$ & -0.17 & 0.36 & 0.95 & 5.6 \\
\hline \multicolumn{7}{|c|}{ C26 } \\
\hline 4 & $1,085.5$ & $1,145.0$ & -0.55 & 0.11 & 1.35 & 23.7 \\
\hline 2 & $1,116.0$ & $1,145.0$ & -0.57 & 0.03 & 1.95 & 4.7 \\
\hline 5 & $1,146.5$ & $1,145.0$ & -0.44 & 0.1 & 1.95 & 26.6 \\
\hline 1 & $1,177.0$ & $1,145.0$ & -0.35 & -0.06 & 1.8 & 9.5 \\
\hline 3 & $1,207.5$ & $1,145.0$ & -0.03 & 0.0 & 1.65 & 25.8 \\
\hline 0 & $1,238.0$ & $1,145.0$ & -0.16 & 0.16 & 1.2 & 12.2 \\
\hline \multicolumn{7}{|c|}{ T1 } \\
\hline 4 & $1,080.5$ & 1,159 & 0.01 & 0.06 & 1.1 & 14.1 \\
\hline 2 & $1,116.0$ & 1,159 & 0.0 & -0.04 & 0.85 & 66.9 \\
\hline 5 & $1,141.5$ & 1,159 & -0.15 & -0.1 & 1.0 & 24.8 \\
\hline 1 & $1,177.0$ & 1,159 & 0.17 & 0.14 & 1.3 & 83.3 \\
\hline 3 & $1,202.5$ & 1,159 & 0.04 & -0.07 & 0.95 & 22.4 \\
\hline 0 & $1,238.0$ & 1,159 & -0.44 & -0.16 & 0.55 & 66.9 \\
\hline \multicolumn{7}{|c|}{ T3 } \\
\hline 4 & $1,080.5$ & 1,155 & -0.2 & 0.2 & 1.15 & 15.8 \\
\hline 2 & $1,116.0$ & 1,155 & -0.24 & -0.05 & 1.3 & 41.5 \\
\hline 5 & $1,141.5$ & 1,155 & -0.05 & -0.02 & 0.85 & 25.2 \\
\hline 1 & $1,177.0$ & 1,155 & 0.0 & 0.0 & 1.45 & 47.1 \\
\hline 3 & $1,202.5$ & 1,155 & 0.0 & -0.07 & 0.8 & 23.8 \\
\hline 0 & $1,238.0$ & 1,155 & -0.42 & -0.28 & 0.7 & 53.0 \\
\hline
\end{tabular}




\begin{tabular}{|c|c|c|c|c|c|c|}
\hline \multicolumn{7}{|c|}{$\begin{array}{l}\text { Table C14 } \\
\text { Velocities, Wave Direction, and Interpolated Wave Height, } \\
\text { Spur, 3.4-m, 8-sec Wave, Ranges C17-C19, C21-C26, T1, and } \\
\text { T3 }\end{array}$} \\
\hline Probe & $X(m)$ & $Y(m)$ & $\mathrm{U}(\mathrm{m} / \mathrm{sec})$ & $\mathrm{V}(\mathrm{m} / \mathrm{sec})$ & Int. Ht (m) & Wave Dir (deg) \\
\hline \multicolumn{7}{|c|}{ C17 } \\
\hline 4 & $1,024.5$ & $1,218.0$ & -0.51 & 0.99 & 4.0 & 15.5 \\
\hline 2 & $1,024.5$ & $1,187.5$ & -0.62 & 1.02 & 4.3 & 18.2 \\
\hline 5 & $1,024.5$ & $1,157.0$ & -0.49 & 0.45 & 4.3 & 12.6 \\
\hline 1 & $1,024.5$ & $1,126.5$ & -0.13 & 0.74 & 3.65 & 36.0 \\
\hline 3 & $1,024.5$ & $1,096.0$ & -0.37 & 0.22 & 4.0 & 22.7 \\
\hline 0 & $1,024.5$ & $1,065.5$ & -0.69 & 0.27 & 4.3 & 15.8 \\
\hline \multicolumn{7}{|c|}{ C18 } \\
\hline 4 & 1,055 & $1,218.0$ & -0.18 & 0.44 & 3.85 & 14.6 \\
\hline 2 & 1,055 & $1,187.5$ & -0.38 & 0.8 & 4.3 & 6.8 \\
\hline 5 & 1,055 & $1,157.0$ & -0.92 & 0.67 & 4.25 & 7.6 \\
\hline 1 & 1,055 & $1,126.5$ & -0.47 & 0.43 & 3.75 & 352.9 \\
\hline 3 & 1,055 & $1,096.0$ & -0.43 & 0.12 & 3.85 & 7.4 \\
\hline 0 & 1,055 & $1,065.5$ & -0.9 & 0.3 & 3.55 & 20.4 \\
\hline \multicolumn{7}{|c|}{ C19 } \\
\hline 4 & $1,085.5$ & 945 & -0.07 & 0.39 & 3.15 & 4.7 \\
\hline 2 & $1,116.0$ & 945 & 0.04 & 0.31 & 2.2 & 18.1 \\
\hline 5 & $1,146.5$ & 945 & -0.11 & 0.74 & 1.5 & 3.6 \\
\hline 1 & $1,177.0$ & 945 & -0.09 & 0.73 & 1.5 & 3.6 \\
\hline 3 & $1,207.5$ & 945 & -0.36 & 0.88 & 1.6 & 32.9 \\
\hline 0 & $1,238.0$ & 945 & -0.15 & 0.8 & 0.95 & 14.0 \\
\hline \multicolumn{7}{|c|}{$\mathrm{C} 21$} \\
\hline 4 & $1,085.5$ & 1,005 & -1.08 & 0.42 & 3.25 & 31.8 \\
\hline 2 & $1,116.0$ & 1,005 & -0.87 & 0.59 & 3.3 & 51.9 \\
\hline 5 & $1,146.5$ & 1,005 & -0.67 & 0.73 & 1.75 & 15.8 \\
\hline 1 & $1,177.0$ & 1,005 & -0.48 & 0.7 & 1.85 & 13.2 \\
\hline 3 & $1,207.5$ & 1,005 & -0.35 & 0.74 & 1.7 & 19.6 \\
\hline 0 & $1,238.0$ & 1,005 & -0.17 & 0.76 & 1.4 & 10.4 \\
\hline \multicolumn{7}{|c|}{$\mathrm{C} 22$} \\
\hline 4 & $1,085.5$ & 1,035 & -1.24 & 0.89 & 3.45 & 10.7 \\
\hline 2 & $1,116.0$ & 1,035 & -1.24 & 0.44 & 2.95 & 12.4 \\
\hline 5 & $1,146.5$ & 1,035 & -0.95 & 0.51 & 2.1 & 17.9 \\
\hline 1 & $1,177.0$ & 1,035 & -0.67 & 0.68 & 1.75 & 16.0 \\
\hline 3 & $1,207.5$ & 1,035 & -0.51 & 0.52 & 2.05 & 13.8 \\
\hline 0 & $1,238.0$ & 1,035 & -0.36 & 0.53 & 1.5 & 8.2 \\
\hline & & & & & & (Continued) \\
\hline
\end{tabular}




\section{Table C14 (Concluded)}

\begin{tabular}{|l|l|l|l|l|l|l|}
\hline Probe & $X(\mathrm{~m})$ & $Y(\mathrm{~m})$ & $\mathrm{U}(\mathrm{m} / \mathrm{sec})$ & $\mathrm{V}(\mathrm{m} / \mathrm{sec})$ & Int. Ht (m) & Wave Dir (deg) \\
\hline
\end{tabular}

\begin{tabular}{|c|c|c|c|c|c|c|}
\hline \multicolumn{7}{|c|}{$\mathrm{C} 23$} \\
\hline 4 & $1,085.5$ & $1,065.5$ & -0.94 & 0.54 & 3.1 & 24.2 \\
\hline 2 & $1,116.0$ & $1,065.5$ & -0.86 & 0.63 & 2.15 & 15.8 \\
\hline 5 & $1,146.5$ & $1,065.5$ & -0.68 & 0.57 & 2.05 & 356.9 \\
\hline 1 & $1,177.0$ & $1,065.5$ & -0.71 & 0.64 & 1.55 & 39.8 \\
\hline 3 & $1,207.5$ & $1,065.5$ & -0.56 & 0.46 & 1.8 & 28.5 \\
\hline 0 & $1,238.0$ & $1,065.5$ & -0.29 & 0.72 & 1.5 & 16.1 \\
\hline \multicolumn{7}{|c|}{$\mathrm{C} 24$} \\
\hline 4 & $1,085.5$ & 1,096 & -0.98 & 0.42 & 2.35 & 7.4 \\
\hline 2 & $1,116.0$ & 1,096 & -0.82 & 0.43 & 2.1 & 14.1 \\
\hline 5 & $1,146.5$ & 1,096 & -0.66 & 0.4 & 1.95 & 4.3 \\
\hline 1 & $1,177.0$ & 1,096 & -0.38 & 0.3 & 1.8 & 35.3 \\
\hline 3 & $1,207.5$ & 1,096 & -0.28 & 0.16 & 1.55 & 0.0 \\
\hline 0 & $1,238.0$ & 1,096 & 0.15 & 0.18 & 1.0 & 22.5 \\
\hline \multicolumn{7}{|c|}{$\mathrm{C} 25$} \\
\hline 4 & $1,085.5$ & $1,126.5$ & -1.76 & 0.64 & 2.4 & 22.6 \\
\hline 2 & $1,116.0$ & $1,126.5$ & -1.35 & 0.26 & 2.0 & 18.3 \\
\hline 5 & $1,146.5$ & $1,126.5$ & -1.06 & 0.25 & 2.15 & 15.5 \\
\hline 1 & $1,177.0$ & $1,126.5$ & -0.78 & 0.06 & 1.75 & 12.9 \\
\hline 3 & $1,207.5$ & $1,126.5$ & -0.65 & 0.23 & 1.95 & 12.4 \\
\hline 0 & $1,238.0$ & $1,126.5$ & 0.13 & 0.12 & 1.15 & 11.0 \\
\hline \multicolumn{7}{|c|}{$\mathrm{C} 26$} \\
\hline 4 & $1,085.5$ & 1,145 & -2.02 & 0.62 & 2.8 & 10.8 \\
\hline 2 & $1,116.0$ & 1,145 & -1.33 & -0.06 & 2.15 & 3.7 \\
\hline 5 & $1,146.5$ & 1,145 & -1.09 & 0.17 & 2.3 & 18.3 \\
\hline 1 & $1,177.0$ & 1,145 & -0.73 & -0.01 & 1.75 & 14.8 \\
\hline 3 & $1,207.5$ & 1,145 & -0.67 & 0.19 & 1.6 & 19.8 \\
\hline 0 & $1,238.0$ & 1,145 & -0.09 & 0.06 & 1.25 & 9.2 \\
\hline \multicolumn{7}{|c|}{ T1 } \\
\hline 4 & $1,080.5$ & 1,159 & -0.71 & 0.97 & 3.05 & 3.5 \\
\hline 2 & $1,116.0$ & 1,159 & 0.05 & -0.31 & 1.3 & 5.5 \\
\hline 5 & $1,141.5$ & 1,159 & -0.21 & 0.08 & 0.9 & 12.9 \\
\hline 1 & $1,177.0$ & 1,159 & 0.02 & 0.04 & 0.9 & 45.6 \\
\hline 3 & $1,202.5$ & 1,159 & 0.0 & -0.1 & 0.85 & 26.1 \\
\hline 0 & $1,238.0$ & 1,159 & -0.2 & -0.19 & 0.6 & 54.0 \\
\hline \multicolumn{7}{|c|}{ T3 } \\
\hline 4 & $1,080.5$ & 1,155 & -0.91 & 0.78 & 2.9 & 0.9 \\
\hline 2 & $1,116.0$ & 1,155 & -0.47 & -0.6 & 1.65 & 7.7 \\
\hline 5 & $1,141.5$ & 1,155 & -0.65 & 0.3 & 1.2 & 18.1 \\
\hline 1 & $1,177.0$ & 1,155 & -0.37 & 0.01 & 1.35 & 31.4 \\
\hline 3 & $1,202.5$ & 1,155 & -0.23 & 0.0 & 1.15 & 20.4 \\
\hline 0 & $1,238.0$ & 1,155 & -0.19 & -0.25 & 0.95 & 35.8 \\
\hline
\end{tabular}




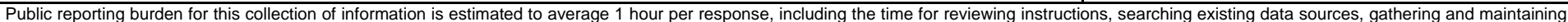

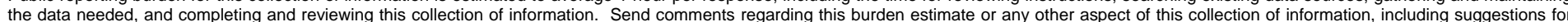

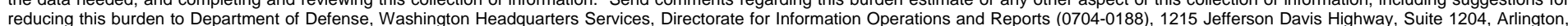

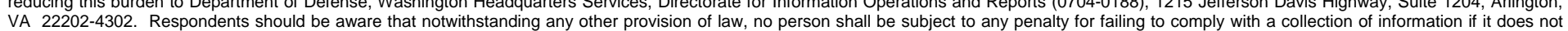
VA 22202-4302. Respondents should be aware that notwithstanding any other provision of law, no person shall be sube
display a currently valid OMB control number. PLEASE DO NOT RETURN YOUR FORM TO THE ABOVE ADDRESS.
1. REPORT DATE (DD-MM-YYYY)
September 2005
Final report

4. TITLE AND SUBTITLE

Laboratory Study of Hydrodynamics Near Absorbing and Fully Reflecting Jetties
3. DATES COVERED (From - To)

5a. CONTRACT NUMBER

5b. GRANT NUMBER

5c. PROGRAM ELEMENT NUMBER

5d. PROJECT NUMBER

5e. TASK NUMBER

5f. WORK UNIT NUMBER

32935

8. PERFORMING ORGANIZATION REPORT NUMBER

ERDC/CHL TR-05-8

U.S. Army Engineer Research and Development Center

Coastal and Hydraulics Laboratory

3909 Halls Ferry Road

Vicksburg, MS 39180

9. SPONSORING I MONITORING AGENCY NAME(S) AND ADDRESS(ES)

10. SPONSOR/MONITOR'S ACRONYM(S)

U.S. Army Corps of Engineers

Washington, DC 20314-1000

11. SPONSOR/MONITOR'S REPORT NUMBER(S)

\section{DISTRIBUTION / AVAILABILITY STATEMENT}

Approved for public release; distribution is unlimited.

\section{SUPPLEMENTARY NOTES}

\section{ABSTRACT}

This physical model study of absorbing and reflecting jetties at coastal inlets was conducted to provide data sets that would aid in the calibration and verification of numerical wave models. The study was performed in the Coastal Inlet Research Program's (CIRP) idealized inlet experimental basin at the U.S. Army Engineer Research and Development Center (ERDC), Coastal and Hydraulics Laboratory (CHL), Vicksburg, MS. Safe navigation, sediment transport into navigation channels, and shoreline erosion are all concerns at coastal inlets and are related to the transformation of waves as they change direction and height due to complex bathymetry and coastal inlet structures. The idealized inlet physical model, created for inlet studies, provided a facility in which to make wave measurements of height and direction and the associated wave-generated currents in enough detail to document the wave height and current variation in a region with complex interactions. Measurements of wave information included use of wave rods for wave height and acoustic Doppler velocity sensors for wave direction and current. Qualitative dye photographs and videos were also obtained.

Wave height and velocity measurements were collected both upcoast of the jetty and between parallel jetties for a number of waves representative of tidal inlets. The composition of the jetty was designed to portray the extremes of an inlet jetty - a jetty that fully reflects the incident wave toward the upcoast shoreline adjacent to the jetty, and an almost fully absorbing jetty, which reflects

\section{SUBJECT TERMS}

Coastal inlet

Coastal Inlet Research Program

16. SECURITY CLASSIFICATION OF:

\section{a. REPORT}

UNCLASSIFIED

\section{Environmental data}

Jetties

Laboratory wave measurements

\begin{tabular}{|l|c|}
\hline $\begin{array}{l}\text { 17. LIMITATION } \\
\text { OF ABSTRACT }\end{array}$ & $\begin{array}{c}\text { 18. NUMBER } \\
\text { OF PAGES }\end{array}$ \\
\cline { 2 - 3 } & 141 \\
\hline
\end{tabular}

Longshore current circulation

Wave-induced currents

(Continued) 


\section{4. (Concluded)}

very little energy. These two extreme conditions created two different circulation patterns associated with each jetty condition. The nearly fully absorbing jetty setup permitted the wave-generated longshore current to approach the jetty and essentially be deflected seaward ninety degrees, along the jetty. The waves fully reflecting from the jetty created a clockwise circulation cell at the intersection of the jetty and the shoreline. This cell was large enough to deflect the offshore movement of littoral currents a significant distance upcoast rather than approaching the base of the jetty before deflecting seaward as for the absorbing jetty setup. 